\title{
Burundi Poverty Assessment
}

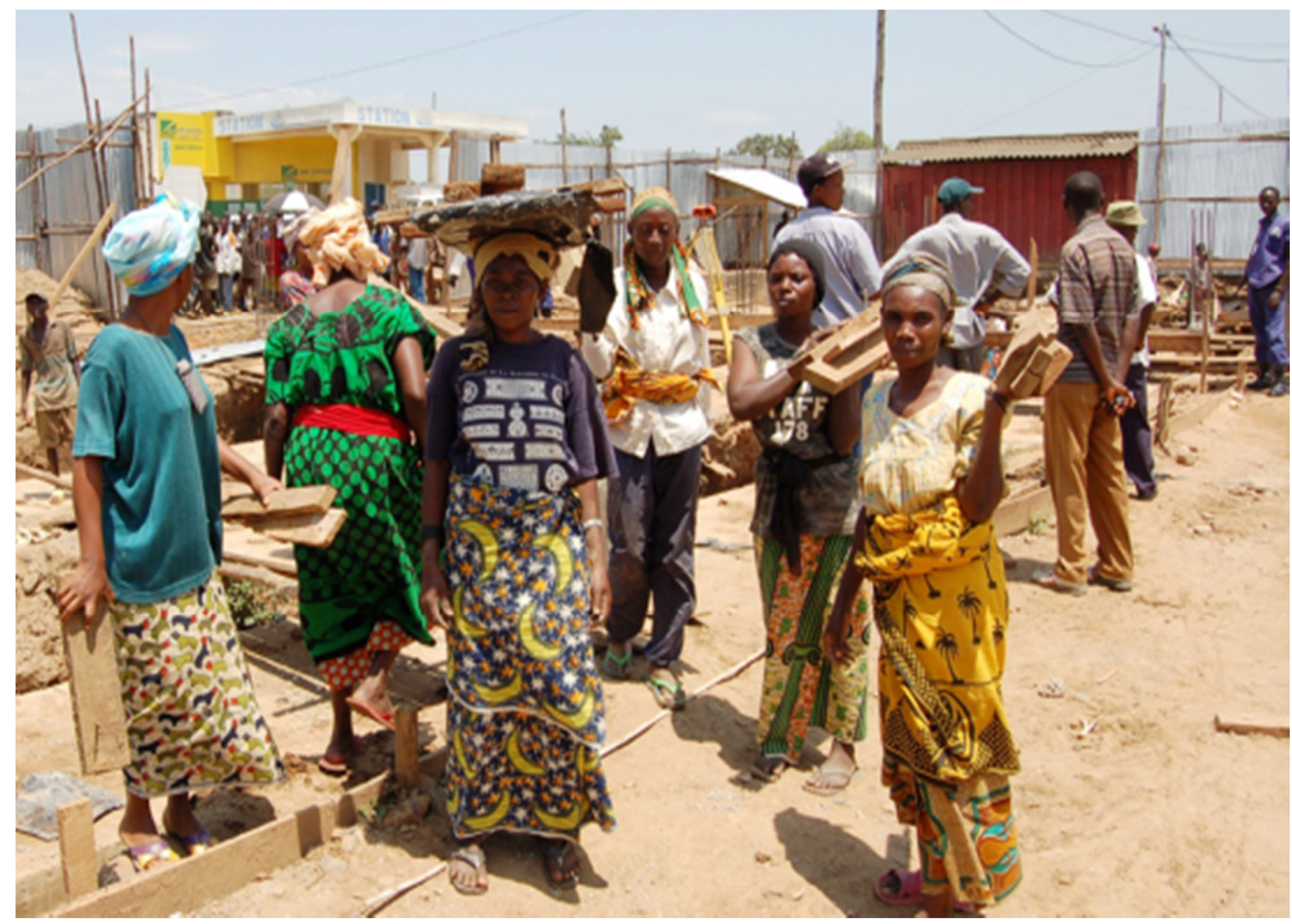

June, 2016

GPV01

AFRICA

(4) 


\section{Contents}

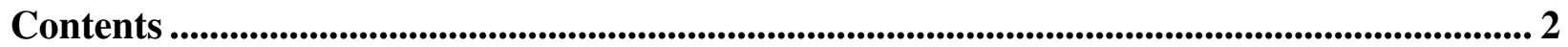

Acknowledgement ......................................................................................................................................... 9

Acronyms And Abbreviations ......................................................................................................... 11

Executive Summary ....................................................................................................................... 12

Chapter I - Country Context: Historical Review, Outlook And Projections .......................... 30

I. A History Of Violence Linked To Poor Economic Performance ............................................... 30

Ii. Recent Events And Macroeconomic Trends …………................................................... 39

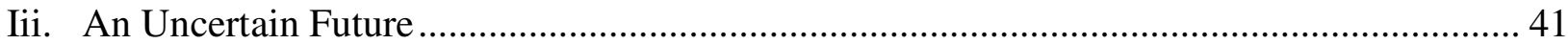

Chapter Ii - The Extent Of Poverty And Inequality .......................................................................... 43

I. Snapshot Of Consumption Poverty In 2013-14 ……............................................................... 44

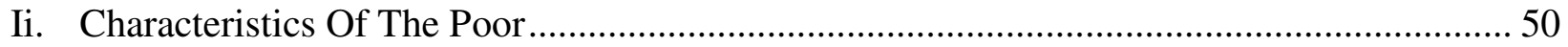

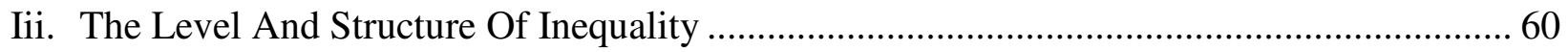

Chapter Iii - Evolution Of Households Living Conditions............................................................. 70

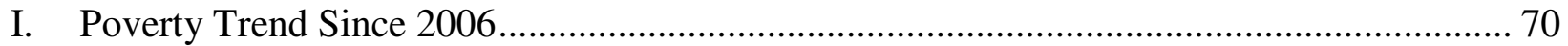

Ii. Household Demographic Characteristics......................................................................... 73

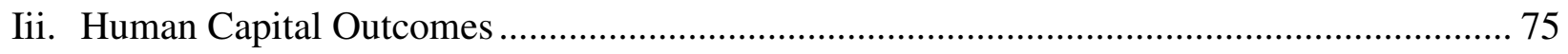

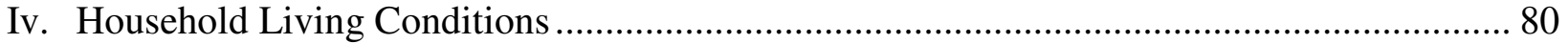

V. Consequences Of Violence On Households Welfare ......................................................... 89

Chapter Iv - Governance, Fragility And Persisting Poverty .......................................................... 92

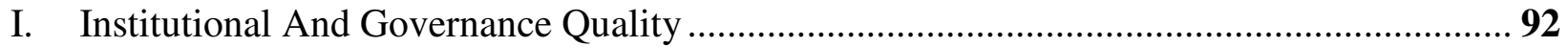

Ii. Impact Of Weak Governance On Poverty And Welfare ...................................................... 102

Chapter V - Employment In Formal And Informal Economy .................................................. 105

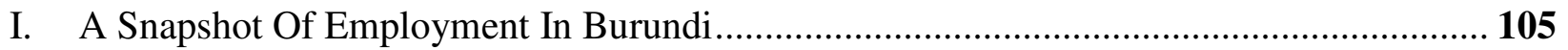

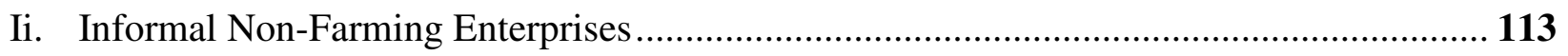

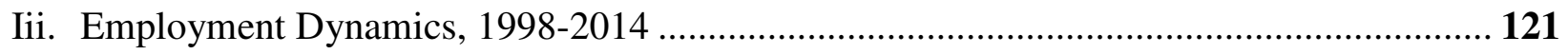

Chapter Vi - Agricultural Situation In Burundi ........................................................................... 130

I. Snapshot Of Agricultural Sector In Burundi's Economy .................................................. 131

Ii. Food Production: Characteristics And Performances .......................................................... 137

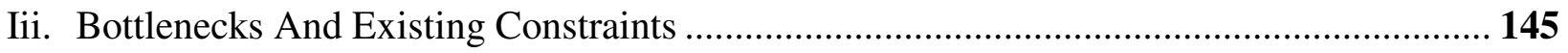


Chapter Vii - Environmental Degradation, Climate Change, And Poverty.

I. Change In Wealth Per Capita And Natural Capital Depletion

Ii. Deforestation, Land Degradation And Poverty

Burundi's Geographic Regions............................................................................................. 162

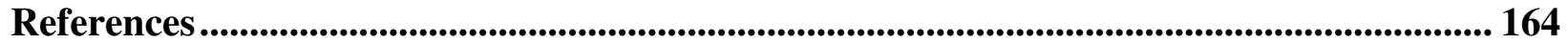

Appendices................................................................................................................................................ 169

Appendix I - Poverty Estimation Data And Methodology................................................. 169

Appendix Ii - The Unconditional Quantile Regression Method ......................................... 177

Appendix Iii - Inefficiency On The Burundian Agriculture ........................................... 180 


\section{List of Tables}

Table I.1: Selected economic indicators (averages 2005-14) for selected benchmark countries...............................35

Table I.2: Selected Economic and Social Indicators, Projections 2015-2018 …....................................................41

Table II.1: The Burundi households' demographic structure in 2014 - Spatial location............................................50

Table II.2: The Burundi households' demographic structure in 2014 - Poverty status. ...........................................50

Table II.3: The Burundi households' demographic structure in 2006 - Spatial location..........................................51

Table II.4: The Burundi households' demographic structure in 2006 - Vulnerability status. ....................................51

Table II.5: Poverty incidences for people living in households with disabled members - Spatial location ................53

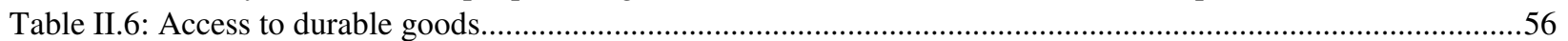

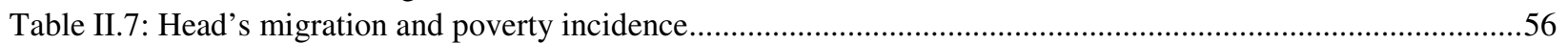

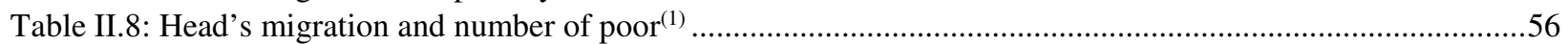

Table II.9: Multivariate regression, select indicators for poverty and wellbeing, migrant/non-migrant HH...............58

Table II.10: Probability regression analysis (logit) for the correlates of migrations vs no migrations in 2014...........58

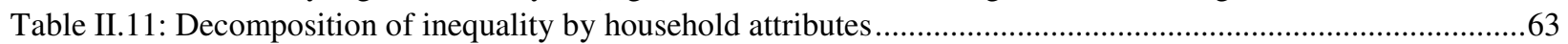

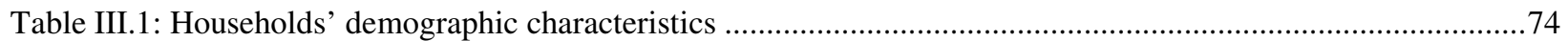

Table III.2: Literacy (read and write in Kirundi or other languages) rate by geographical area (percentage).............75

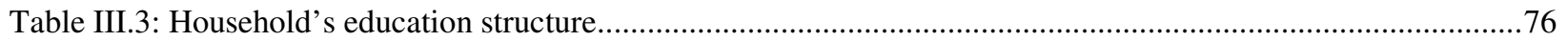

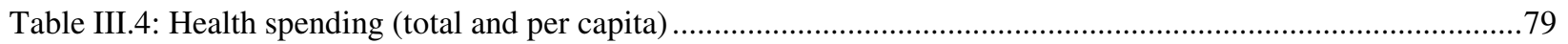

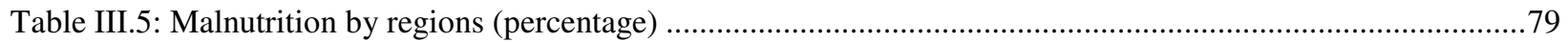

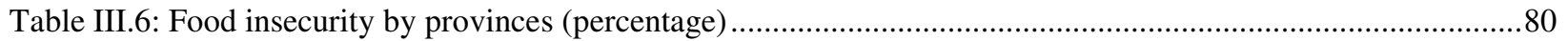

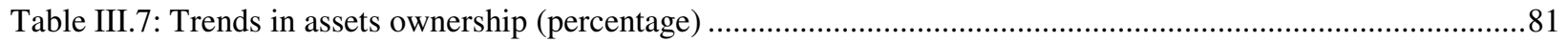

Table III.8: Trends in dwelling conditions and access to basic services (percentage) ..............................................81

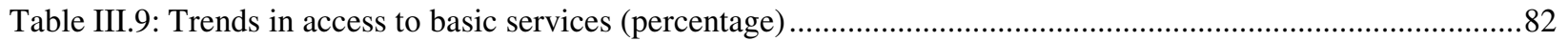

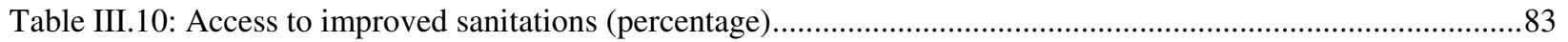

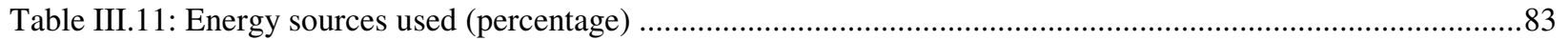

Table III.12: Access to improved domestic waste and sewage disposal (percentage) ...............................................84

Table III.13: Illness/injuries during last 4 weeks (percentage) ...............................................................................8

Table III.14: Households' consultation of health facility or traditional healer during last 4 weeks (percentage) ........88

Table III.15: Key reasons for not consulting health services while the person was sick or injured (percentage)........88

Table V.1: Employment by Gender and Employment Status (Employment share by job category, 2014)..............108

Table V.2: Employment by Age Category and Employment Status (Employment share by job category, 2014) ....109

Table V.3: Share of workers with a secondary job in and outside of agriculture (percentage) ...............................110

Table V.4: Worker characteristics by employment category (percentage) ...........................................................111

Table V.5: Employment by Type of Worker and Production Unit (Percentage of total workforce employed) ........113

Table V.6: Non-Farming Informal Employment by Age Group and Urban/Rural (percentage) ..............................114

Table V.7: Non-Farming Informal Employment by Level of Education and Gender (Percentage) .........................115

Table V.8: Non-farming UPI by Sector and Geographical Area (percentage) ......................................................115

Table V.9: Non-farming Informal Employment by Industry, Geographical Area, and Gender (Percentages)..........116

Table V.10: Size of UPI by Geographical Location (percentage) ........................................................................117

Table V.11: Non-farming Informal Employment by Employment Status and Geographical Area (Percentage)......118

Table V.12: Average Yearly Income by Type of Worker, Economic Sector, and Nature of Employment ..............119

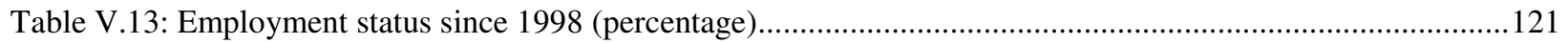

Table V.14: Employment status between 2008 and 2014 by gender (percentage) ................................................123

Table V.15: Share of workers with earnings data by employment status (percentage) ..........................................126

Table V.16: Median annual earnings of non-farm employees, by location, sector, and education............................127

Table VI.1: Relief of the Farms by Province (Percentage) ................................................................................134

Table VI.2: Food Production by Type of Crop (CE metric tons) .......................................................................142

Table VI.3: Food Crop Yields (selection) in East African Community (2012, Tons per Hectare - T/ha) ...............144

Table VI.4: Food Yields by Type of Crop and Year (in Tons per Hectare - T/ha) ...............................................145

Table VI.5: Fertilizer's Use by Agricultural Season and by Type of Fertilizer (metric tons) ................................148

Table 1. A-1: Consumption/expenditure data collection approaches ......................................................................170 


\section{List of Figures}

Figure ES.1: Burundi and Sub-Sahara Africa GDP growth (1960-2014) .............................................................12

Figure ES.2: Poverty and Extreme Poverty Incidence (in percentage) .................................................................14

Figure ES.3: International Poverty Estimates in Burundi and Other Developing Countries (in percentage) ..............14

Figure ES.4: Poverty and Extreme Poverty Incidence (in percentage) ..................................................................15

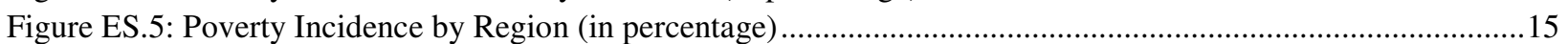

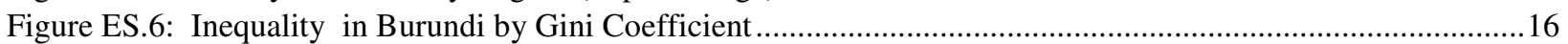

Figure ES.7: Poverty Trends in Burundi, 2006-2013/14 (percentage) .....................................................................18

Figure ES.8: Poverty Trends by Geographic Area, 2006-2013/14 (percentage) .........................................................18

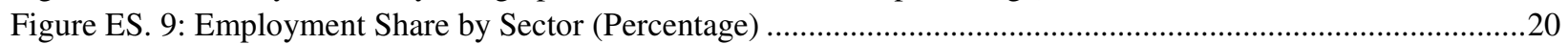

Figure ES. 10: Formal and Informal Employment by Sector (Percentage) ….........................................................20

Figure ES.11: Non-farming UPI by Sector and Geographical Area (Percentage) ......................................................21

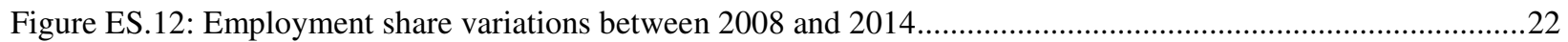

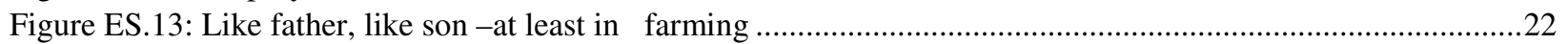

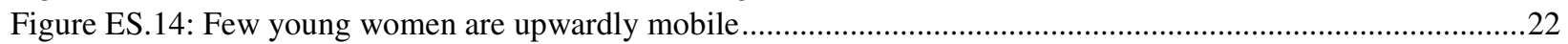

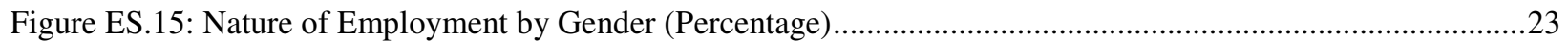

Figure ES.16: Informal Employment by Form of Contract and Gender (Percentage)..............................................23

Figure ES.17: Food Production by Type of Crop (CE metric tons)....................................................................

Figure ES.18: Food Crop Yields (selection) in East African Community (2012, Tons per Hectare - T/ha).............25

Figure I.1: GDP per capita between 1960 and 2014 (constant 2005 US\$) ...........................................................32

Figure I.2: Annual economic growth and annual coffee prices, 1961-2014 .......................................................32

Figure I.3: Burundi and Sub Saharan Africa Index of GDP per capita (constant 2005 US\$; 1960=100)...................33

Figure I.4: Contribution of production factors to economic growth ...................................................................33

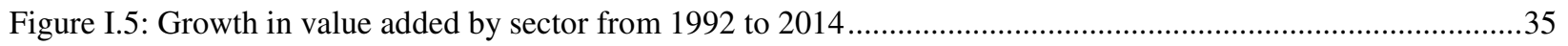

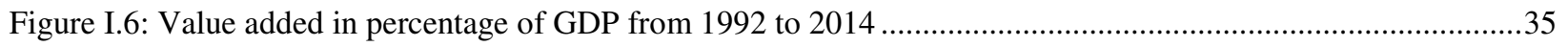

Figure I.7: Total Factor Productivity growth (average 2005-2014) ........................................................................37

Figure I.8: Agriculture value added per worker (constant 2005 US\$) .....................................................................38

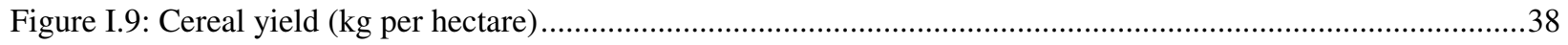

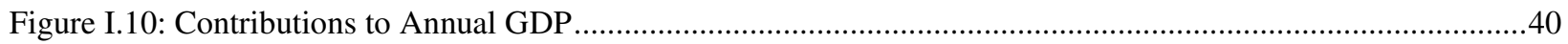

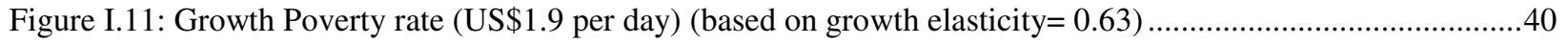

Figure II.1: Poverty Indicators in Burundi 2013-14 (percentage)...........................................................................4

Figure II.2: Poverty Incidence by Geographic Domains 2013-14 ……................................................................46

Figure II.3: Distribution of Poor Population by Geographic Area (million, percentage) ...........................................46

Figure II.4: Poverty Incidence by Geographic Area 2013-14 (percentage) ...........................................................46

Figure II.5: Extreme Poverty by Geographic Area 2013-14 (percentage) ..............................................................46

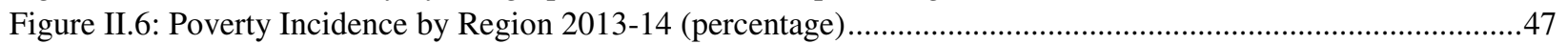

Figure II.7: Poverty Incidence by Province 2013-14 (percentage) .......................................................................47

Figure II.8: Disbursements of Aid by Region and Province in 2012-2013 (million USD)........................................48

Figure II.9: Poverty Estimates in Burundi and Other Developing Countries by Percentage ......................................49

Figure II.10: Sensitivity of Poverty Rate from Change in Poverty Line ..............................................................49

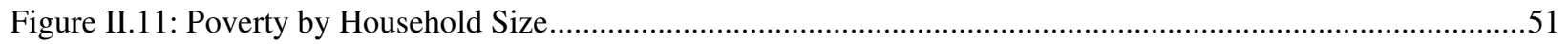

Figure II.12: Poverty Incidence by Number of children aged 0-14 years ............................................................52

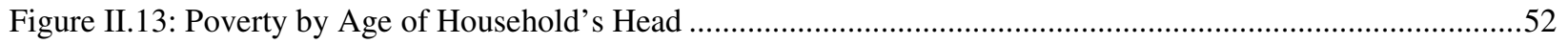

Figure II.14: Poverty Incidence by Family Type ...........................................................................................52

Figure II.15: Poverty Incidence by Head's Gender and Marital Status (percentage) …............................................52

Figure II.16: Households with disabled members ...........................................................................................53

Figure II.17: Poverty incidence by Education of Household's Head (percentage) ...................................................54

Figure II.18: Poverty incidence by Employment of Household's Head (percentage) …............................................54

Figure II.19: Access to infrastructure and basic services (percentage) ....................................................................55

Figure II.20: Lorenz curve and inequality coefficients .....................................................................................61

Figure II.21: Unconditional Quintile Decomposition of Urban-Rural Inequality of per C. Consumption ..................67 
Figure II.22 Unconditional Quintile Decomposition of Regional Inequality of Real Monthly per C. Consumption ..69 Figure III.1 Poverty Trends in Burundi, 2006-2013/14 (percentage).....................................................................72

Figure III.2 Extreme Poverty Trends in Burundi, 2006-2013/14 (percentage) .........................................................72

Figure III.3 Poverty Trends by Geographic Area, 2006-2013/14 (in percentage) .....................................................72

Figure III.4 Extreme Poverty Trends by Geographic Area, 2006-2013/14 (in percentage) ......................................72

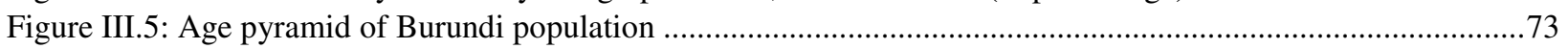

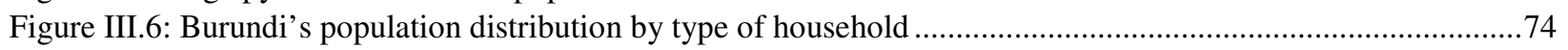

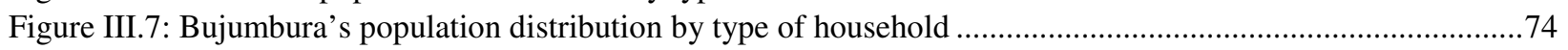

Figure III.8: Population by level of education (percentage) .................................................................................75

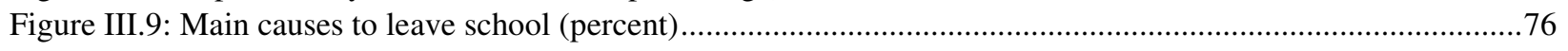

Figure III.10: Education level of households' members by geographical area........................................................77

Figure III.11: Health situation of population by geographical area, gender, and age group (percentage) ....................78

Figure III.12: Access to improved water sources by geographical areas (percentage) ...............................................82

Figure III.13: Access to public primary school by geographical area (percentage)..................................................8

Figure III.14: Access to public secondary school by geographical area (percentage) ...............................................8

Figure III.15: Access to public kindergarten by geographical area (percentage) .....................................................85

Figure III.16: Access to public health facility by geographical area (percentage).....................................................85

Figure III.17: Access to public pharmacy by geographical area (percentage) ..........................................................85

Figure III.18: Access to private primary school by geographical area (percentage) ...................................................8

Figure III.19: Access to private secondary school by geographical area (percentage) ...............................................86

Figure III.20: Access to private kindergarten by geographical area (percentage) .....................................................8

Figure III.21: Access to private health facility by geographical area (percentage) …….........................................8

Figure III.22: Medical consultation rate by place of residence, gender, and age group (percentage).........................89

Figure III.23: Probability of finishing primary school, by birth cohort ...........................................................90

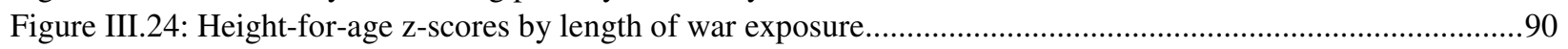

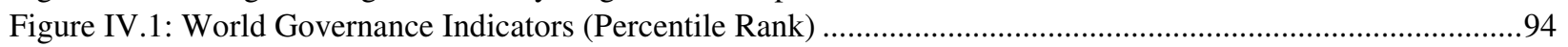

Figure IV.2: IIAG Index (score/100) from 2000 to 2014 ..................................................................................94

Figure IV.3: Score on the items of the public sector management and institutions cluster, CPIA, Burundi and SSA 95

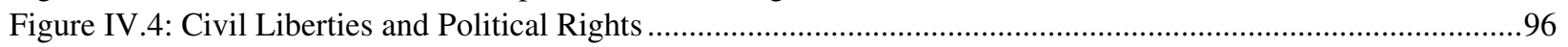

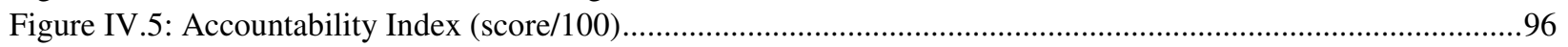

Figure IV.6: Burundi National Security (left) and Personal Security (right) versus African average ........................97

Figure IV.7: GCI score (1-7) of African economies, 2007 compared with 2015 ...................................................98

Figure IV.8: Evolution Education (left) and Health (right) in the IIAG Index ...................................................98

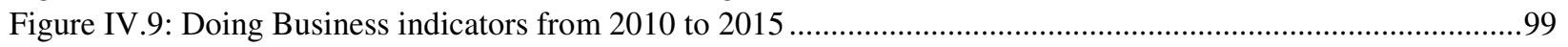

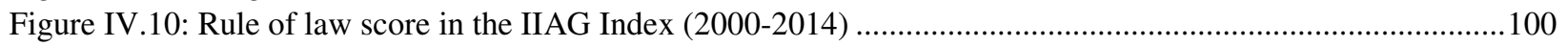

Figure IV.11: Disaggregated indicators of rule of law (2000-2014) …...........................................................100

Figure IV.12: Main problems the government should address identified by respondents (percentage) ....................101

Figure IV.13: Gap in poverty between countries affected by violence and those not experiencing violence.............103

Figure V.1: Burundi's Labor Force by Age (percentage of Total Workforce) .........................................................106

Figure V.2: Burundi's Labor Force by Education Level (percentages) .................................................................106

Figure V.3: A snapshot of jobs in Burundi (Number of Workers by Job Category, 2014) ....................................106

Figure V.4: Employment Share by Sector (Percentages) ......................................................................................107

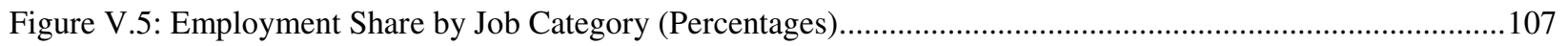

Figure V.6: Employment by Gender and Sector (Percentages) ..............................................................................108

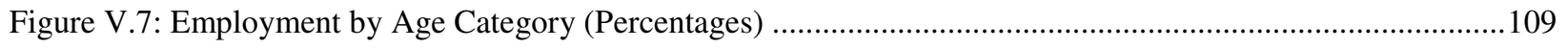

Figure V.8: Nature of Employment by Gender (Percentage) …….........................................................................109

Figure V.9: Employment by Employment Status, Gender and Age Category (Percentage) ....................................109

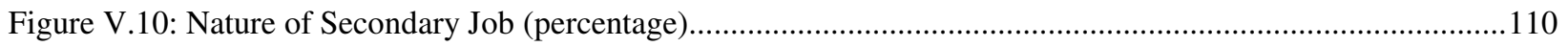

Figure V.11: Farm workers are largely uneducated ……...............................................................................110

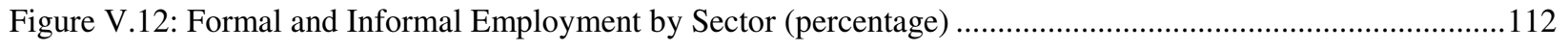

Figure V.13: Formal and Informal Enterprises (percentage) ……...............................................................112

Figure V.14: Sectoral Composition of Formal and Informal Employment (percentage) .......................................112 
Figure V.15: Geographic Distribution of Formal and Informal Workers (percentage)

Figure V.17: Non-Farming Informal Employment by Age Group and Gender (Percentages) .................................114

Figure V.18: Non-farming UPI by Sector (percentage) ..................................................................................115

Figure V.19: Distribution of Non-farming Informal Employment by Employment Status (Percentage) ..................118

Figure V.20: Distribution of Non-farming Informal Employment by Employment Status and Geographical Area 118

Figure V.21: Informal Employment by Form of Contract (Percentages) ..............................................................119

Figure V.22: Informal Employment by Form of Contract and Gender (Percentages) ............................................119

Figure V.23: Informal Employment by Nature of Payment (percentage)...............................................................120

Figure V.24: Informal Employment by Nature of Payment and Gender (Percentages) ..........................................120

Figure V.25: Secondary and Tertiary sectors employment share between 1998 and 2008 (percentage)...................121

Figure V.26: Government, domestic services and construction account for the bulk of wage employment .............122

Figure V.27: Share of workers with non-farming jobs by age group ..............................................................123

Figure V. 28: Secondary and Tertiary sectors employment share between 2008 and 2014 (percentage)..................123

Figure V.29: Occupation of son by occupation of father, 2014 (percentage) .........................................................124

Figure V.30: Occupation of daughter by occupation of mother, 2014 (percentage)................................................125

Figure V.31: Median annual earnings for private sector employees, by establishment size (in BIF)......................127

Figure V.32: Type of employment the unemployed higher-educated look for (percentage) ...................................128

Figure V.33: Type of employer the unemployed higher-educated look for (percentage) .........................................128

Figure V.34: Employment of higher-educated workers (percentage) .....................................................................128

Figure VI.1: Burundi's Farming Population by Age (Percentage) .................................................................... 131

Figure VI.2: Farming Population by Literacy in Kirundi (Percentage) ..................................................................1 131

Figure VI.3: Farming Population by Literacy in Kirundi and Asset Quintile (Percentage).....................................132

Figure VI.4: Heads of Households by Literacy in Kirundi and Asset Quintile (Percentage) ..................................132

Figure VI.5: Farming Population by Size of Household and Welfare Quintile (Percentage) ...................................133

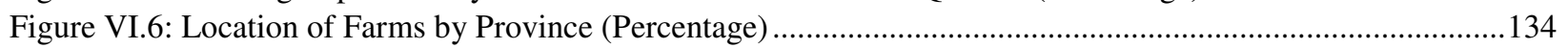

Figure VI.7: Average Plot Size by Province (Squared meter) ............................................................................135

Figure VI.8: Farm Size by Welfare Quintile and Asset Quintile (Squared meter) ................................................135

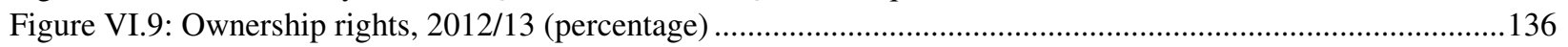

Figure VI.10: Share of Plots Planted with Improved Seeds by Crop (Percentage).................................................137

Figure VI.11: Share of Households and Plots using Chemical Fertilizers (Percentage)...........................................137

Figure VI.12: Farming activity by gender and welfare quintile (percentage of households)....................................138

Figure VI.13: Farming activity by provinces (percentage of households) ..........................................................138

Figure VI.14: Crop prevalence in households (percentage of households using the crop) .....................................139

Figure VI.15: Share of Food Production by Season and Type of Crop (Percentage) ..............................................139

Figure VI.16: Number of crops per farm by gender and welfare quintiles (percent of households) .........................140

Figure VI.17: Number of crops per farm by provinces (percent of households) ....................................................141

Figure VI.18: Diversification out of agriculture by gender and welfare quintiles (percentage of households) .........142

Figure VI.19: Diversification out of agriculture by provinces (percentage of households ......................................142

Figure VI.20: Food crop yields dynamics from 2012 A to 2013 C (MT/ha) .......................................................143

Figure VI.21: Provider of advisory services by gender and welfare quintile (percentage of households) ................147

Figure VI.22: Provider of advisory services by provinces (percentage of households) ...........................................147

Figure VI.23: Household's Output and Share of Household's Plots Treated with DAP Fertilizer by Region ...........148

Figure VI.24: Erosion-control method by ways the land was received (percentage of farms) .................................150

Figure VI.25: Food yields of plots by erosion schemes $(\mathrm{kg} / \mathrm{ha})$.......................................................................151

Figure VII.1: Change in wealth per capita components (\% of GDP per capita), 2010 ..........................................154

Figure VII.2: Evolution of Burundi's change in wealth and natural capital depletion, in \% of GDP per capita........154

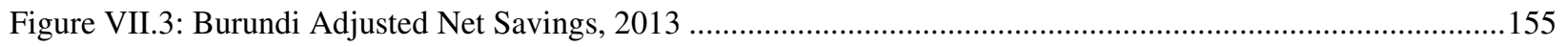

Figure VII.4 Deforestation over the 2000-2011 period in selected countries, in average annual \%........................157

Figure VII.5 Land Degradation in Burundi by Severity Classification, 2014 ......................................................158

Figure VII.6 Land degradation levels (Low, Medium, High, Very High) in Burundi, 2014 ................................158

Figure VII.7 Poverty rates by communes in Burundi, in \%, data from 2008 and 2014 ........................................158 
Figure VII.8 Tree forest loss and poverty headcount rate (high, medium and low) in Burundi ..............................159

Figure VII.9 Soil erosion and poverty headcount rate (high, medium and low) in Burundi....................................159

Figure VII.10 Map of flood risks (high, medium and low) in Burundi ..............................................................161

Figure VII.11 Map of landslides risks (high, medium, and low) in Burundi..........................................................161

Figure 1. A-1: Number of transactions recorded since households receive the diary .............................................174 


\section{Acknowledgement}

The members of the core team that prepared this report are Nadia Belhaj Hassine Belghith (GPV01 and TTL), Tom Bundervoet (GPV01), Aurelien Beko (GPV01) and Clarence Tsimpo (GPV01). Additional research and writing support was provided by Pierre de Boisseson (GPV01); Dan Pavelesku (GPV01); Mireia Duran Mate (GPV01); and Mamadou Ndione (GMF07).

The background analysis on the inefficiencies in the agricultural sector was prepared by Jean Louis Arcand and Beatrice d'Hombres (University of Clermont Ferrand, France). The analysis of the violence and fragility benefitted from the research of Philip Verwimp (Universite Libre de Bruxelles). The core team worked closely with the researchers to ensure the consistency of the analytical methods, findings, and main messages.

The team would like to extend its sincere thanks to the Institut des Statistiques et Etudes Economiques du Burundi (ISTEEBU) and the Burundi Ministry of Finance for the important support and critical feedback provided throughout the preparation of the report.

The team would like also to acknowledge the support generously provided by the Belgian Embassy in Burundi to some of the core analyses that underpinned the report.

The team would like to extend its thanks to Diane Steel (DECDG) for her support in the analysis of the quality of ECVMB 2013/14 and to Michael Vaislic (GENDR) for his help in preparing the analysis of Environmental Degradation, Climate Change and Poverty. Throughout the development of this report, the team benefitted from fruitful discussions with and guidance from Andrew Dabalen (GPV01).

The team would like also to thank constructive comments and suggestions from Paola Agostini (GENGE), Pierella Paci (GPV01), Aparajita Goyal (GPV01), Chiara Bronchi (GG019), and Yutaka Yoshino (AFCE1).

The team gratefully acknowledges guidance from Pablo Fajnzylber (Practice Manager GPV01) and Bella Bird (Country Director AFCE1). 
Finally, the team offers its sincere thanks to Martin Buchara (GPV01), Senait Yifru (GPV01), Arlette Sourou (GPV01), and Clarette Rwagatore (AFMBI) for their valuable assistance during the preparation of the report. 


\section{Acronyms and Abbreviations}

$\begin{array}{ll}\text { AfDB } & \text { African Development Bank } \\ \text { BIF } & \text { Burundian Franc } \\ \text { BRB } & \text { Central Bank of Burundi (Banque de la République du Burundi) } \\ \text { CBN } & \text { Cost of Basic Needs } \\ \text { CE } & \text { Cereal equivalent } \\ \text { EAC } & \text { East African Community } \\ \text { GDP } & \text { Gross domestic product } \\ \text { GOB } & \text { Government of Burundi } \\ \text { FAO } & \text { Food and Agriculture Organization } \\ \text { FDI } & \text { Foreign Direct Investment } \\ \text { FGT } & \text { Foster Greer Thorbecke } \\ \text { FLN } & \text { National Front for Liberty (Front National pour la Libération) } \\ \text { HA } & \text { Hectare } \\ \text { IFDC } & \text { International Fertilizer Development Center } \\ \text { ISTEEBU } & \text { National Statistical Office (Institut des Statistiques et d'Etudes Economiques du Burundi) } \\ \text { KG } & \text { Kilogram } \\ \text { MDG } & \text { Millennium Development Goal } \\ \text { MICS } & \text { Multiple Indicators Cluster Survey } \\ \text { MINAGRIE } & \text { Ministry of Agriculture and Livestock } \\ \text { MPI } & \text { Multidimensional Poverty/Deprivation Indicator } \\ \text { NGO } & \text { Non-Governmental Organization } \\ \text { PMS } & \text { Minimum Package of Health Services (Paquet Minimum de Services de Santé) } \\ \text { PNIA } & \text { National Plan of Agricultural Investment (Plan National d'Investissement Agricole) } \\ \text { PRSP } & \text { Poverty Reduction Strategy Paper } \\ \text { QUIBB } & \text { Core Welfare Indicators Questionnaire (Questionnaire des Indicateurs de Base du Bien- } \\ \text { RBF } & \text { être) } \\ \text { REGIDESO } & \text { Result Based Financing } \\ \text { RIF } & \text { Agency for Production and Distribution of Water and Electricity } \\ \text { SRDI } & \text { Recentered Influence Function } \\ \text { RGPH } & \text { Société Régionale de Développement de l'Imbo } \\ \text { SSA } & \text { General Census of Population and Housing (Recensement Général de la Population et de } \\ \text { WB } & \text { l'Habitat) } \\ \text { Sub-Saharan Africa } \\ \text { The World Bank } \\ & \\ & \end{array}$




\section{Executive Summary}

Since early 1990's, Burundi underwent periods of repetitive socio-political tensions, characterized by violent conflicts within the population, positioning the country as a fragile State and one of poorest in the World. Up until the early 1990s, Burundi's economic growth outpaced Sub Sahara Africa's and per capita GDP was about 50 percent higher than it had been in 1960. The onset of the war in 1993 saw GDP levels plummeting, and they have not recovered since. While Sub Sahara Africa has been rising since the early 2000s, Burundi has been stagnating (Figure ES .1). In per capita terms, growth has averaged a paltry 1.1 percent per annum over the past 10 years, which appears insufficient to result in any marked improvements in living conditions. GDP per capita in 2014 was lower than in early 1970's.

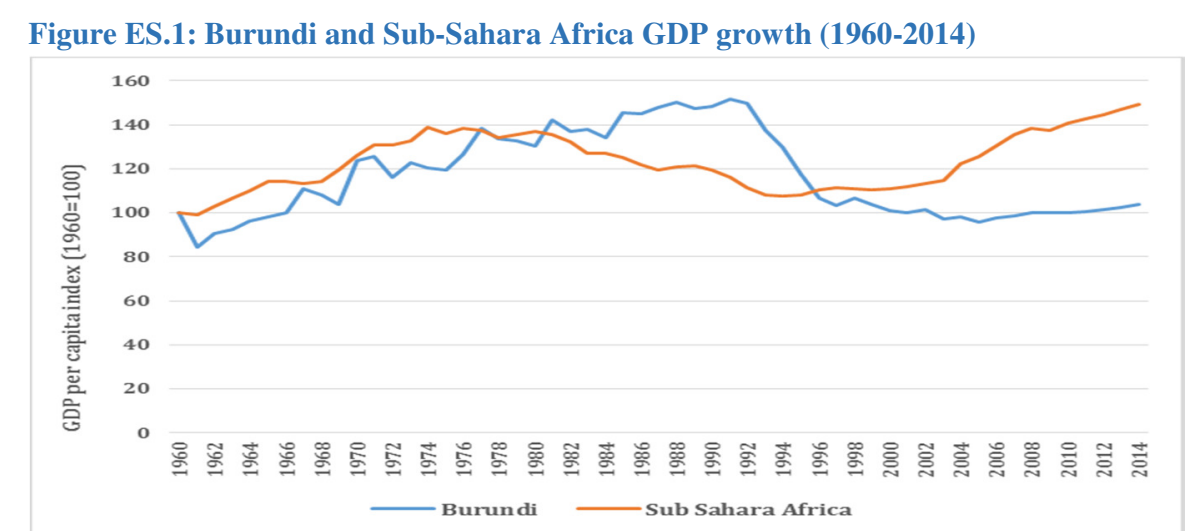

Source: World Development Indicators (WDI, 2015). Index of GDP per capita, constant 2005 US\$;

$1960=100)$

While there have been progress toward economic recovery and some improvements in households living conditions since the restoration of peace in 2006, the country continues to bear out the consequences of fragility. A large proportion of the population continues to suffer from severe deprivations in basic consumption needs. Fertility levels remain high at 6.4 children per woman. This results in a population growth of over 3 percent per year and dilutes any gains among an ever increasing population. Agriculture, which represents the main source of livelihood and jobs for around 85 percent of the population, suffers from low productivity and severe structural problems. The sector has grown by less than 2 percent during the last ten years and remains dominated by small-scale subsistence and rainfall farming, highly vulnerable to shocks. It also faces serious competitiveness and diversification issues, and offers little opportunities for the poor to have more productive jobs and better living standards. Food insecurity is alarming as the country ranks the lowest position in the 2013 Global Hunger Index with a score of 38.8. Almost one in two households (around 4.6 million people) are food insecure and over half of the children are stunted (WFP, 2014 and 2016). Access to water and sanitation is very low and less than 5 percent of the total population has access to electricity. The economy continues to be vulnerable to external shocks and highly dependent on donors, although external 
aid reduced meaningfully during recent years. The economic prospects are quite pessimistic. Burundi is projected to be the world's poorest country by 2030 and the seventh main contributor to global poverty, an astonishing feat given the country's small size (World Bank, 2015c).

National development policies, including the second Poverty Reduction Strategy (PRSP-II), put an important emphasis on reducing poverty and vulnerability, enhancing equity in education and health access, and promoting more inclusive growth. The participative consultations conducted during the preparation of PRSP-II pointed out to the difficulty of consistently assessing the scope and structure of poverty and to the importance of strengthening Burundi's Government capacity to monitor poverty and improve the understanding of its causes. This effort has been viewed as critical in helping speed up progress towards the Twin Goals of eliminating extreme poverty and promoting shared prosperity, and in laying the foundation for effective corrective actions. The available household survey, namely EPCVM 1998, QUIBB 2006 and PMS 2012, represented the main sources of primary data for the analysis of vulnerability for framing antipoverty programs. However, these surveys focus on social and nonmonetary aspects of welfare and are limited in terms of data collected on living standards, such as consumption and income, required for a consistent analysis of monetary poverty and a full-fledged poverty assessment. The recently completed Household Budget Survey (ECVMB) for 2013/14 allows to overcome part of this limitation and to provide a comprehensive analysis of poverty and inequality with their underlying causes.

The poverty assessment for Burundi aims to respond to this need. This report uses the availability of the ECVMB 2013/14 to provide a robust diagnostic of poverty and inequality in Burundi and bring new evidence to better inform policies aimed at poverty alleviation and equity. This is complemented by data from various sources, including previous household surveys and the National Agricultural Surveys (ENAB) for 2011/12 and 2012/13. These are used to examine other areas such as labor market, agriculture or governance, which are closely interlinked with poverty. It is hoped that empirical insights generated by the report will help through a pro-active consultation and dissemination approach, to mainstream the key findings and recommendations into local public policy debates.

The first chapter of the report will provide an overview on the country's context and the remaining chapters are as follows. Chapter 2 assesses the incidence and structure of consumption poverty and inequality using the most recent survey, ECVMB 2013/14. The third chapter examines the evolution of living conditions since 2006. Chapter four examines the linkage between governance and fragility and their impact on persisting poverty. Chapter five analyzes the labor market situation and investigates the informal employment. The last two chapters focus on agriculture, environmental sustainability, and climate change and their impact on poverty. 


\section{Widespread poverty with uneven spatial pattern}

Burundi is home to over six million poor people, ranking among the poorest Sub-Saharan and Low Income Countries. The Survey on Households Living Conditions (ECVMB 2013-14), shows that 64.9 percent of the population (around 6.1 million people) lives below the national basic needs poverty line of BIF 41,054 per adult per month. About 3.6 million Burundians (38.7 percent) live in extreme poverty and cannot meet the minimum nutritional requirements of 2,200 kilocalories (Kcal) per adult equivalent per day (Figure ES.2). Using the international poverty line of US\$1.9 per capita per day (in 2011 Purchasing Power Parity exchange rate), Burundi's poverty rate stands at 72.9 percent, around 8 percentage points higher than the national poverty rate. This indicates that poverty is around 30 percentage points higher than LIC and SSA averages of 47.2 percent and 42.7 percent, respectively. Compared with countries with similar income level, Burundi's poverty rate is lower than only Congo Democratic Republic's and Madagascar's poverty levels (Figure ES.3).
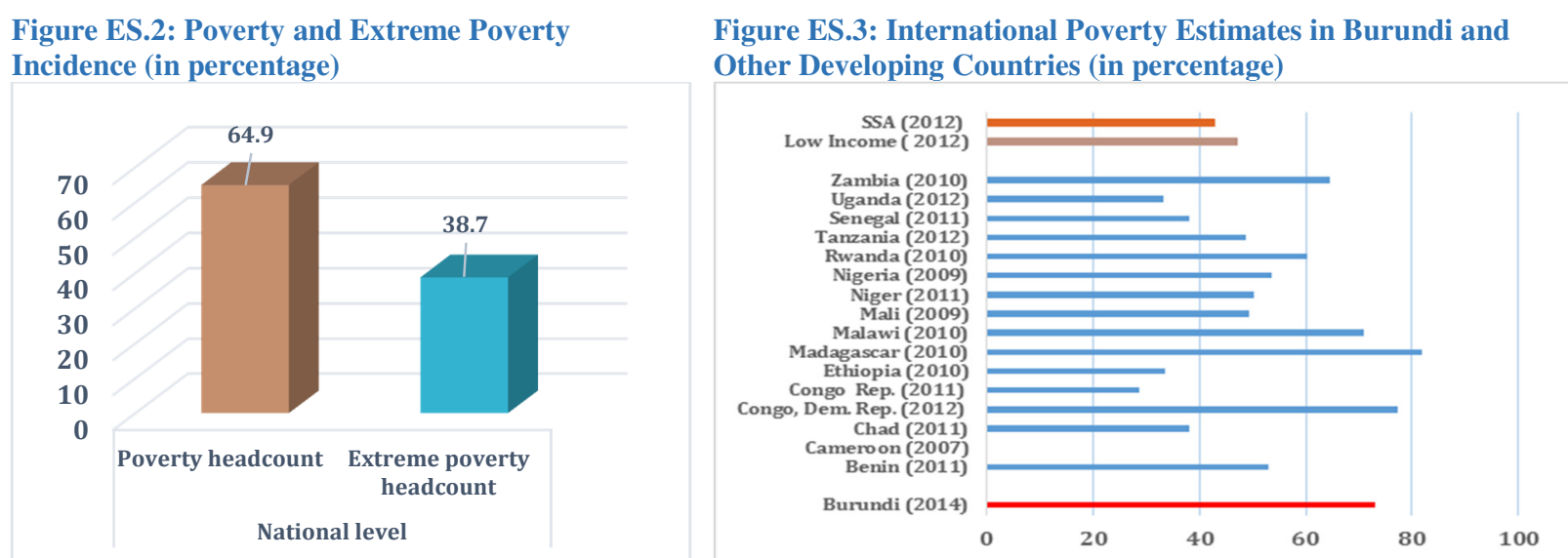

Source: ECVMB 2013-14 and World Development Indicators (WDI, 2015). Note: international poverty estimates based on the poverty line of US\$ 1.9 per person per day (in 2011PPP exchange rate).

A large share of the non-poor population is clustered just above the poverty line and is highly vulnerable to fall into poverty. Around 50 percent of the non-poor population stagnates at a consumption level right above the poverty line, within a range of around US\$ 0.5 per capita per day (in 2011 PPP). They are therefore prone to fall back into poverty in case of unexpected economic shocks. Any slight increase in the value of the poverty line would induce a significant rise in the estimated poverty levels. However, while most of the non-poor are close to the poverty line and are vulnerable to economic downturns, the majority of the poor are far below the poverty line (with an average consumption level of about 75 percent of the poverty threshold) and would need substantial assistance and special care in the development programs to help them enhance their livelihoods and productivity.

The geographic distribution of poverty is uneven, being more pervasive in the rural sector as well as in the Center-East and the North. About 95 percent of the poor people live in the 
rural sector where the incidence of poverty is estimated at 68.9 percent against, respectively, 40.9 and 20.8 percent in the other urban areas and Bujumbura mairie (the capital city). In rural Burundi, extreme poverty is estimated at 41.3 percent and is four times higher than in the capital (10.4 percent) and around double than in the other urban areas (22.7 percent) (Figure ES.4). Poverty is also less prevalent in the West and South of Burundi, where poverty rates are respectively estimated at 46 percent and 58 percent compared to a poverty level of above 70 percent in the Northern and Center-Eastern regions (Figure ES.5). There are also wide spatial disparities in poverty within regions, with the largest differences being observed in the West and the South.

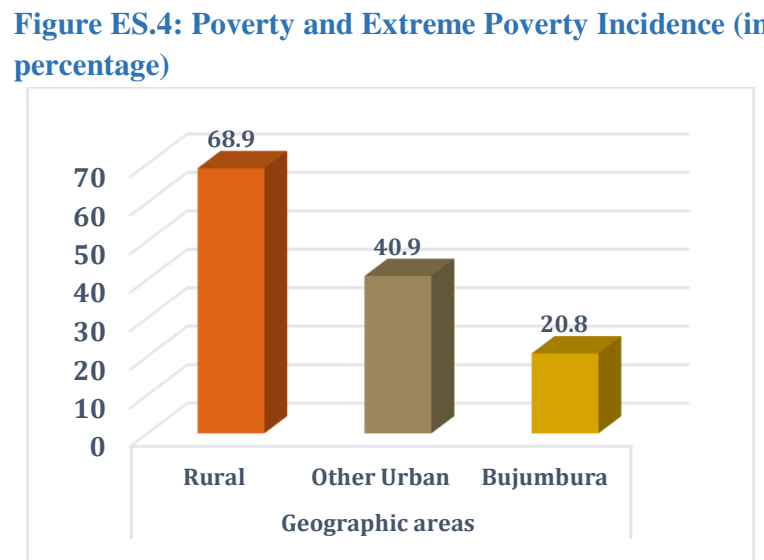

Figure ES.5: Poverty Incidence by Region (in percentage)

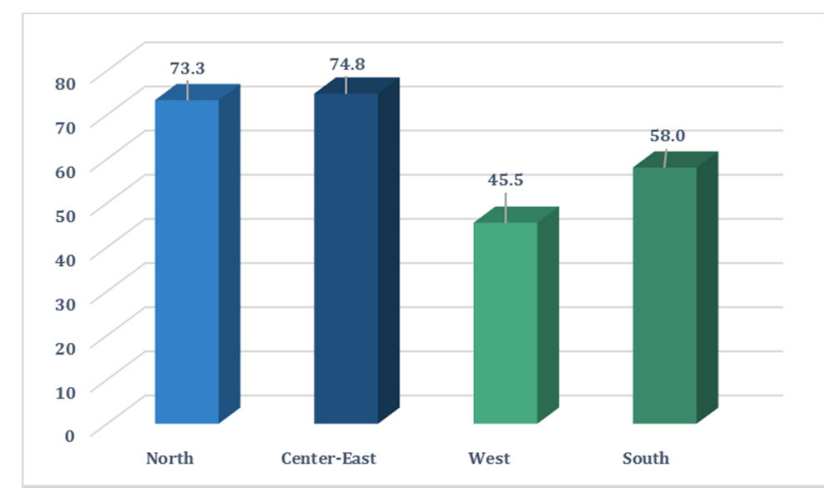

Source: ECVMB 2013-14

The uneven spatial distribution of poverty is likely related to the pattern of economic growth. Economic growth was almost entirely centered in Bujumbura and some urban areas, where most of the expanding and flourishing sectors are concentrated. These include services, which have been expanding by 7.1 percent per annum from 2006 to 2014 and to a lesser extent small industries, which have been growing by 5.7 percent per annum in the same period. Imbalances in the aid flow seem to contribute to the spatial disparities in poverty, as provinces in the West are likely to have benefitted from larger support than in the rest of the country.

The spatial poverty pattern resonates with the inequality between geographic regions. The Gini coefficient of real per capita monthly consumption indicates that the overall level of inequality for Burundi is approximately 37.3, below the SSA average of 45.1 and the lowincome countries average of 40 (Figure ES.6). However, the positive picture of moderate inequality in Burundi hides large welfare disparities between population groups. Inequalities between rural and urban areas are quite substantial and are mainly driven by significant differences in households' endowments of livelihood assets. More specifically, urban households are better off than their rural counterparts because they have better access to basic services and infrastructure (e.g., electricity, health, markets and roads), higher education and higher ownership of communication and transportation means. These differences are particularly significant for the poorest income groups of the population. There are also significant 
inequalities between households located in the West and South of Burundi and those located in the Center-East and North. These inequalities are mainly due to differences in access to basic services and infrastructure, followed by differences in education and asset ownership. These divergences seem to contribute significantly to the interregional welfare gap, but the magnitude appears to be stronger at the upper quintiles.

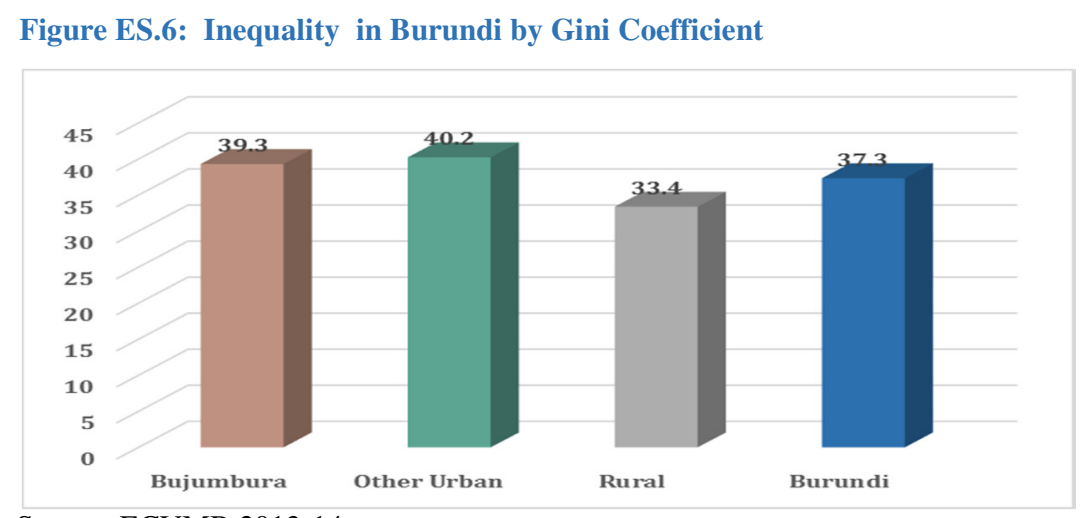

Source: ECVMB 2013-14

Poverty is associated with agricultural employment, larger families, lower education, low access to infrastructure, and migration

Households with large numbers of children, handicapped members or headed by single/widowed women are more likely to fall into poverty. Poor households have on average 6.1 members, compared to 6.4 among extremely poor households and 5.2 for non-poor households. Poorer households also have a higher number of dependents and children under the age of 14 than non-poor, a gap that has been widening since 2006. The dependency ratio is 53 percent compared to 47 percent in non-poor households. In addition to household size, the age of the head also correlates with poverty. The poverty headcount of families with younger (15-35 years old) heads is 15 percent lower, as they have a lower number of children. Meanwhile, households led by women are poorer as long as the woman is single or widowed. Women that are married or in a free union are likely to receive additional financial support from their male partner and thus present lower levels of poverty. Finally, households with handicapped or disabled members, most of them due to war-related injuries, present a 3 percent higher poverty headcount, with greater incidence in the South and the West of Burundi.

Lack of access to higher levels of education, infrastructure, basic services and durable goods appears to be very common among poor households. Low levels of education are frequent among poor households: 66 percent of these households have a head with no formal education. Poverty among university graduates is virtually nonexistent, which suggests that this level of education is unattainable for poor households. Over 80 percent of heads of poor households are self-employed or employed in the agricultural sector, with higher incidence of poverty. Furthermore, the poorest 40 percent of the population lack access to infrastructure and basic services. On average, only 4 percent of the bottom 40 has access to electricity, sanitation 
services, good sewage connections and trash collection. Access to drinking water is better, reaching 72 percent of the poor, but most of the population has to procure water outside the household. Possession of assets, such as cell phones, power supply, refrigerators, TV or DVD, is linked with lower levels of poverty.

\section{Poverty levels are substantially lower among migrant households than among non-migrant}

households. Households with a migrant head present a poverty incidence close to 17 percentage points lower than those with non-migrant heads on average, with the exception of Bujumbura where the poverty incidence is nearly identical between both groups. This is a consequence of higher literacy in regional languages and higher likelihood of working in the non-agricultural sector among migrant-headed households. In addition, households headed by migrants are more likely to have greater financial capacity than non-migrants due to the costs of migration. With regards to gender dynamics, it appears that women are more likely to lead a migrant household than a non-migrant household. The majority of migrant women become self-employed, typically selling fresh or moderately transformed agricultural products and local alcohol beverages.

Some positive, but slow, outcomes in living standards, with remaining low human development

Poverty reduction in Burundi has failed to keep pace, declining only 5 percent since 2006. Extreme poverty seems to have declined faster and more steadily than basic needs poverty, dropping from 46 percent in 2006 to 38.7 in 2013/14 (Figure ES.7). There are also significant regional differences: while poverty has decreased 11 percent and 16 percent in Bujumbura and secondary cities respectively over the last decade, poverty levels in rural areas remain practically unchanged (Figure ES.8). Indeed, improvements in living standards and poverty reduction seem to have been driven by a move towards the service sector in urban areas. Improved living conditions can also be explained by reductions in household size, particularly in urban areas. Household size decreased around 5-6 percent in rural areas and 7-8 percent in urban areas in the last decade. The age pyramid of Burundi is changing slightly with the 5-9 year-old bracket becoming the largest group in 2013 as opposed to the predominant 0-4 year-old bracket in previous years. 

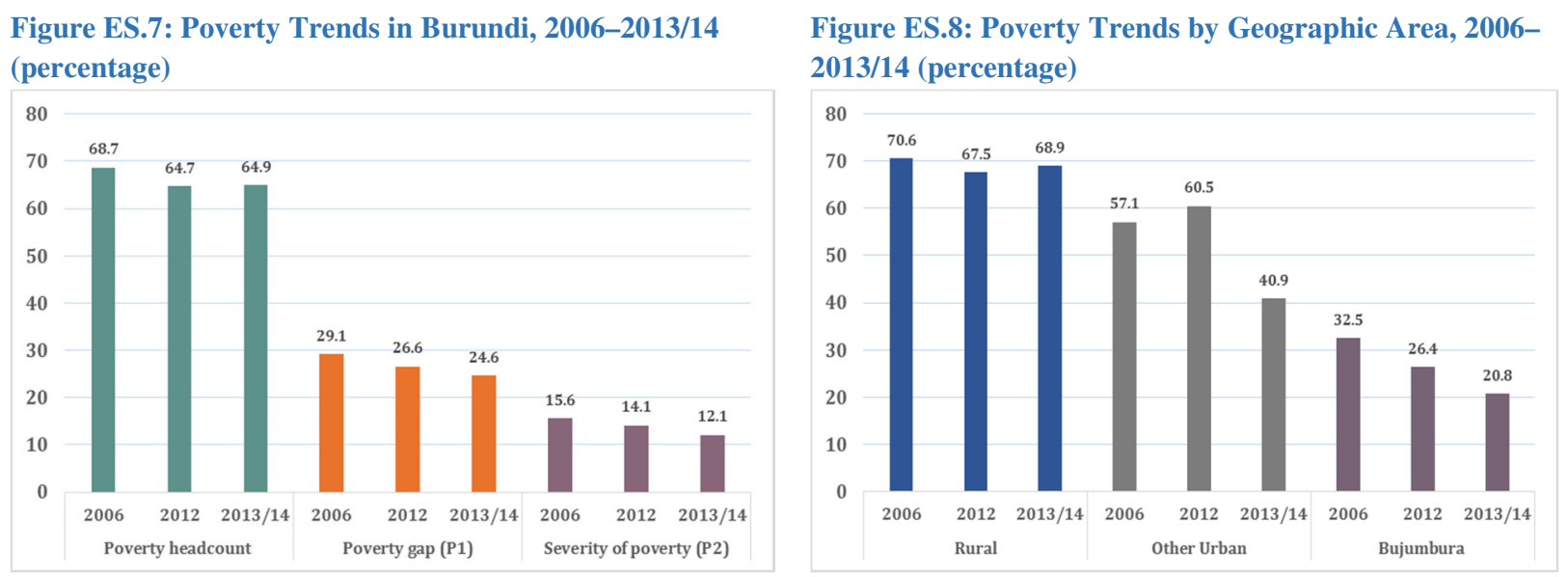

Source: ECVMB, 2013-14.

Education levels have somewhat increased over the last decade, but overall levels are low. Burundi's complete illiteracy has decreased from a 62 percent of heads of household with no formal education in 2006 to a 58 percent in 2014. Despite this improvement, education levels remain very low, as 45 percent of the population has no formal education and about 47 percent has primary education only (mostly incomplete primary). In addition, the gender gap has widened over the same period. In 2006, the differential between the literacy rates of men and women was 12 percent points compared to 15 percent points in 2014. There are also regional disparities in regards to access to public schools. There appears to be a greater number of public schools in Bujumbura to the detriment of other regions of the country.

Burundi has made little progress in some health indicators, but the situation remains alarming particularly regarding food security and nutrition. There have been some improvements, though very limited, in life expectancy, fertility rates and infant mortality, during the last decade. However, the food security and nutrition situation are alarming. Burundi was at the $78^{\text {th }}$ position (the lowest) in the Global Hunger Index of 2013 with a score of 38.8. Chronic malnutrition is highly prevalent and around 58 percent of children under five are stunted. The stunting rate exceeds 60 percent in rural areas as well as in the North and Center-East. In 2014, the incidence of illnesses/injuries during the last 4 weeks has returned to 2006 levels driven by a large increase of this rate in urban areas besides Bujumbura mairie. Similarly, access to public health facilities remains limited, with stark differences between Bujumbura and other territories, in favor of the capital.

There have been some improvements in living conditions and access to basic services, but these are mainly concentrated in urban areas. More Burundians have gained access to floor, wall and roof materials of higher quality, although access to improved floor materials remains significantly lower compared to the other two (only 15.5 percent of the population had floor made of tile cement and brick in 2014). Access to drinking water has also improved on average, but worsened in rural areas. Besides Bujumbura, which uses piped water, most of the population has to procure water outside the household, with a significantly high percentage of people purchasing water from unprotected sources (up to 28 percent in the South of the country). Access 
to better sanitation facilities has only been observed in the capital, while it has declined around $15 / 20$ percent in rural areas in 2006-14. Similar regional differences are observed in access to electricity. While access has increased around 45 percent in urban areas, electricity remains largely inaccessible in rural settings. Cooking fuel, mostly firewood and charcoal, is basically universal in both urban and rural areas.

\section{Political instability and fragility have taken their toll on economic growth and poverty alleviation}

Years of civil war and violence have deeply affected the country, hindering efforts to improve good governance and therefore the living conditions of the population. Chronic fragility and a succession of governance failures are the main reasons for the lack of development and poverty reduction in Burundi, and any progress is unlikely to take place until these constraints are addressed. Violence and fragility keep people from going about their usual activities, keep children out of school, keep investors out of the country, and stunt development prospects in general. The Burundian government has made some efforts to stabilize and rebuild the country in recent years, putting security and peace consolidation on top of the agenda in 2013. However, the current political crisis is pushing the country to the brink of economic collapse.

Linked to violence, institutional failure is also an important driver of poor performance in Burundi. Public sector governance in Burundi remains very weak and below SSA averages, mainly in terms of political stability, government effectiveness, rule of law and control of corruption, which have been critical constraints to post-war development in Burundi. Corruption appears to be particularly salient. Checks and balances against corruption have greatly deteriorated over the last decade. The Corruption Perception Index classified Burundi as the sixth most corrupt country in Sub-Saharan Africa in 2014 and 2015. Meanwhile, investment since independence has generally been allocated in response to needs for patronage and rent-seeking rather than based on economic efficiency. Similarly foreign aid and agricultural rents -through price controls, particularly on export crops- have been largely captured by political elites. These circumstances largely explain the slow growth that Burundi has experienced since independence.

Violence and fragility largely affected household's welfare, with potential long-lasting effects on human capital. The effect of conflict is persistent as households affected by violence during Burundi's civil war still had lower consumption levels in 2012 than those observed before the war started. During the years of civil war life expectancy fell from 51 to 46 and undernourishment increased 20 percent. The probability of completing primary school plummeted and school-age children dropped out due to the conflict and never returned to school. The war's effect on education will likely have a negative effect on long-run living conditions of affected cohorts. Children under the age of five that were exposed to violence were much more likely to be stunted. Considering the negative effects of malnourishment on human 
capital and social outcomes later in life, adverse economic opportunities remained long after the violence stopped.

The economy lacks the prerequisites for productive transformation and jobs creation. Infrastructure falls short, with the provision of electricity being particularly problematic and access to roads very limited. The country is further hampered by its landlocked position with a high population density, limited and degraded natural resources, low human capital and very limited qualified labor. This, combined with institutional weaknesses and political instability, holds back private investment and productive economic activity. Consequently, most of the population rely on agriculture and non-agriculture informal jobs and are likely to continue working in these sectors for the foreseeable future.

\section{Employment dominated by agriculture and informality, with low mobility}

The vast majority of Burundi's labor force is employed in agriculture and other informal activities. Over 85 percent of the working-age adults had their main job in agriculture in 2014, essentially as independent farmers or unpaid family farmers (Figure ES.9). Informal employment dominates across all sectors, accounting for over 95 percent of the total number of jobs. Agricultural employment is mostly informal, while less than 15 percent of the jobs in the industrial and trade sectors are formal. The situation seems to be more balanced in the service sector where about 44 percent of the jobs are reported as formal employment (Figure ES. 10). Also, informality seems to be less prevalent in the Capital city and other urban areas.

Figure ES. 9: Employment Share by Sector (Percentage)

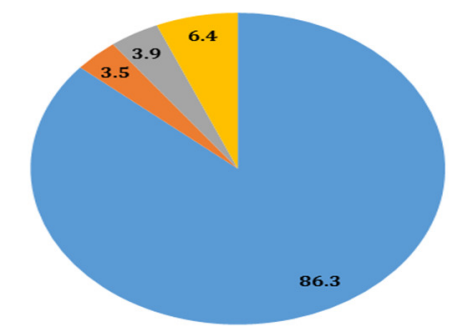

Source: ECVMB, 2013-14.
Figure ES. 10: Formal and Informal Employment by Sector (Percentage)

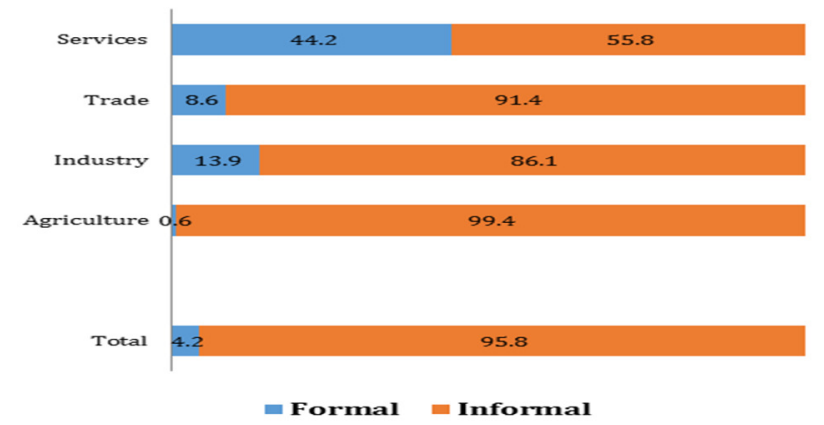

Non-farm informal enterprises are small and operate with low skilled workers in low productivity sectors. Informal units of production (UPI) contribute to over 50 percent of the jobs outside agriculture. An overwhelming majority of non-agricultural UPI is found in the rural sector and is concentrated in wholesale and retail, manufacturing, and accommodation and restaurants (Figure ES. 11). Over half of UPI are own-accountants and about 80 percent operate with three employees or less. More than three quarters of workers in non-farming informal jobs have not completed basic education and less than 4 percent have been able to go beyond primary education. 
Figure ES.11: Non-farming UPI by Sector and Geographical Area (Percentage)
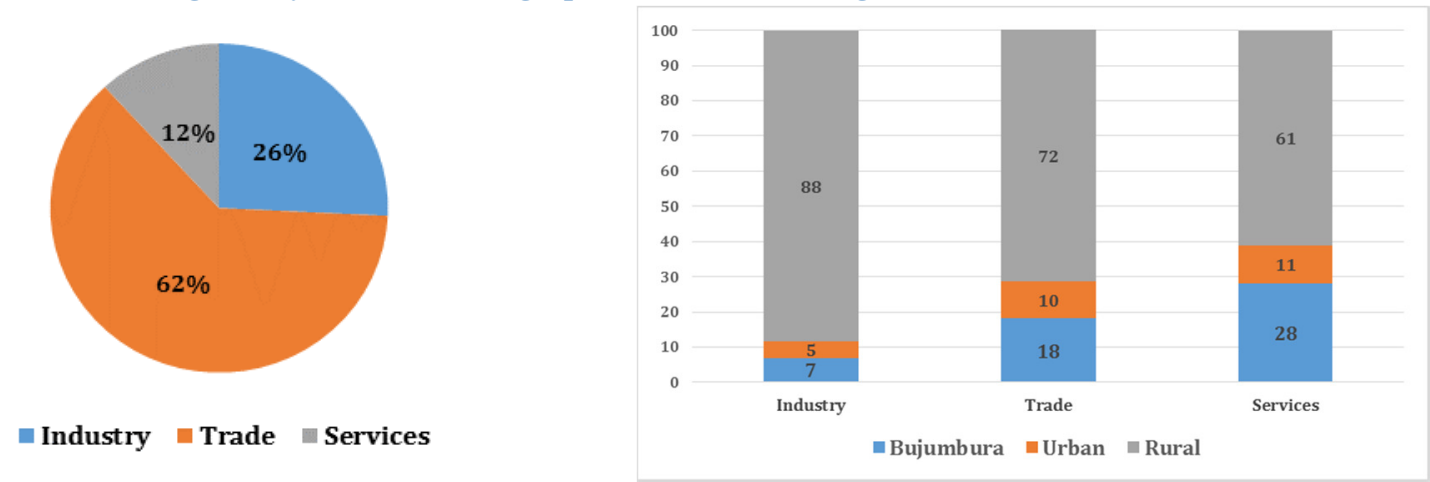

Source: ECVMB, 2013-14.

Poor working conditions are common in the informal sector. While nonfarm informal workers have higher incomes than those employed in agriculture, they continue to be much less paid than formal employees. Non-agricultural informal workers earn twice the amount of agricultural workers but five times less than nonfarm formal workers. The overwhelming majority receives income under the form of profits. Around 7 percent only receive irregular payments, which means that workers are contracted on a one-time basis and receive a flat payment for a specific task performed. The non-farming informal workforce also lacks social benefits and social protection. Most of them work with self-contract or verbal agreement and do not perceive any leave protection or social security. Around 12 percent only receives bonuses under the form of profit sharing, while only 9 percent obtain in-kind benefits. Other forms of benefits within the informal workforce are almost inexistent. Less than 5 percent of informal workers benefit from paid sick leave, paid annual leave, and end-of-the-year premium.

The labor market is characterized by high inertia, with very slow employment transitions since the late 1990s. Between 1998 and 2008, agriculture's share of employment remained constant at over 90 percent. Since 2008, there has been a modest move towards non-farm employment, with agriculture's employment share declining by 7 percentage points. Young men have driven the recent move to non-farm employment (and in particular wage employment). In 2014, over 90 percent of women still were employed in agriculture, compared to 75 percent of men (Figure ES.12). Occupational persistence is particularly high in agriculture: 76 percent of young men with a farming father also work in agriculture, and this rises to 94 percent for young women. 
Figure ES.12: Employment share variations between 2008 and 2014
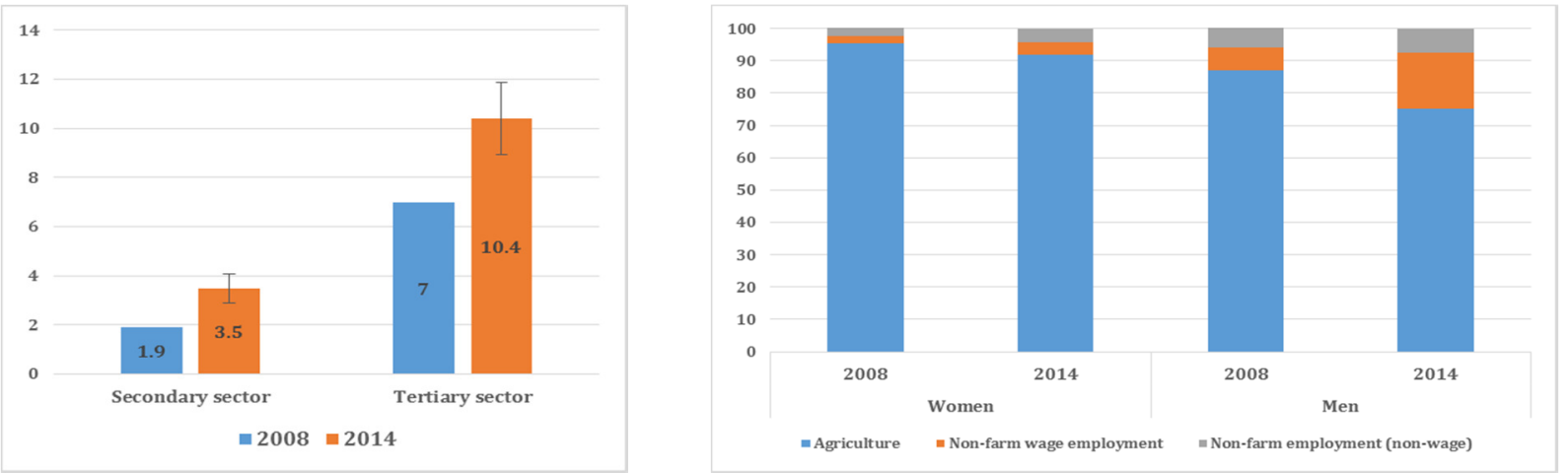

Source: PHC, 2008; ECVMB, 2013-4. Primary sector not shown in the first graph for the sake of readability.

Intergenerational mobility was also low. Young workers (15-30) are largely doing the same occupations as older workers (30+), and intergenerational occupational mobility is particularly limited among women. 92 percent of young women are doing the same occupation as their mother, and 73 percent of young men work in the same sector as their father (mainly farming) (Figure ES.13 and ES.14). There are also signs of inertia in the small modern labor market: the lion's share of higher-educated workers have never changed employers and are not planning to do so, especially those employed by the public sector. Unemployment among higher-educated workers is high (20 percent), and data suggest that the educated unemployed are waiting for a public sector job to become available.

Figure ES.13: Like father, like son -at least in farming

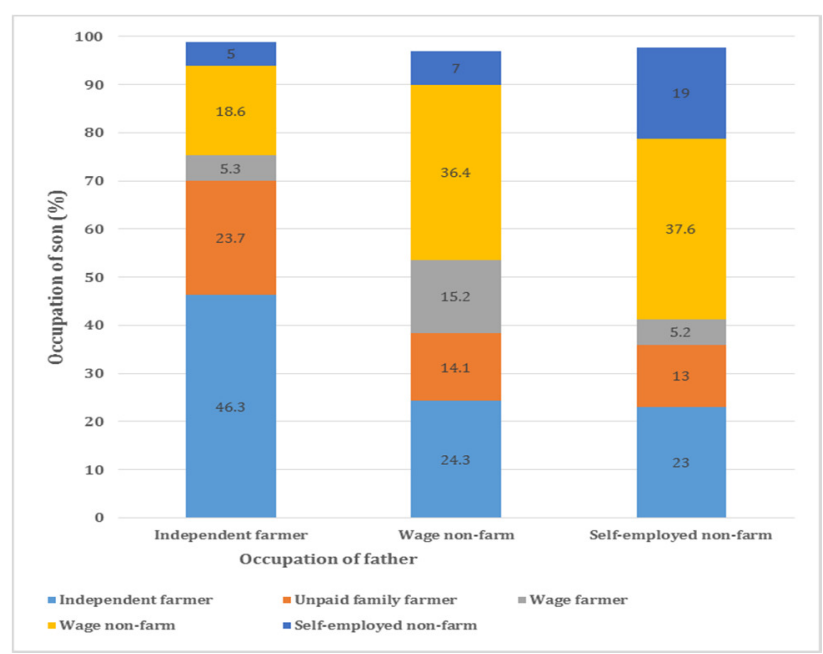

Figure ES.14: Few young women are upwardly mobile

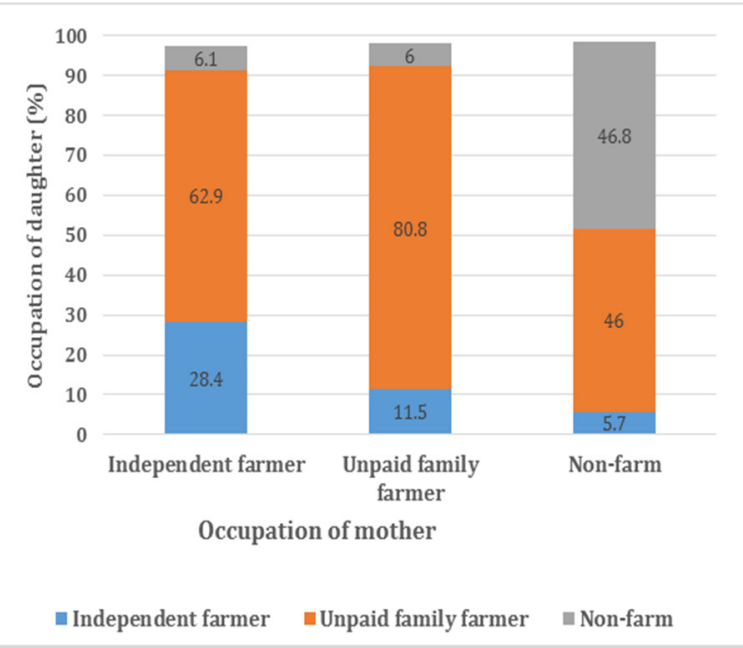

Source: ECVMB, 2014.

Significant gender gaps in the labor market

Women are particularly disadvantaged in the labor market. There are large gender discrepancies regarding the nature and status of employment. Close to 90 percent of unpaid employment is done by women and less than 40 percent of public sector employees are female 
(Figure ES.15). Over 92 percent of women have agriculture as their main occupation, compared to 75 percent of men, and less than four percent has a wage job in the non-farm sector. Even within agriculture, women are overrepresented in the less desirable occupations: two thirds of women have their main job in unpaid family farming, compared to nine percent of men. Women are less likely than men to be independent farmers (to be the "boss" of a family farm) and to be self-employed outside agriculture.

Figure ES.15: Nature of Employment by Gender (Percentage)

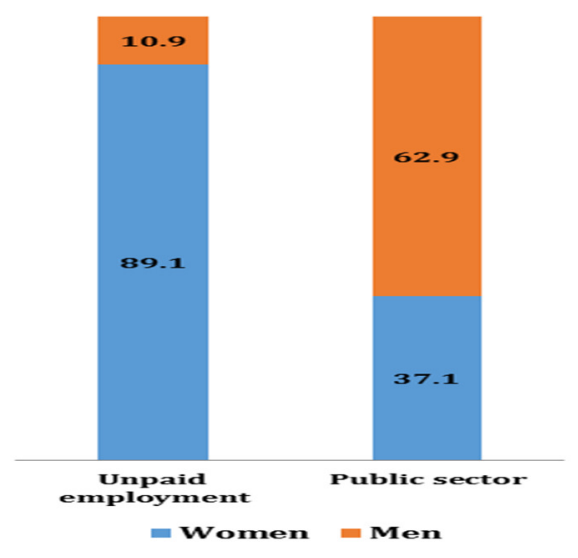

Figure ES.16: Informal Employment by Form of Contract and Gender (Percentage)

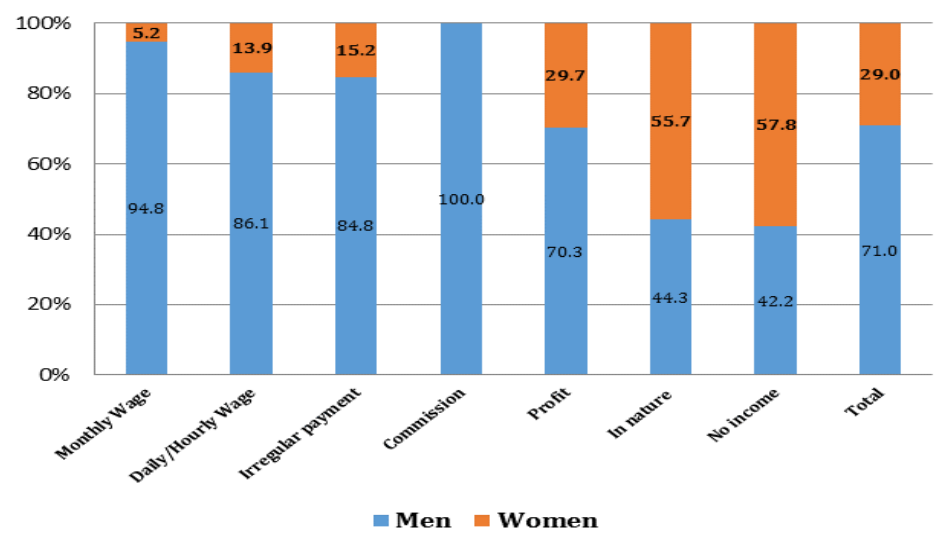

Source: ECVMB, 2013-14.

Women bear the largest share of disadvantages in the non-farm informal sector. Men benefit from more secured and stable payments such as monthly wages and daily/hourly wages, while women are disproportionately disadvantaged in regards to less secured and unequal forms of payment (Figure ES.16). Around 56 percent of the informal workers receiving in-kind payments are women and close to 60 percent of those who do not benefit from any form of income are also women. Those figures stem from the prevalence of women involved in nonfarming informal activities without any form of contract, as more than half of the non-contracted informal workers are female. Since many women often carry tasks related to the main economic activity of the household, the income generated generally accrues to the male head of household, leaving women without any proper form of payment.

\section{Underperforming agriculture: predominantly traditional, operated on small size plots} and depending on family labor

\section{Population employed in the agricultural sector has on average lower levels of income and} welfare. The agricultural population tends to live in large households and tend to be poorer as a large household does not always imply more land to farm. Often, individuals from the same household rely on the same small plots and limited food production. In addition, a young population with limited education marks the farming community. Nearly 60 percent of population is less than 19 years old and more than half cannot read or write in Kirundi. There are also few farmers' organizations/associations, which limits the sharing of knowledge and good 
practices. Despite proximity to farms -they are mostly found inside the community- most of them are located in hilly areas (85 percent), which creates challenges in terms of erosion and the design of schemes addressing the degradation of hill-flanked plots.

Agriculture in Burundi remains highly traditional as a result of small plot size, lack of technology and limited used of enhanced seeds and chemical fertilizers. There has been a slight improvement of 23.5 percent on the average size of a plot per person. However, the average plot size remains very low, with the average plot size being less than a tenth of a hectare. Smaller plots are found on average among women owners, lower quintiles and specific provinces (e.g. Buragane). Small plot size will potentially yield serious challenges in terms of economies of scales, and technology adoption. Meanwhile, land is usually transferred through inheritance and commercial transactions remain limited. As a result of those trends, agriculture in the country remains very traditional and neither animal traction nor modern mechanization exists in Burundi. Farmers use a range of tools that are owned by the household with very little technology involved. In addition, improved seeds are limited, with only 5 percent of the plots planted with such seeds (with the exception of rice, whose incidence accounts for 10 percent). Finally, there has been an increase over time in the use of chemical fertilizers. However, while two fifths of households use these fertilizers, they only do so on a limited subset of the plots they own, depending on the type of crops being grown.

Seasonality, regional discrepancies and lack of income diversification mark the agricultural sector in Burundi. Burundi's main agricultural activities entail rain-fed crops, truck farming, and livestock, and the main crops are maize, cassava, banana, beans, and sweet potato. Conditions of Burundi allow farmers to cultivate crops three times per agricultural year, with differentiated food crop production by agricultural seasons. The most important season, from mid-February to mid-June, supplies 40.5 percent of yearly national food production. In addition, production is specialized by regions and crops are usually combined with others at the farm level, with only one third of the cultivated land allocated to a single crop and up to 20 percent of land allocated to four crops or more. Meanwhile, diversification outside the agricultural sector remains limited, with 90 percent of households reporting not having any additional source of income outside agriculture. This makes Burundians highly vulnerable to weather and price shocks and less likely to increase their income and assets.

There have been some gains in food productivity but on average, levels remain low. Between 2012 and 2013, Burundi food production increased 21.1 percent, which may have helped families to improve their daily lives (Figure ES.17). Households living in the South experienced the largest food production gains, with an increase of 33.9 percent. However, the Centre Eastern and Northern regions have the largest food production levels. Compared to similar countries such as Rwanda, Burundi has become a low productivity country mainly due to protracted environment, social, and political shocks. In addition, yields in some of the main crop categories -cereals and leguminous - have shown no improvement from 2011-2013, and yield levels remain low compared to regional peers (Figure ES.18). Finally, differences in land size 
and yields across gender, welfare and regions, has resulted in a concentration of crops among small population groups.

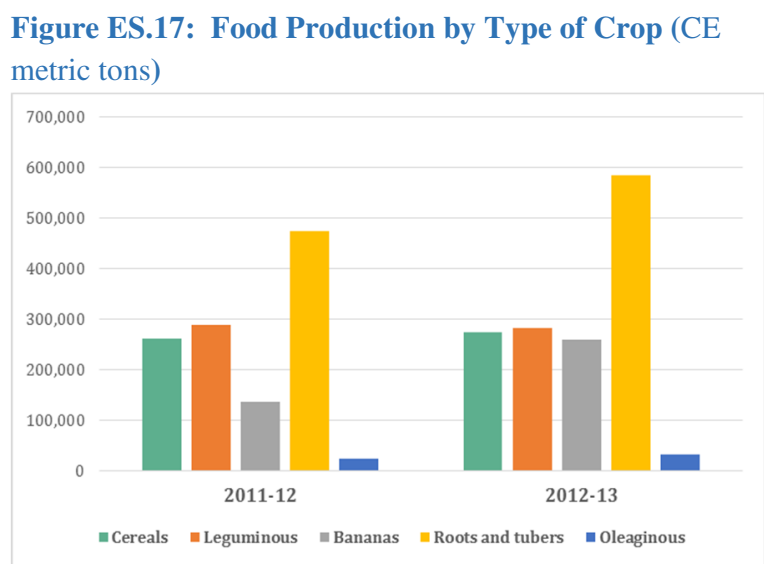

Source: ENAB 2011-12 and 2012-13

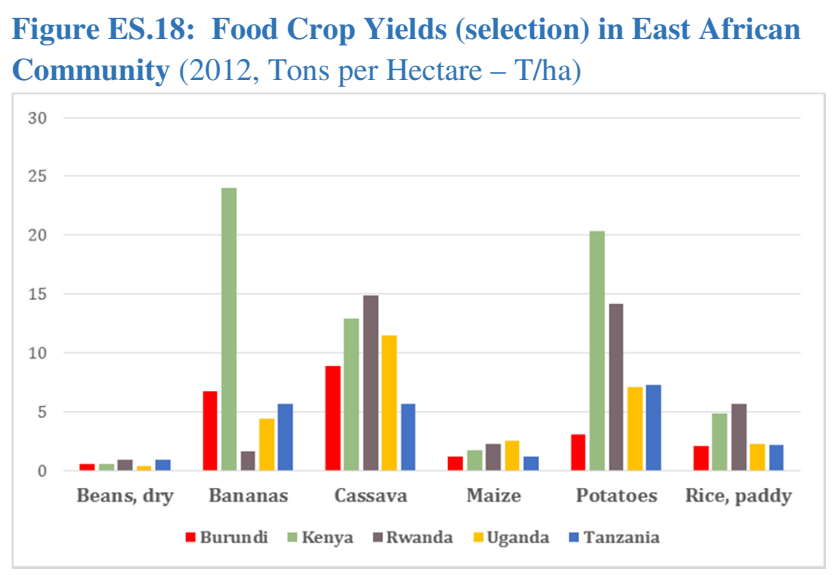

Source: FAOSTAT

Land degradation and climate change threaten to weaken an economy already hobbled by primary sector dependency. Environmentally, unsustainable practices can be linked to the persistence of poverty in Burundi's hinterland. Eight of the most impoverished provinces (Muyinga, Ruyigi, Gitega, Cankuzo, Kayanza, Kirundo, Karusi, Rutana) are also identified as being among the most heavily environmentally degraded in the country. The exposure to climate change is further exacerbating the situation. Due to El Niño climate phenomenon, the rainy season have extended. This resulted in heavy rainfalls that affected yields and food security, and led to house destruction and spread of diseases such as cholera.

\section{Agricultural inefficiencies mainly driven by low access to finance and markets imperfections}

Financial services in Burundi are not accessible to farmers, which undermine agricultural productivity and rural revenues. In Burundi, banks and microfinance institutions seldom finance agricultural activities mainly due to high risks associated with price volatility and climatic shocks, lack of professionalism among farmers and lack of guarantees to secure repayment in case of default. As a result, 90 percent of farmers are excluded from the formal banking system and are being forced to rely on informal financing (e.g. mutual aid associations) and self-financing through households' cash crops sales. Extension and advisory services are also very low in Burundi with the government and NGOs providing them in different parts of the country. In addition, there is an ongoing reform of land ownership aimed to provide farmers with valuable collateral that could be used to seek financial credit and loans. However, the increasing incidence of land-led conflicts has challenged the implementation and enforcement of the new regulation.

In the Burundi context, access and use of fertilizers have become one of the most significant impediments to increase yields and productivity in the agricultural sector. Although its 
diffusion remains limited, the demand for fertilizers has improved over the last few years with an increment of 76 percent between 2012 and 2013. This presumably explains part of the period's aggregate food production increase, which is why regional authorities and development partners have focused on increasing access to fertilizers, in particular DAP. Indeed, three out of four regions in Burundi experienced large increases in the use of fertilizers and achieved significantly larger food production levels in 2013 compared to 2012. The fourth region, the West, experienced a decline in the incidence of household users of fertilizers and also obtained the lowest total food production per household. Nonetheless, the prevalence of rural users of DAP fertilizer remains low (between 7-22 percent) across the country with the exception of the Centre Eastern region (54-60 percent) due to higher deficit of soil nutrients and higher levels of education, producer organization and female headed households. In addition, Burundi's agricultural lands are exposed to intense and rapid erosion, although very limited schemes are designed and implemented to prevent and slow this phenomenon.

Labor market inefficiencies also constrain agricultural productivity. Burundi appears to experience inefficiencies in resource allocation both within and between households. The inefficient allocation of labor resources is driven by three major constraints. First, credit market constraints and imperfection in the labor market makes it difficult for households to hire sufficient labor. This leads to large misallocation of hired labor between households. Second, a binding credit market constraint combined with insurance market failure leads to misallocations of female family labor on plots where climbing beans are cultivated. Third, there is a major misallocation of family labor inputs driven by the gender of the person who manages the land: plots managed by women made excessive use of female family labor while insufficient use is made of male family labor on plots managed by men.

\section{The current political crisis is further compounding the situation}

The economy has contracted in 2015, with real GDP declining 2.5 percent. Interruption in activities in 2015 led the economy to a standstill position, particularly in urban areas. Industrial production declined by 8.5 percent with output contracting in almost all the manufacturing industries as well as in utilities and construction sectors. Trade, tourism and transport sectors were also hit and the service sector is expected to have declined by 5 percent. On the demand side, investment and export of services are the main drivers of the contraction. As a result, poverty rate based on the international poverty line ( $\$ 1.90 /$ day) is projected to have increased from 72 percent in 2014 to 77.4 percent in 2015.

The health situation has worsened, putting the poorest and most vulnerable at risk. Preliminary reports from the World Food Program show a very alarming situation on the nutrition front with food insecurity increasing by 11 percent since 2014 and severe food insecurity by 4 percent. The UN Office for the Coordination of Humanitarian Affairs (UNOCHA) announced that based on the latest Emergency Food Security Assessment (EFSA) conducted in April 2016 in 18 provinces, nearly 4.6 million people are food insecure. Of these, 590,000 were found severely food insecure and in need of emergency food aid. 15 out of the 18 
provinces in Burundi were particularly hit by the increase in food insecurity, with dramatic spikes in Kirundo (33 percent), Makamba (25 percent), Cankuzo (24 percent), and Rutana and Bujumbura rural ( 23 percent). The political crisis effects were further exacerbated by the limited availability and fertility of land, climate change effects in 2015-16 (El Niño effects, droughts and flooding), limited coping strategies of poor households and job losses, increasing dependence on markets, increases in food prices and declining purchasing power. The health situation has also deteriorated with Malaria cases expected to have tripled in 2016 and maternal mortality to have doubled in 2015. Frequent stock-outs of drugs and therapeutic foods in many public health facilities are forcing patients, users, and free health care beneficiaries, to buy essential drugs from private pharmacies. According to UNICEF estimates, the situation affected more than 1 million under-5 children and 400,000 pregnant women in 2015 alone.

\section{Implications for Policy and Research}

Burundi appears to be trapped in a double vicious circle arising from vulnerable agriculture and environmental degradation that affect food production, which in turn, combined with high population density, fragility, and conflicts, favor the prevalence of food insecurity and poverty. The consequences of years of conflicts and instability have clearly taken a heavy toll on the living conditions of the population and human development outcomes. Peace and security breakthroughs appear to have resulted in steady, but slow, economic growth and some progress in socio-economic conditions since 2006. However, the improvements remain very low and were mostly concentrated in the urban sector. The country is off-track in meeting the MDG targets and World Bank twin goals of eradicating poverty and shared prosperity, and the prospects are not very optimistic.

The findings reveal high prevalence of poverty, illiteracy and low education levels, poor access to basic services and infrastructure and significant inequalities between geographic regions. The agriculture sector, where the vast majority of the population is employed, is underperforming and those working outside agriculture rely mostly on informal jobs. There are modest signs of labor force shifts towards nonfarm activities, but the changes are very slow and were centered in the urban sector. In general occupational mobility is very low and the labor market is inert. Governance and institutional failures are holding back the wheel of progress and stifling economic growth. The current crisis is further exacerbating the already existing problems for food security, health, and vulnerability.

Burundi's challenges are many and cannot be effectively addressed through stand-alone policy approaches. They would require a cohesive multi-sectorial strategy that is beyond the scope of the Poverty Assessment. However, the analysis in this report provides pointers for potential priority areas for policy action. The basic tenets of conventional poverty reduction strategies such as investment in human capital and infrastructure, income and employment generation, and control over fertility and family sizes largely remain, and are even more relevant in the current situation, but they are not sufficient. They need to be combined with two groups of actions. 
The first group consists in providing emergency support to the population groups who are in severely food deficit situation and health care needs. A quick reengagement of the Donors and close coordination with local NGOs and humanitarian organization is instrumental. Interventions in this group are aimed at preventing further deterioration in human capital, stabilization of the economy and prompting back international assistance.

The second group consists in restoring political stability and confidence in the government for the economic activity to resume and flourish. Higher and faster economic growth is the necessary condition for improving people's living standards and accelerating poverty reduction. An indispensable prerequisite is political and social stability as well as building of trust within the society and between the state and the citizens. This will require greater transparency and accountability as well as increased space for dialogue and reform. Key actions could include promoting participatory dialogue between the government and citizens, including media, Civil Society Organizations and NGOs, and engagement on critical political and governance reforms, with a focus on increasing equitable and inclusive decision making. The institutional and governance failures are deep-rooted and require a long-term horizon to be addressed, but important opportunities exist for mitigating them through delivering gains in the short or medium term. Interventions in this group should not necessarily focus on transforming the economy or changing radically the economic opportunities for the population, but rather on initiating the recovery process and gradually improving livelihoods. Policy programs could focus on improving the delivery of basic services and helping the population meet their basic needs:

- Expanding the provision of basic services and amenities across the country would not only strengthen human capital capacity, but also enhance the legitimacy of the State and ensure more equal economic opportunities. Better service delivery requires also an improved coordination with social protection programs to help poor population groups enhance their livelihoods and productivity and advance the inclusiveness of the most vulnerable ones in the economic system.

- The development of rural economy and agriculture will be instrumental for an effective poverty-reduction strategy in Burundi. Agriculture is and will remain the largest source of employment and the main livelihood activity of the poor. There is no escaping the need to galvanize this sector. Stimulating agriculture through improving farmers' access to modern production means and quality inputs, fostering their access to finance, enhancing their connectivity to infrastructure and markets, and encouraging a more commercial agriculture is key for rural poverty reduction.

- Agricultural development alone will not meet the poverty challenge, as it will not be able to absorb the expanding young labor force and generate jobs commensurate with the aspirations of the youthful workforce. Higher diversification towards nonfarm activities can play an important role in boosting the local economy, promoting job creation and alleviating poverty. Efforts to accelerate the process of diversification could yield quite 
significant benefits in terms of increased employment opportunities and reduced poverty, not only in the rural sector but also in secondary cities in urban areas.

On the basis of the analysis in the report, the following areas call for further research and investigation:

$\checkmark$ Strengthening statistical and analytical capacities. Access to timely and quality data is of high importance for monitoring appropriately the evolution of poverty and household living conditions. Understanding the potential drivers and consequences of the recent political events is of critical importance, particularly for the donor's engagement and agenda. More frequent household surveys (mainly household budget surveys and labor force surveys) will enable better analysis on poverty, employment, and growth, and would promote evidence-based and effective policymaking. Timely population and agricultural census (including data on industrial crops such coffee and tea) would also be of tremendous importance in this process.

$\checkmark$ A deeper understanding of the underlying causes of spatial inequalities and the reasons of the relative success achieved in the West, and to a lesser extent the South, will help to better shape future interventions to reduce poverty in the rest of the country, particularly the Centre-East. The analysis of the constraints faced by poor farmers in raising productivity, accessing markets and diversifying (both within farming and into non-farm activity) would help to design better focused policies and programs.

$\checkmark$ The absence of information on land ownership and use in the household survey is quite limiting. Understanding how land ownership affects poverty, particularly in a country suffering from limited land resources and high population density is very important. It would be useful also to explore how land reforms impact on household's productivity and welfare.

$\checkmark$ Climate variability and soil fertility would have significant effects on livelihoods in rural regions. Exploring their effects on farmers' productivity and poverty would help to better inform the design of strategies to strengthen resources management sustainability and household's resilience.

$\checkmark$ Better understanding the underlying drivers of diversification to nonfarm activities and how these can be enhanced and promoted. 


\section{Chapter I - Country Context: Historical Review, Outlook and Projections}

\section{Key Messages}

- Burundi's history has been marked by several episodes of violence and political instability that have seriously damaged the economy and led it to perform below its SSA peers.

- After slow recovery following the restoration of peace and stability in 2006, the economy seems to go in a recession again due to recent political turmoil and violence.

- Future efforts to grow and reduce poverty will depend on improvements in the security situation and full reengagement of donors.

This chapter provides an overview of Burundi's history to better understand the events that has led the country into the current situation of low economic performance and high levels of poverty. The chronic fragility of Burundi and its history of violence have hindered efforts to develop and grow. Even though peace and reconciliation was achieved in 2006, growth and development failed to take off significantly, and recent violence have put the country, once again, at the edge of economic collapse.

This chapter examines, first, the history of Burundi's political crisis and violence, as well as its consequences to the economy. Second, it describes the current situation in the country and examines as much as possible the effects of recent political unrest on the economy. Finally, it analyzes the macroeconomic and poverty projections as well as different risks and uncertainties.

\section{A History of Violence Linked to Poor Economic Performance}

Burundi has suffered from cycles of violence and fragility that undermined economic growth and led it to perform lower than SSA peers

Years of civil war and violence have deeply affected Burundi, hindering efforts to improve the living conditions of the population. Military repression has dominated most of Burundian history since its independence in 1962 from Belgium. Massacres in 1965, 1972, 1988, 1991 \& 1993 led to the deaths of hundreds of thousands people, and large number of internal displacements and refugees (Box I.1). Civil war broke out in Burundi in June 1994 and ended in August 2005. More civil war broke out again in early 2006, headed by the Palipehutu-FNL rebel group, and ended after a regionally brokered truce in 2009. Between 1994 and 2005, several rounds of peace negotiations were initiated. Three major agreements including provisions for power-sharing were signed, but implemented with different degrees of success. Political instability and conflict has widened poverty, increased basic social needs, and damaged basic economic infrastructure. After several disarmament, demobilization, and reintegration programs, Burundi still has to face several challenges in diversifying the economy, reducing its vulnerability to shocks and strengthening good governance and anti-corruption practices. 


\section{Box I.1 A brief history of Burundi's crises ${ }^{1}$}

Since independence in 1962, Burundi has been plagued by a series of successive crises, which many authors describe as different episodes of the same fundamental conflict. Turmoil began at the eve of Independence, when Prince Louis Rwagasore, a descendant of the royal family and the charismatic leader of the Independence struggle, won the 1961 elections but was assassinated in October 1961 after only two weeks in office as Prime Minister. His assassination was followed by political instability, with five prime ministers between the end of 1961 and mid-1965, two of whom were assassinated as well.

In the wake of the monarchy's refusal to acknowledge the gains by Hutu candidates in the first post-independence legislative elections (1965), a group of Hutu officers tried to overthrow the monarchy. The following year, King Mwambutsa was deposed by his son, who appointed army captain Michel Micombero as prime minister. Mr. Micombero overthrew the monarchy a couple of months later, declaring the first Republic and establishing a military regime ruled by the Hima (a clan from southern Burundi).

In 1976, colonel Bagaza overthrew Mr. Micombero's regime in a coup. In 1987, Mr. Bagaza was himself overthrown by his cousin, major Pierre Buyoya, in another palace coup. Mr. Buyoya was the third consecutive president hailing from the exact same commune in Burundi (Rutovu commune). Though Mr. Buyoya advocated national unity and democratic reform, violence escalated during the early years of his presidency, resulting in tens of thousands of deaths between 1988 and 1991. In 1991, Mr. Buyoya approved a new constitution and announced democratic elections in 1993.

The 1993 legislative elections resulted in a win for FRODEBU (Democratic Front of Burundi), an opposition party founded in Rwanda in the 1980s. A couple of months later, the presidential elections were won by FRODEBU's candidate Melchior Ndadaye, with the incumbent (Buyoya) coming a distant second. Mr. Ndadaye was the first Hutu president, and also the first civilian president. In October 1993 however, Mr. Ndadaye was assassinated by the Tutsi-dominated army, resulting in mass killings of Tutsi civilians in late October, army reprisals, and the progressive development of large-scale civil war. The civil war pitched the Tutsi-dominated army against a multitude of Hutu rebel groups, with CNDD-FDD (National Council for the Defense of Democracy-Forces for the Defense of Democracy) and FNL (National Liberation Forces) being the main ones, but also witnessed substantial infighting among the various rebel groups. An estimated 300,000 people, mainly civilians, were killed between 1993 and 2005, and many more were displaced or sought refuge in neighboring countries.

In 2000, the Arusha peace agreement was signed between the government, led by Mr. Buyoya, and several smaller Hutu rebel groups. As CNDD and FNL did not sign the agreement, fighting went on in the countryside. Finally, in 2003, CNDD, the main rebel group, signed a peace deal and joined the transitional government. Democratic elections were held in 2005, resulting in a win for the former rebels of CNDD-FDD. CNDD's leader, Pierre Nkurunziza, was elected president by Parliament. In 2009, FNL signed a peace deal, putting an official end at a 16-year-long civil war.

In 2010, Mr. Nkurunziza was re-elected for a second term, and in April 2015, the president announced he would be seeking a third term. Following violent protests in the capital, Mr. Nkurunziza won the presidential elections of July 2015. By April 2016, it is estimated that around four hundred people had died and more than 250,000 had fled the country, mainly to neighboring Rwanda and Tanzania. The economy collapsed amidst rising violence, with the IMF predicting GDP to contract by over seven percent in 2015 .

\section{Following the continuous political crisis, macroeconomic performance since the early 1960s} has been fairly disappointing. Though GDP grew on average by 2.6 percent per year between 1960 and 2014, population grew at the same rate, cancelling out any effect on per capita income levels. On a per capita basis, Burundi's GDP was the same in 2014 as in 1960 (Figure I.1). While the onset of the civil war in 1993 is responsible for most of the overall stagnation of the past 55 years, the end of the conflict has barely brought significant economic improvements: between 2006 and 2014 GDP per capita grew at less than one percent per year (flat line in Figure I.1) and on a per person level GDP remains 30 percent lower than it was in the early 1990s.

\footnotetext{
${ }^{1}$ Largely based on Chretien (1997), Chretien and Mukuri (2000), and Lemarchand (1994). This is a simplification and most likely does injustice to the complex intricacies of the successive crises.
} 
Figure I.1: GDP per capita between 1960 and 2014 (constant 2005 US\$)

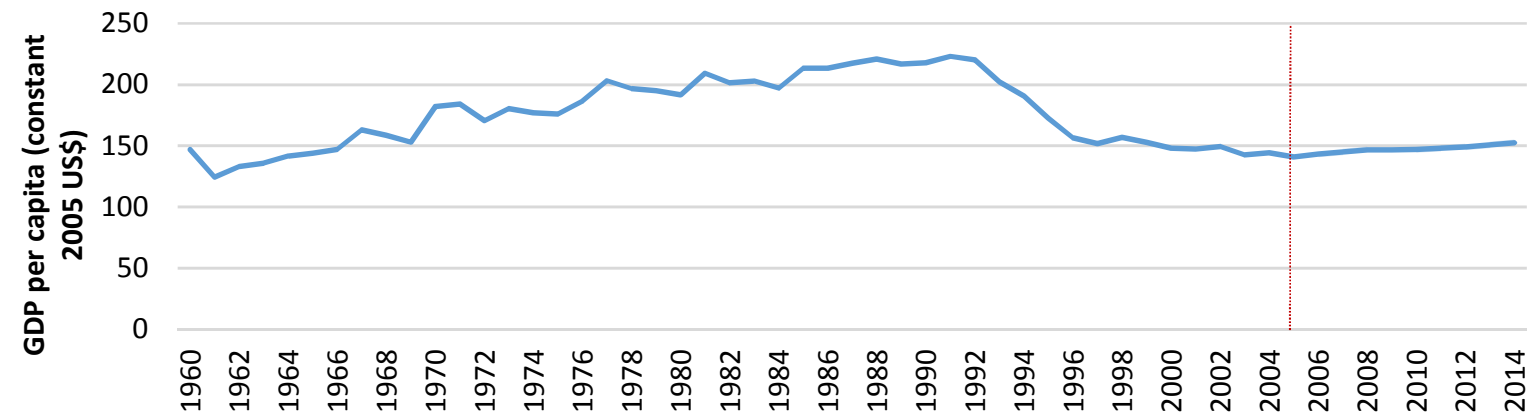

Source: World Development Indicators, 2015. Vertical red line denotes the first post-war elections.

Burundi's modest performance has been linked to international coffee prices and violent events (Figure I.2). Years with the lowest growth were 1961 (elections to pave the way for Independence and the assassination of Rwagasore), 1972 (large massacres), the period between 1993 and 1997 (assassination of Ndadaye followed by large-scale civil war), and 2015 (renewed violence following elections). Years with extremely high growth rates tend to correspond with sharp increases in coffee prices $\left(1970,1977\right.$, and 1985) ${ }^{2}$ Curiously, the doubling of coffee prices between 2005 and 2011 has however not been accompanied by growth spikes.

Figure I.2: Annual economic growth and annual coffee prices, 1961-2014

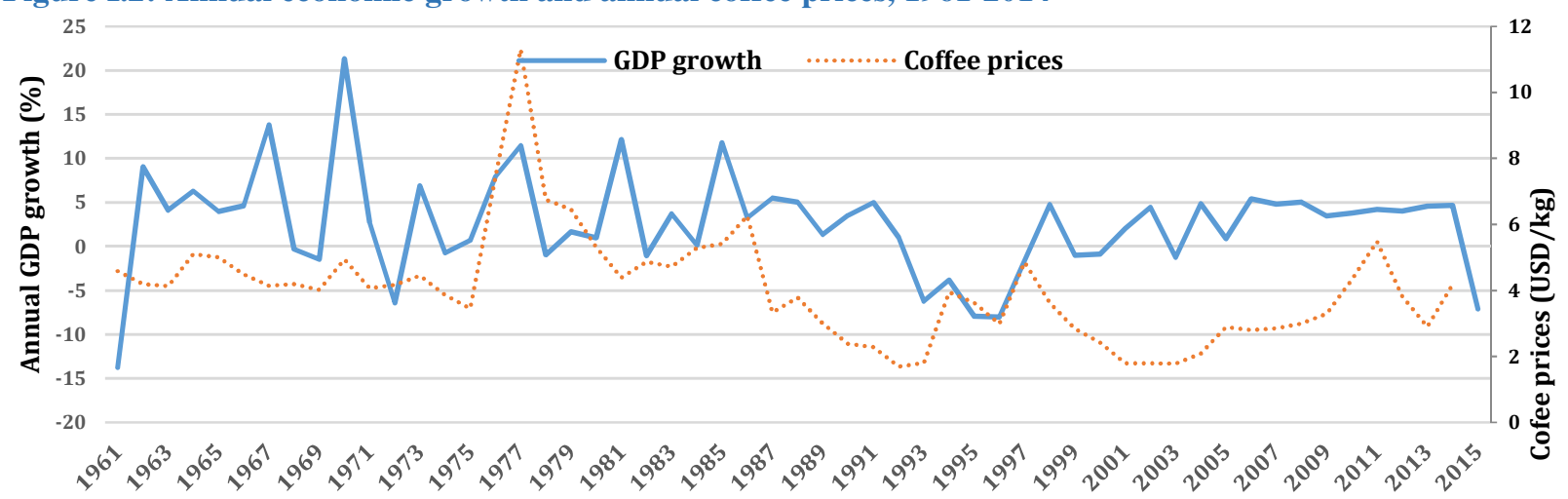

Source: World Development Indicators, 2015; Global Economic Monitor, 2015.

Compared to Sub Sahara Africa, Burundi's economic growth was not particularly low up until the early 1990s. Though initially, post-independence instability and the 1972 events (Box I.1) were associated with below-average growth (Figure I.3), Burundi avoided the Africa-wide economic decline of the 1980s (the so-called lost decade). In 1990, Burundi's per capita GDP was about 50 percent higher than it had been in 1960, compared to 20 percent for Sub Sahara Africa. ${ }^{3}$ The onset of the war in 1993 saw GDP levels plummeting, and they have not recovered

2 In more technical terms, the unlagged cross-correlation between coffee prices and growth is 0.26 , showing that economic growth in year $t$ is positively lined to coffee prices in year t. The one-lag cross-correlation is 0.19 , meaning the growth in year $t$ is still positively affected by coffee prices in year ( $t-1)$.

3 Figure shows the evolution of per capita GDP in relative terms. In absolute terms however, Burundi's GDP per capita was still four times lower than Africa's in 1990. 
since. While Sub Sahara Africa has been rising in the first decade of the 2000s, Burundi has been stagnating. In Sub Sahara Africa as a whole, GDP per capita expanded by almost 40 percent between 2000 and 2014. In Burundi, it expanded by three percent (Figure I.3).

Figure I.3: Burundi and Sub Saharan Africa Index of GDP per capita (constant 2005 US\$; 1960=100)

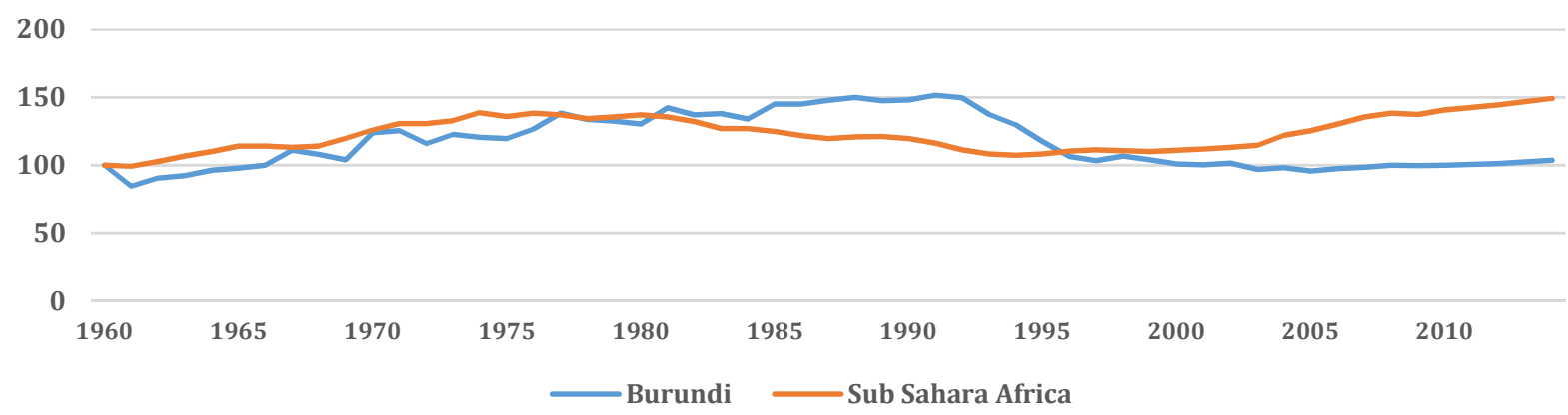

Traditional growth accounting shows productivity growth has been negative throughout most of the past five decades. While physical and human capital increased, GDP stagnated, hinting at persistent decreases in productivity over time. Even in the post-war period (2004-13) productivity growth was negative. Only in 2011 did productivity exert a positive influence on overall growth (Figure I.4). This seems consistent with Burundi's reality: investment since independence seems to respond to patronage and rent-seeking needs rather than economic efficiency. ${ }^{4}$

Figure I.4: Contribution of production factors to economic growth

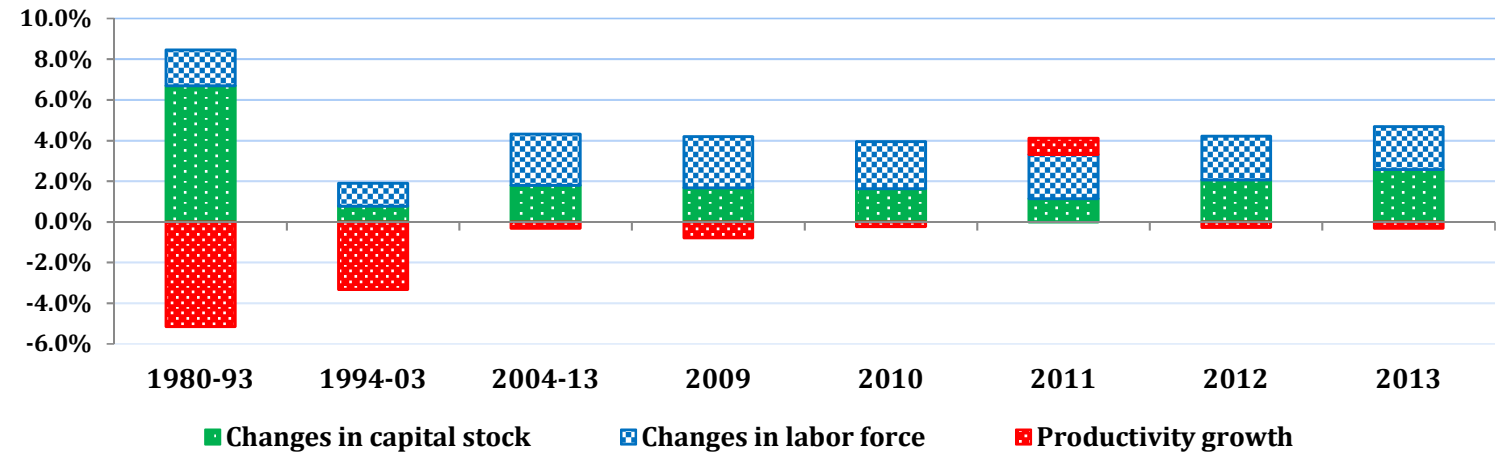

Source: Burundi Economic Update, 2014.

\section{Before 2005, Burundi's economic performance was low due to political instability with sharp GDP contractions during the civil war period.}

The first decade after independence (1962-1972) witnessed timid economic growth of less than two percent per capita per year. The sluggish growth during this period was mainly due to a drop of value-added in agriculture and poor productivity in other sectors, amidst postindependence instability (Box I.1). In 1972, civil strife caused GDP to contract by about seven

4 Basdevant (2009) also finds evidence of a lower than average efficiency of investment in Burundi. 
percent. Overall, per capita GDP increased by a modest 16 percent in the ten years following independence. $^{5}$

The period 1973 to 1991 was characterized by fewer political tensions and modest economic growth. This period witnessed increased investment, which doubled from an average of 6.3 percent of GDP in 1962 to 1972 to an average of 13.8 percent of GDP in 1973 to 1991. External resources financed most of the investment, and Official Development Assistance (ODA) increased from an average of 3.3 percent of GDP to 17 percent. Although Burundi's economy grew at an average rate of 4.1 percent, this period, and in particular the mid-1980s, was marked by increasing debt and resource mismanagement (Wagner (2009) finds that growth in this period can largely be accounted for by aid). In 1972, external debt as share of GDP was only 2.8 percent, but in 1991 it reached 82.5 percent.

In 1993, Burundi's already weak economy collapsed with the onset of the civil war. Between 1993 and 2005, per capita GDP contracted by almost 40 percent, bottoming out at a paltry US\$ 140 in 2005. Chronic power shortages due to sabotage on transmission lines took a heavy toll on the economy, with industry contracting by almost 17 percent in 1995 alone. In addition, following the second coup d'état by Pierre Buyoya in 1996, the international community imposed an embargo on Burundi, further deteriorating the economic situation. Between 1992 and 1999, the Burundi Franc slid by 16 percent per year, while average yearly inflation amounted to 23 percent. Military spending consumed about half of the government budget. The exchange rate was overvalued by about 80 percent, and the gap between the official and parallel market was larger in the 1990s than at any other time. In the absence of a well-established and regulated financial system, this created opportunities for arbitrage and increased corruption.

\section{Starting from 2005 the situation improved slowly driven by decreased violence and a growing tertiary sector}

Following the end of the hostilities, Burundi's GDP growth was stable and moderately positive during 2005-2014 period. Since 2005 the Government of Burundi has managed to stabilize the country's economy in a fragile environment with real GDP and GDP per capita growth averaging 4.1 and 1.1 percent per year respectively. The breakthrough in the peace process and reduction in violence, combined with better macroeconomic management and important aid inflow, triggered the rebound in economic performance. The main drivers of the economic growth were household consumption and government spending.

However, Burundi's economic performance compared poorly with a selected list of benchmark countries. Economic recovery was strong in many post-conflict countries in the first decade of peace (Table I.1). Real GDP increased by more than 7.5 percent in Rwanda and Sierra Leone between 2005 and 2014, while it exceeded 6 percent in Liberia, and DRC. However, Burundi's peace dividend has been lower, with economic growth falling below the average of Sub-Saharan developing economies.

5 World Bank (2008). 
Table I.1: Selected economic indicators (averages 2005-14) for selected benchmark countries

\begin{tabular}{|c|c|c|c|c|c|c|c|c|c|c|c|}
\hline & & $\begin{array}{c}\text { GDP } \\
\text { growth } \\
\text { (annual\%) }\end{array}$ & $\begin{array}{l}\text { Agriculture, } \\
\text { value added }\end{array}$ & $\begin{array}{l}\text { Industry, value } \\
\text { added }\end{array}$ & $\begin{array}{l}\text { Services, etc., } \\
\text { value added }\end{array}$ & $\begin{array}{c}\text { Exports of } \\
\text { goods and } \\
\text { services }\end{array}$ & $\begin{array}{c}\text { Imports of } \\
\text { goods and } \\
\text { services }\end{array}$ & $\begin{array}{c}\text { Gross fixed } \\
\text { capital } \\
\text { formation } \\
\end{array}$ & $\begin{array}{c}\text { Gross fixed } \\
\text { capital } \\
\text { formation, } \\
\text { private sector }\end{array}$ & $\begin{array}{c}\text { Foreign direct } \\
\text { investment, net } \\
\text { inflows }\end{array}$ & $\begin{array}{c}\text { Gross } \\
\text { domestic } \\
\text { savings }\end{array}$ \\
\hline & & \multicolumn{10}{|c|}{ In $\%$ of GDP, unless otherwise indicated } \\
\hline Burundi & & 4.1 & 40.8 & 17.2 & 42.0 & 8.1 & 37.8 & 26.1 & 11.5 & 0.1 & -3.5 \\
\hline \multicolumn{12}{|c|}{ Peer Benchmarking } \\
\hline & Central African Reput & -1.2 & 55.4 & 13.5 & 31.1 & 12.8 & 25.0 & 11.7 & - & 2.3 & -0.6 \\
\hline & Guinea-Bissau & 3.0 & 45.6 & 13.8 & 40.7 & 19.1 & 30.2 & 6.0 & -- & 2.0 & -4.9 \\
\hline & Liberia & 6.7 & - & - & - & 54.1 & 163.7 & 19.5 & 12.3 & 30.6 & -90.1 \\
\hline & Mali & 4.3 & 38.9 & 22.2 & 38.9 & 25.5 & 28.6 & 19.5 & 10.9 & 3.6 & 18.8 \\
\hline & Sierra Leone & 7.7 & 54.8 & 11.8 & 33.3 & 15.7 & 27.9 & 13.5 & 11.8 & 10.4 & 1.3 \\
\hline & Comoros & 2.2 & 40.1 & 11.6 & 48.3 & 15.8 & 50.5 & 14.2 & -- & 1.7 & -17.6 \\
\hline & Haiti & 2.1 & -- & - & - & 15.7 & 49.7 & -- & -- & 1.6 & -5.2 \\
\hline & West Bank and Gaza & 3.6 & 6.5 & 24.0 & 69.5 & 16.6 & 65.0 & 21.9 & -- & 1.4 & -27.0 \\
\hline & Bangladesh & 6.2 & 17.9 & 26.3 & 55.9 & 17.7 & 24.2 & 26.9 & 21.6 & 1.1 & 20.4 \\
\hline & India & 7.7 & 18.3 & 29.4 & 52.2 & 22.3 & 26.7 & 31.3 & 24.4 & 1.9 & 31.2 \\
\hline & Myanmar & 8.4 & -- & - & - & -- & -- & -- & -- & 2.6 & - \\
\hline \multicolumn{12}{|c|}{ Neighboring countries } \\
\hline & Rwanda & 7.7 & 34.4 & 13.2 & 52.4 & 13.5 & 28.0 & 21.8 & 9.9 & 2.0 & 8.0 \\
\hline & Kenya & 5.3 & 27.1 & 20.7 & 52.3 & 21.3 & 34.1 & 20.1 & 16.2 & 0.7 & 7.3 \\
\hline & Tanzania & 6.6 & 31.5 & 22.5 & 46.0 & 18.7 & 29.5 & 30.2 & 16.0 & 4.2 & 18.0 \\
\hline & Uganda & 6.9 & 26.4 & 23.2 & 50.4 & 18.5 & 29.9 & 24.8 & 19.1 & 4.8 & 13.7 \\
\hline & Congo, Dem. Rep. & 6.5 & 23.1 & 33.5 & 43.4 & 33.7 & 39.7 & 16.7 & 10.5 & 1.9 & 10.2 \\
\hline & Malawi & 5.5 & 31.5 & 18.1 & 50.4 & 31.7 & 48.1 & 19.3 & 11.1 & 6.9 & 5.2 \\
\hline \multicolumn{12}{|c|}{ Global Benchmarking } \\
\hline & LCs & 6.2 & 33.0 & 21.1 & 45.9 & 24.5 & 40.7 & 22.2 & 12.4 & 4.0 & 8.1 \\
\hline & SSA & 4.6 & 16.1 & 29.0 & 54.9 & 31.3 & 32.9 & 19.8 & 14.2 & 2.6 & 19.0 \\
\hline & Fragile countries & 3.6 & 17.4 & 36.0 & 46.6 & 38.4 & 44.0 & 19.6 & 10.7 & 3.1 & 19.4 \\
\hline
\end{tabular}

Source: World Development Indicator (2015)

The non-agricultural sector, mainly the tertiary sector, has been the main driver of the economic growth. The service sector expended by 7.1 percent yearly from 2006 to 2014 and industry grew by 5.7 percent per year in the same period. On average, the value added in the sector increased by 6.2 percent. In contrast, growth remained very low in the agriculture and rural sector. On average, the sector grew by only 1.5 percent per year, pulled down by poor performance in 2007 (-8.8 percent) and 2008 (-2.1 percent). From 2009 to 2014, value added in agriculture increased by 3.5 percent per year, slightly above the population growth.

Figure I.5: Growth in value added by sector from 1992 to 2014

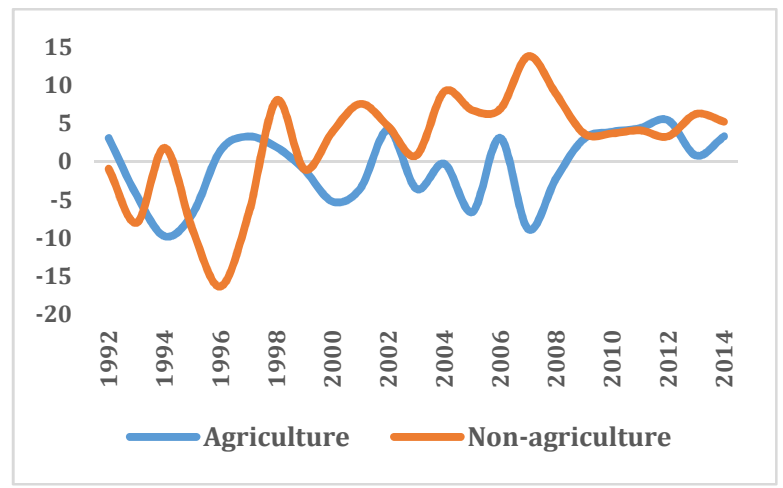

Source: ISTEEBU/MFBP/WBG
Figure I.6: Value added in percentage of GDP from 1992 to 2014

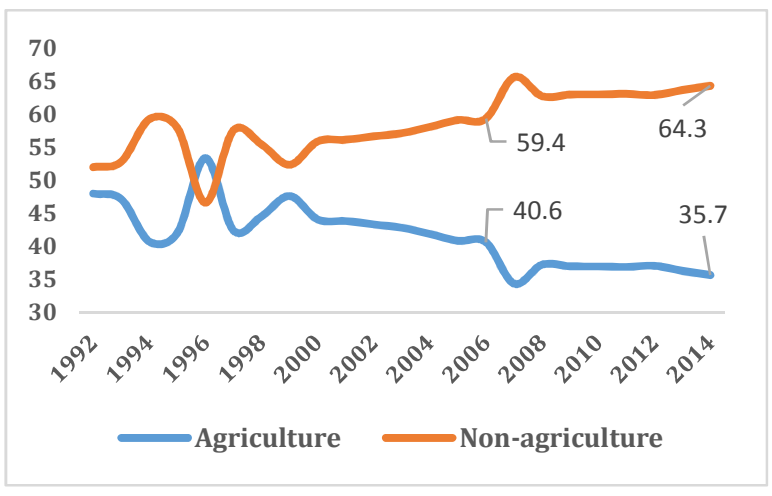

Source: ISTEEBU/MFBP/WBG 
Burundi has shown some signs of economic transformation in the tertiary sector, supported by a slightly growing secondary sector. As a result of the aforementioned dynamics, services became the predominant sector in 2013, accounting for 39 percent of GDP. Growth in the tertiary sector has been driven by a thriving telecommunications and banking system, better maintained transport networks and new roads, as well as a clear take-off in tourism. In addition, the service sector is not only benefiting from the expansion of the public sector and its ensuing public markets (procurement) but also from new activities and markets generated by a more dynamic secondary sector, which accounted for 16.4 percent of GDP in 2013. The drivers of growth for this sector have been robust construction activities, transformative industries yet to be scaled up, and a boost in extractives activities. Most of these activities have been taking advantage of regional integration to EAC mainly through more mobility in production factors and services from Kenya, Tanzania, and Uganda.

While the agriculture continues to create relatively smaller value added, the sector still employs the majority of the active population. With a slower growth, the share of agriculture in the total value added declined from 44.1 percent in 2000 to 40.6 percent in 2006 and 35.7 percent in 2014. In contrast, over 80 percent of the active population is employed in the agricultural sector. Low productivity and repeated climate shocks (land sliding, flooding, etc.) explain the weak performance in this sector. Agricultural exports are mainly based on coffee and tea production, but their share was less than 2 percent of nominal GDP during the period 200613, except in 2006 and 2008 where it exceeded 3 percent. Burundi's food production increased 25.6 percent in 2006-2012. As shown in Figure I.8, Burundi has the lowest value added per worker in the world. From 2006 to 2014, agriculture value added per worker averaged US\$126 in 2005 constant prices, less than one fifth of the average of SSA developing countries.

\section{Despite slow improvements, Burundi has remained vulnerable to shocks with widening current account deficits, high inflation and low productivity}

Despite the modest economic recovery, Burundi's current account deficit and dependence on donors have been increasing. After reaching a peak of 25 percent in 2006, the current account deficit declined slightly and widened again in 2011 due to the narrow export base and heightened food and fuel international prices. The current account deficit attained 18.7 percent of nominal GDP in 2011-13 as a result of important trade imbalances. In 2011-12, Burundi's imports were 6-7 times higher than its exports, surpassing many EAC where imports exceeded exports by 2-4 times. Trade imbalances have been aggravated by import increases of 2.5 percent and sharp export decreases of 35.5 percent, mainly due to a bad coffee campaign in 2013-14. The current account deficit has been financed by (bilateral and multilateral) concessional loans, small FDI, and official reserves.

To reduce vulnerability to external shocks, the government tried to address high inflation from the upswings of world prices. Following the international food and fuel price crisis that started in 2007, inflation peaked at 24.1 percent in 2008 before declining to 11.0 percent in 2009 , 
and then to 6.4 percent in 2010. It rose again to 9.7 percent in 2011, with a peak of 25 percent in March-April 2012. To modulate the poverty impact of high inflation and maintain macroeconomic stability, the Bank of the Republic of Burundi (BRB) took appropriate measures to bring inflation down. In 2012, the BRB tightened the monetary policy by increasing slightly its policy rate, so bringing headline inflation from its 25-percent peak of March-April down to 11.8 percent at end-year. As inflation pressures eased to reach 10.0 percent, the BRB lowered slightly its policy rate in early 2013, leading to greater private sector credits, private investments, and growth.

Despite efforts to reduce inflation, Burundi has failed to catch up with best performing countries in the region. With inflation averaging 11.3 percent in 2003-12, the country has done slightly better than Kenya, but it has lagged behind Tanzania and Rwanda which have kept inflation below 9 percent. To compare with other post-conflict countries, Burundi has done relatively better than Sierra Leone, but worse than Liberia or Mozambique. By end-2013, the adequacy of the monetary policy of Burundi led to an 8 percent inflation rate, which remains higher than in many EAC or SSA countries. By maintaining the momentum of price stability supported by the consistent fiscal policy applied so far, the government will help accelerate the economic transformation that has buttressed the country's actual growth results.

Overall, the productivity of Burundi's economy has remained low. Over the last decade, the efficiency of the economy has improved substantially but the contribution of total factor productivity (TFP) to economic growth remains negative, showing room for further improvement. Burundi's TFP contrasts with that in post-conflict countries like Cote d'Ivoire and Mozambique, where data is available (Figure I.7). Significant bottlenecks have to be removed to increase the country's growth potential, expand the non-agricultural sector, and create enough jobs to absorb the excess supply of labor in the agricultural sector and rural areas. An isolated Burundi needs to be better linked to its neighboring markets, both regionally and globally. In this context, greater regional integration is critical to reduce the transport, energy and communication infrastructure deficit. While the country is likely below the threshold size to attract investors for infrastructure projects, this disadvantage can be overcome at regional level.

Figure I.7: Total Factor Productivity growth (average 2005-2014)

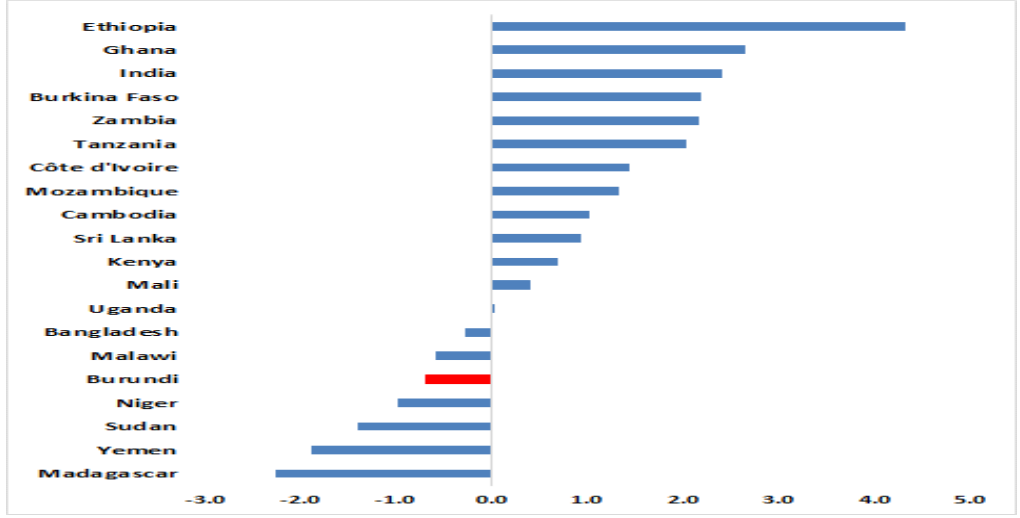

Source: The Conference Board Total Economy Database and Bank staff for Burundi 
Though land productivity remains an issue in Burundi, the low value added per worker reflects mainly the high population density. Between 2006 and 2014, Burundi produced 1.3 ton of cereal per hectare of land, scoring at 6 percent below the average of SSA and 26 percent below its closest neighbor Rwanda. Land productivity explains only a small part of the huge gap between Burundi and SSA. The main reason seems to be the significantly high concentration of labor force in the agricultural sector. Burundi's population density is among the highest in SSA. The population density has more than doubled during the last years, reaching 394.3 inhabitants per $\mathrm{km}^{2}$ in 2012 and 421.2 in 2014. According to the last censuses of EAC countries, only Rwanda has a higher density than Burundi, with 416 inhabitants per $\mathrm{km}^{2}$ in 2012 and 459.5 in 2014. ${ }^{6}$ Hence, greater labor mobility, especially movement from agriculture to non-agriculture may have positive impact in poverty reduction.

Figure I.8: Agriculture value added per worker (constant 2005 US\$)

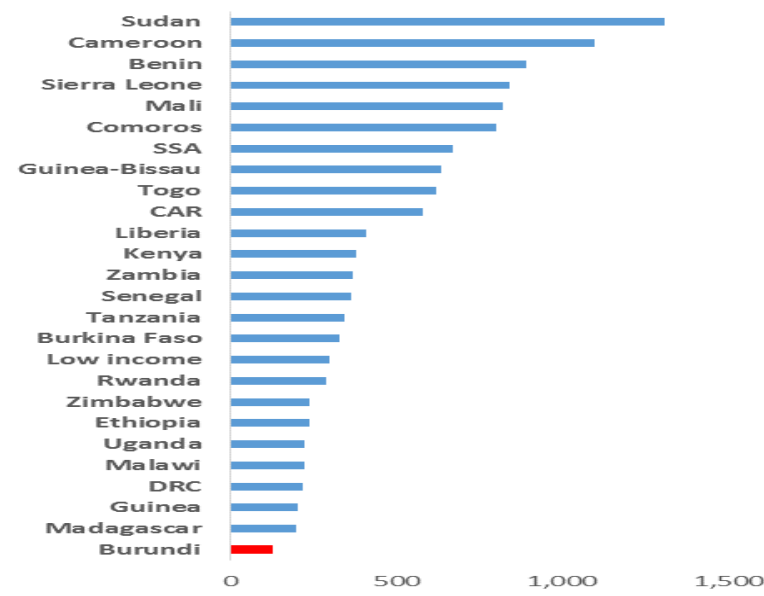

Source: WDI (2015)
Figure I.9: Cereal yield (kg per hectare)

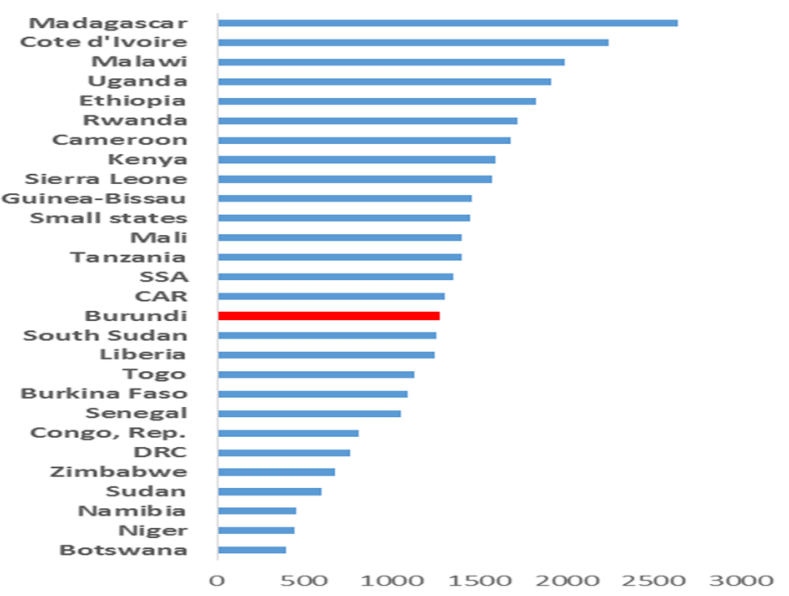

Source: WDI (2015)

High demographic growth has also undermined the capacity of agriculture to ensure food sufficiency and nutrition. Demographic growth, of 22 percent during 2006-2012, resulted in annual per capita food production of $148-152 \mathrm{~kg}$ of CE, still significantly below the required 190 $\mathrm{kg}$ of CE estimated by FAO (Figure I.9). ${ }^{7}$ Demographic growth weighs heavily on the country's economic growth and its capacity to reduce poverty. It is also undermining food productivity and farmers' revenues in densely populated regions, and exerting a high pressure on basic social and economic infrastructure (Figure I.8). To modulate Burundi's strong population growth, the authorities and partners have kept the momentum of health reforms. They have intensified implementation of family planning measures through sensitization campaigns for behavioral changes and elimination of women contraceptives' stock-outs in health facilities.

\footnotetext{
${ }^{6}$ Statistics for 2014 are from WDI, 2015.

${ }^{7}$ This is equivalent to an annual growth rate of 3.7 percent between 2006 and 2012.
} 


\section{Recent Events and Macroeconomic Trends}

\section{After slow "take off" following the restoration of peace and stability, the economy seems to go in a recession again due to renewed violence}

In recent years the government of Burundi has focused on stabilizing and rebuilding the country from the devastation and deployment caused by the conflict. According to the Government of Burundi 2013 report, the country is making the transition from a post-conflict to a stable and growing economy. The government argued that after significant improvements in security and peace consolidation, the country's development program is shifting towards modernizing public finance, strengthening basic social services, and upgrading economic infrastructure and institutions, particularly in the energy, mining, and agricultural sector, with increasing participation of the private sector. The goal was to grow a stable, competitive and diversified economy with opportunities for productive employment and improved standards of living (GoB, 2013).

However, Burundi's political stability has deteriorated further since last year. In April 2015, following president Nkurunziza's declaration that he would seek a third term, violent protests broke out in the capital. Tensions between the government, opposition parties and human rights activists kept increasing in most areas. Civil society and NGOs have also expressed concern about constitutional changes that would reduce the powers of the vice president which, among other changes proposed by the ruling party, could drive the country towards increasing instability.

The recent political crisis is pushing the country on the brink of economic collapse. Real GDP contracted by 2.5 percent in 2015 , the first time since the end of the civil war. Interruption in activities led the economy to a standstill position in April-May. Recovery after the elections was subdued by weak domestic demand as growing insecurity stifled the aid industry, the economy's main growth engine. While the economy would expand by 3 percent in 2016, macroeconomic imbalances are expected to grow. Without donors' quick reengagement, the government policy mix will involve partial fiscal consolidation, with the fiscal deficit expected to decline but still high at 5.2 percent.

A sharp drop of the urban economy has driven 2015 Burundi's economy contraction. Due to urban riots, commercial activities were stopped in the capital Bujumbura for several weeks in April and May 2015, putting the economy to a standstill position. While the riots triggered the crisis by constraining the supply, weak domestic demand resulted from businesses and donors response to the crisis. Increased insecurity is holding the economy on a low equilibrium. Industrial production declined by 8.5 percent in 2015 with output contracting in almost all the manufacturing industries as well as in utilities and construction sectors. Though the telecommunication sector showed some resilience, trade, tourism and transport sectors were particularly hit. Overall, the service sector is expected to have contracted by 5 percent. On the demand side, investment and export of services are the main drivers of the contraction. As a 
result, poverty rate based on the international poverty line $(\$ 1.90 /$ day) is projected to have increased from 72 percent in 2014 to 77.4 percent in 2015 (1.9\$/ day, 2011 PPP) (Figure I.11).

Figure I.10: Contributions to Annual GDP

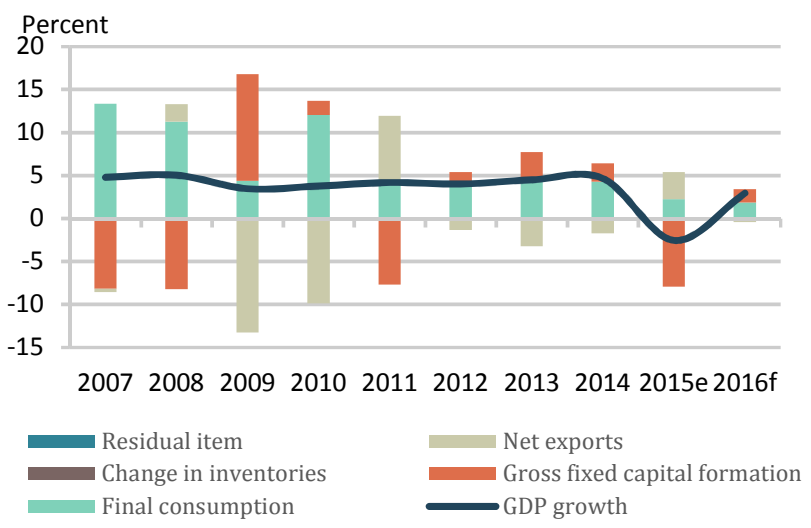

Figure I.11: Growth Poverty rate (US\$1.9 per day) (based on growth elasticity $=0.63$ )

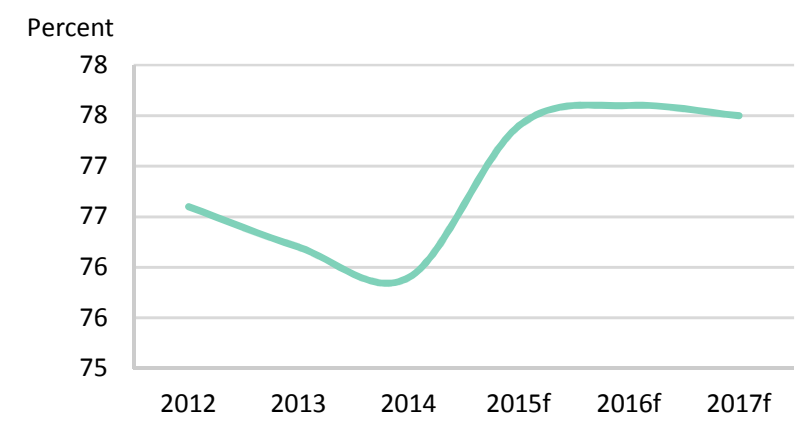

Source: World Bank (2016) Macro-Poverty Outlook

The economic situation could have been more severe, had the Central Bank (BRB) not acted to rescue the state. The contraction reduced dramatically the revenue base. Tax revenue to GDP ratio declined to 10.4 percent in 2015, down from 12 percent in 2014, while donors reduced aid from 13 percent of GDP in 2014 to 10.3 percent of GDP in 2015. Those developments put significant pressure on the budget and pushed the government to increase domestic borrowing, as new spending needs on security limited the government's ability to cut spending. Overall, the fiscal deficit increased to 7.1 percent of GDP, up from 3.4 percent in 2014. The deficit was financed mainly by the Central Bank's advance and issuance of treasury bills. By the end of 2015, the Government has issued around FBI 386 billion of treasury bills in the domestic market but subscriptions reached only 78 percent. Domestic public debt rose to 20.3 percent of GDP, up from 14.4 percent in 2014.

Accommodating monetary policy helped to limit the propagation of the crisis to the banking sector but pressure on the exchange rate augmented. The Central Bank increased liquidity injection, as both money demand and the proportion of unpaid loans increased. Interest rates doubled in the six months following the beginning of the crisis before declining in November 2015. However, inflation remained moderated at 5.5 percent, reflecting weak domestic demand, good agricultural production, and the decline of world commodity prices. Interventions in the foreign exchange market, including restrictions on foreign exchanges, also contributed to lower domestic prices of imported goods and the widening of the current account deficit (-18.6 percent of GDP). The exchange rate depreciated by 2.8 percent and the market premium soared to 20 percent, up from 5 percent in 2014. The overall balance of payments showed a wide deficit, financed mainly by foreign reserves, which declined to 2 months of imports. 


\section{An Uncertain Future}

Burundi's macroeconomic outlook remains fragile and uncertain in the post-electoral period. Growth is expected to recover gradually and reach 3.0 percent in 2016, but the current macroeconomic imbalances will likely persist. The country will not be able to stimulate domestic demand without further worsening the macroeconomic imbalances. With the slimness of the financial sector, fiscal policy is more effective in stimulating domestic demand. However, easing access to credit could promote quick recovery by facilitating business access to liquidity. Without donors' quick reengagement, the government policy mix will involve partial fiscal consolidation, expansionary monetary policy, and more flexible exchange rate policy. The fiscal deficit is expected to decline but will remain high at 5.2 percent in 2016, financed mainly by domestic financing, including Central Bank direct financing. Eviction effects will be attenuated by higher money supply through more frequent liquidity injections as started in late 2015 .

\section{The macroeconomic outlook and poverty levels are subject to improvements in the security} situation and full reengagement of donors. Growth is expected to return to its level before the 2015 crisis (5 percent), but inflation is expected to rise to 8 percent in 2016, as household demand gradually picks up and import prices adjust in local currency. Despite declining world prices, the current account deficit is expected to increase to 19.1 percent as importers gain confidence and resume activity and donors gradually reengage in the country. The exchange rate will likely depreciate: as imports pick up, the government will lack enough foreign reserves to maintain it around current levels. Provided a recovery in economic growth, poverty would continue to increase to reach 77.6 percent in 2016 and then start declining slowly. However, Burundi is projected to be the world's poorest country by 2030 and the seventh main contributor to global poverty. ${ }^{8}$

Table I.2: Selected Economic and Social Indicators, Projections 2015-2018

\begin{tabular}{|c|c|c|c|c|c|c|c|}
\hline & 2012 & 2013 & $2014 \mathrm{e}$ & $2015 \mathrm{f}$ & $2016 \mathrm{f}$ & $2017 \mathrm{f}$ & $2018 \mathrm{f}$ \\
\hline Real gross domestic product & 4 & 4.5 & 4.7 & -2.5 & 3 & 3.5 & 4 \\
\hline Private consumption & 4.1 & 4.8 & 4.6 & 3.2 & 3.3 & 4.5 & 5 \\
\hline Government consumption & 2 & 2 & 2 & -0.4 & -1.9 & -1.6 & 2 \\
\hline Gross fixed capital investment & 8.6 & 18.3 & 10.5 & -36.5 & 10.7 & 8 & 5 \\
\hline Change in inventories, $\%$ contrib & 0.1 & 0 & 0 & 0 & 0 & 0 & 0 \\
\hline Statistical discrepancy (\% GDP) & 0 & 0 & 0 & 0 & 0 & 0 & 0 \\
\hline Exports, goods \& services & 6.6 & 3 & 5.4 & -1.9 & 3.5 & 7 & 7 \\
\hline Imports, goods \& services & 4.6 & 8 & 5 & -7.3 & 1.8 & 3.2 & 5.2 \\
\hline GDP, at factor prices & 4 & 4.5 & 4.7 & -2.2 & 2.9 & 3.5 & 4 \\
\hline Agriculture & 5.5 & 0.8 & 3.3 & 6.6 & 3.2 & 3.2 & 3.4 \\
\hline Industry & 4.1 & 11.2 & 8 & -10.7 & 3.7 & 5 & 4.8 \\
\hline Services & 2.7 & 4.7 & 4.4 & -5 & 2.4 & 3.3 & 4.1 \\
\hline Output Gap & 1.1 & 0.6 & 0.1 & 5.5 & 1.6 & 1.6 & 1.5 \\
\hline CPI Inflation, period average & 18 & 7.9 & 4.4 & 5.5 & 8 & 10 & 9 \\
\hline Current account balance, $\%$ of GDP & -17.5 & -19.1 & -15.2 & -18.6 & -19.1 & -20.8 & -14.1 \\
\hline Fiscal balance, $\%$ of GDP & -3.7 & -1.7 & -3.4 & -7.1 & -5.2 & -3.7 & -2.6 \\
\hline
\end{tabular}

Source: World Bank (2016) Macro-Poverty Outlook

${ }^{8}$ World bank, 2015b 
There are significant risks to the macroeconomic outlook. First, security situation remains tense and volatile following the presidential and legislative elections. A worsening of the situation could hamper private sector confidence and prevent activity resuming in Bujumbura. Second, some donors linked their development assistance to the engagement in an open dialogue between the government and the opposition, which may take longer than initially expected. If reconciliation is delayed, aid could decline faster than expected and further stress the government's fiscal and external position. The exchange rate could depreciate faster as observed in 1993 and trigger an inflation-depreciation spiral that would worsen urban households' living conditions and trigger new urban unrest. Third, the declining commodity prices, coffee and gold in particular, could affect negatively the country's export sector and widen the current account deficit. Those risks also negatively affect the outlook for poverty reduction. 


\section{Chapter II - The Extent of Poverty and Inequality}

\section{Key Messages}

- High poverty, particularly prevalent in rural areas and Center East regions.

- With over 70 percent of the population living on less than US\$ 1.9 per capita, per day, Burundi ranks among the poorest Sub-Saharan Africa and Low Income Countries.

- Poverty is more prevalent among large households and those with disabled members as well as households with low education, employed in agriculture and those who lack access to infrastructure and assets. Migration seems to be associated with lower poverty.

- Overall consumption inequality is moderate, but spatial disparities are large.

- Rural-urban welfare gaps are driven by disparities in households' endowments, while inequality between regions is driven by differences in returns to households' characteristics.

- Overall, disparities in access to basic services and infrastructure, ownership of assets and education are the main drivers of spatial inequalities.

The analysis of the poverty trend is challenged by the lack of comparability among data sets. The "Enquête sur les Conditions de Vie des Ménages au Burundi" (ECVMB) for 2013/14 is the first nationally representative household budget survey conducted in Burundi since the turn of the millennium. The quality of data in Burundi is a challenge for any assessment of poverty and the previous households' surveys -such as the ECVMB or standard Household Budget Surveys- are not up to the level required for a standard poverty assessment. Therefore, only a snapshot with detailed information on the prevalence and incidence of poverty in 2013/14 can be provided.

More than six out of ten Burundians live in poverty while the extreme poor account for over a third of the population. Also, an important proportion of the population in the poorest groups is likely to be trapped in persistent poverty. The "Burundian poor" are not a homogeneous group and poverty is not a single problem that can be solved with a stand-alone or uniform package of policy measures. In order for the government and other stakeholders to instigate appropriate propoor measures, it is necessary to understand the characteristics and profiles of the most disadvantaged groups and the different constraints they face.

The first section of this chapter examines the consumption poverty in 2013/14, drawing a sketch of a rural country with high prevalence of poverty. In particular, the data allows us to run a sensitivity test and to underline the high vulnerability of the non-poor. Burundi poor people are identified as those facing consumption shortfalls, but poverty is not a single economic condition and it goes beyond consumption deficits. Thus the second section focuses on the core socioeconomic characteristics of the poor, comparing them with the small share of Burundi's population that is non-poor. The third section investigates the evolution and structure of 
inequality. The section draws on the analysis of the differences in endowment in and returns on the assets to explain inequality discrepancies between regions and households.

\section{Snapshot of consumption poverty in 2013-14}

\section{High poverty, particularly prevalent in rural areas and Center East regions}

Poverty is highly prevalent in Burundi with 64.9 percent of the population living in poverty and 38.7 percent in extreme poverty. According to the 2013/14 Burundi Survey on Households Living Conditions (ECVMB 2013-2014), 64.9 percent of the population (around 6.1 million people) is poor, meaning they have a real monthly consumption per adult equivalent below the basic needs poverty line. In addition, 38.7 percent (around 3.6 million Burundians) lives in extreme poverty, below the food poverty line, and hence cannot afford to buy enough food to meet the minimum nutritional requirements of 2,200 kilocalories (Kcal) per adult equivalent per day (see Box II.1 for details). ${ }^{9}$ The poverty gap (or depth of poverty), which measures the average consumption expenditure shortfall of the poor as a share of the poverty threshold, indicates that the average consumption level of a poor Burundian is around 75 percent of the national poverty line. This suggests that many of the poor are far from of the poverty line and need a significant increase of their living standards to move out of poverty. The severity of poverty (or squared poverty gap) is estimated at 12 percent reflecting an important inequality among the poor. (Figure II.1).

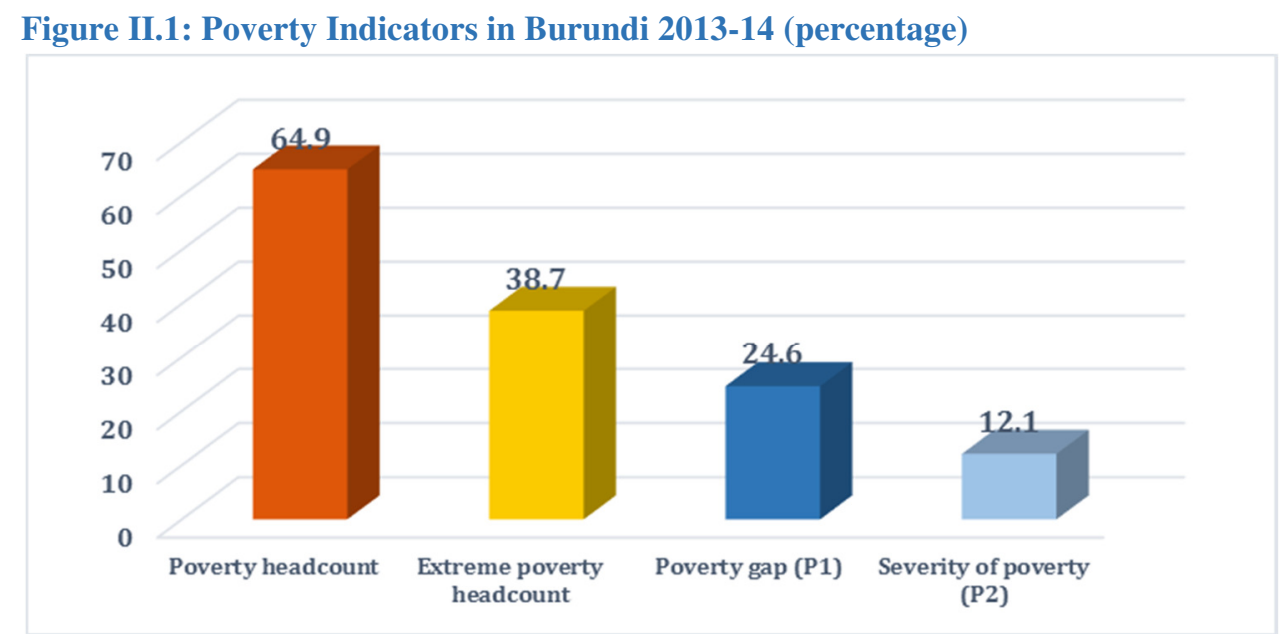

Source: ECVMB 2013/14

\footnotetext{
${ }^{9}$ The official poverty numbers published by ISTEEBU show a very close poverty rate of 64.6 percent. However, the estimates are based on a higher poverty line and higher consumption levels due to differences in the methodology used for the measurement of the consumption aggregates. More details are provided in Appendix I.
} 


\section{Box II.1 Measuring Poverty in the ECVMB 2013/14}

As it is typically the case in Sub-Saharan Africa (SSA), the ECVMB 2013/14 uses consumption as the key welfare measure to analyze poverty. This consumption aggregate comprises food consumption, including food produced by households themselves, as well as expenditures on a range of nonfood goods and services (e.g., clothing, utilities, transportation, communication, health, education, housing-related expenditures and imputed rent, etc.). However, the consumption aggregate does not include expenditures on larger consumer durable items (such as cars, TVs, computers, etc.), nor does it include expenditures on ceremonies (marriage, funerals, etc.). To the extent that better-off households devote a larger proportion of their total consumption to durable goods, this omission creates certain biases and underestimates real consumption among wealthier families. This is less important for poverty analysis, where the focus lies on the bottom-end of the distribution, but it can have a significant impact on estimated inequality.

The ECVMB 2013/14, as most household surveys, collects consumption data at household level. For the purpose of poverty and welfare analysis total household consumption needs to be adjusted for differences in household size and composition. This is to account for the fact that, for instance, a single-person household requires less consumption than a family of five. One possible approach is to compute consumption per capita, which implicitly assumes that all members of the household require the same level of consumption. Another approach is to compute consumption per "adult equivalent." This approach is widespread in the context of SSA, where typically a large share of consumption is spent on food items. Adult equivalent requires equivalence scales to convert household members of different age and sex into a standardized adult based on assumptions about caloric requirements. The ECVMB 2013/14 poverty analysis follows this method as it uses consumption per adult equivalent as the key welfare measure. Price deflators are used to adjust consumption per adult equivalent for price differences across geographic domains.

The poverty lines are based on the cost-of-basic-needs approach. The ECVMB 2013/14 food poverty line (BIF 28,201.5 per adult per month) is based on the cost of a food basket that delivers 2,200 calories per adult per day (given consumption patterns in a reference population). The basic needs poverty line (BIF 41,054 per adult per month) adds an allowance for basic non-food necessities to the food poverty line. Further technical details on the construction of the ECVMB 2013/14 consumption aggregate, adult equivalence scale, price deflators, and poverty line can be found in Appendix I.

The basic needs headcount poverty rate (or as used in the text, poverty rate) measures the proportion of the population whose monthly (price-adjusted) total household consumption per adult equivalent is below the basic needs poverty line. The extreme headcount poverty rate (used in the text as extreme poverty rate) measures the proportion of the population whose monthly (price-adjusted) total household consumption per adult equivalent is below the food poverty line.

Poverty is overwhelmingly rural, with more than 95 percent of the poor and extreme poor Burundians living in rural areas. Around 90 percent of the total population lives in rural areas where the incidence of poverty is estimated at 68.9 percent against, respectively, 40.9 and 20.8 percent in other urban areas and Bujumbura mairie (Figures II.2 and II.4). In rural Burundi, extreme poverty is estimated at 41.3 percent. It is four times higher than in Bujumbura mairie (10.4 percent) and around double than in other urban areas (22.7 percent). This translates to around 5.8 million of the rural population living in poverty and 3.5 million in extreme poverty, compared to respectively less than 264 thousand and 140 thousand people who live in poverty and extreme poverty in urban settings (Figures II.3 and II.5). 
Figure II.2: Poverty Incidence by Geographic Domains 2013-14

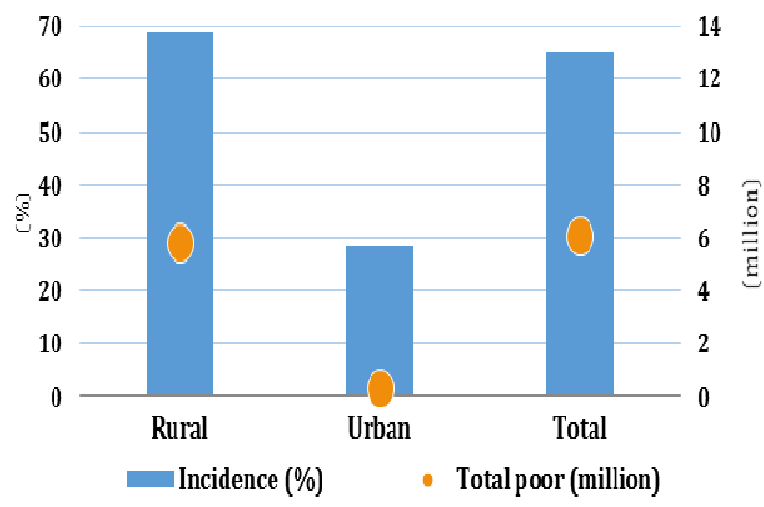

Source: ECVMB 2013-14
Figure II.3: Distribution of Poor Population by Geographic Area (million, percentage)

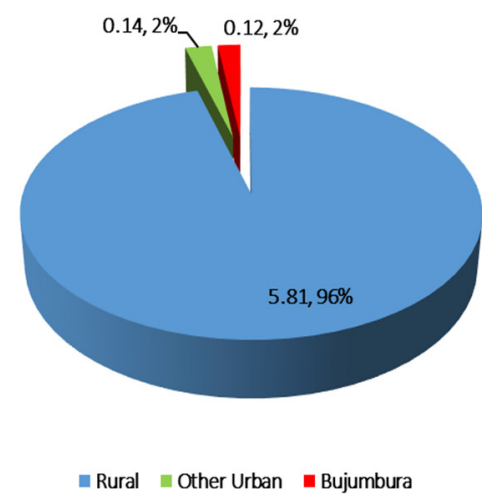

Source: ECVMB 2013-14

The depth and severity of poverty are also more pronounced in the rural settings. In rural areas, the average consumption level of a poor individual is around 74 percent of the poverty line. For other urban areas and Bujumbura this percentage is estimated at around 85 percent and 93 percent, respectively. Likewise, poverty severity is significantly higher in rural areas, almost three times higher than in the capital city and around two times higher than in other urban areas.

Figure II.4: Poverty Incidence by Geographic Area 2013-14 (percentage)

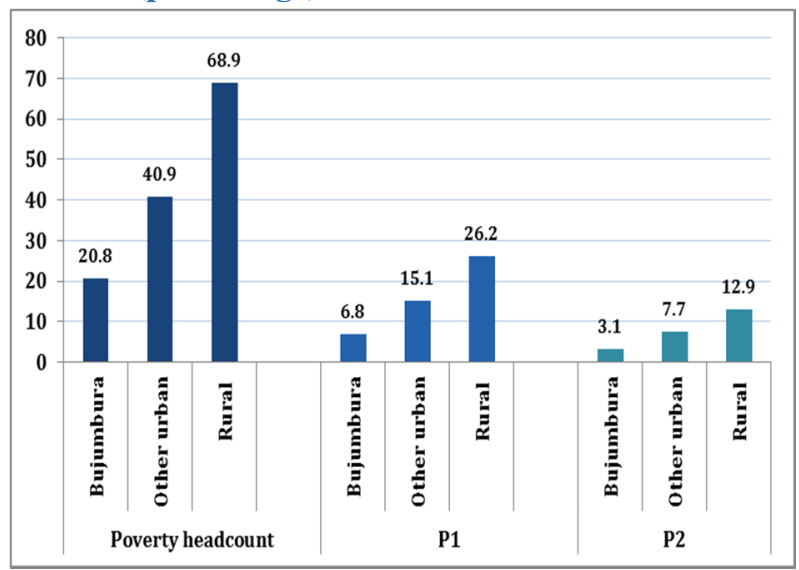

Source: ECVMB 2013-14
Figure II.5: Extreme Poverty by Geographic Area 2013-14 (percentage)

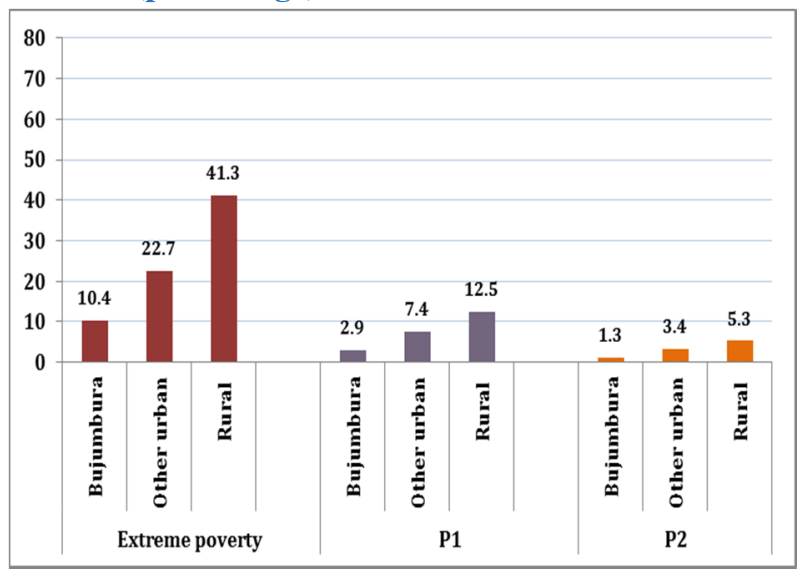

Source: ECVMB 2013-14

High prevalence of poverty is found in the Center East and the North. Households in the West and the South of Burundi seem to have a higher standard of living. They are also less likely to be poor than those located in the North and Center East. As apparent from Figure II.6, around 75 percent of the population in the Center East, and 73 percent in the North, is poor. This translates to more than two million people living in poverty in each region against less than one million in the West and the South, respectively. There are also wide spatial disparities in poverty within regions. In the North, the poverty levels vary from the low of 60.7 percent in the province of Ngozi to the high of 83.5 percent in the province of Muyinga and in the Center East it varies 
between 60 percent in Mwaro to over 85 percent in Ruyigi. ${ }^{10}$ In the West, poverty is lowest in Bujumbura-mairie at 20.8 percent and highest in Bubanza at 63.9 percent, while in the South, Bururi seems to be the less poor province with a poverty level of 46.3 percent and Rutana the poorest at 71.6 percent (Figure II.7).

Poverty is not only more prevalent among population in the Center East and the North, it is also deeper and more severe. The monthly real consumption per adult-equivalent in these regions is, on average, 29 percent lower than the poverty line. This indicates a need for more substantial assistance programs in the North and Center East than in the South and West, where the average consumption level is 20 percent lower than the poverty line.

Figure II.6: Poverty Incidence by Region 2013-14 (percentage)

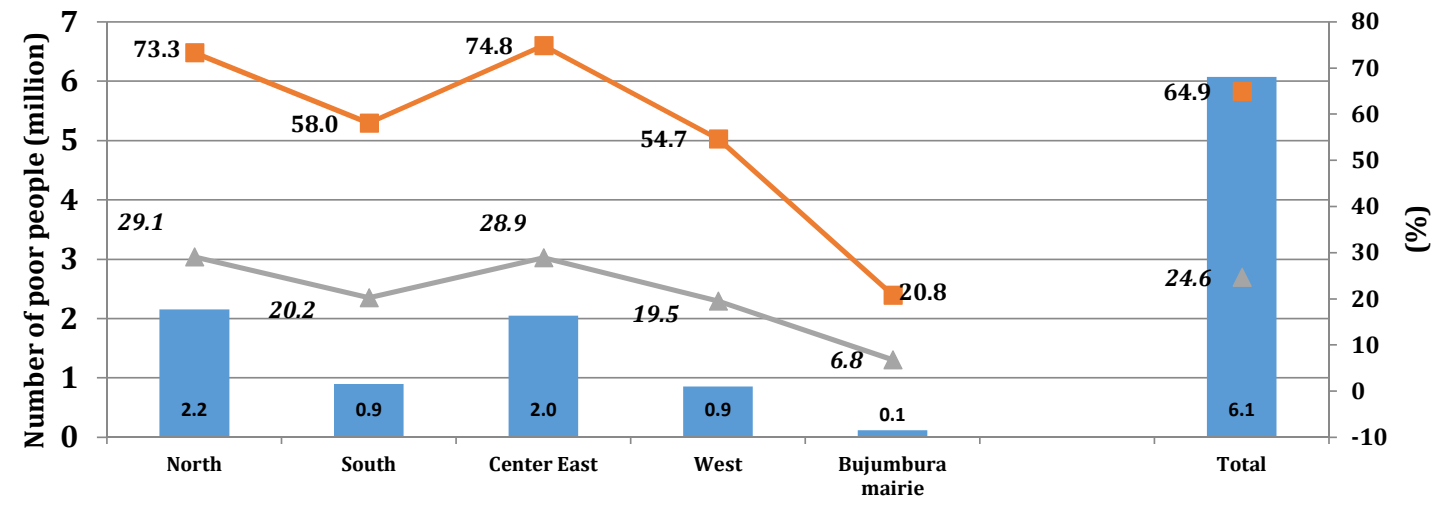

Burundian poors (left axis) - Poverty rate (right axis) - Poverty gap (right axis)

Source: ECVMB 2013-2014.

Figure II.7: Poverty Incidence by Province 2013-14 (percentage)

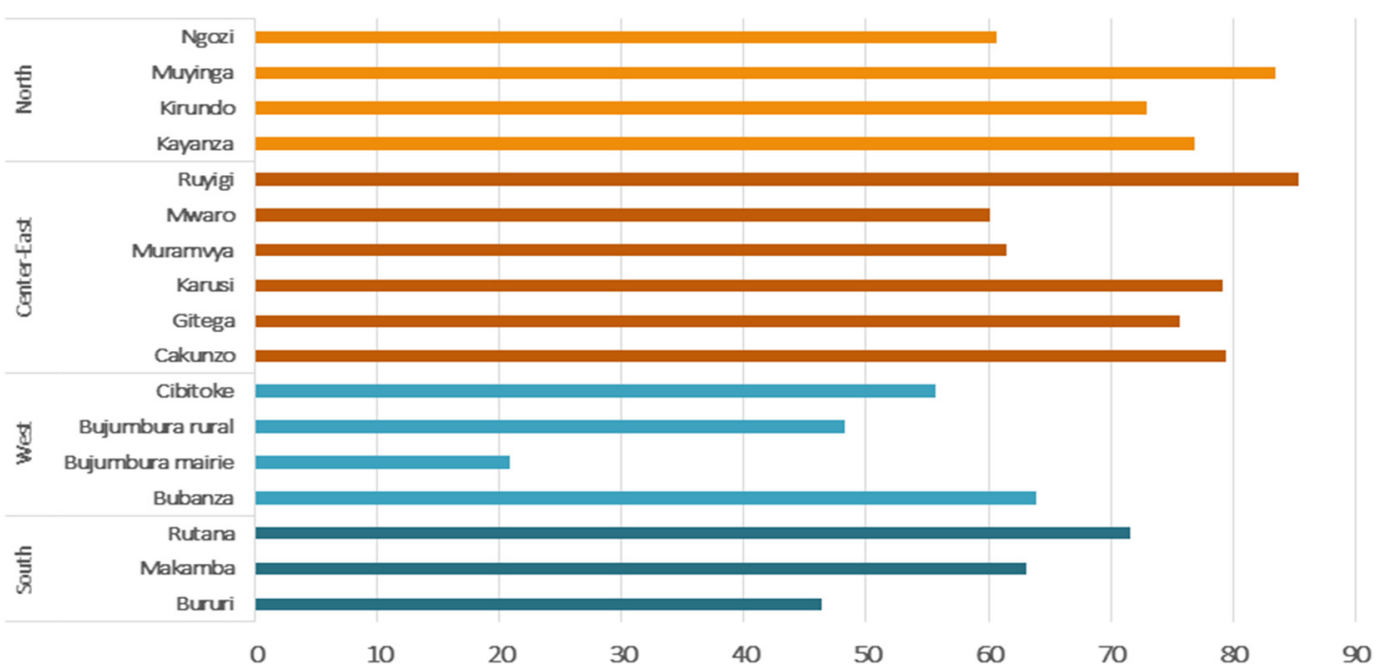

Source: ECVMB 2013-2014.

\footnotetext{
${ }^{10}$ See Burundi map at the end of the document.
} 


\section{Imbalances in the aid flow seem to contribute to the spatial disparities in poverty}

Western regions seem to have the highest share of aid. According to the "Rapport d'Aide Publique au Développement Edition 2012-2013" by the National Committee of aid coordination (CNCA), the aid flow is around 25 percent higher in the West than in the North and Center East. It is also over 60 percent higher than in the South (Figure II.8). Overall, these regions have benefitted from infrastructure projects for the development of rural areas, labor-intensive projects such as roads paving and projects for food assistance and supporting community recovery.

At provincial level, it seems that provinces in the West has also benefitted from larger support. Some provinces in other regions where poverty is less prevalent seem also to have obtained a relatively larger share of aid. This seems to be particularly the case in the province of Ngozi and Bujumbura Rural as well as in Muramvya (Center East, with poverty rate at 61.5 percent), Makamba (South, with poverty at 63.1 percent) and Cibitoke (West, 55.6 percent). Ruyigi and Rutana where poverty is highly prevalent received less aid. However, other provinces such as Bubanza and Kirundu seem to have received important shares of aid, while they have high poverty levels. Therefore, while this evidence would suggest some links between regional disparities in poverty and aid imbalances, further investigation is needed to fully understand these dynamics.

Figure II.8: Disbursements of Aid by Region and Province in 2012-2013 (million USD)
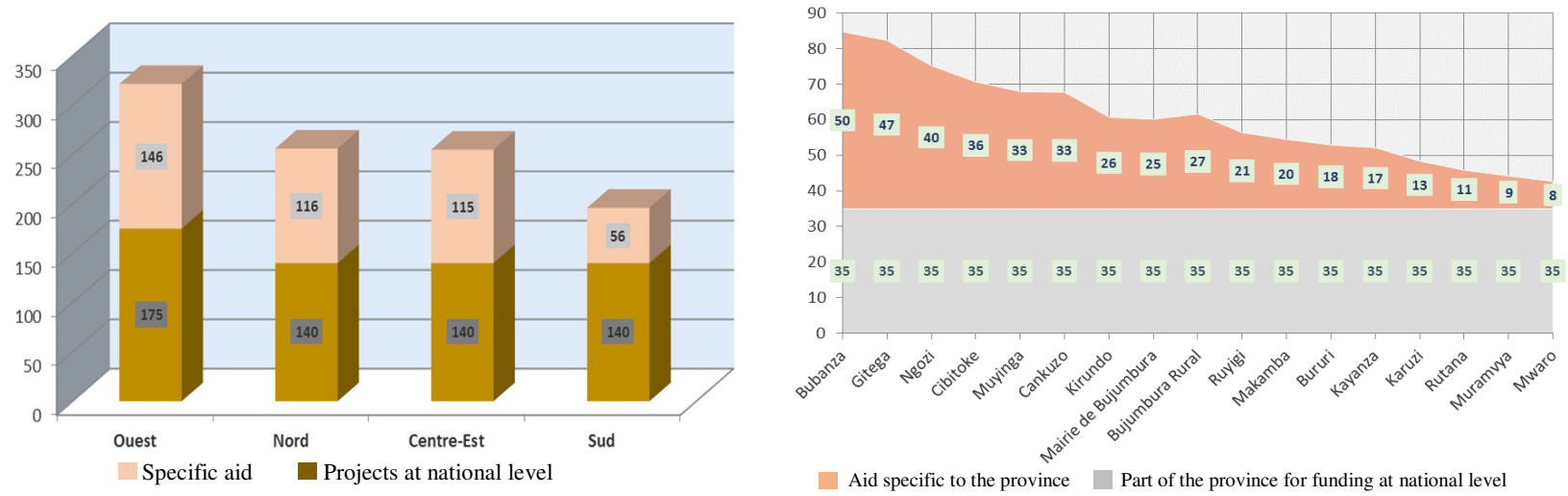

Source: DAD, Rapport d'Aide Publique au Développement Edition 2012-2013 (CNCA)

Internationally, Burundi ranks among the poorest SSA countries

Burundi's international poverty rate is 72.9 percent, significantly higher that Sub-Saharan Africa (SSA) and Low Income Countries (LIC) averages. Burundi's national poverty line reflects the country's specific costs of basic consumption needs, but it is difficult to compare this with other countries' poverty thresholds. To overcome this issue, the international poverty line of US\$1.9 per capita per day (in 2011 Purchasing Power Parity (PPP) exchange rate) is often used to evaluate a country's poverty record vis-a-vis other developing countries or regions.

The international poverty rate is 72.9 percent, around 8 percentage points higher than the national poverty rate. It shows that poverty is more pervasive in Burundi than in most SSA and 
LIC. Burundi's international poverty rate is, around 30 percentage points higher than LIC and SSA averages of 47.2 percent and 42.7 percent, respectively. Compared with countries with similar income level, Burundi's poverty rate is only lower than Congo Democratic Republic's and Madagascar's (Figure II.9).

Figure II.9: Poverty Estimates in Burundi and Other Developing Countries by Percentage

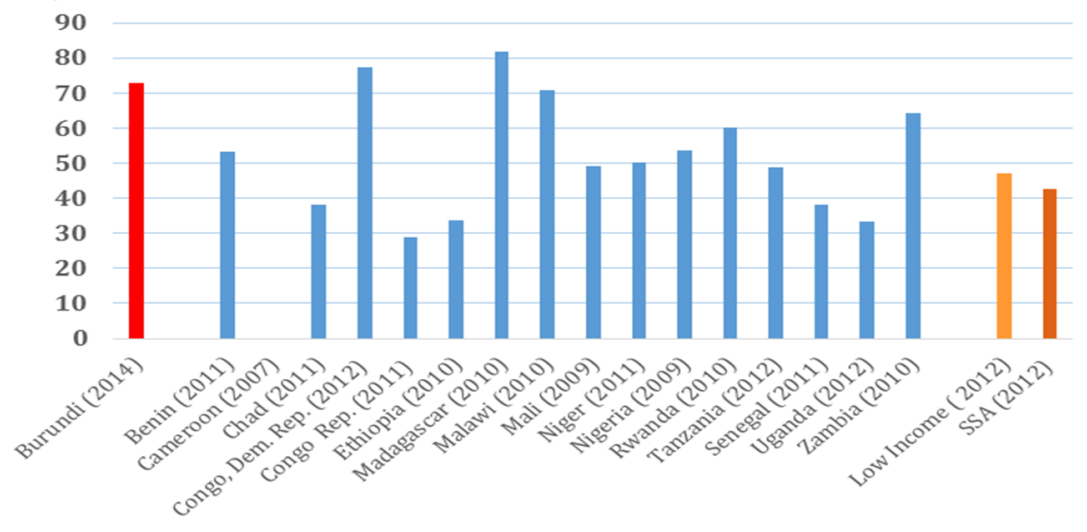

Source: World Development Indicators (2015)

A large share of the non-poor population is clustered just above the poverty line and is highly vulnerable to fall into poverty. Around 50 percent of the non-poor population stagnates at a consumption level right above the poverty line, within a range of BIF 623 per adult per day (around US\$ 0.5 per capita per day above the international line, in 2011 PPP). They are therefore prone to fall back into poverty in case of unexpected economic shocks. In fact, the vast majority of the Burundian population, around 89 percent, lives on less than US\$ 3.1 per day (Figure II.10). However, while most of the non-poor are close to the poverty line and are vulnerable to an economic downturn, most of the poor are far below the poverty line and would need substantial assistance and special care in development programs to help them enhance their livelihoods and productivity.

Figure II.10: Sensitivity of Poverty Rate from Change in Poverty Line

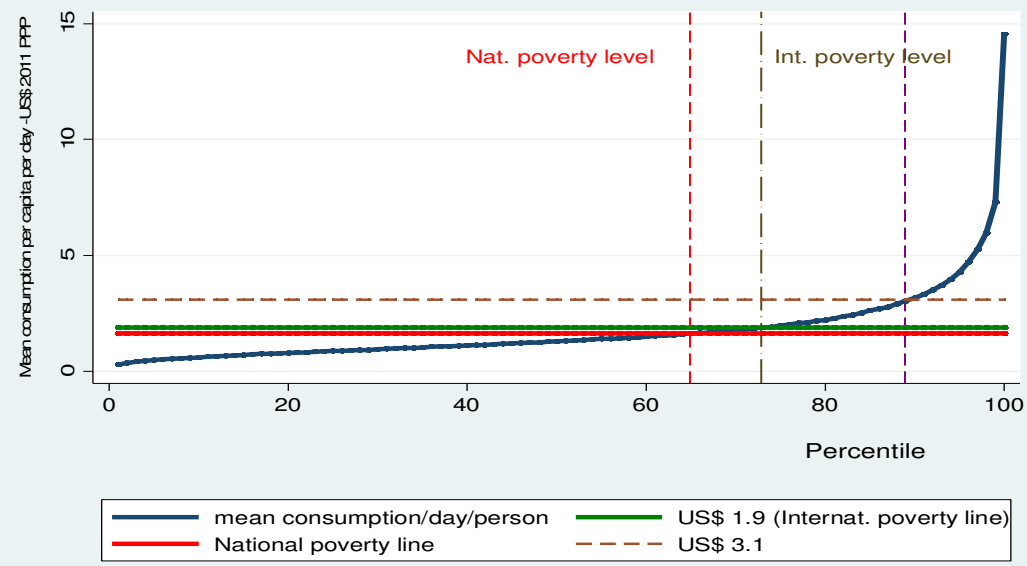

Source: ECVMB 2013-2014. 


\section{Characteristics of the poor}

\section{Poor households are larger in size and have more dependents}

Average household size is significantly larger in poor households than in non-poor households. Poor households report an average of 6.1 household members, compared to 5.2 among non-poor households. Meanwhile in households living in extreme poverty this number is 6.4, compared to 5.5 among families that are not (Table II.2). As seen in Table II.2 and Table II.4, national household size has declined in the last eight years from 6.1 members in 2006 to 5.8 members in 2014. For poor households, this number has declined at a slightly faster rate, from 6.4 members in 2006 to 6.1 in 2014. Successful family planning programs may explain this trend.

Poor households also have a higher number of dependents and children under the age of $\mathbf{1 4}$ than do non-poor households. Dependents constitute 53 percent of poor households, compared to 47 percent of non-poor households, and 54 percent of extremely poor households, compared to 49 percent of households that are not extremely poor. Table II.4 shows that the dependency ratio gap between poor and non-poor households has widened in 2014 compared to 2006. As seen in Figure II.14, poverty rates are highest among households with children, followed by elderly families. Poverty is particularly high among households with five or more children. The relationship between poverty and family size can be seen as bidirectional - while the high number of children in the household contributes to poverty, it is also an expression of poor households' inability to invest in the human capital of their children, and as an insurance against infant mortality, thereby trapping them in a vicious cycle of poverty.

Table II.1: The Burundi households' demographic structure in 2014 - Spatial location.

\begin{tabular}{|c|c|c|c|c|c|c|c|c|}
\hline & \multicolumn{4}{|c|}{ Region } & \multicolumn{3}{|c|}{ Residence } & \multirow[b]{2}{*}{ Burundi } \\
\hline & North & South & Center East & West & The Capital & $\begin{array}{l}\text { Other } \\
\text { urban }\end{array}$ & Rural area & \\
\hline Household size & 5.4 & 6.4 & 5.6 & 6.1 & 6.3 & 6.2 & 5.8 & 5.8 \\
\hline Dependency ratio $^{(l)}$ & 0.5 & 0.5 & 0.5 & 0.5 & 0.4 & 0.5 & 0.5 & 0.5 \\
\hline Children aged $<=14$ (numb.) & 2.9 & 3.4 & 2.9 & 3.3 & 2.6 & 3.1 & 3.0 & 3.0 \\
\hline Adult women (numb.) & 1.2 & 1.3 & 1.2 & 1.2 & 1.5 & 1.4 & 1.2 & 1.2 \\
\hline Adult men (numb.) & 1.0 & 1.1 & 1.0 & 1.1 & 1.7 & 1.2 & 1.0 & 1.1 \\
\hline Head is a male $(\%)$ & 82.8 & 85.0 & 79.6 & 83.5 & 83.1 & 82.2 & 82.4 & 82.4 \\
\hline Head's age (year) & 42.6 & 44.8 & 44.6 & 43.1 & 43.4 & 42.5 & 43.7 & 43.7 \\
\hline
\end{tabular}

Source: ECVMB 2013-2014. Note: ${ }^{(1)}$ The dependency ratio is measured by the proportion of children aged from 0 to14 years and elderly aged from 65 years to above that, in the household. The denominator is the total household size.

Table II.2: The Burundi households' demographic structure in 2014 - Poverty status.

\begin{tabular}{|c|c|c|c|c|c|}
\hline & \multicolumn{2}{|c|}{ Poor } & \multicolumn{2}{|c|}{ Extreme poor } & \multirow{2}{*}{ Burundi } \\
\hline & '"No & Yes & No & Yes & \\
\hline Household size & 5.2 & 6.1 & 5.5 & 6.4 & 5.8 \\
\hline Dependency ratio ${ }^{(l)}$ & 0.5 & 0.5 & 0.5 & 0.5 & 0.5 \\
\hline Children aged $<=14$ (numb.) & 2.5 & 3.3 & 2.7 & 3.5 & 3.0 \\
\hline Adult women (numb.) & 1.2 & 1.3 & 1.2 & 1.3 & 1.2 \\
\hline Adult men (numb.) & 1.1 & 1.1 & 1.1 & 1.1 & 1.1 \\
\hline Head is a male $(\%)$ & 79.8 & 83.8 & 82.1 & 82.8 & 82.4 \\
\hline Head's age (year) & 42.4 & 44.4 & 42.8 & 45.0 & 43.7 \\
\hline
\end{tabular}

Source: ECVMB 2013-2014. Note: ${ }^{(1)}$ The dependency ratio is measured by the proportion of children aged from 0 to14 years and elderly aged from 65 years to above that, in the household. The denominator is the total household size. 
Table II.3: The Burundi households' demographic structure in 2006 - Spatial location.

\begin{tabular}{|c|c|c|c|c|c|c|c|c|}
\hline & \multicolumn{4}{|c|}{ Region } & \multicolumn{3}{|c|}{ "Residence } & \multirow[b]{2}{*}{ Burundi } \\
\hline & North & South & Center East & West & The Capital & $\begin{array}{l}\text { Other } \\
\text { urban }\end{array}$ & Rural area & \\
\hline Household size & 5.9 & 6.5 & 5.9 & 6.2 & 6.6 & 7.1 & 6.0 & 6.1 \\
\hline Dependency ratio ${ }^{(l)}$ & 0.5 & 0.5 & 0.5 & 0.5 & 0.4 & 0.5 & 0.5 & 0.5 \\
\hline Children aged $<=14$ (numb.) & 3.1 & 3.4 & 3.0 & 3.3 & 2.8 & 3.6 & 3.2 & 3.1 \\
\hline Adult women (numb.) & 1.2 & 1.3 & 1.3 & 1.2 & 1.5 & 1.4 & 1.2 & 1.3 \\
\hline Adult men (numb.) & 1.1 & 1.3 & 1.1 & 1.2 & 1.6 & 1.4 & 1.1 & 1.2 \\
\hline Head is a male $(\%)$ & 82.9 & 85.6 & 84.8 & 84.7 & 79.6 & 80.4 & 84.3 & 84.1 \\
\hline Head's age (year) & 43.3 & 44.3 & 44.2 & 42.6 & 43.6 & 43.3 & 43.6 & 43.6 \\
\hline
\end{tabular}

Source: QUIBB 2005-2006. Note: ${ }^{(1)}$ The dependency ratio is measured by the proportion of children aged from 0 to14 years and elderly aged from 65 years to above that, in the household. The denominator is the total household size.

Table II.4: The Burundi households' demographic structure in 2006 - Vulnerability status.

\begin{tabular}{|c|c|c|c|c|c|}
\hline & \multicolumn{2}{|c|}{ Poor } & \multicolumn{2}{|c|}{ Extreme poor } & \multirow{2}{*}{ Burundi } \\
\hline & '"No & Yes & "'no & Yes & \\
\hline Household size & 5.4 & 6.4 & 5.6 & 6.5 & 6.1 \\
\hline Dependency ratio ${ }^{(l)}$ & 0.5 & 0.5 & 0.5 & 0.5 & 0.5 \\
\hline Children aged $<=14$ (numb.) & 2.7 & 3.4 & 2.8 & 3.5 & 3.1 \\
\hline Adult women (numb.) & 1.2 & 1.3 & 1.2 & 1.3 & 1.3 \\
\hline Adult men (numb.) & 1.1 & 1.2 & 1.2 & 1.2 & 1.2 \\
\hline Head is a male $(\%)$ & 85.3 & 83.4 & 84.5 & 83.6 & 84.1 \\
\hline Head's age (year) & 41.9 & 44.4 & 42.5 & 44.6 & 43.6 \\
\hline
\end{tabular}

Source: QUIBB 2005-2006. Note: ${ }^{(1)}$ The dependency ratio is measured by the proportion of children aged from 0 to14 years and elderly aged from 65 years to above that, in the household. The denominator is the total household size. The vulnerability status is based on the deprivation in basic consumption needs.

On the surface, poverty appears to be lower in households with younger heads. Household heads aged 15-35 report a relatively low incidence of poverty (55.7 percent), compared to relatively higher incidences of poverty among households whose heads aged 36-45 and 46-55 (72.5 percent and 70.7 percent respectively). This difference reflects the higher number of children in the household, as younger heads have only just started a family (Figure II.13).

Figure II.11: Poverty by Household Size

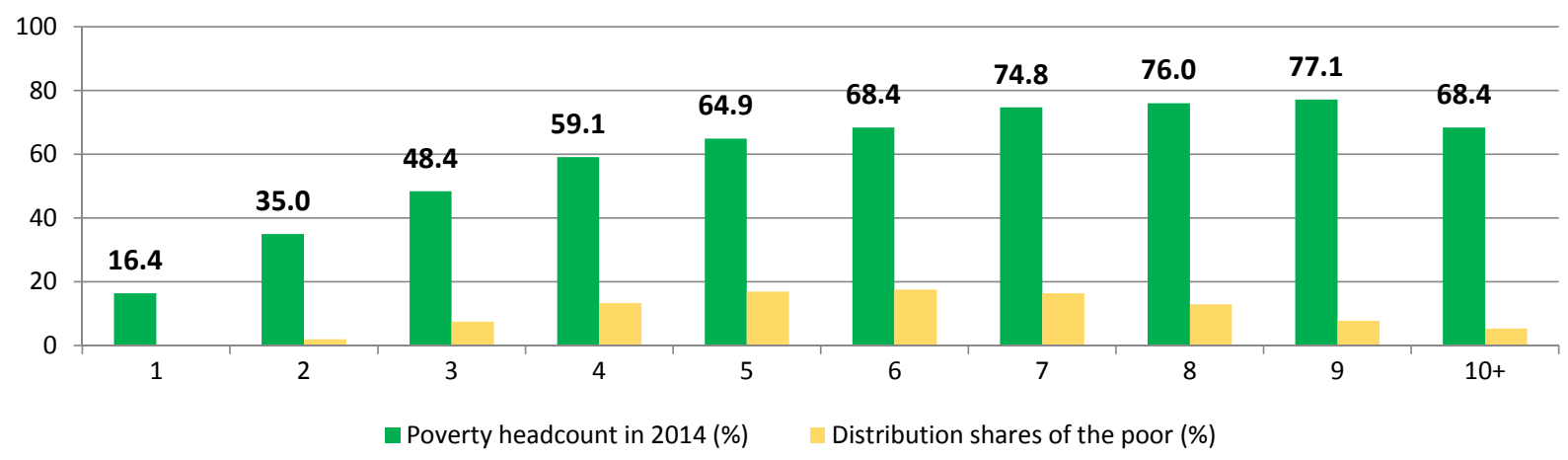

Source: ECVMB 2013-2014. 
Figure II.12: Poverty Incidence by Number of children aged 0 -14 years

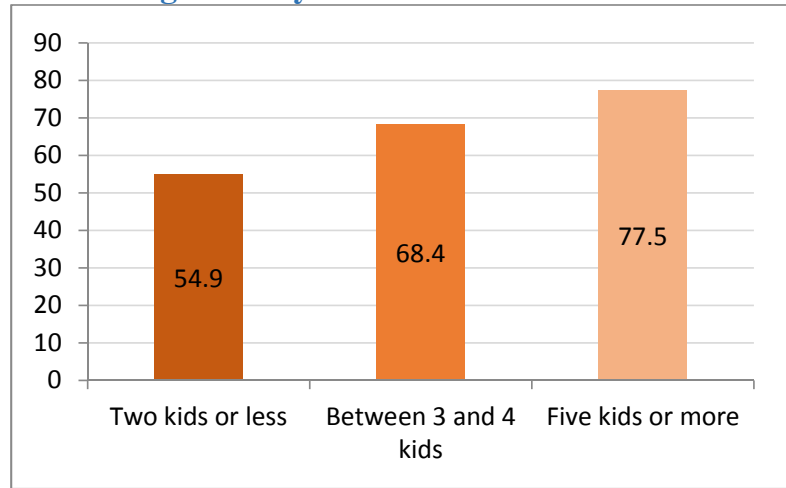

Source: ECVMB 2013-2014.

Figure II.14: Poverty Incidence by Family Type

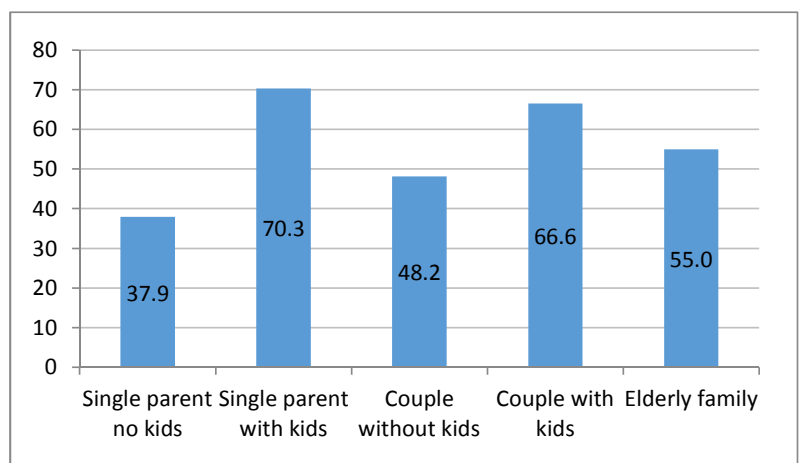

Source: ECVMB 2013-2014.
Figure II.13: Poverty by Age of Household's Head

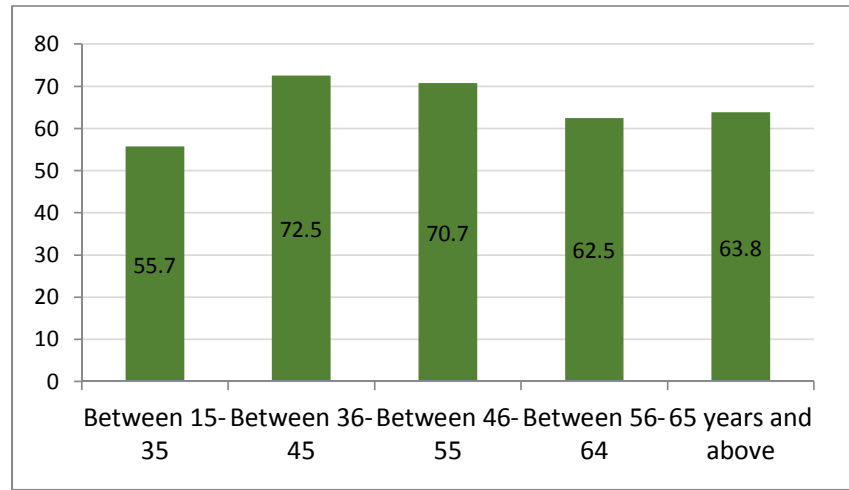

Source: ECVMB 2013-2014.

Figure II.15: Poverty Incidence by Head's Gender and Marital Status (percentage)

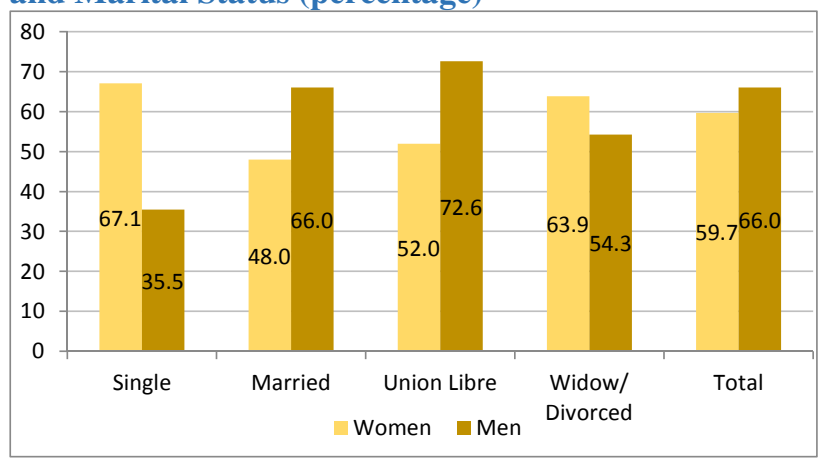

Source: ECVMB 2013-2014

There is no significant correlation between the gender of the household head and poverty.

On aggregate, poverty appears to be lower among households with female heads: out of all poor households, about 18 percent are led by women versus 82 led by men. However, further disaggregation reveals that only households headed by married women and women in free unions ("union libre") have a lower incidence of poverty, while households headed by single and widowed women suffer from higher levels of poverty (Figure II.15). A likely explanation for this difference is that women head of households that are married or cohabitating receives additional financial support from their male partner.

\section{Poverty is likely more prevalent among households with handicapped and disabled members}

Burundian households with handicapped or disabled members display a higher incidence of poverty than families without handicapped or disabled members. In 2014, 264,403 persons suffered from a disability or handicap. 80.7 percent of these suffered from a physical disability, a number that may be a result of war-related injuries. In total, 1,174,743 Burundian households were comprised of at least one member with a disability or handicap. The incidence of poverty among these households is estimated at 68.2 percent, compared to 64.4 percent among households with no members with disabilities. 
At the same time, poverty incidence differentials vary significantly across regions. The greatest differentials are found in the South and the West, while in the North, households with handicapped or disabled members report a slightly lower incidence of poverty than households without handicapped or disabled members. A possible explanation for this variation may be better, community-based targeting schemes in the North, and poorly performing targeting schemes in the South and West regions. Moreover, Western Burundi has seen a high incidence of armed clashes, possibly contributing to more severe conflict-related disabilities among the regional population.

Figure II.16: Households with disabled members

$1,174,743$

Persons living in households with disabled members

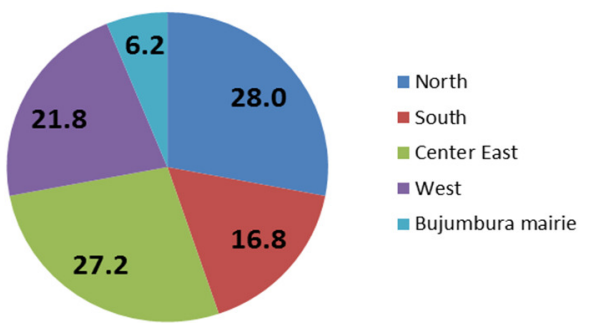

Source: ECVMB 2013-2014

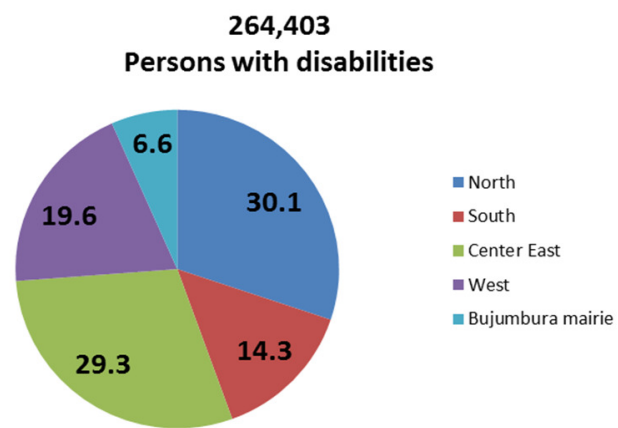

Source: ECVMB 2013-2014

Table II.5: Poverty incidences for people living in households with disabled members - Spatial location

\begin{tabular}{|c|c|c|c|c|c|}
\hline & \multicolumn{3}{|c|}{ " Household with disabled member ${ }^{(\mathbf{1})}$} & \multicolumn{2}{|c|}{ Estimated population } \\
\hline & \multicolumn{2}{|c|}{ Poverty rate } & \multirow{2}{*}{$\begin{array}{c}\text { Number of affected } \\
\text { households }\end{array}$} & \multirow{2}{*}{ Poverty rate } & \multirow{2}{*}{ Number of people } \\
\hline & No & Yes & & & \\
\hline North & $73.6 \%$ & $71.1 \%$ & 69,628 & $73.3 \%$ & $2,937,226$ \\
\hline South & $56.9 \%$ & $66.1 \%$ & 34,280 & $58.1 \%$ & $1,541,941$ \\
\hline Center East & $74.3 \%$ & $78.6 \%$ & 62,895 & $74.8 \%$ & $2,737,794$ \\
\hline West & $52.8 \%$ & $64.3 \%$ & 46,921 & $54.7 \%$ & $1,565,403$ \\
\hline Bujumbura & $19.6 \%$ & $29.3 \%$ & 13,119 & $20.8 \%$ & 576,553 \\
\hline Burundi & $64.4 \%$ & $68.2 \%$ & 226,842 & $64.9 \%$ & $9,358,917$ \\
\hline
\end{tabular}

Source: ECVMB 2013-2014. Note: ${ }^{(1)}$ Population weights are used to estimate individual poverty.

The education level and employment sector of the household head contributes significantly to wellbeing

Poverty is closely associated with the education level among heads of households. Among an overwhelming high proportion of poor households, the head has no formal education. As seen in Figure II.17, higher education levels among household heads corresponds to declining incidences of poverty. Meanwhile, households where heads have a university education have a much lower incidence of poverty. However, the virtual absence of poor among university graduates suggests that this level of education in practice is unattainable for poor households. 
Higher education levels of the household's head seem to be associated with better incomegenerating opportunities and significantly lower poverty levels. Education positively affects living standards and poverty reduction both directly and indirectly through its impact on health, productivity, social integration, and so forth. Although primary education continues to be of crucial importance for fighting poverty, it alone seems no longer sufficient to increase poor people's opportunities for economic mobility and for moving out of poverty. Low education continues to be highly prevalent in Burundi as over half of the households are headed by a person with no formal education and about 30 percent have heads who did not complete primary education. This indicates that, under a certain level, labor may not be able to generate enough returns for years of schooling.

Wage employment and nonfarm businesses are associated with lower poverty. Poverty rates are lowest among households headed by government and public sector employees followed by employees in the private sector and NGOs. In contrast, households relying on agriculture seem to be the poorest, with close to two third of them living in poverty and about half in extreme poverty. Households employed in nonfarm seem to be better off and only half of them live in poverty (Figure II.18).

Figure II.17: Poverty incidence by Education of Household's Head (percentage)

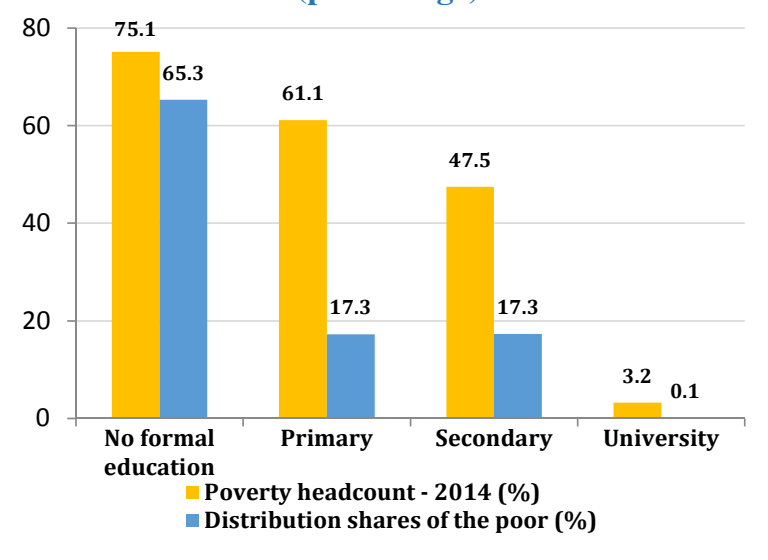

Figure II.18: Poverty incidence by Employment of Household's Head (percentage)

Source: ECVMB 2013-2014.

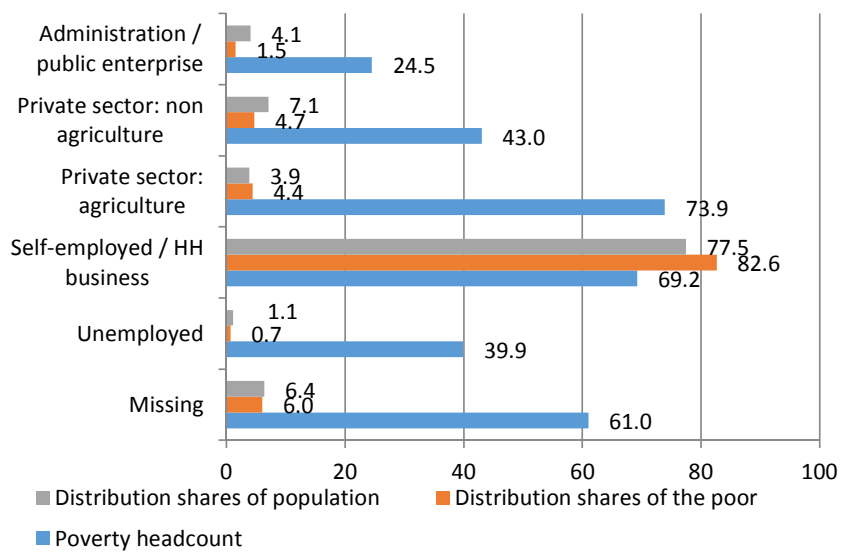

Source: ECVMB 2013-2014.

Access to infrastructure and assets are linked with lower poverty

The poor and bottom 40 percent of the population lack access to infrastructure and basic services. Among the extreme poor, or bottom 40 percent of the income distribution, only 8.9 percent live closer than one kilometer from the nearest asphalted road. Access to electricity, improved sanitation services, good sewage connections and trash collection is also non-existent for the vast majority of the poor and bottom 40 percent, and this despite the slight improvements in the access to these amenities that have been observed during the last eight years. Access to drinking water is higher and has improved quite significantly since 2006, but access to piped water remains quite low with one fourth of poor households and less than 20 percent of bottom 40 having access to this amenity (Figure II.19). 
Access to infrastructure and basic services is substantially greater in urban than in rural areas. Residents of urban areas enjoy far greater access to infrastructure and services across the board. Urban areas have also seen the greatest improvements of electricity and sanitation in the last 8 years, with an 8.5 percent increase in access to electricity and an 8.1 percent increase in access to improved sanitation, compared to increases of 0.4 percent and 0.9 percent respectively in rural areas. On the other hand, access to drinking water has increased at a higher rate in rural areas as compared to urban areas, with increases of 15.6 percent and 9.4 percent respectively, but this is mostly for protected sources and not piped water.

Figure II.19: Access to infrastructure and basic services (percentage)
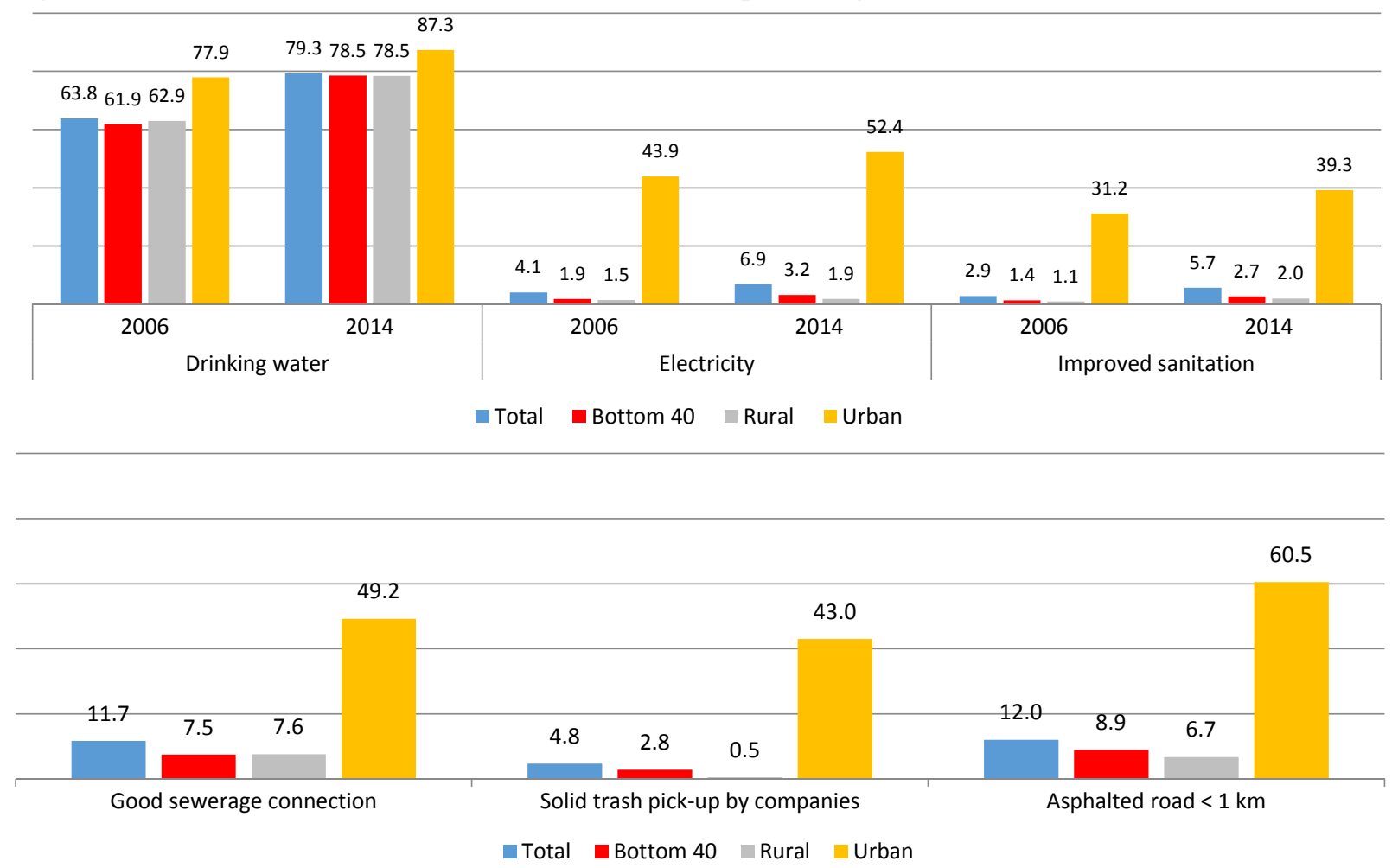

Source: ECVMB 2013-2014

Possession of durable goods is related to lower incidences of poverty. Most imported durable goods that require a reliable power supply or the supply of hydrocarbons (gasoline or diesel) are out of the reach of poor households. Only a small segment of poor households have access to electrical or digital durable goods like refrigerators, television sets or DVD readers (Table II.6). Cell phones are found in a larger number among non-poor households than poor ones and their ownership is associated with significantly lower poverty. Ownership of bicycles does not indicate lower incidences of poverty, while ownership of hoes is associated with a higher incidence of poverty. 
Table II.6: Access to durable goods

\begin{tabular}{|c|c|c|c|c|}
\hline \multirow{3}{*}{ Asset } & \multicolumn{4}{|c|}{ Household possesses the asset? } \\
\hline & No & Yes & No & Yes \\
\hline & \multicolumn{2}{|c|}{ Poverty incidence (\%) } & \multicolumn{2}{|c|}{ Population share (\%) } \\
\hline Generator & 65.0 & 0.0 & 99.8 & 0.2 \\
\hline Computer & 65.0 & 0.0 & 99.9 & 0.1 \\
\hline Freezer & 65.0 & 0.0 & 99.8 & 0.2 \\
\hline Stove / cooker & 65.0 & 0.0 & 99.9 & 0.1 \\
\hline Gas heater / burner & 64.9 & 0.0 & 100.0 & 0.0 \\
\hline Kerosene heater / burner & 64.9 & 0.0 & 99.9 & 0.1 \\
\hline Gas bottle / cylinder & 64.9 & 0.0 & 100.0 & 0.0 \\
\hline Laptop & 65.6 & 1.6 & 99.0 & 1.0 \\
\hline Air conditioner & 64.9 & 4.3 & 100.0 & 0.0 \\
\hline Refrigerator & 65.8 & 5.1 & 98.4 & 1.6 \\
\hline Ventilator / Fan & 65.1 & 5.6 & 99.7 & 0.3 \\
\hline Music apparel / device & 65.2 & 7.8 & 99.4 & 0.6 \\
\hline Digital antenna & 65.3 & 8.3 & 99.3 & 0.7 \\
\hline TV set & 67.7 & 9.5 & 95.1 & 4.9 \\
\hline DVD/VCD reader & 66.7 & 9.7 & 96.9 & 3.1 \\
\hline Vehicle & 65.4 & 11.4 & 99.0 & 1.0 \\
\hline Dresser / Wardrobe & 67.2 & 14.5 & 95.5 & 4.5 \\
\hline Camera & 65.2 & 18.2 & 99.3 & 0.7 \\
\hline Motorbike / Moped & 65.6 & 20.9 & 98.5 & 1.5 \\
\hline Fax machine & 64.9 & 22.1 & 99.9 & 0.1 \\
\hline Horse / Donkey & 64.9 & 22.8 & 100.0 & 0.0 \\
\hline Electrical ironer & 67.9 & 24.5 & 93.1 & 6.9 \\
\hline Charette & 65.0 & 30.0 & 99.7 & 0.3 \\
\hline Land phone & 65.1 & 36.9 & 99.2 & 0.8 \\
\hline Moulinette (small mill) & 65.0 & 37.0 & 99.8 & 0.2 \\
\hline Dining lounge / salon & 70.4 & 43.2 & 79.7 & 20.3 \\
\hline Cell phone & 74.5 & 48.6 & 62.9 & 37.1 \\
\hline Radio set & 69.6 & 58.4 & 57.8 & 42.2 \\
\hline Bicycle & 64.7 & 65.7 & 82.5 & 17.5 \\
\hline Hoe & 30.3 & 68.0 & 8.1 & 91.9 \\
\hline
\end{tabular}

Source: ECVMB 2013-2014.

\section{Internal migration is likely related to lower poverty}

Poverty incidence is substantially lower among migrant households than among nonmigrant households. Nationwide, households with a migrant head report a poverty incidence of 53.2 percent, compared to 67.9 percent among households with non-migrant heads, as seen in Table II.7. While there are regional variations, the poverty incidence is lower among migrant households than among non-migrant households in all major regions. The exception is the Bujumbura Province, where the poverty incidence is nearly identical between both migrant and non-migrant households. Migrant-headed households also score higher on basic wellbeing indicators, including access to durable goods in the house of habitation (see more details on internal migration in Burundi in Box II.2).

Table II.7: Head's migration and poverty incidence

\begin{tabular}{llll}
\hline \hline & Non migrant & Migrant & Total \\
\hline North & 73.6 & 71.1 & 73.3 \\
South & 58.6 & 56.1 & 58.0 \\
Center East & 75.2 & 72.8 & 74.8 \\
West & 56.2 & 49.5 & 54.7 \\
Bujumbura & 20.7 & 20.8 & 20.8 \\
\hline Burundi & 67.9 & 53.2 & 64.9 \\
\hline \hline
\end{tabular}

Source: ECVMB 2013-2014.
Table II.8: Head's migration and number of poor ${ }^{(1)}$

\begin{tabular}{llll}
\hline \hline & Non migrant & Migrant & Total \\
\hline North & 1.90 & 0.25 & 2.15 \\
South & 0.71 & 0.19 & 0.90 \\
Center East & 1.75 & 0.30 & 2.05 \\
West & 0.68 & 0.18 & 0.86 \\
Bujumbura & 0.03 & 0.09 & 0.12 \\
\hline Burundi & 5.06 & 1.01 & 6.07 \\
\hline \hline
\end{tabular}

Source: ECVMB 2013-2014. Note ${ }^{(\mathbf{1})}$ number per 1,000,000 
Lower incidences of poverty among migrant-headed households correlate with a higher level of literacy in regional languages. In order to attempt to better characterize migrant households, a multivariate analysis of the probability of migrating versus not migrating, controlling for interdependency effects and place of birth, was conducted. ${ }^{11}$ The findings suggest that knowledge of French or Swahili facilitates access to new local labor markets or financial resources provided by social networks. People speaking Swahili form a large community of merchants, provides Swahili-speaking migrants with potential opportunities to do businesses or obtain relatively high-paying jobs. The same applies to French, which is seen as an invaluable asset in Burundi's labor market, especially for non-agricultural skilled jobs. Higher literacy in Swahili and French may therefore explain the negative correlation between employment in lowincome jobs (such as farming) and migrant-headed households. Overall, Burundian migrant heads appear to be better equipped than their non-migrant counterparts to compete for jobs in the non-agricultural sector, which provide higher income prospects. ${ }^{12}$

Due to the cost of migration, households headed by migrants are more likely to have greater financial capacity than non-migrant headed households. Minimum financial capacity is required to finance the overall costs of migration, including costs of departure (trip fees) and subsequently costs in the destination place (rent, food, transport, health, etc.) until the migrant gets a job. To account for this effect in the multivariate regression analysis, information on the repayment of real estate loan / credit is used as a proxy for people's capacity to leverage these financial means before departure. ${ }^{13}$ The positive correlation found between incidence of repaying a real estate loan and probability to migrate suggests that migrant heads might have better access to some form of financial support, not only after migrate but also before undertaking the intended migration.

\section{There is a significant difference in gender dynamics between migrant and non-migrant} households. 27.7 percent of migrant households are headed by women, compared to 15.1 percent in non-migrant households. At the same time, heads of households being married or in a couple are less likely to be found in migrant households. The probability regression analysis confirms a positive correlation between being female and being head of a migrant family (Table II.9). In most cases, women decide to engage in migration to make money for themselves or their families. The majority (73.6 percent) of these women become self-employers, particularly in the capital, Ngozi, Kirundo, Bujumbura rural, and Gitega, typically selling fresh or moderately transformed agricultural products and local alcohol beverages. In other situations, women

\footnotetext{
11 The purpose of the analysis was to identify the characteristics of migrant households in Burundi in 2014, taking into account the following limitations: (i) inability to track migrant households through time; (ii) lack of information prior to the decision to migrate; and (iii) lack of baseline data on potential earnings in place of departure and information on financial support from families or friends to the migrant.

12 This is the basic argument of Harris and Todaro (1970) explaining migrations in developing countries facing huge rural population and massive urban unemployment.

13 The incidence of repaying a real estate loan is introduced to ensure that the correlation coefficients obtained without this variable are not different in terms magnitude and statistical significance. This is a highly endogenous variable to migration decisions, which cannot be measured for the whole population before the migration project. Her introduction in the probability regressions aims only to check out the stability of the other more or less exogenous variables.
} 
migrations - often short-term movements - can be spurred by violence or be the result of the discrimination that excludes them from land and other meaningful means of investment.

Migrant heads of households are slightly older than non-migrant heads of households. On average, migrant heads of households are 1.3 years older than non-migrant heads. Despite its statistically significance, the relatively small difference would suggest that age is not a critical factor in the decision to migrate and its ensuing poverty and wellbeing benefits.

Table II.9: Multivariate regression, select indicators for poverty and wellbeing, migrant/non-migrant HH

\begin{tabular}{|c|c|c|c|c|c|c|}
\hline & & & Non migrant & Migrant & Burundi & Difference $^{(*)}$ \\
\hline Age & & (year) & 43.4 & 44.7 & 43.7 & $* * *$ \\
\hline Female & & $(0 / 1, \%)$ & 15.1 & 27.7 & 17.6 & $* * *$ \\
\hline Married / couples & & $(0 / 1, \%)$ & 87.3 & 77.1 & 85.2 & $* * *$ \\
\hline \multirow{3}{*}{ Literacy in: } & French & $(0 / 1, \%)$ & 20.0 & 34.2 & 22.9 & $* * *$ \\
\hline & Kirundi & $(0 / 1, \%)$ & 55.8 & 63.0 & 57.2 & $* * *$ \\
\hline & Swahili & $(0 / 1, \%)$ & 7.7 & 22.4 & 10.6 & $* * *$ \\
\hline \multirow{2}{*}{$\begin{array}{l}\text { Self-employment as income earning activity } \\
\text { from: }\end{array}$} & Private agriculture & $(0 / 1, \%)$ & 74.2 & 55.0 & 70.3 & $* * *$ \\
\hline & $\begin{array}{l}\text { Private non- } \\
\text { agriculture }\end{array}$ & $(0 / 1, \%)$ & 4.9 & 8.7 & 5.7 & $* * *$ \\
\hline \multirow[t]{3}{*}{ Repaying real estate loan } & & $(0 / 1, \%)$ & 4.5 & 7.5 & 5.1 & $* * *$ \\
\hline & Basic wel & lbeing ind & ators & & & \\
\hline & Wall & $(0 / 1, \%)$ & 11.2 & 26.9 & 14.3 & $* * *$ \\
\hline \multirow[t]{2}{*}{ Durable materials in the house of habitation: } & Roof & $(0 / 1, \%)$ & 76.9 & 82.4 & 78.0 & $* * *$ \\
\hline & Soil & $(0 / 1, \%)$ & 11.0 & 32.0 & 15.3 & $* * *$ \\
\hline Poverty headcount & & $(0 / 1, \%)$ & 67.9 & 53.2 & 64.9 & $* * *$ \\
\hline Extreme poverty & & $(0 / 1, \%)$ & 40.0 & 33.6 & 38.7 & $* * *$ \\
\hline Poverty gap & & Rate (\%) & 25.6 & 20.8 & 24.6 & $* * *$ \\
\hline
\end{tabular}

Source: ECVMB 2013-2014. Note : ${ }^{(*)}$ In order to estimate the statistical significance of mean differences, we use (bivariate) weighted ordinary least squares whereby the left-hand side variable is one of the indicators we want to examine and the right-hand side variable is the dummy variable "migrant head" taking on value 1 for migrant heads and taking on value 0 for non-migrant heads. Using un-weighted regressions give us the same results for all indicators, except migrant head's age that becomes not statistically significant. *** indicate that the difference is statistically significant at 1 percent confidence level.

Table II.10: Probability regression analysis (logit) for the correlates of migrations vs no migrations in 2014.

\begin{tabular}{|c|c|c|c|c|c|}
\hline & & Coefficient & Z-Statistic & Coefficient & Z-Statistic \\
\hline Age & year & 0.004 & 1.45 & 0.004 & 1.46 \\
\hline Female & $0 / 1$ & $0.858 * * *$ & 6.89 & $0.851 * * *$ & 6.84 \\
\hline Married / couples & $0 / 1$ & -0.124 & -0.96 & -0.135 & -1.04 \\
\hline Literacy in French & $0 / 1$ & $0.348 * * *$ & 3.14 & $0.350 * * *$ & 3.15 \\
\hline Literacy in Kirundi & $0 / 1$ & 0.031 & 0.30 & 0.032 & 0.31 \\
\hline Literacy in Swahili & $0 / 1$ & $0.814^{* * *}$ & 6.23 & $0.799 * * *$ & 6.06 \\
\hline Self-employed in private agriculture & $0 / 1$ & $-0.584 * * *$ & -6.44 & -0.577 & -6.37 \\
\hline Self-employed in private non agriculture & $0 / 1$ & 0.098 & 0.60 & 0.103 & 0.63 \\
\hline Repaying real estate loan & $0 / 1$ & na & na & $0.347 * *$ & 1.99 \\
\hline Number of observations & & 6681 & & 6681 & \\
\hline Pseudo R2 & & 0.1003 & & 0.1012 & \\
\hline Population weight & & Yes & & Yes & \\
\hline Province of birth of head & & Yes & & Yes & \\
\hline
\end{tabular}

Source: ECVMB 2013-2014. Note: *** the coefficient are statistically significant at 1 percent confidence level, ** at 5 percent level, and * at 10 percent level. 


\section{Box II.2 $\quad$ Internal Migration in Burundi}

In 2014, the internal migrant population represented about 20 percent of Burundi's population. The top provinces of origin of Burundian migrants are Gitega (11.8 percent), Ngozi (11.2 percent), Kayanza (10.0 percent), Bururi (9.7 percent), and Muramvya (7.6 percent).. The Center East and Northern regions provide the largest migrant populations, with 25.4 percent and 21.3 percent respectively.

Bujumbura has been the geographic area of attraction for the vast majority of Burundian migrants. Most of the migrant households living or working in Bujumbura Mairie come from the provinces immediately bordering to the capital - namely Bujumbura rural (42.3 percent), Mwaro (33.8 percent) and Muramvya (23.7 percent). A significant number of migrant households in Bujumbura Mairie also come from Bururi and Gitega (24.2 percent and 20.2 percent respectively). These five provinces are all located close to the capital, and are bound together by relatively high-quality interprovincial and secondary roads. Besides Bujumbura, the province of Bubanza has also attracted a significant number of migrant households, located in the West of the country, at the border with the Democratic Republic of Congo.

The data likely fails to capture the magnitude of migration flows in the far North of Burundi, i.e., in Muyinga and Kirundo, which link mobile populations from Burundi, Rwanda, and Tanzania. A large portion of migration outflows directed to Rwanda or Tanzania (including the diaspora and a large number of short term migrants) cannot be captured at all. This explains the unexpectedly low figures (3.4 percent and 4.0 percent, respectively) we obtain for the contributing shares of Muyinga and Kirundo to the whole population of migrants in Burundi.

The high number of migrants originating in the Muramvya province is explained by its high economic activity. The region attracts dynamic short term workers who migrate frequently in order to seek wage labor in agriculture, domestic work, construction and carpentry. In addition, the city of Muramvya is close to the city of Bugarama, which annually attracts seasonal migrant workers, who either settle for longer periods or use the city for transiting to Bujumbura Mairie. Bugarama similarly functions as a transportation hub for travel to the north of the Center East region of Burundi. These factors explain the high proportion of migrant heads born in Muramvya compared to the overall population of the area. They also explain the large share of migrant heads born in Mwaro, as the two provinces were part of the same province until 1999.

The poverty incidence is significantly lower for migrant-headed households born in areas that are considered long-term migrant provinces, compared to newer migrant provinces. The former category includes Bujumbura rural and Bururi, and to some extent Bujumbura Mairie. Figure B.1 shows the poverty rates for migrants originating in these provinces, which are the lowest in the country.

In Burundi, migrations of household heads seem to be strongly correlated to population size in the province of birth of those heads. The provinces of Gitega, Ngozi, and Kayanza, where 33 percent of migrant household heads were born, rank among the five most populated provinces of Burundi ${ }^{14}$. Often considered as provinces of late population movements, observers of Burundi's rural development claim that migrations from this part of the country have been spurred by increasing scarcity of fertile agricultural lands, and demographic pressure. As suggested in Figure B.2, the larger the relative population size of a province (as measured by the percentage of the country's population going to a given province), the larger the relative number of migrant heads born in that province. Reaching a level of 0.60 , the correlation coefficient between these two variables is positively strong and statistically significant at 5 percent level ( $p$-value of 0,0108$)$.

Figure B.II.1: Poverty incidence is significantly lower for migrants born in said early migration provinces

1) Poverty by province of birth of heads of migrant households ${ }^{(1)}$.

2) Province of birth of heads of migrant households.

\footnotetext{
${ }^{14}$ Gitega and Ngozi ranks respectively $1^{\text {st }}$ and $2^{\text {nd }}$, while Kayanza ranks $5^{\text {th }}$, according to the national census of population and habitat of 2008.
} 


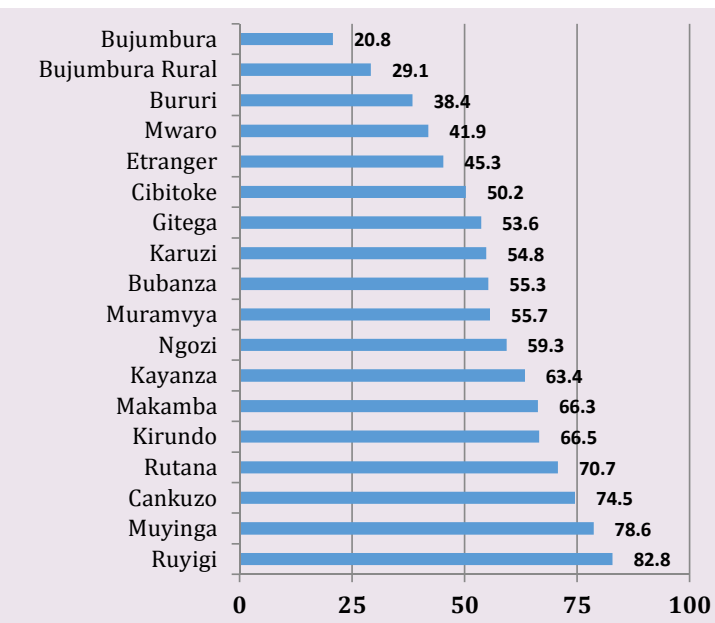

Poverty headcount

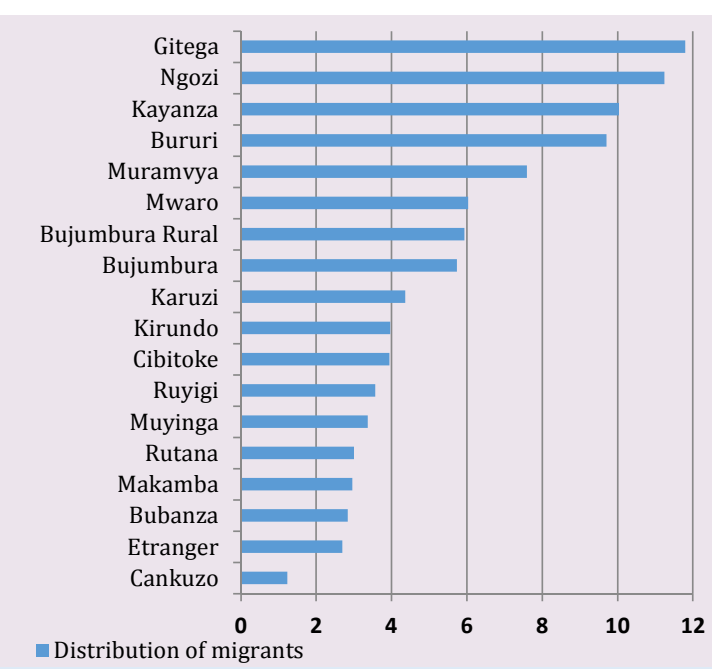

Source: ECVMB 2013-2014.

Note: ${ }^{(1)}$ The province of birth of the entire population in a household is assumed to be the province of birth of the head of the household.

Figure B.II.2: In Burundi, migration of household heads seems to be strongly correlated to the population size in the province of birth of those heads.
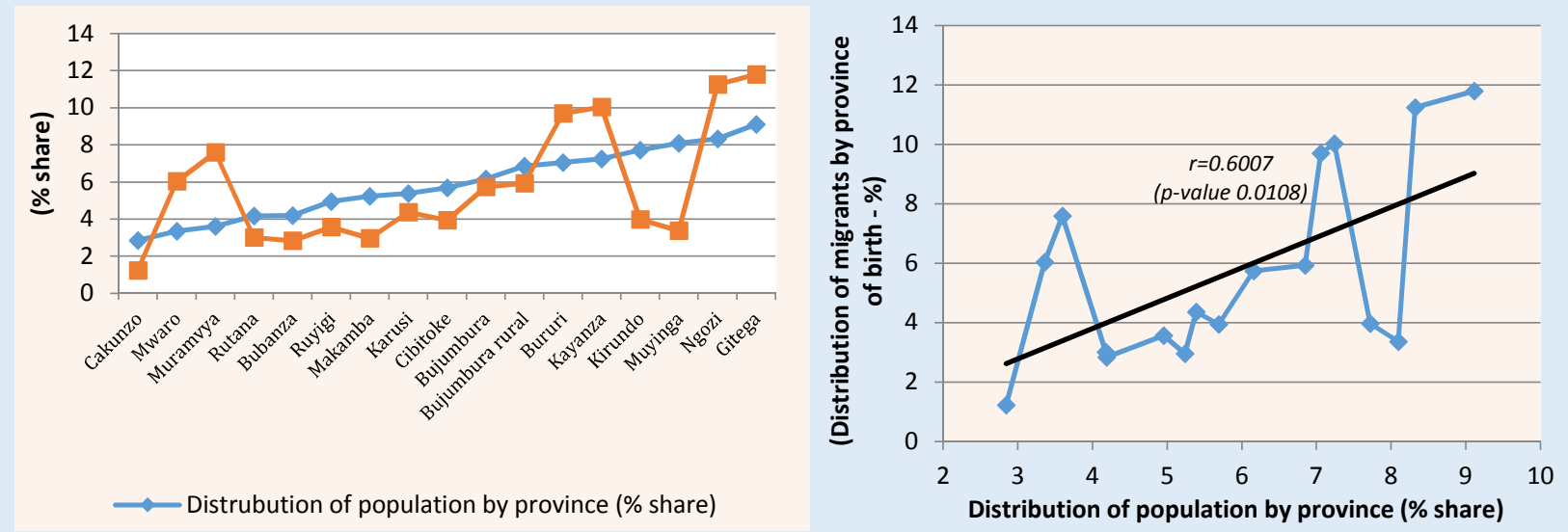

Source: ECVMB 2013-2014.

\section{The level and structure of inequality}

\section{Consumption inequality is moderate by SSA standards}

\section{Consumption-based inequality in Burundi is moderately high by international standards} but lower than Sub-Saharan average inequality. The Gini coefficient of real per capita monthly consumption indicates that the level of inequality for Burundi is approximately 37.3, below the SSA average of 45.1 and the low-income countries average of 40.15 Among East African countries, Burundi's Gini coefficient is below that of the Democratic Republic of Congo, Kenya, Madagascar, Malawi, Rwanda, and Uganda and is higher than Ethiopia and Tanzania. ${ }^{16}$ It is on par with levels of inequality in South and East Asia, which range around 38.4, and

\footnotetext{
15 See Africa's Pulse, 2013.

16 The Gini coefficients in some East African countries are 42.1 for DRC in 2012; 33.6 in Ethiopia 2011; 48.5 in Kenya 2006; 40.6 in Madagascar 2010; 46.1 in Malawi 2010; 51.3 in Rwanda 2011; 36.8 in Tanzania 2012; and 42.4 in Uganda in 2012.
} 
significantly lower when compared to parts of South America where levels of inequality range from 47 to 55.17 .

The levels of inequality in Burundi are likely significantly higher than the figures reported here. The available survey fails to sample the richest households and to capture the concentration of wealth among people at the top end of the distribution. Also, the trimming of outliers could have led to bias inequality downwards. Furthermore, the consumption aggregate used to measure inequality excludes expenditures on durable goods. Expanding the food and nonfood expenditure aggregates to include these expenses would probably increase inequality. Finally, expenditure-based measures of inequality tend to underestimate income inequality because expenditure is closer to permanent income and is less dispersed than current income. Previous studies using QUIBB 2006 and PMS 2012 as well as Panel Surveys for 1998, 2007 and 2012 show much higher inequality levels in Burundi with the Gini coefficient ranging between 44 and $62 .{ }^{18}$ This calls for caution in concluding that inequality is moderate in Burundi as the results might be driven by top-coding and trimming of the data.

Rural areas, where the prevalence of poverty is the highest, seem to have a more equal distribution of consumption. Disregarding the potential underestimation of inequality levels, the results indicate that inequality is more prevalent in the urban sector than in the rural areas -with Gini coefficients of respectively 33.4, 40.2, and 39.3 for rural areas, secondary towns and the capital city. As Gini coefficients hide the potential variations that exist between individual income groups, the Gini indicators are complemented with income shares of population quintiles to explore whether there are large differences in the shares of individual income groups between the geographic areas. The results indicate that the bottom quintile in rural areas received almost 8 percent of total welfare (consumption), around 40 percent more than in the urban sector. The rural middle class also received a larger share (though at a lower extent) of income than the urban middle class (Figure II.20).

Figure II.20: Lorenz curve and inequality coefficients
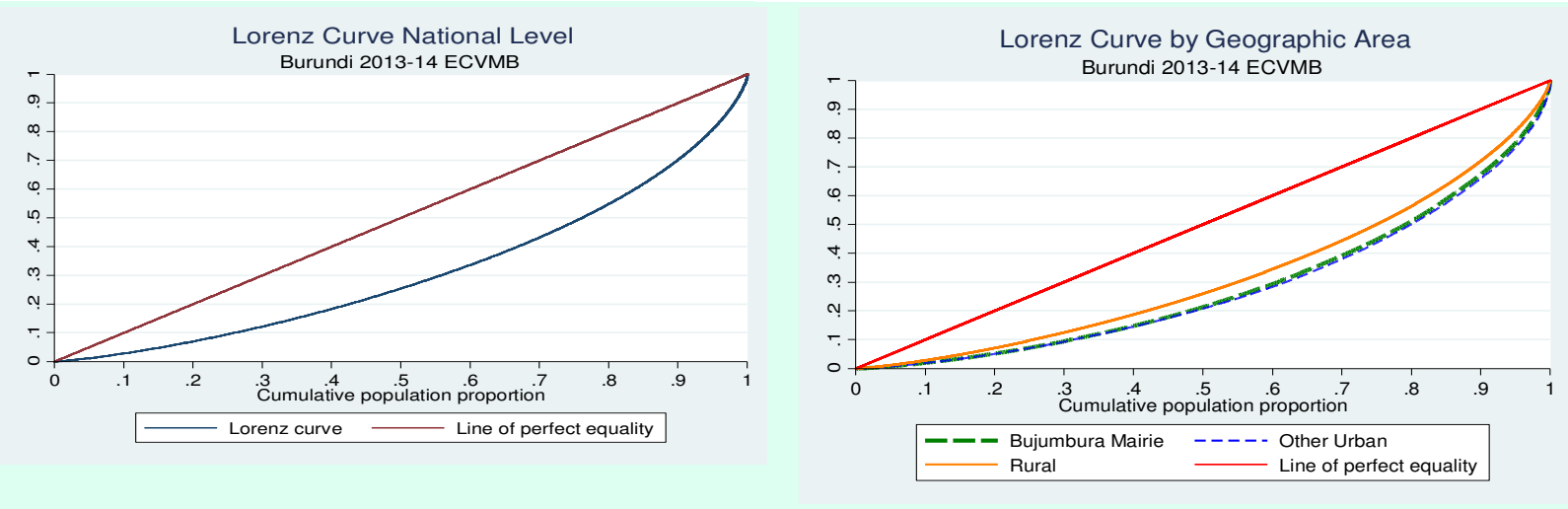

\footnotetext{
${ }^{17}$ World Development Indicators database (WDI 2015). The GINI coefficient for Latin American countries is based on income which generally shows higher variability than consumption.

${ }^{18}$ See World Bank report AUS6966 (2015) and Mercier $e t$ al. (2015).
} 


\begin{tabular}{lccccc}
\hline \hline & Gini & p90/p10 & \multicolumn{3}{c}{ Income Shares } \\
& & & Lowest Quintile & Middle Class & Top Quintile \\
\hline National & 37.3 & 5.1 & 7.0 & 26.6 & 45.1 \\
Rural & 33.4 & 4.5 & 7.7 & 28.7 & 41.6 \\
Other Urban & 40.2 & 6.6 & 5.5 & 25.6 & 45.7 \\
Bujumbura Mairie & 39.3 & 6.5 & 5.7 & 26.2 & 44.9 \\
\hline \hline
\end{tabular}

Source: ECVMB 2013-2014. Note: Lowest and top quintiles are respectively the bottom and highest 20 percent in the distribution of consumption. The middle class includes the second and third quintiles.

\section{The positive picture of moderate inequality in Burundi may hide large inequalities between} population groups. It is important, thus, to examine the structure of inequality and explore how the differences in households' characteristics affect the distribution of consumption and welfare. This investigation can be carried out by the decomposition of inequality by population subgroups, which consists of separating overall inequality in the distribution of consumption into inequality within population subgroups and inequality between them. The group partitions of inequality help to better understand the underlying structure of per capita consumption distribution in Burundi.

Table II.11 provides summary results of the shares of inequality explained by the between-group differences in eight household attributes (gender, age, educational level, activity status and sector of employment of the household head, regional location, urban/rural status and demographic composition of the household). ${ }^{19}$ Technical details on the decomposition procedure are found in Box II.3.

\footnotetext{
${ }^{19}$ Age is split into five categories: (i) under 30, (ii) 30-39, (iii) 40-49, (iv) 50-59, and (v) 60+ years. Education is classified into six categories: (i) no education \& illiterate; (ii) less than completed primary; (iii) completed primary; (iv) incomplete secondary cycle $1 ;(v)$ complete secondary cycle $1 ;$ and (vi) secondary cycle 2 and higher. Three groups are considered for the activity status: (i) employed; (ii) unemployed; and (iii) inactive, disabled or retired. The employment sector comprises four categories: (i) farmers including unpaid family workers ; (ii) wage non-farm work; (iii) self-employed and employers outside agri.; and (iv) others. The regional locations are: (i) North, (ii) Center East, (iii) West, and (iv) South. Households demographic types are: (i) "single parent with no kids", (ii) "single parent with kids", (iii) "couple with no kids"; (iv) "couple with kids", and (v) "families of elderly whose head is aged 65 years old or above".
} 


\section{Box II.3 Inequality Decomposition}

The static decomposition of inequality enables one to explore how the differences in households' characteristics affect the level of inequality and provide important clues for understanding the underlying structure of real per capita consumption distribution in Burundi.

The decomposition follows the approach of Cowell and Jenkins (1995) and consists of separating total inequality in the distribution of consumption into inequality between the different household groups in each partition, IBetw, and the remaining within-group inequality, $I_{\text {Within. }}$. As the most commonly decomposed measures in the inequality literature come from the General Entropy class, mean log deviation (Theil_L) and the Theil_T indices in real per capita monthly consumption expenditure are used to identify the contribution of between-group differentials to total inequality. The General Entropy inequality measures allow total inequality to be equal to $I_{\text {Betw }}+I_{\text {Within }}$ and the amount of inequality explained by households attributes (or group of attributes) is measured by $I_{\text {Betw }} / I_{\text {total }}$, where between and within group inequalities are defined, respectively, for Theil_L and Theil_T indices as

$$
\begin{gathered}
I_{\text {Betw }}=\left[\sum_{j=1}^{k} f_{j} \log \left(\frac{\mu}{\mu_{j}}\right)\right] \quad I_{\text {Within }} \\
=\sum_{j=1}^{k} f_{j} G E_{0}^{j} \\
I_{\text {Betw }}=\left[\sum_{j=1}^{k} f_{j}\left(\frac{\mu_{j}}{\mu}\right) \log \left(\frac{\mu_{j}}{\mu}\right)\right] \quad I_{\text {Within }} \\
=\sum_{j=1}^{k} v_{j} G E_{1}^{j}
\end{gathered}
$$

Table II.11: Decomposition of inequality by household attributes

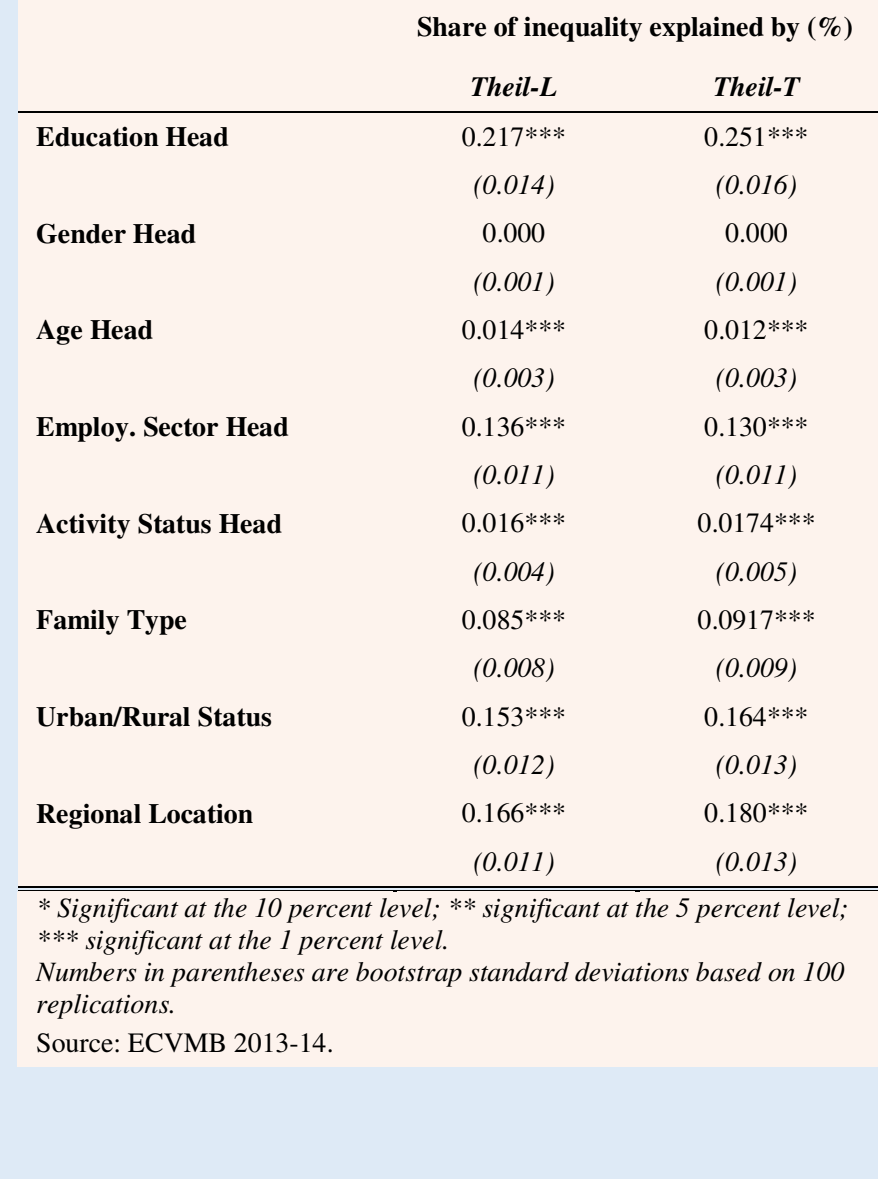

with $\boldsymbol{f}_{\boldsymbol{j}}$ the population share, $\boldsymbol{v}_{\boldsymbol{j}}$ the consumption share, and $\boldsymbol{\mu}_{\boldsymbol{j}}$ the mean consumption of subgroup $j ; \mu$ total mean consumption, $\boldsymbol{G} \boldsymbol{E}_{\mathbf{0}}^{\boldsymbol{k}}$ Theil_L index, and $\boldsymbol{G}_{\mathbf{1}}^{\boldsymbol{k}}$ Theil_T index of subgroup $j$.

with: Theil_L $=1 / n \sum_{i=1}^{n} \log \left(\frac{\bar{y}}{y_{i}}\right) \quad$ and $\quad$ Theil_T $=1 / n \sum_{i=1}^{n}\left(\frac{y_{i}}{\bar{y}}\right) \log \left(\frac{y_{i}}{\bar{y}}\right)$

$y_{i}$ : is real monthly per capita consumption expenditure for household $i$ and $\overline{\boldsymbol{y}}$ is mean real monthly per capita consumption expenditure.

The educational level of the household head followed by regional and urban/rural locations of the household are the most important determinants of consumption inequality. Over 20 percent of total per capita consumption inequality can be accounted for by inequality between six groups of households sorted by the educational attainment of the head. Mean consumption levels of the different educational groups increase with the education of household head, and is almost three times higher for households headed by secondary school (and higher) graduates compared to those with completed primary education heads.

Inequalities between urban and rural locations and disparities between geographic regions are the second most important contributors to inequality. Disparities between geographic locations account for more than 17 percent of overall inequality. The average consumption levels 
are highest in the West, followed by the South, with the Center East and the North in the last place. The consumption levels in the latter two regions are around 70 percent and 25 percent lower than in the West and the South, respectively. The welfare gaps between urban and rural areas is also quite substantial, accounting for around 16 percent of overall inequality, and with average consumption levels being over two times higher in the urban areas than in the rural ones.

The share of total inequality attributable to disparities between sectors of employment groups is around 13 percent. Household groups headed by non-farm wage workers, followed by those headed by employers and self-employed are much better off than groups with heads employed in the other sectors, particularly farmers.

Differences in households' demographic composition account for a quite significant share of total inequality, amounting to around 9 percent. Households comprised of only adults all over 14 years old, whether single or in couples, are much better off than the rest of household groups, while single parents with kids seem to face severe hardships and have the lowest mean per capita consumption levels. Elderly households, whose head is 65 years old or over, are slightly better off than families with children. In recent years, many of the elderly families have been under the attention of emergency food aid donors and NGOs, which classify them as particularly vulnerable due to the difficulties they face in accessing and exploiting land.

The gender, age, and activity status of the household head have marginal explanatory powers barely exceeding 1 percent. The low proportion of woman-headed households in the sample, amounting to less than 20 percent, can explain the low share of gender in these decompositions. Similarly, the particular status of women who head their own households, as most are widowed, running their own agricultural business, or benefitting from remittances from family abroad also contribute to the low share of gender in the decomposition.

\section{Significant rural-urban welfare gaps, driven by disparities in households' endowments}

The important spatial disparities revealed by the analysis of the structure of inequality are worrisome as it can undermine inclusive growth and shared prosperity prospects. The decomposition of inequality discussed above, while informative regarding the role played by certain household attributes, gives little information regarding the importance of interregional and urban-rural welfare gaps across the various quintiles of the distribution and about the sources of these gaps. This section attempts to address this drawback by analyzing the difference in the distribution of consumption expenditures between geographic locations, and by examining the contribution of households' characteristics to the gaps at different points of the welfare distribution. It first investigates the determinants of urban-rural inequality and then explores the sources of inequality between the West-South and the Center East-North.

The analysis uses the unconditional quintile regression method proposed by Firpo, Fortin, and Lemieux (2009) to decompose inequality between regions into a component that is due to geographic differences in the distributions of household characteristics or endowments. These 
include education, demographic structure, ownership of assets, and so forth, and a component explained by differences in the returns to these characteristics (differences in the returns to education, assets, and so forth). More specifically, this study decomposes the consumption gap between geographic regions into (i) a component that is due to differences in household characteristics only (endowment effects), considering for example, the gap in consumption that is due to the fact that urban dwellers have higher education levels than rural ones but assuming that people with same education levels receive the same remunerations across different locations; and (ii) a component that is due to differences in returns to those characteristics only (returns effect), considering for example, the gap in consumption that is due to the fact that a secondary school graduate in urban areas receives a higher remuneration than a secondary school graduate in rural areas. More technical details are in Appendix II.

Urban households are better off than their rural counterparts because they have superior endowments such as education, access to basic services, and ownership of assets. Inequality between urban and rural areas is essentially due to the fact urban households have higher endowments than their rural counterparts. As shown in Figure II.21, the contribution of the difference in households' endowments to the urban-rural gap significantly dominates the contribution of disparity in returns to those endowments across the entire distribution. This indicates that urban households have higher consumption levels because they have superior levels in a range of selected characteristics compared to those in rural areas.

Inequality between better-off urban and rural households is larger than inequality between poor urban and rural households. The difference in real per capita consumption between urban and rural households at upper quintiles is more than double the difference between urban and rural households at the lower tail of the distribution (see Figure II.21). ${ }^{20}$ This is driven by larger gaps between urban and rural better-off households in both endowments and returns than between urban and rural poor households. The urban-rural difference in household endowments is the main source of urban-rural inequality for the poorest segments of the population, while the difference in market returns to household characteristics does not seem to be important. This is probably due to the fact that these households are generally employed in sectors that pay slightly above the subsistence level. However, the difference in returns is affecting households at upper quintiles, particularly the wealthiest. As apparent from Figure II.21, the magnitude of the returns effects is increasing proportionately more than the magnitude of endowments effects at upper quintiles. This shows that even though all urban households continue to have superior endowments to those of their rural counterparts, the contribution of differences in returns to households' attributes to inequality is gaining importance for most well-off households.

Differences in access to basic services, followed by differences in human capital and ownership of assets contribute the most to explain inequality between urban and rural households. The findings reveal large gaps in access to basic services and infrastructure, mainly

\footnotetext{
${ }^{20}$ Quantiles are values taken at regular intervals from the inverse of the cumulative distribution function of per capita real monthly consumption. If there are 5 quantiles then each quantile will correspond to a quintile ( 20 percent of the population) and if there are 10 quantiles then each quantile will correspond to a decile (10 percent of the population) and so forth.
} 
electricity, safe drinking water, sanitation, health centers, markets and roads, between urban and rural households. These differences are particularly important for less well-off segments of the population. Differences in assets ownership, such as cell phones and transportation means, are found to significantly contribute to the welfare gap between urban and rural households, particularly for the lowest and highest quintiles. The effect of differentials in household human capital (measured by the level of education of the household head and his spouse) on urban-rural inequality is significantly high for poorest and middle-class households. ${ }^{21}$

Differences in returns to human capital and basic infrastructure are among the dominant factors explaining the rural-urban gap in returns to household characteristics. There is a quite important difference in the returns to education between urban and rural areas, but this difference contributes more to inequality between the poorest segments of the population. This might be explained by the prevailing low levels of education (particular in rural areas where over 90 percent of the population did not complete primary education) and the types of employment where less well-off households are most likely to be. The vast majority of rural poor households are engaged in subsistence farming where there are almost no returns to education, while around half of poor urban households are engaged in wage nonfarm activities and self-employment where the schooling level matters and education is better rewarded. At the upper quintiles, differences in returns to basic infrastructure seem to matter the most for urban-rural inequality. This might be explained by the fact that urban better-off households who are engaged in nonfarm businesses own more communication and transportation means than their rural counterparts. Hence, they have been better able to benefit from the higher access to basic infrastructure (mainly roads and markets) and earn higher returns.

\footnotetext{
${ }^{21}$ Middle-class households are those at the median of the distribution and are below the poverty line, as poverty rate is over 60 percent.
} 
Figure II.21: Unconditional Quintile Decomposition of Urban-Rural Inequality of Real Monthly per Capita Consumption

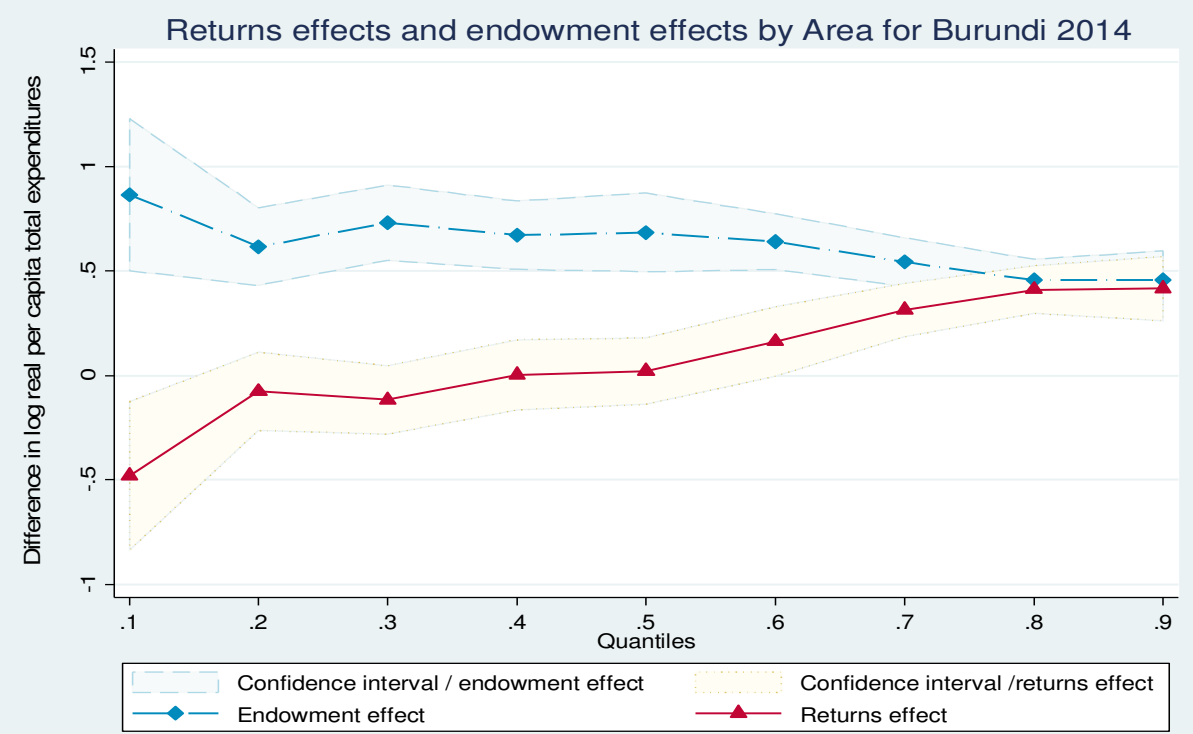

\begin{tabular}{lccc}
\hline \hline & Lowest percentile & Middle percentile & Top percentile \\
\hline Total Gap & $0.386^{* * *}$ & $0.707^{* * *}$ & $0.873^{* * *}$ \\
& {$[0.040]$} & {$[0.026]$} & {$[0.036]$} \\
\hline Endowments & & & \\
Total Endowments & $0.866^{* * *}$ & $0.686^{* * *}$ & $0.457^{* * *}$ \\
& {$[0.078]$} & {$[0.043]$} & {$[0.063]$} \\
Human capital & $0.176^{* * *}$ & $0.238^{* * *}$ & $0.058^{*}$ \\
& {$[0.042]$} & {$[0.023]$} & {$[0.033]$} \\
Sector of employment & 0.106 & 0.012 & 0.033 \\
& {$[0.070]$} & {$[0.037]$} & {$[0.055]$} \\
Assets & $0.153^{* *}$ & 0.040 & $0.243 * * *$ \\
& {$[0.064]$} & {$[0.033]$} & {$[0.051]$} \\
Access basic Services & $0.189^{* * *}$ & $0.246^{* * *}$ & 0.005 \\
& {$[0.064]$} & {$[0.034]$} & {$[0.050]$} \\
\hline Returns & & & \\
Total returns & $-0.480^{* * *}$ & 0.021 & $0.417 * * *$ \\
& {$[0.085]$} & {$[0.045]$} & {$[0.068]$} \\
Human capital & $0.193^{* * *}$ & 0.004 & $-0.174^{* * *}$ \\
Sector of employment & {$[0.043]$} & {$[0.023]$} & {$[0.036]$} \\
Assets & 0.052 & -0.045 & -0.066 \\
Access basic Services & {$[0.124]$} & {$[0.071]$} & {$[0.114]$} \\
& 0.058 & $-0.196^{*}$ & -0.207 \\
\hline \hline
\end{tabular}

Note: Numbers in brackets are bootstrap standard deviations based on 100 replications. $*$ Significant at the 10 percent level; ** significant at the 5 percent level; *** significant at the 1 percent level.

Source: ECVMB 2013-14. 
Interregional inequality essentially driven by differences in returns to households' characteristics

Inequality between households located in the West and South of Burundi and those in the Center-East and North is due to differences in returns to households' characteristics. The results in the previous sections reveal significantly higher living standards and lower poverty levels in Western and Southern regions than in Northern and Center-Eastern ones. The decomposition of the welfare gap between these regions shows that inequality between households at lower and middle tails of the distribution is driven by differences in returns to their characteristics, while inequality between better-off households is explained by differences in their endowments. Poor households in the West and the South enjoy higher endowments than their counterparts in the other regions, but except for the wealthiest segments of the population, inequality is mainly explained by the higher reward of these characteristics (Figure II.22).

Regional disparities in returns are mostly due to large differences in returns to human capital followed by differences in returns to assets. Households in the West and Southern part of the country seem to have been better able to earn higher returns to their education, and to a lower extent, to their assets than their counterparts in the other regions. This might be explained on one hand by higher engagement in nonfarm activities and self-employment in the West and the South, which provide higher rewards to education, and on the other hand, by better access to infrastructure that allows a more efficient use of assets and higher productivity.

The interregional disparities in endowments mask important differences in the contribution of specific attributes to inequality. While the contribution of the overall gap in endowments to interregional inequality seems negligible, particularly for poor households, this likely hides significant gaps in the specific attributes, mainly, human capital, assets ownership, and access to basic services and infrastructure. The results in Figure II.22 indicate significant differences in access to basic services and infrastructure, followed by education and assets ownership, between households located in the West and the South and those in the Center-East and North. These differences seem to significantly contribute to the interregional welfare gap across the entire distribution, but the magnitude of these effects seems stronger at the upper quintiles. The results also indicate important disparities between regions in the sector of employment of the head that are significantly contributing to inequality, particularly for middle and better off households. This is explained by the significantly higher engagement of households in wage nonfarm activities in the West and the South compared to the Center East and North.

Results indicate that despite the development policies and efforts to tackle some of the poor population's problems, levels of poverty and deprivation remain extremely high and spatial inequalities quite sharp. Policies, such as combating illiteracy and promoting basic education, facilitating access to assets, and so forth, did not adequately address the needs of rural households and those located in the North and Center-East to help them catch up with their urban and Western counterparts. Efforts to promote education and access to basic services and assets 
remain in their infancy and substantial work is required to improve living conditions all over the country. Policies to promote education, service delivery and access to assets should be further enhanced to improve the endowments of marketable characteristic for households at the lower end of the income-consumption distribution. These efforts need to be accompanied, on one hand, by policies targeting rural households (and those in Center East and North) at upper quintiles to help them catch up with their urban (and West- South) counterparts. On the other hand, policies to promote local economies' development and dynamism and expand productive activities are necessary in order to increase the returns of endowments in the less favored regions.

Figure II.22 Unconditional Quintile Decomposition of Regional Inequality of Real Monthly per Capita Consumption

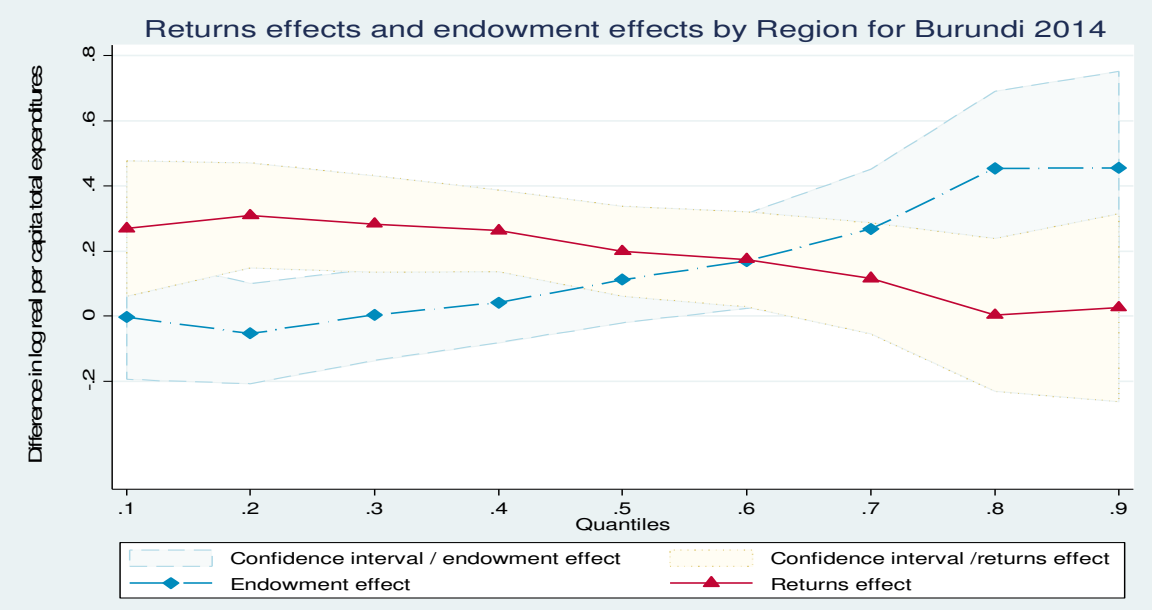

\begin{tabular}{lccc}
\hline \hline & Lowest percentile & Middle percentile & Top percentile \\
\hline Total Gap & $0.265^{* * *}$ & $0.311^{* * *}$ & $0.481^{* * *}$ \\
& {$[0.025]$} & {$[0.019]$} & {$[0.031]$} \\
\hline Endowments & & & $0.456^{* * * *}$ \\
Total Endowments & -0.003 & 0.111 & {$[0.124]$} \\
& {$[0.120]$} & {$[0.084]$} & $0.073^{* * *}$ \\
Human capital & $0.027^{* * *}$ & $0.040^{* * *}$ & {$[0.011]$} \\
& {$[0.009]$} & {$[0.007]$} & $0.025^{* * *}$ \\
Sector of employment & 0.010 & $0.012^{*}$ & {$[0.010]$} \\
& {$[0.009]$} & {$[0.007]$} & $0.063^{* * *}$ \\
Assets & $0.025^{*}$ & $0.045^{* * *}$ & {$[0.016]$} \\
& {$[0.015]$} & {$[0.010]$} & $0.100^{* * *}$ \\
Access basic Services & $0.047 * * *$ & $0.064^{* * *}$ & {$[0.019]$} \\
\hline Returns & {$[0.018]$} & {$[0.013]$} & 0.026 \\
Total returns & & & {$[0.125]$} \\
Human capital & $0.269^{* *}$ & $0.199 * *$ & $-0.122^{* * *}$ \\
Sector of employment & {$[0.122]$} & {$[0.086]$} & {$[0.026]$} \\
& $0.072^{* * *}$ & $0.080^{* * *}$ & -0.078 \\
Assets & {$[0.024]$} & {$[0.017]$} & {$[0.114]$} \\
Access basic Services & 0.124 & 0.019 & -0.258 \\
& {$[0.104]$} & {$[0.072]$} & {$[0.163]$} \\
\hline \hline
\end{tabular}

Note: Numbers in brackets are bootstrap standard deviations based on 100 replications. * Significant at the 10 percent level; $* *$ significant at the 5 percent level; *** significant at the 1 percent level.

Source: ECVMB 2013/14. 


\section{Chapter III - Evolution of Households Living Conditions}

\section{Key Messages}

- Burundi has shown slow and geographically uneven progress in poverty reduction since 2006.

- A young population and high prevalence of low education characterize Burundi.

- There have been slow improvements in livings conditions and human capital outcomes, with overall levels remaining very low.

- Violence is at the root of high levels of poverty and low human capital outcomes.

This chapter examines the evolution of poverty and household's living conditions between 2006 and 2014. Analyzing changes in poverty over time is challenged by the absence of household surveys comparable to ECVMB 2013/14. The analysis draws on QUIBB 2006, PMS 2012 and ECVMB 2013-14. The first section uses prediction methods to attempt to address the comparability issues and assess the evolution of poverty over the past eight years. The other sections examine the evolution of nonmonetary dimensions of welfare and explore how these factors have evolved over time for both the whole population and the most disadvantaged groups. Section two focuses on the demographic structure, section III focuses on human capital outcomes, section IV examines living conditions, and section V focuses on the consequences of violence and conflict.

\section{Poverty trend since $\mathbf{2 0 0 6}$}

\section{Slow progress in poverty reduction since 2006}

The analysis of the poverty trend is challenged by the lack of comparability among data sets. The ECVMB 2013/14 is the first nationally representative household budget survey conducted in Burundi since the turn of the millennium. The previous available surveys are the Minimum Package of Health Services (PMS) survey for 2012 and the Questionnaire on the Basic Indicators of Wellbeing (QUIBB) survey for 2006. Both QUIBB and PMS surveys focus on socio-demographic and health indicators, but include a consumption module that collects quite detailed information on food and nonfood consumption expenditures. However, these surveys are not up to the level required for a standard poverty assessment as does the ECVMB (or standard Household Budget Surveys) and cannot be used to estimate the poverty trend. Box III.1 gives more details on the characteristics and quality of the surveys.

The comparability challenges are addressed through prediction methods. The QUIBB 2006 and PMS 2012 surveys include detailed information on households' socio-demographics characteristics, assets ownership and access to amenities that is nationally representative and 
comparable to ECVMB data. These surveys can thus be used to estimate predicted consumption and poverty trends. The prediction approach is based on the Multiple Imputations Chained equations, implemented in STATA with the mi impute chained command. ${ }^{22}$ The method is similar to the Small Area estimation poverty mapping technique and consists in filling in missing values for multiple variables using iterative methods and chained equations. The approach accommodates arbitrary missing-value patterns and uses less restrictive assumptions than the poverty mapping method.

\section{Box III.1 1 PMS 2012 and QUIBB 2006 surveys}

PMS and QUIBB are both nationally representative and similar in design to the Multiple Indicator Cluster Surveys (MICS), with PMS including more detailed information on health and access to care services. Both surveys contain data on household consumption components that are collected using comparable consumption expenditures modules and applying 15-days recall for food items and 12-months recall for nonfood consumption. The food consumption modules, in both surveys, include food purchased and food consumed from own production, gifts and donations for around 50 main items.

The 12 months recall module on nonfood items probes for around 8 main categories each including about 10 different items. The number of food and nonfood items in these surveys is much lower than the number in standard Household Budget Surveys. While the list of consumption expenditures items was created by focusing on the categories that represent the most important share in household's bundle of goods, these aggregated lists of items can result in lower estimated levels of consumption and thus higher poverty estimates (Jolliffe, 2001; Beegle et al., 2012).

In addition to this, two important problems related to the quality of the data were noticed. The first concerns the use of nonstandard units of measurement in the consumption expenditures questionnaires. There are more than thirty units of measure for which the National Bureau of Statistics, ISTEEBU, has created conversion factors into conventional units (kg/liter). This has led to several problems including errors in the conversion factors and the variability of the same non-standard unit across the products and between the regions (a basket of potato does not weigh the same as a basket of tomato, and a basket of potato in Bujumbura may not weigh the same as a basket of potato in Makamba). Given the difficulties faced by households to value consumption from own production/gifts/donations (often they only report quantities), it is important to accurately estimate the conversion factors in order to measure correctly the value of consumption. Furthermore, questions about whether the household consumed from harvested food crops or existing stocks, often resulted in confusion between production and consumption.

The second main problem relates to the comparability of the consumption data across the two surveys. Although both surveys use comparable consumption questionnaires, the data were collected at two different periods of the harvest season. QUIBB 2006 consumption expenditures data were collected just after the harvest season, a period where consumption is relatively high as households lack storage facilities and tend to over consume. PMS 2012 data were collected just before the harvest season, a where the stocks are exhausted and households tend to have lower consumption levels as they lack staple products such as cereals, rice etc. Changes in consumption expenditures levels, between 2006 and 2012 due to seasonal fluctuations, can be misleadingly attributed to changes in Burundian households' living standards.

Prediction methods reveal a slow decline in poverty since 2006. The results indicate a decline of poverty from 68.7 percent in 2006 to 64.7 percent in 2012 and then a negligible increase to 64.9 percent in 2013/14, suggesting a slow decline of around 0.5 percentage points per year over the last eight years. Extreme poverty seems to have declined faster, dropping from 46 percent in 2006 to 42 percent in 2012 and then to 38.7 percent in 2013/14. However, poverty and extreme poverty remain highly prevalent. There has been also some improvements in the depth and severity of poverty, but overall progress seems very slow (Figures III.1 and III.2).

\footnotetext{
22 This method is based on Rubin's (1987) work to deal with missing values generated by nonresponse in survey-based research.
} 
Figure III.1 Poverty Trends in Burundi, 20062013/14 (percentage)

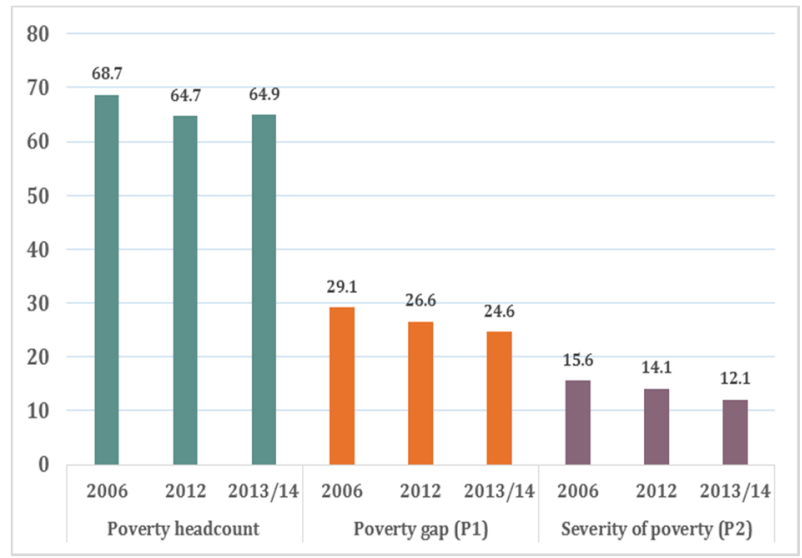

Figure III.2 Extreme Poverty Trends in Burundi, 2006-2013/14 (percentage)

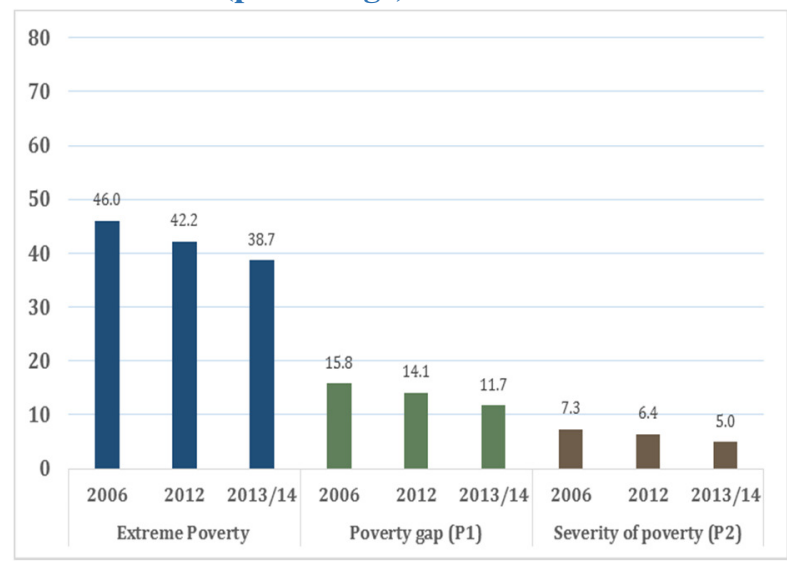

Source: QUIBB 2006, PMS 2012 and ECVMB 2012.

The decline in poverty is geographically uneven

Most of the improvements in the poverty indicators occurred in Bujumbura, while rural poverty remained unchanged. Between 2006 and 2013/14, poverty seems to have declined by around 11 percentage points in Bujumbura and 16 percentage points the secondary cities and towns, while it remained almost unchanged in the rural areas, declining by less than 2 percentage points only (Figure III.3). While the decline of poverty was steady over the past eight years in Bujumbura, the secondary cities seem to have witnessed an increase in poverty between 2006 and 2012 and then a sharp decline. However, the results about secondary towns must be considered with caution as the data show potential changes in the way these have been classified in 2013/14 survey compared to 2006 and 2012.

Figure III.3 Poverty Trends by Geographic Area, 2006-2013/14 (in percentage)

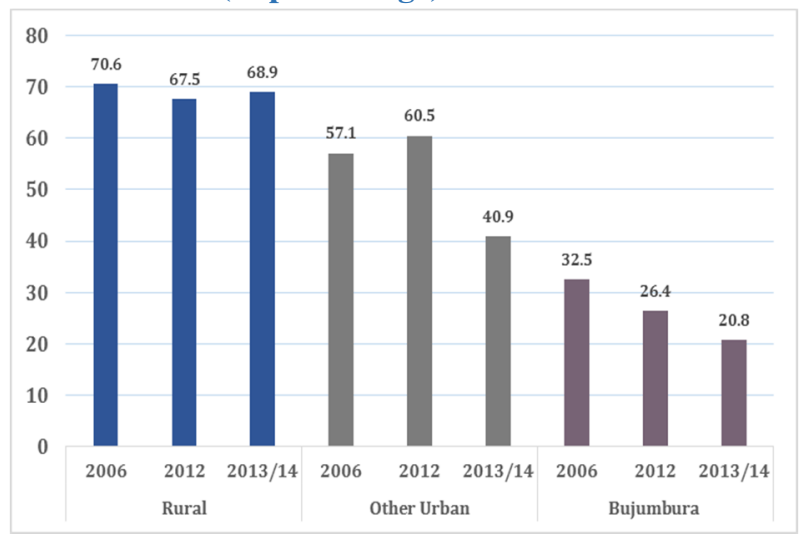

Source: QUIBB 2006, PMS 2012 and ECVMB 2012.
Figure III.4 Extreme Poverty Trends by Geographic Area, 2006-2013/14 (in percentage)

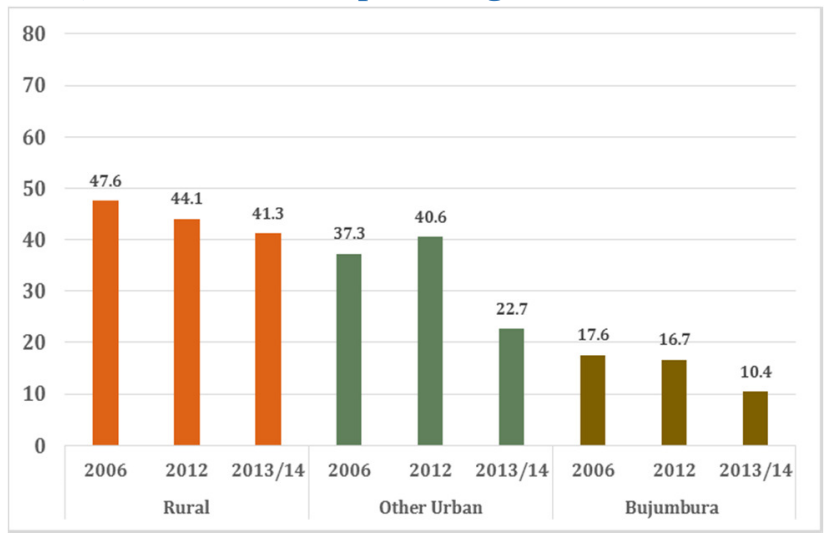

Poverty seems to have declined only in the Western and Southern parts of the country. The sharpest decline in poverty, between 2006 and 2013/14, seems to have occurred in the Western part of the country, probably due to the significant poverty reduction in Bujumbura. The 
Southern regions seems also to have witnessed improvements in households living conditions, with poverty being reduced by around 16 percentage points. Poverty seems to have slightly improved in the Center-East and the North between 2006 and 2012 but then worsened in 2013/14.

The progress in poverty reduction seems to have been driven by a move towards service sectors in urban areas. While it is difficult to assess the drivers of the changes in poverty reduction due to the assumption on which the predictions have been estimated, some changes in the labor market during the last eight years may explain those poverty dynamics. There seems to be a move towards the service sector, and to a lower extent, public administration and manufacturing in the urban areas and Bujumbura. This might have induced improvements in households' living standards and therefore a decline in poverty.

\section{Household demographic characteristics}

\section{Burundi is marked by a young population with a large but decreasing number of members in its households.}

Burundi's population is characterized by the predominance of young people. Almost one in two Burundians are less than 15 years old and around 57 percent of the population is less than 20 years old (Figure III.5). There seems to be a slight change at the base of the age pyramid compared with previous years. The proportion of children between 5-9 years old is now the largest class age. This change could have been determined either by a decline in births, or by an increase of the child mortality rate. ${ }^{23}$

Figure III.5: Age pyramid of Burundi population

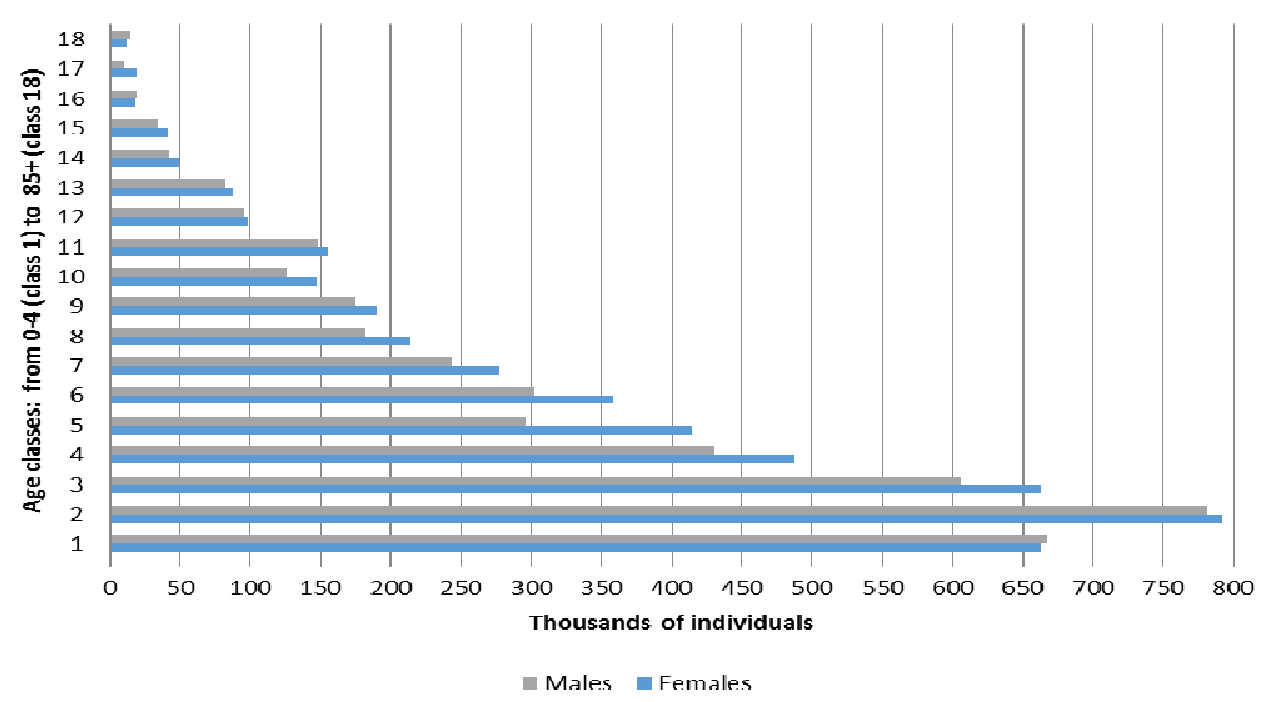

Source: ECVMB 2013-14.

${ }^{23}$ The decline of the age class 0-4 may be an indicator of initial demographic transition in Burundi if this decline is due to birth's reduction. 
While household size is decreasing faster in urban areas, the proportion of children under 15 years old remains similar in both urban and rural settings. In 2014, the proportion of dependent children reached 49.1 percent in rural sectors compared with 49.0 percent in urban areas and 37.7 percent in Bujumbura (Table III.1). These trends are consistent with previous years. The proportion of dependent children tends to be higher in the North and South of Burundi than in the other regions. In addition, households' size is decreasing around 5-6 percent in rural areas and 7-8 percent in urban areas. On average, 18 percent of households are headed by women.

Table III.1: Households' demographic characteristics

\begin{tabular}{llllllllll}
\hline \hline & \multicolumn{2}{l}{ National } & \multicolumn{3}{c}{ Rural } & \multicolumn{3}{c}{ Urban } \\
& $\mathbf{2 0 0 6}$ & $\mathbf{2 0 1 2}$ & $\mathbf{2 0 1 3}$ & $\mathbf{2 0 0 6}$ & $\mathbf{2 0 1 2}$ & $\mathbf{2 0 1 3}$ & $\mathbf{2 0 0 6}$ & $\mathbf{2 0 1 2}$ & $\mathbf{2 0 1 3}$ \\
\hline Household size & 6.07 & 6.16 & 5.81 & 6.03 & 6.12 & 5.76 & 6.69 & 6.62 & 6.20 \\
Dependency Ratio (\%) & 51.2 & 51 & 51.1 & 51.5 & 51.7 & 52.0 & 45.6 & 43.8 & 43.3 \\
No. of child. below 15 years & 3.14 & 3.17 & 3 & 3.15 & 3.19 & 3.03 & 3.03 & 2.95 & 2.73 \\
Numb. of adult women & 1.25 & 1.32 & 1.49 & 1.24 & 1.30 & 1.46 & 1.51 & 1.51 & 1.75 \\
Numb. of adult men & 1.16 & 1.26 & 1.32 & 1.14 & 1.23 & 1.28 & 1.57 & 1.64 & 1.71 \\
Head women & 15.95 & 13.00 & 17.81 & 15.67 & 12.55 & 17.80 & 20.18 & 17.97 & 17.90 \\
Age of head (years) & 43.56 & 42.73 & 43.73 & 43.58 & 42.80 & 43.84 & 43.50 & 42.00 & 42.79 \\
\hline \hline
\end{tabular}

Source: QUIBB 2006, PMS 2012 and ECVMB 2013-14.

In Burundi, single person households and couples without children are very rare. Households formed by couples with children represent 64 percent of entire population, while extended families are estimated at 18 percent (Figure III.6). Meanwhile in the capital, Bujumbura, the larger group type is extended families. This is due to confiage, meaning that children from rural households are put in the custody of urban households, and the presence of domestic workers that live in the same house as the employer.

Figure III.6: Burundi’s population distribution by type of household

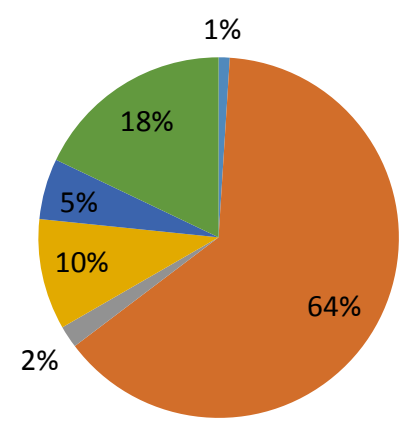

Source: ECVMB 2013-14
Figure III.7: Bujumbura's population distribution by type of household

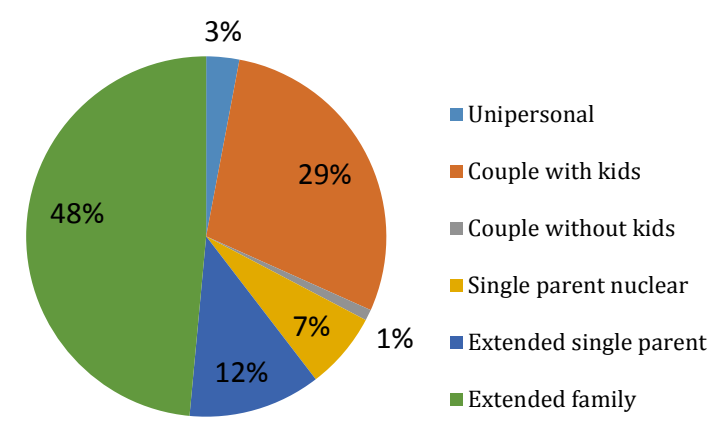

Source: ECVMB 2013-14 


\section{Human capital outcomes}

Education levels in Burundi remain very low with fewer educational opportunities for women and high dropout ratios among children.

Low levels of education and literacy characterize Burundi's population. 45 percent of Burundians have no education, 47 percent reached primary education (mostly incomplete primary) and around 7 percent reached secondary education in 2014 (Figure III.8). Less than 1 percent (only 0.8 percent) of the population could go to higher levels of education than secondary. Literacy rates improved compared to 2006, but remain low particularly in rural areas. At the national level, the capacity to read and write Kirundi or other languages was around 58 percent of the population at the age of 15 and above. People living in the North remained the least literate of the country in 2006 (37 percent) and in 2014 (56 percent), while the most literate population is located in the Western region of Burundi (70 percent) due to the high levels of education present in Bujumbura (87 percent).

Gender inequalities in accessing literacy opportunities have affected women's education over the years. In 2014, about 66 percent of men aged 15 and above could read and write Kirundi or other languages, surpassing by a margin of 15 percentage points their female counterparts (Table III.2). The gap was slightly lower in 2006 (12 percentage points), which indicates an increase of gender inequalities in terms of literacy rates. The literacy gender gap declined in urban areas between 2006 and 2014, due to a significant decline in the capital city, while it increased in rural areas.

Figure III.8: Population by level of education (percentage)

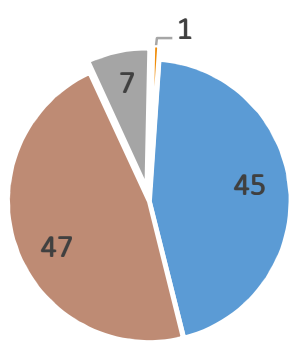

- No education

- Secondary

- Primary

- Higher education
Table III.2: Literacy (read and write in Kirundi or other languages) rate by geographical area (percentage)

\begin{tabular}{|c|c|c|c|c|c|c|}
\hline & \multicolumn{3}{|c|}{2006} & \multicolumn{3}{|c|}{2014} \\
\hline & Male & Female & Total & Male & Female & Total \\
\hline \multicolumn{7}{|l|}{ Area } \\
\hline Urban & 75.5 & 64.0 & 68.5 & 86.3 & 78.6 & 82.2 \\
\hline Rural & 48.0 & 36.0 & 41.0 & 64.1 & 48.4 & 55.0 \\
\hline \multicolumn{7}{|l|}{ Region } \\
\hline Northern & 43.6 & 33.6 & 37.2 & 63.4 & 48.5 & 55.6 \\
\hline Southern & 54.1 & 37.3 & 45.1 & 68.3 & 53.1 & 61.3 \\
\hline Centre East & 53.5 & 43.7 & 47.5 & 66.1 & 54.7 & 60.4 \\
\hline Western & 49.0 & 34.8 & 41.6 & 76.6 & 63.0 & 69.6 \\
\hline Bujumbura mairie & 73.2 & 62.2 & 66.4 & 90.6 & 84.3 & 87.1 \\
\hline Burundi & 49.4 & 37.4 & 42.4 & 66.4 & 51.1 & 57.7 \\
\hline
\end{tabular}

Source: QUIBB 2006 and ECVMB 2013-14

Source: ECVMB 2013-14.

School failure is the principal reason of children leaving the education system. Other factors that significantly affect dropout incidence are cost of education and illness or disability (respectively accounting for 13.9 and 12.2 percent). Refusal of parents and marriages/pregnancies are responsible for approximately one out of ten dropouts. In 2014, only 5 percent of students left the education system after they completed their studies (Figure III.9). 
Figure III.9: Main causes to leave school (percent)

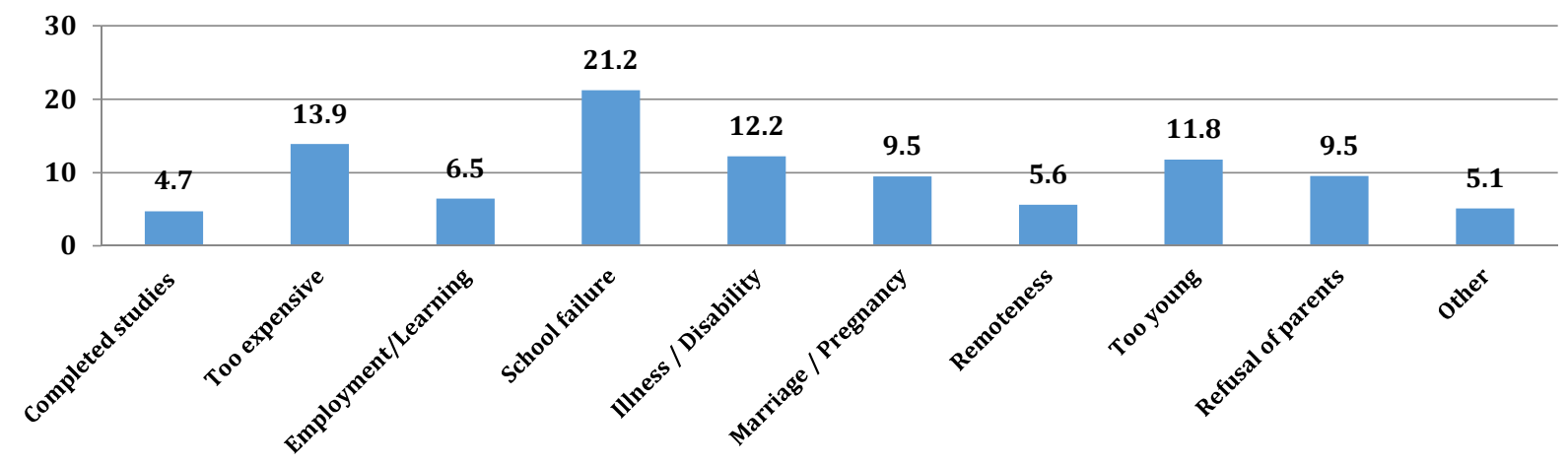

Source: ECVMB 2013-14.

Complete illiteracy is decreasing in Burundian households. There is an important downward trend in the share of households headed by an individual with no education, in particular in urban areas. Similarly, there have been improvements in the education levels of the heads and spouses with an increase of the proportion of households headed by a person with lower secondary education or having a spouse at this education level. However, most of the improvements seem to have occurred in urban areas. School enrolment increased for children aged 5 to 15 years old and the proportion of girls is surpassing that of boys, but only in urban areas while gender gaps remain in the rural sector (Table III.3).

Table III.3: Household's education structure

\begin{tabular}{|c|c|c|c|c|c|c|}
\hline & \multicolumn{2}{|c|}{ National } & \multicolumn{2}{|c|}{ Rural } & \multicolumn{2}{|c|}{ Urban } \\
\hline & 2006 & 2014 & 2006 & 2014 & 2006 & 2014 \\
\hline & \multicolumn{6}{|c|}{ Education level of Head } \\
\hline No Education & 62.3 & 57.7 & 64.0 & 61.1 & 33.6 & 26.2 \\
\hline Incomplete primary & 30.8 & 31.8 & 30.7 & 32.0 & 32.8 & 30.1 \\
\hline Complete primary & 2.8 & 3.5 & 2.7 & 3.1 & 4.3 & 6.4 \\
\hline Lower secondary & 2.9 & 5.3 & 2.2 & 3.4 & 14.8 & 22.6 \\
\hline \multirow[t]{2}{*}{ Higher education levels } & 1.3 & 1.8 & 0.5 & 0.4 & 14.4 & 14.8 \\
\hline & \multicolumn{6}{|c|}{ Education level of Spouse } \\
\hline No education & 66.8 & 64.0 & 68.8 & 67.2 & 29.7 & 28.6 \\
\hline Incomplete primary & 28.1 & 28.8 & 27.7 & 28.8 & 36.7 & 28.5 \\
\hline Complete primary & 1.8 & 2.3 & 1.7 & 1.9 & 4.3 & 6.5 \\
\hline Lower secondary & 2.4 & 3.8 & 1.7 & 1.9 & 16.5 & 25.3 \\
\hline \multirow[t]{2}{*}{ Higher education levels } & 0.8 & 1.1 & 0.2 & 0.2 & 12.8 & 11.3 \\
\hline & \multicolumn{6}{|c|}{ Children School enrollment (btw 5 and 15 years) } \\
\hline Prop. boys \& girls & 52.0 & 70.2 & 51.3 & 69.1 & 62.0 & 80.9 \\
\hline Proportion of girls & 29.4 & 42.2 & 28.8 & 41.5 & 39.1 & 48.5 \\
\hline Proportion of boys & 31.5 & 40.0 & 31.3 & 66.4 & 33.9 & 46.7 \\
\hline
\end{tabular}

Source: QUIBB 2006 and ECVMB 2013-14 
Despite improvements in literacy rates, most of the population in Burundi has not completed primary education. Pre-primary education and literacy programs are relevant at national levels, in particular in rural settings. Urban areas present higher levels of primary (around 30 percent) and secondary education (around 10 percent) but pre-primary remain the most common level of education (Figure III.10). The relatively high number of people under literacy programs reflects a lack of higher and formal educational opportunities of rural population -which is most of the population- in the country.

Figure III.10: Education level of households' members by geographical area

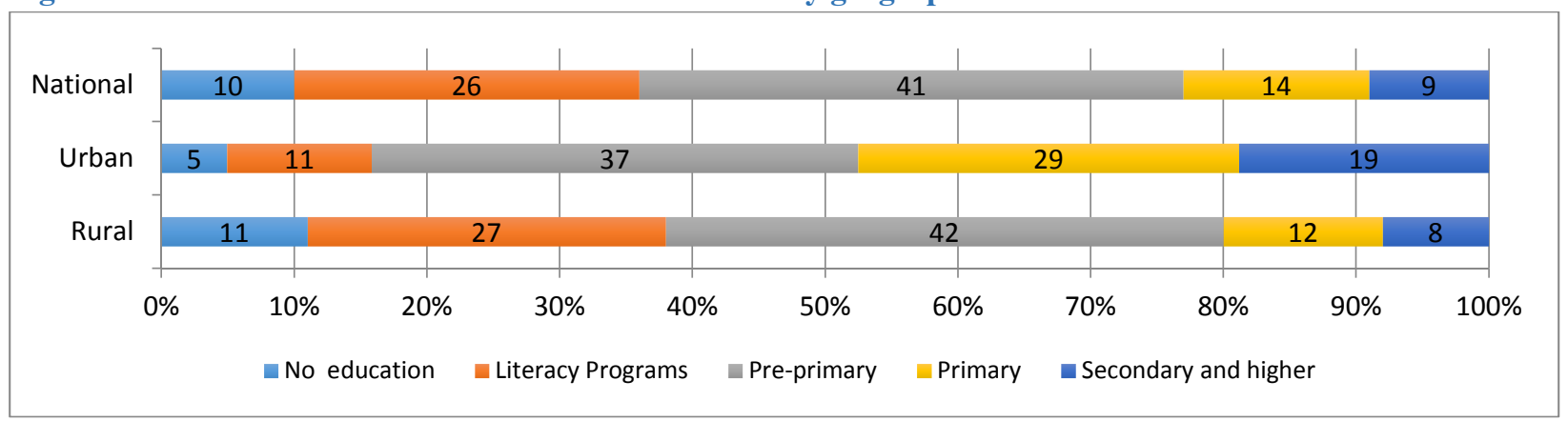

Source: ECVMB 2013-14

Some improvements in health outcomes, but levels remain very low

Despite some progress, health outcomes remain very low, with important risks of food insecurity, and are at risk to worsen following the on-going political crisis. The main outcomes observed are life expectancy at birth, women's fertility rate, under-5 and infant mortality, maternity mortality, and fertility rates.

Life expectancy is slowly progressing, down from a very low level in the past decade. In 2014, life expectancy in Burundi was 57 years old. It dramatically fell between 1993 and 2003 from 51.1 to 46.3 years old, but the indicator is gradually recovering though from a very low basis.

Under-5 and infant mortality remains high although it has experienced some progress over the last 20 years. According to Burundi DHS of 2010 (EDSB-II), between 2005 and 2010, under-5 children mortality stood at 96 per 1,000 births. It represents a slight improvement compared to 2000-2015 period when under-5 children mortality was at 59 per 1,000 and to the 1995-2000 period when it was at 115 per 1,000 births. Over the same periods, infant mortality less than year old- also decreased from 204 per 1,000 births to 96 per 1,000 births. Infant mortality in Burundi shows important variations across rural-urban areas with a rate of $79 \%$ in urban areas against $131 \%$ in rural areas. Similarly, factors such as mothers' education and geographical area seem to play a role: infant mortality rises to $141 \%$ o when the mother has no education against $47 \%$ o for mothers with secondary education or more; and the northern region experiences high infant mortality rate at $155 \%$ while Bujumbura Mairie stand at a nationallylow $69 \%$. 
Maternity mortality is also important and is driven by limited prenatal care. Maternity mortality remains high, with an average of 500 deaths per 100,000 births over the period 20042011 (EDSB-II 2010). Although 99 percent of mothers reported at least one prenatal consultation at a trained facility (doctors, nurses, or midwives) over the period 2004-2011, only one third of them visited such facilities four times, as recommended. Mothers in poor household are also more at risk. In 2010, 51 percent of the mothers belonging to the poorest household quintile had not been assisted by trained personal during childbirth.

Fertility rates remain high, with only a marginal decrease over the last $\mathbf{3 0}$ years. The 2010 DHS estimated the total fertility rate at 6.4 children per woman, down only marginally from 6.9 in 1987. Urban areas tend to have a lower rate with an average of 4.8 children per woman, compared to 6.6 children per woman in rural areas. For instance, the rate varies from 7.1 children per woman in the West region to a low 4.2 children per woman in Bujumbura mairie. Similarly, education attainment is positively correlated with lower fertility rates. Women without education give birth on average to 6.8 children, while the rate for women with at least secondary education goes down to 4.4 children.

Overall, Burundians perceive their health situation as "acceptable" but not as "good". The majority of citizens in Burundi feel that their health conditions are acceptable, in particular in urban areas and among older people (Figure III.11). On average, 67 percent of Burundians reported to have acceptable levels of health and 33 percent to have good levels of health. This difference is more acute in urban settings where 95 percent of people reported to have acceptable levels of health but only 5 percent perceive their health as good. Similarly, 84 percent of people older than 50 years perceive their health as acceptable, while only 14 percent describe it as good. There are not significant differences on health perceptions by gender or in the 5-14 and 15-49 age classes.

Figure III.11: Health situation of population by geographical area, gender, and age group (percentage)

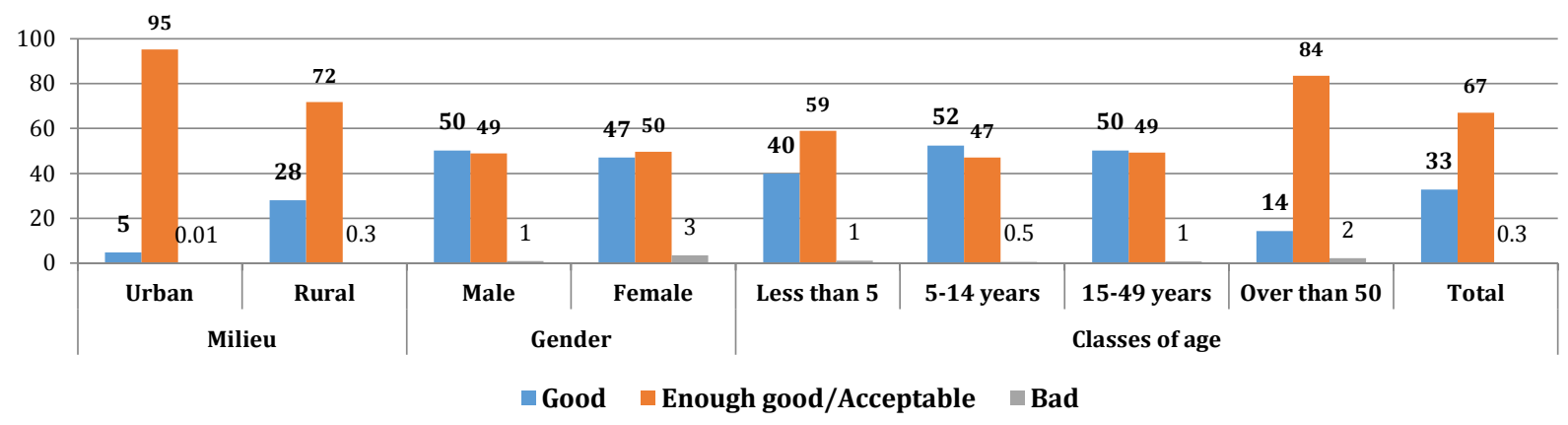

Source: ECVMB 2013-14

This situation is partly explained by the stagnation and slight decrease of health spending per capita. While health spending has globally increased, the rapid increase of the population translates in a stagnation of health spending per capita in current BIF. Controlling for changes in the cost of living, the total health spending in constant BIF has decreased over the last ten years. 
As shown in table III.4, the share of health spending in the budget is decreasing from 10 percent in 2007 to 8.6 percent in 2012 after a slight increase to 12.2 percent in 2010 . The depreciation of the Burundian Franc is intensifying the decrease of health spending per capita in US dollars between 2010 and 2012.

Table III.4: Health spending (total and per capita)

\begin{tabular}{|c|c|c|c|}
\hline & 2007 & 2010 & 2012 \\
\hline Current Health Spending (million BIF) & & 285.864 & 308.407 \\
\hline Total Health Spending (million BIF) & 147.116 & 304.195 & 327.628 \\
\hline Total Health Spending (share of GDP) & $10.0 \%$ & $12.2 \%$ & $8.6 \%$ \\
\hline Total Health Spending per capita (current BIF) & 18.848 & 36.022 & 36.999 \\
\hline Total Health Spending per capita (constant BIF) - 2007) & 18.848 & 22.071 & 19.472 \\
\hline Total Health Spending per capita (USD) & 17 & 29 & 26 \\
\hline
\end{tabular}

Source: OMS, CNS 2014, MSPLS/CNS 2014 and WB calculation

\section{Malnutrition and Stunting are highly prevalent, reaching alarming levels in some regions}

Chronic malnutrition is severe at national level, but shows high geographical discrepancies and regions in an alarming situation. According to 2010 DHS and 2012 PMS, around 58 percent of the children under five years old are stunted, with the malnutrition and stunting being significantly more prevalent in rural areas compare to urban sectors. There are also wide disparities between the different regions. Table III.5 shows that malnutrition rates are significantly lower in Bujumbura Mairie (26.8 percent), while the Northern region experiences a rate higher than 60 percent.

Table III.5: Malnutrition by regions (percentage)

\begin{tabular}{lcc}
\hline \hline Regions & No & Yes \\
\hline North & 37,9 & 62,1 \\
South & 43,0 & 57,0 \\
Center East & 40,3 & 59,7 \\
West & 42,5 & 57,5 \\
Bujumbura Mairie & 73,2 & 26,8 \\
\hline Burundi & 41,9 & 58,1 \\
\hline \hline
\end{tabular}

Source: PMS 2012

Nutritional security stands at very low levels across all provinces, but the problem is more acute in rural areas. Overall, only 31 percent of Burundi's population is considered as foodsecured (Table III.6). While 37 percent is in a state of limited food insecurity, 25 and 5 percent are respectively in a situation of moderate ${ }^{24}$ and severe ${ }^{25}$ food insecurity. Provinces such as Cibitoke, Gitega, Karusi, Muramvya, and Rutana have double-digit rates of severe food insecurity. The province of Muramvya stands out with only 17 percent of its population foodsecured and 25 percent of them in a state of severe food insecurity.

\footnotetext{
${ }^{24}$ This means the household has significant food consumption gaps and/or is able to meet minimum food needs but by using irreversible coping strategies.

${ }^{25}$ This means that the household has extreme food consumption gaps and/or has extreme loss of livelihood assets that will lead to food consumption gaps.
} 
Table III.6: Food insecurity by provinces (percentage)

\begin{tabular}{lcccc}
\hline \hline & Food Security & Limited Food Insecurity & Moderate Food Insecurity & Severe Food Insecurity \\
\hline Bubanza & 23 & 42 & 27 & 8 \\
Bujumbura rural & 31 & 38 & 26 & 5 \\
Bururi & 35 & 45 & 19 & 2 \\
Cankuzo & 47 & 38 & 12 & 4 \\
Cibitoke & 30 & 35 & 25 & 10 \\
Gitega & 32 & 33 & 25 & 10 \\
Karusi & 16 & 37 & 31 & 16 \\
Kayanza & 28 & 30 & 33 & 9 \\
Kirundo & 25 & 42 & 30 & 4 \\
Makamba & 53 & 34 & 10 & 4 \\
Muramvya & 17 & 33 & 32 & 25 \\
Muyinga & 34 & 35 & 29 & 5 \\
Mwaro & 26 & 40 & 31 & 8 \\
Ngozi & 23 & 41 & 29 & 8 \\
Rutana & 24 & 37 & 21 & 15 \\
Ruyigi & 28 & 39 & 31 & 4 \\
Bujumbura M. & 52 & 37 & 8 & 1 \\
Burundi & 31 & 25 & 7 \\
Source: L'Anawa.k.
\end{tabular}

The ongoing political crisis has worsened the health situation and has put the poorest and most vulnerable at risk. Malnutrition and food insecurity are dependent on food supplies and potential shortages and therefore particularly sensitive to political changes. The current crisis seems to have worsened the situation on that front. The UN Office for the Coordination of Humanitarian Affairs (UNOCHA) announced that based on the latest Emergency Food Security Assessment (EFSA) conducted in April 2016 in 18 provinces, nearly 4.6 million people are food insecure. Of these, 590,000 were found severely food insecure and in need of emergency food aid. Preliminary reports from the World Bank show that malaria cases tripled in 2016 and maternal mortality doubled in 2015. Frequent stock-outs of drugs and therapeutic foods in many public health facilities are forcing patients, users, and free health care beneficiaries, to buy essential drugs from private pharmacies. According to UNICEF estimates, the situation affected more than 1 million under-5 children and 400,000 pregnant women in 2015 alone.

\section{Household living conditions}

\section{Living conditions and access to basic services have improved but regional disparities remain high.}

In general asset ownership by households has increased since 2006, particularly cell phone ownership and ownership of small appliances. The largest increments of asset ownership is observed for cell phones, coming from 1.7 percent up to 33.3 percent in 2014. As a consequence, ownership of landline telephones decreased over the same period. Small appliance ownership and ownership of agricultural tools were highly widespread in Burundi in 2014. Other items that presented increases include TV ownership (although it remains low), and ownership of radios and bicycles. Regional differences are particularly large in the case of TV ownership (only 0.8 in 
rural areas versus 42.8 in the capital), other big assets ( 0.4 percent versus 13.2$)$ and other means of transportation (1.1 versus 12.8).

Table III.7: Trends in assets ownership (percentage)

\begin{tabular}{l|ccc|ccc|ccc|ccc}
\hline \hline & \multicolumn{3}{|c|}{ National } & \multicolumn{3}{|c|}{ Rural } & \multicolumn{3}{|c|}{ Urban } & \multicolumn{3}{|c}{ Bujumbura M. } \\
& 2006 & 2012 & 2014 & 2006 & 2012 & 2014 & 2006 & 2012 & 2014 & 2006 & 2012 & 2014 \\
\hline TV ownership & 2.9 & 4.3 & 3.9 & 0.4 & 1.4 & 0.8 & 14.0 & 17.9 & 17.9 & 33.3 & 45.2 & 42.8 \\
Cell phone Ownership & 1.7 & 12.5 & 33.3 & 0.8 & 9.1 & 28.5 & 10.3 & 35.4 & 66.8 & 19.2 & 58.3 & 85.0 \\
Landline telephone & 1.2 & 0.6 & 0.7 & 0.2 & 0.2 & 0.4 & 6.9 & 1.1 & 2.8 & 21.4 & 7.2 & 3.8 \\
Radio & 35.9 & 44.5 & & 33.8 & 45.5 & & 67.4 & 33.6 & & 25.1 & 54.3 & \\
Other Big assets & 1.9 & 2.2 & 1.3 & 0.8 & 0.7 & 0.4 & 6.9 & 4.9 & 4.1 & 22.9 & 26.4 & 13.2 \\
Small appliances & 78.5 & 60.0 & 95.1 & 77.8 & 58.9 & 94.6 & 89.9 & 72.4 & 96.4 & 88.7 & 71.8 & 87.9 \\
Bicycle & 12.3 & 25.8 & 15.2 & 12.1 & 26.7 & 15.7 & 17.7 & 28.3 & 14.1 & 11.2 & 9.7 & 9.9 \\
Other transp. means & 0.4 & 0.3 & 1.0 & 0.2 & 0.2 & 1.1 & 2.1 & 7.8 & 3.1 & 10.1 & 9.2 & 12.8 \\
Agricultural tools & & 82.9 & 92.6 & & 88.0 & 97.4 & & 46.6 & 74.6 & & 17.0 & 27.2 \\
\hline \hline
\end{tabular}

Source: QUIBB 2006, PMS 2012 and ECVMB 2013/14

There have been improvements on dwelling conditions and access to basic services. Households in Burundi have more access to floor, wall and roof materials of higher quality (Table III.8). Access to roofs made of tiles or metal sheets have always been high, registering a flat variation in the 7-years period analyzed. In 2013, the change in access to walled dwellings decreased -0.3 percent from 2012 and increased 31 percent from 2006. As opposite, floor materials have improved in 2013 to 16 percent, from 9 percent in 2006 and 12 percent in 2012. Access to better wall materials show the largest increments from 45 percent in 2006 to 98 percent in 2013, with particular improvements in rural areas.

Table III.8: Trends in dwelling conditions and access to basic services (percentage)

\begin{tabular}{|c|c|c|c|c|c|c|c|c|c|}
\hline & \multicolumn{3}{|c|}{ National } & \multicolumn{3}{|c|}{ Rural } & \multicolumn{3}{|c|}{ Urban } \\
\hline & 2006 & 2012 & 2014 & 2006 & 2012 & 2014 & 2006 & 2012 & 2014 \\
\hline Floor dwelling & 9.1 & 12.4 & 15.5 & 5.9 & 8.5 & 9.7 & 56.7 & 54.4 & 66.8 \\
\hline Wall dwelling & 44.8 & 83.8 & 98.5 & 42.7 & 84.0 & 87.0 & 76.5 & 81.3 & 99.6 \\
\hline Roof dwelling & 59.7 & 78.3 & 78.0 & 57.3 & 77.0 & 98.4 & 96.6 & 92.2 & 96.4 \\
\hline Mosquito Net & 22.7 & 68.8 & - & 20.1 & 68.5 & - & 63.6 & 71.7 & - \\
\hline
\end{tabular}

Note: Floor of dwelling are floor made of tile cement and brick, wall of dwelling indicates walls made of adobe bricks and pise, roof of dwelling are roofs made of tiles or metal sheets.

Source: QUIBB 2006, PMS 2012 and ECVMB 2013-14

The percentage of households with access to basic services has increased from 2006 to 2013. Households in Burundi with access to drinking water increased on average, mainly due to greater access is urban areas (more than double from 2006 to 2013). Nonetheless, access to drinking water decreased in rural settings (Table III.9). Similarly, access to piped water increased at the urban level and decreased at the rural level, which has resulted in large regional discrepancies: 80 percent of households have access in urban areas, while only 10 percent have access in rural areas. In addition, access to protected sources of water increased and access to unprotected sources decreased, particularly in rural settings. While 67 percent of households procure water from protected sources at the national level, only 20 percent procure from protected sources in urban areas (due to the use of piped water in these areas, Table III.9). With regards to sanitation, urban areas present better conditions than rural areas, whose sanitation facilities have declined by $-15 / 20$ percent from 2006 and 2012. Finally, while access to both cooking fuel and electricity has 
increased, electricity still remains largely inaccessible in rural Burundi. Cooking fuel is basically universal in rural areas (99.86 percent in 2013) and electricity, despite its low levels at national level, showed important improvements in urban settings (around +60 percent from 2012).

Table III.9: Trends in access to basic services (percentage)

\begin{tabular}{|c|c|c|c|c|c|c|c|c|c|}
\hline & \multicolumn{3}{|c|}{ N National } & \multicolumn{3}{|c|}{ Rural } & \multicolumn{3}{|c|}{ Urban } \\
\hline & 2006 & 2012 & 2014 & 2006 & 2012 & 2014 & 2006 & 2012 & 2014 \\
\hline \multicolumn{10}{|l|}{ Water access } \\
\hline Drinking water & 4.0 & 2.9 & 4.5 & 4.0 & 2.7 & 3.8 & 5.4 & 4.4 & 10.5 \\
\hline Piped Water & 13.4 & 27.9 & 14.5 & 9.9 & 24.0 & 8.2 & 66.6 & 71.0 & 79.8 \\
\hline Protected sources & 50.5 & 55.7 & 66.7 & 53.0 & 59.4 & 71.1 & 11.5 & 15.5 & 19.9 \\
\hline Unprotected sources & 36.2 & 16.4 & 18.9 & 37.1 & 16.7 & 20.7 & 21.9 & 13.5 & 0.3 \\
\hline Sanitation facilities & 28.9 & 30.2 & 24.3 & 28.3 & 29.1 & 21.6 & 39.0 & 42.0 & 48.4 \\
\hline Cooking Fuel & 87.3 & 98.3 & 99.7 & 86.7 & 98.3 & 99.9 & 93.4 & 98.1 & 98.3 \\
\hline Electricity & 4.1 & 5.6 & 7.2 & 1.5 & 2.4 & 2.0 & 43.9 & 40.7 & 65.0 \\
\hline
\end{tabular}

\section{Besides Bujumbura, that uses piped water, most Burundians procure water from protected} sources. In Bujumbura, 78 percent of households use piped water, which is significantly different from what is observed in other areas (Figure III.12). Besides the capital, the Western region of Burundi is the area that gathers more people with access to piped water (34 percent), but procurement from protected sources remains predominant (51 percent). The Southern region of Burundi present a more serious situation: 28 percent of households procure water from unprotected sources, which is twice as many as those who have access to piped water. Center East and North Burundi also present high levels of access to unprotected sources of water.

Figure III.12: Access to improved water sources by geographical areas (percentage)

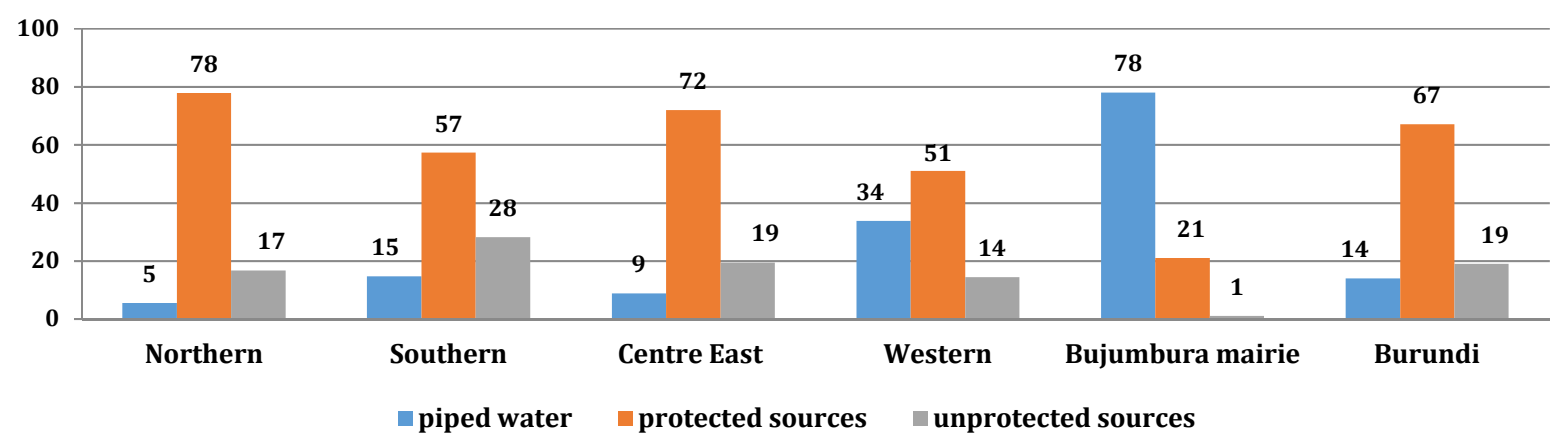

Source: ECVMB 2013-14

Improved sanitation has only been observed in Bujumbura. The capital presents a positive trend in terms of better sanitation facilities, with 58.6 percent of people having access to such facilities in 2013 (Table III.10). There is a negative trend in the number of households using improved sanitation facilities in the Western and Northern region, while in the Centre East and in Bujumbura the tendency is positive. In the Southern region sanitation improved sharply in 2012 and decline further in 2013, reaching lower levels than those in 2006. Levels of improved 
sanitation facilities in rural areas and other urban areas have gotten worse over the years, reaching only 22 percent and 23 percent of the population in 2013.

Table III.10: Access to improved sanitations (percentage)

\begin{tabular}{lccc}
\hline \hline & 2006 & 2012 & 2013 \\
\hline Residence & & & \\
Bujumbura mairie & 43.0 & 51.5 & 58.6 \\
Other urban & 23.1 & 30.1 & 22.3 \\
Rural & 28.3 & 29.1 & 21.6 \\
\hline Region & & & \\
Northern & 39.4 & 19.7 & 21.2 \\
Southern & 13.6 & 61.2 & 12.7 \\
Centre East & 21.6 & 24.4 & 33.6 \\
Western & 34.0 & 29.7 & 24.9 \\
Bujumbura mairie & 43.0 & 51.5 & 58.6 \\
\hline Burundi & $\mathbf{2 8 . 9}$ & $\mathbf{3 0 . 2}$ & $\mathbf{2 4 . 3}$ \\
\hline Source: QUIBB 2006, PMS 2012 and QUIBB 2013 & & \\
\hline
\end{tabular}

Source: QUIBB 2006, PMS 2012 and QUIBB 2013

Consumption of electricity, generators and solar energy used for dwellings show a positive tendency over the years, while sources of energy used for cooking have a less clear trend. Only 8.5 percent of households have access to the aforementioned sources of energy used for dwellings, despite the improvement over time. Wood, candles and kerosene lamps are used more intensively in Burundian houses, as well as of other sources of energy. As for energy used to cook, firewood and oil are the most frequent among Burundian households with positive increments in recent years (89 percent of population used this energy in 2013). However, charcoal is the predominant source of energy to cook in Bujumbura with sharp increases since 2006. Gas and electricity are rarely used, with no significant differences across regions (Table III.11).

Table III.11: Energy sources used (percentage)

\begin{tabular}{|c|c|c|c|c|c|c|c|c|c|c|c|c|}
\hline & \multicolumn{4}{|c|}{2006} & \multicolumn{4}{|c|}{2012} & \multicolumn{4}{|c|}{2013} \\
\hline & $\begin{array}{c}\text { Buja } \\
\text { mairie }\end{array}$ & $\begin{array}{l}\text { Other } \\
\text { urban }\end{array}$ & Rural & Total & $\begin{array}{c}\text { Buja } \\
\text { mairie }\end{array}$ & $\begin{array}{l}\text { Other } \\
\text { urban }\end{array}$ & Rural & Total & $\begin{array}{c}\text { Buja } \\
\text { mairie }\end{array}$ & $\begin{array}{l}\text { Other } \\
\text { urban }\end{array}$ & Rural & Total \\
\hline \multicolumn{13}{|l|}{ For dwelling } \\
\hline Electricity & 47.8 & 34.1 & 1.6 & 4.4 & 52.3 & 12.6 & 1.7 & 4.9 & 65.0 & 3.4 & 2.0 & 7.2 \\
\hline Generator & 0.2 & 0.5 & 0.5 & 0.5 & 0.5 & 0.1 & 0.0 & 0.1 & 0.5 & 0.4 & 0.5 & 0.4 \\
\hline Solar & 0.0 & 0.0 & 0.1 & 0.1 & 1.0 & 0.3 & 0.7 & 0.7 & 0.6 & 0.8 & 0.8 & 0.8 \\
\hline Kerosene lamp & 38.4 & 39.4 & 36.8 & 36.9 & 13.2 & 21.1 & 22.4 & 21.8 & 6.0 & 14.2 & 14.9 & 14.2 \\
\hline Wood & 5.5 & 16.5 & 55.8 & 52.8 & 1.6 & 13.5 & 16.1 & 15.2 & 0.3 & 27.3 & 27.0 & 24.6 \\
\hline Candle & 6.0 & 6.9 & 2.9 & 3.1 & 23.3 & 23.5 & 10.0 & 11.3 & 22.0 & 14.4 & 15.7 & 16.5 \\
\hline Others & 2.2 & 2.7 & 2.3 & 2.3 & 8.0 & 29.0 & 49.2 & 46.1 & 5.6 & 39.6 & 39.1 & 36.3 \\
\hline \multicolumn{13}{|l|}{ To cook } \\
\hline Gas and electricity & 1.28 & 0.55 & 0.22 & 0.28 & 2.73 & 1.79 & 0.57 & 0.72 & 0.18 & 0.24 & 0.23 & 0.22 \\
\hline Firewood and oil & 21.91 & 43.69 & 84.06 & 80.60 & 10.66 & 34.38 & 86.31 & 80.67 & 6.86 & 95.02 & 94.04 & 88.70 \\
\hline Charcoal & 72.62 & 46.60 & 2.59 & 6.47 & 83.60 & 63.83 & 11.64 & 17.09 & 90.50 & 4.59 & 3.60 & 10.79 \\
\hline Others & 4.19 & 9.16 & 13.12 & 12.66 & 3.02 & & 1.48 & 1.52 & 2.47 & 0.14 & 0.14 & 0.29 \\
\hline
\end{tabular}

Source: QUIBB 2006, PMS 2012 and ECVMB 2013-14

Domestic waste and sewage disposal have similar trends, with higher reliance on house composting for domestic waste and the use of nature and rivers for sewage disposal. Levels of home composting remain similar and high in 2013 and in 2012, while individuals who use 
collective bins have decreased to one third at the national level. There is a 10 percent increase in households that dispose their waste directly in the field. Septic tanks, courts and other ways to dispose water fall during 2012-2103 (Table III.12). In addition, waste disposal in channels, roads and streets have increased. In particular, the practice of dumping used water in the nature or rivers has augmented significantly, from 16 percent in 2012 to 43 percent in 2013.

Table III.12: Access to improved domestic waste and sewage disposal (percentage)

\begin{tabular}{lcccccccc}
\hline \hline & \multicolumn{4}{c}{2012} & & & \multicolumn{2}{c}{2013} \\
& $\begin{array}{c}\text { Buja } \\
\text { mairie }\end{array}$ & $\begin{array}{c}\text { Other } \\
\text { urban }\end{array}$ & Rural & Total & $\begin{array}{c}\text { Buja } \\
\text { mairie }\end{array}$ & $\begin{array}{c}\text { Other } \\
\text { urban }\end{array}$ & Rural & Total \\
\hline Domestic waste & & & & & & & & \\
Compost & 17.10 & 43.55 & 64.46 & 61.28 & 17.34 & 61.37 & 62.95 & 59.64 \\
Bin (individual/collective) & 65.06 & 36.79 & 8.51 & 12.41 & 64.55 & 0.85 & 0.53 & 4.80 \\
Field & 3.40 & 14.08 & 25.80 & 24.24 & 17.81 & 37.40 & 36.18 & 35.21 \\
Other & 14.44 & 5.58 & 1.23 & 2.07 & 0.30 & 0.37 & 0.35 & 0.34 \\
\hline Sewage disposal & & & & & & & & \\
Septic tank (sump/well/collector) & 16.31 & 17.18 & 6.47 & 7.32 & 15.86 & 1.38 & 1.42 & 2.47 \\
Channel / Road / Street & 41.10 & 31.03 & 5.11 & 7.83 & 54.86 & 6.91 & 6.37 & 10.14 \\
Court & 36.22 & 38.24 & 59.84 & 57.92 & 22.53 & 44.78 & 45.07 & 43.40 \\
Nature (Brush) / River & 3.11 & 11.65 & 17.43 & 16.49 & 6.53 & 46.17 & 46.40 & 43.29 \\
Other & 3.27 & 1.90 & 11.14 & 10.44 & 0.21 & 0.75 & 0.75 & 0.70 \\
\hline \hline
\end{tabular}

Note: For these services, comparisons were only possible for 2012 and 2013.

Source: PMS 2012 and ECVMB 2013-14

Public schools seem to be quite widely spread across Burundi with higher concentrations in Bujumbura. On average, more than half of Burundians consider themselves to be very close to the location of primary school facilities (Figure III.13) and kindergartens (Figure III.15). However, this percentage declines to one third of the population with regards to secondary public school facilities (Figure III.14). Nearness and remoteness in other urban areas and rural settings follow the same distribution as the one observed at the national level, with larger numbers of people reporting being "very close" to school facilities. Only 1-2 percent of households consider public schools "rather far" in Bujumbura, as most of them perceive these facilities to be "very close". This indicates larger numbers of public schools in Bujumbura to the detriment of other regions of the country: between $65-80$ percent of household reported being very close to school facilities in the capital versus 35-55 percent in the rest of the country.

Figure III.13: Access to public primary school by geographical area (percentage)

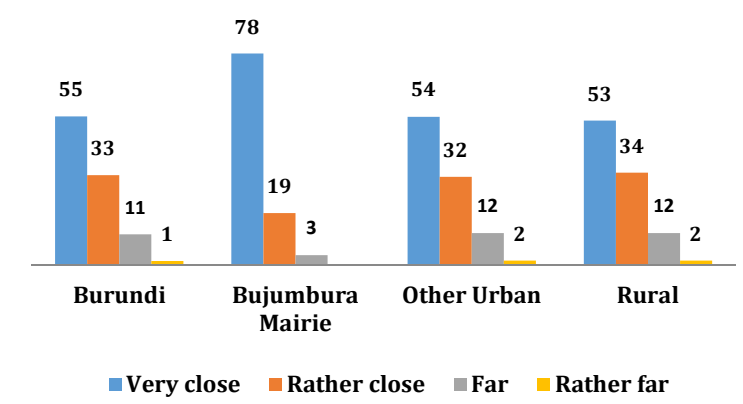

Source: ECVMB 2013-14
Figure III.14: Access to public secondary school by geographical area (percentage)

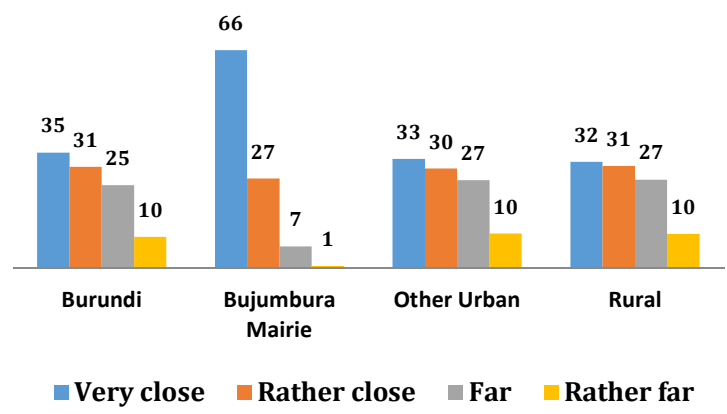

Source: ECVMB 2013-14 
Figure III.15: Access to public kindergarten by geographical area (percentage)

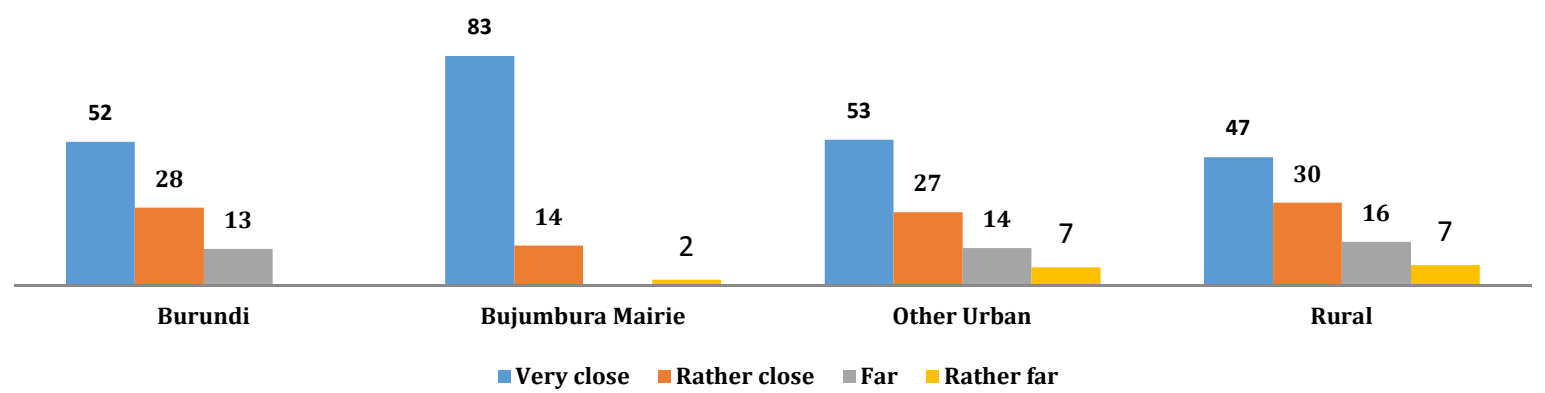

Source: ECVMB 2013-14

Meanwhile, access to public health facilities is perceived as more difficult. At national level, most of the population considers public health facilities to be "far" (32 percent). Public pharmacies follow a similar pattern, as 26 percent of people reported them to be "far" and 28 percent "rather far". The differences between Bujumbura and other territories seem to be more acute in the case of public health infrastructure, particularly for pharmacies (Figures III.16-17). In addition, while other urban and rural populations perceive health facilities as "far", most of them reported pharmacies to be "very far".

Figure III.16: Access to public health facility by geographical area (percentage)

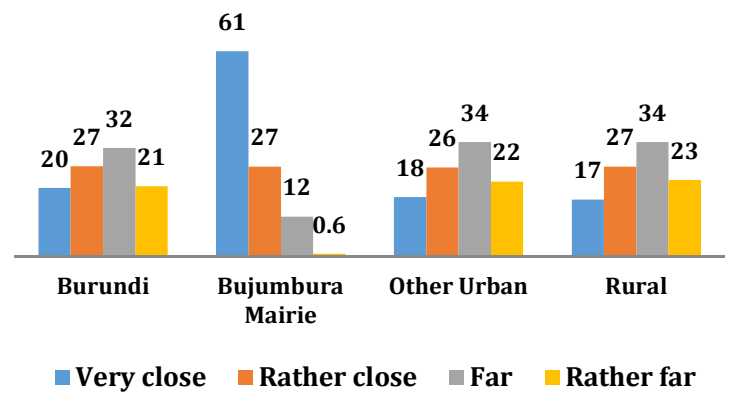

Figure III.17: Access to public pharmacy by geographical area (percentage)

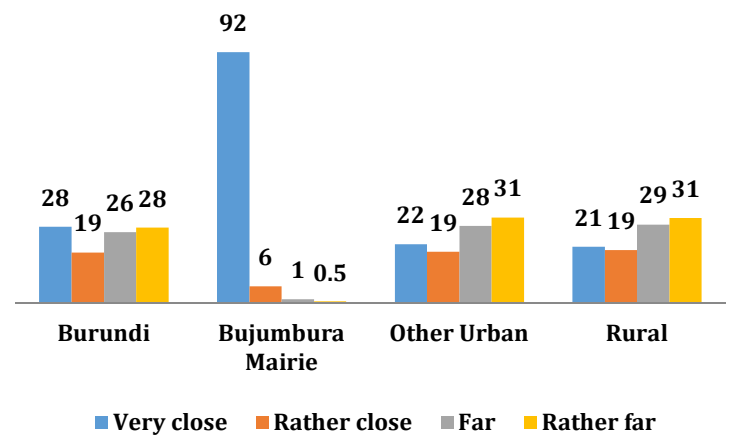

Source: ECVMB 2013-14

Disparities between Bujumbura and other territories are more accentuated in the case of private infrastructure. The 'Bujumbura gap' is evident in the educational sector (Figure III.1819), where the number of people who perceive primary school facilities to be "very close" were around 90 percent in Bujumbura as compared to 50 percent at the national level, 26 percent in other urban areas and 19 percent in rural settings. Private secondary schools and kindergartens follow a similar pattern with larger disparities in the case of kindergarten facilities (92 percent of individuals reported to be "very close" to those facilities in the capital). "Rather close" is the most frequent response for proximity to primary and secondary schools in other urban areas and rural settings, while "very close" is a more prevalent response for kindergartens. Overall, private infrastructure in the education sector seem well distributed at the national level, with at least 45 
percent of the population considering them 'very close' and only around 10 percent perceiving them as 'very far'.

Figure III.18: Access to private primary school by geographical area (percentage)

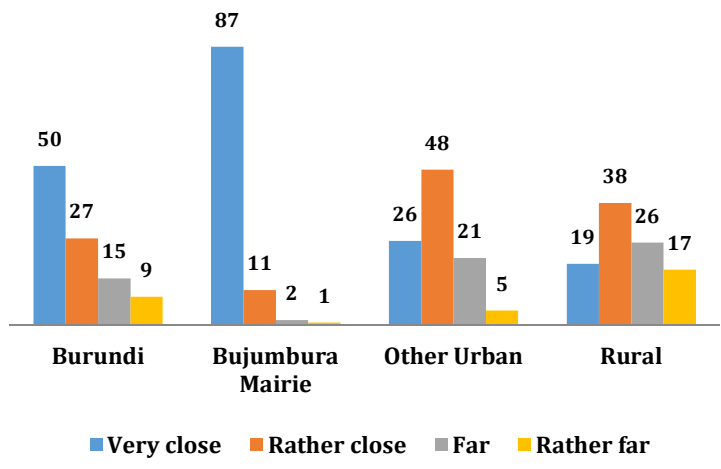

Figure III.19: Access to private secondary school by geographical area (percentage)

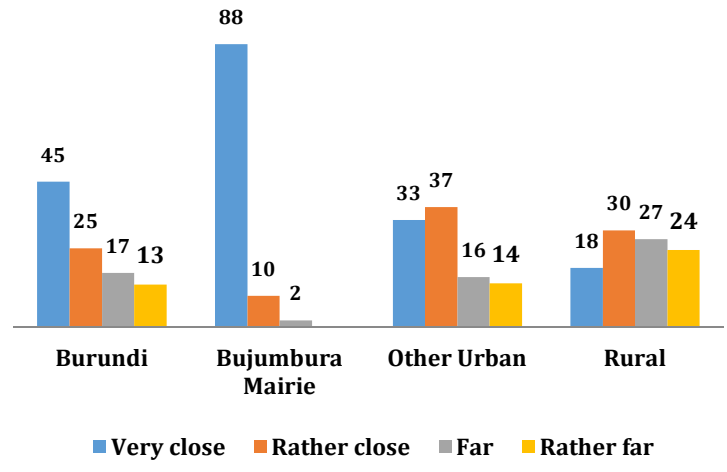

Source: ECVMB 2013-14

Figure III.20: Access to private kindergarten by geographical area (percentage)

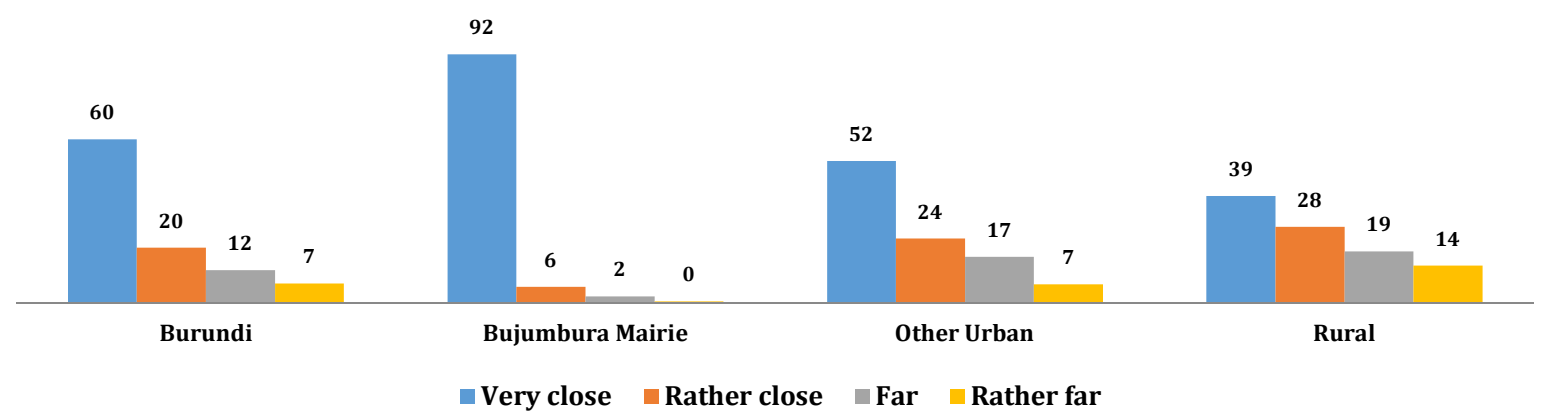

Source: ECVMB 2013-14

On the other hand, access to private health facility appears quite difficult for Burundians, even if they are more accessible than public ones. Only one third of households think that private health facilities are 'very close' (Figure III.21), as opposed to the higher percentage observed for private education infrastructure. Similarly, there are larger numbers of households who perceive private infrastructure as "rather far" (26 percent) and "far" (23 percent) compared to education facilities. Similar divergences between Bujumbura and other areas are observed in this case. 
Figure III.21: Access to private health facility by geographical area (percentage)

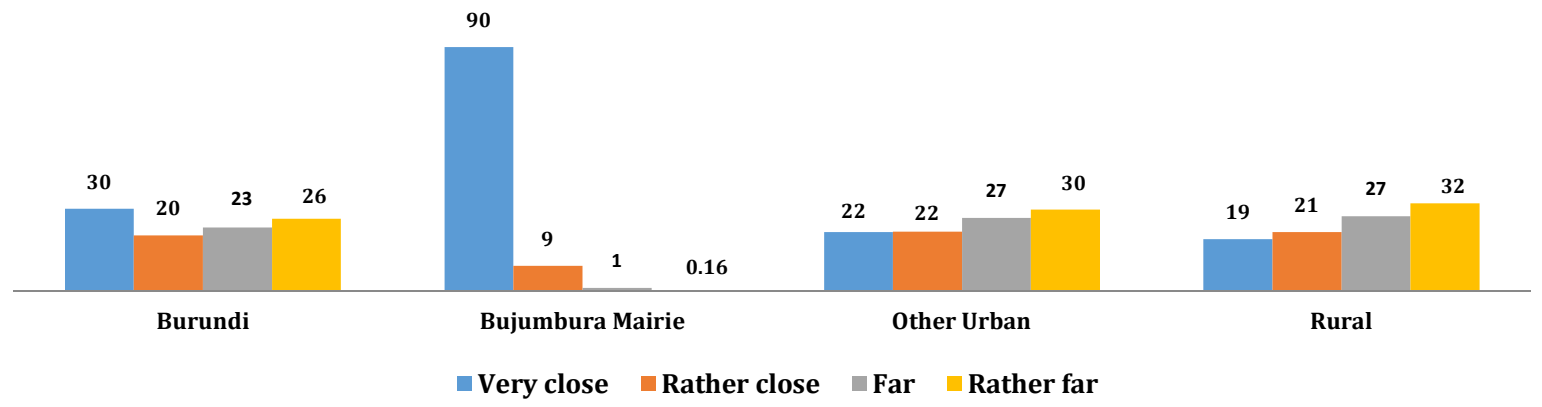

Source: ECVMB 2013-14

The consequence is that the incidence of illnesses/injuries seems to have returned to 2006 levels. The percentage of ill/injured individuals during the last 4 weeks declined 2 percent in rural areas and 4 percent in the Centre East part of the country from 2006 to 2014 (Table III.13). However, the rates of illnesses/injuries have registered a great increase in other urban areas compared to 2006. In general, the large reduction of illness and injuries observed in 2012 was reversed in 2013. This suggests that PMS data and QUIBB data may have some comparability problems that requires further investigation, as such a U-shaped trend appears quite odd. ${ }^{26}$

Table III.13: Illness/injuries during last 4 weeks (percentage)

\begin{tabular}{lccc}
\hline \hline & 2006 & 2012 & 2014 \\
\hline Residence & & & \\
Bujumbura mairie & 21.6 & 12.7 & 21.9 \\
Other urban & 21.9 & 14.6 & 30.7 \\
Rural & 32.8 & 16.6 & 30.7 \\
\hline Region & & & \\
Northern & 36.7 & 20.8 & 34.8 \\
Southern & 27.1 & 11.5 & 25.4 \\
Centre East & 31.7 & 15.3 & 27.8 \\
Western & 29.8 & 14.9 & 29.8 \\
Bujumbura mairie & 21.6 & 12.7 & 21.9 \\
\hline Burundi & 32.2 & 16.3 & 30.0 \\
\hline \hline Source: QUIBB 2006, PMS 2012 and ECVMB 2013-14
\end{tabular}

Source: QUIBB 2006, PMS 2012 and ECVMB 2013-14

Consultation at health facilities or with a traditional healer slightly declined with respect to 2006 levels but increased compared to 2012 levels. Regional disparities are observed from 2006 to 2013. The northern region has the greatest levels of consultation, followed by the West and Centre East regions (Table III.14). The second largest increment of consultation services are recorded in urban areas (2014 rate were 6 percent higher than that in 2006 and 9 percent higher than that in 2012), while the largest increment are found in the capital.

\footnotetext{
${ }^{26}$ At first sight, a problem in the data management was taken into account (e.g. data for PMS at the head of household level, instead at individual level), but that was not the case. Looking at the (weighted) data, there were 11,477 (29.34\%) ill individuals in 2006 (vs 27,634 not injured - 70.66\%), 6,281 (14.71\%) vs 36,207 (84.79\%) in 2012, 10,194 (30.01\%) vs 23,775 (69.99\%) in 2013.
} 
Table III.14: Households' consultation of health facility or traditional healer during last 4 weeks (percentage)

\begin{tabular}{|c|c|c|c|c|c|c|c|c|c|}
\hline & \multicolumn{3}{|c|}{2006} & \multicolumn{3}{|c|}{2012} & \multicolumn{3}{|c|}{2014} \\
\hline & Male & Female & Total & Male & Female & Total & Male & Female & Total \\
\hline \multicolumn{10}{|l|}{ Residence } \\
\hline Bujumbura mairie & 14.1 & 16.8 & 17.9 & 8.0 & 12.9 & 10.4 & 14.8 & 21.0 & 14.5 \\
\hline Other urban & 15.5 & 16.1 & 15.4 & 11.8 & 13.1 & 12.5 & 19.2 & 24.1 & 21.1 \\
\hline Rural & 21.6 & 25.1 & 23.7 & 13.1 & 15.7 & 14.4 & 19.3 & 24.3 & 21.2 \\
\hline \multicolumn{10}{|l|}{ Region } \\
\hline Northern & 23.9 & 26.5 & 25.4 & 16.5 & 19.3 & 17.9 & 23.8 & 27.8 & 25.7 \\
\hline Southern & 18.5 & 19.8 & 19.6 & 8.5 & 10.5 & 9.5 & 14.0 & 20.2 & 16.0 \\
\hline Centre East & 20.7 & 24.7 & 22.9 & 12.2 & 14.7 & 13.5 & 17.0 & 21.7 & 18.9 \\
\hline Western & 21.2 & 26.7 & 23.7 & 12.8 & 15.0 & 13.9 & 18.4 & 25.0 & 20.0 \\
\hline Bujumbura mairie & 14.1 & 16.8 & 17.9 & 8.0 & 12.9 & 10.4 & 14.3 & 14.4 & 14.5 \\
\hline Burundi & 21.2 & 24.6 & 23.4 & 12.8 & 15.4 & 14.1 & 18.9 & 24.1 & 20.7 \\
\hline
\end{tabular}

Source: QUIBB 2006, PMS 2012 and ECVMB 2013-14

The main reasons for not using the health system are the costs of services and the idea that these are not necessary. High costs appear to be responsible for not consulting health services in more than half of the cases, whereas one fourth of the households considered consultation services unnecessary (Table III.15). In addition, around 11 percent of households do not ask for consultation services because they think health services are useless. People in the capital mostly listed "not necessary" and "needless/don't want" as reasons for not consulting health facilities, while "remoteness" and "expensiveness" are more prevalent responses in rural and other urban areas.

Table III.15: Key reasons for not consulting health services while the person was sick or injured (percentage)

\begin{tabular}{|c|c|c|c|c|c|c|c|c|c|c|c|c|}
\hline & \multicolumn{4}{|c|}{2006} & \multicolumn{4}{|c|}{2012} & \multicolumn{4}{|c|}{2014} \\
\hline & $\begin{array}{c}\text { Bujumbura } \\
\text { mairie }\end{array}$ & $\begin{array}{l}\text { Other } \\
\text { urban }\end{array}$ & Rural & Total & $\begin{array}{l}\text { Bujumbura } \\
\text { mairie }\end{array}$ & $\begin{array}{l}\text { Other } \\
\text { urban }\end{array}$ & Rural & Total & $\begin{array}{c}\text { Bujumbura } \\
\text { mairie }\end{array}$ & $\begin{array}{l}\text { Other } \\
\text { urban }\end{array}$ & Rural & Total \\
\hline Not necessary & 19.8 & 26.5 & 10.1 & 10.5 & 38.0 & 16.8 & 26.5 & 26.7 & 32.7 & 24.9 & 25.0 & 25.7 \\
\hline Expensive & 61.3 & 66.3 & 79.0 & 78.5 & 37.2 & 60.1 & 38.0 & 38.8 & 47.3 & 57.4 & 57.0 & 56.3 \\
\hline Remote & 0.0 & 0.0 & 1.7 & 1.6 & 0.0 & 0.0 & 5.3 & 4.9 & 3.7 & 5.6 & 5.9 & 5.7 \\
\hline Long waiting time & 0.0 & 1.2 & 0.4 & 0.4 & 0.8 & 0.0 & 2.4 & 2.2 & - & - & - & - \\
\hline No trained staff & 0.0 & 0.0 & 0.1 & 0.1 & 0.0 & 0.0 & 0.2 & 0.2 & - & - & - & - \\
\hline No drugs & 0.0 & 0.0 & 0.9 & 0.9 & 1.8 & 6.6 & 4.2 & 4.2 & - & - & - & - \\
\hline Needless/Don't want & & & & & & & & & 13.7 & 10.3 & 10.3 & 10.6 \\
\hline Other & 18.9 & 6.0 & 7.7 & 7.9 & 22.2 & 16.5 & 23.4 & 23.1 & 2.6 & 1.9 & 1.7 & 1.8 \\
\hline Total & 100 & 100 & 100 & 100 & 100 & 100 & 100 & 100 & 100 & 100 & 100 & 100 \\
\hline
\end{tabular}

Source: QUIBB 2006, PMS 2012 and ECVMB 2013-14.

Rural households, women and children younger than 5 years old are the groups that demand more consultation services. 16 percent of households ask for medical consultations in urban areas versus 21.2 percent in rural settings (Figure III.22). By gender, around 20 percent of men request for medical consultation versus 24 percent in the case of women. With regards to age classes, individuals between 5-14 and 15-49 years old are the least likely to request medical consultation (ratio of 14 and 18 percent respectively), whereas children at the age of 5 or younger constitute the group most likely to use medical services (40 percent of medical consultation rate). 
Figure III.22: Medical consultation rate by place of residence, gender, and age group (percentage)

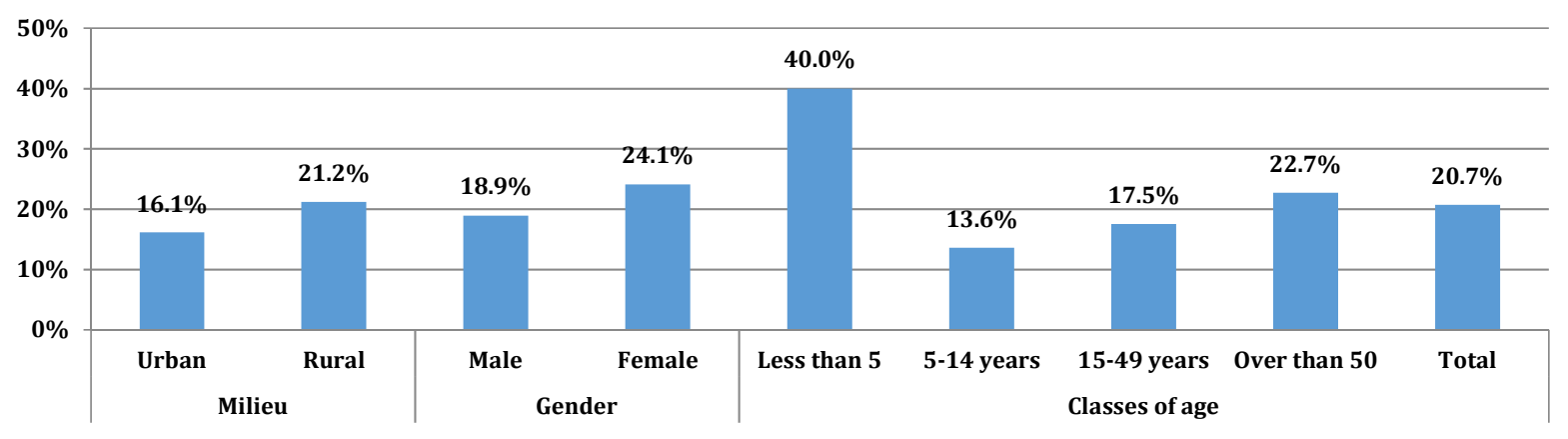

Source: ECVMB 2013-14

\section{Consequences of Violence on Households Welfare}

\section{Violence has deeply affected poverty levels and overall human capital outcomes}

The social and economic impacts of the latest episode of the Burundian conflict (1993-2005) have been widely studied in the economic literature. The availability of a representative multitopic household survey implemented amidst the war (the 1998 Priority Survey) and a number of follow-ups implemented by researchers enabled the examination of the impact of Burundi's war on several outcomes at household and individual level. This section briefly summarizes the main findings.

Next to the devastating impact on national output, the conflict in Burundi had large adverse effects on the welfare levels of households. Income per capita halved from USD 163 in 1993 to USD 83 in 2003. Rural poverty headcount increased from 40 percent in 1993 to just over 70 percent in 2003, making Burundi one of the world's poorest countries (IMF, 2007). Social indicators also worsened: life expectancy fell from 51.1 in 1993 to 46.3 in 2003, and the prevalence of undernourishment increased 20 percentage points (67 percent in 2003). Increases in poverty were linked to the incidence of violence. Households living in areas affected by violence experienced lower consumption growth, with every 25 battle-related deaths or wounded reducing consumption growth by 10 percent, and were less likely to escape poverty. ${ }^{27}$ The effect of violence is persistent: households affected by violence during Burundi's civil war still had lower consumption levels in 2012, seven years after the end of hostilities. ${ }^{28}$

Next to death and destruction of physical capital and infrastructure, the conflict in Burundi also affected human capital, potentially with long-lasting effects. In almost all lowincome countries, educational attainment increases in each successive cohort, as younger cohorts benefit from an expansion in access to education prioritized by governments and development partners. This was also the case in Burundi: The share of people who completed primary school increased from about 15 percent for the cohorts born around 1970 to almost 30 percent for

27 Verwimp and Bundervoet, 2009.

28 Mercier, Ngenzebuke, and Verwimp, 2015. 
cohorts born only eight years later, in 1978 (Figure III.23). For cohorts born after 1978 however, the probability of completing primary school plummeted, as school-age children dropped out due to the conflict and never returned to the school. Examining the causes, Verwimp and Van Bavel (2013) find that Burundian boys exposed to the conflict were 11 percentage points less likely to finish primary school relative to non-exposed boys, a formidable effect knowing that only 20 percent of the cohorts in their study finished primary school. As educational attainment is among the main determinants of living standards, the war's effect on education will likely have a negative effect on long-run living conditions of affected cohorts.

Figure III.23: Probability of finishing primary school, by birth cohort

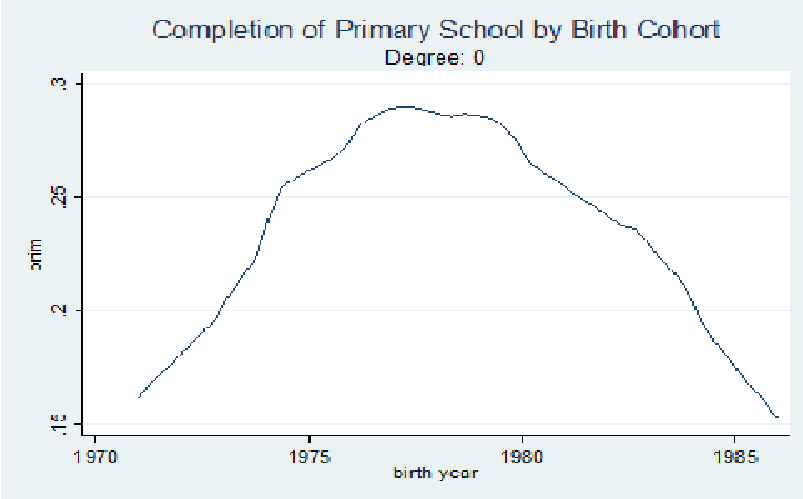

Source: Verwimp and Van Bavel, 2013.
Figure III.24: Height-for-age z-scores by length of war exposure

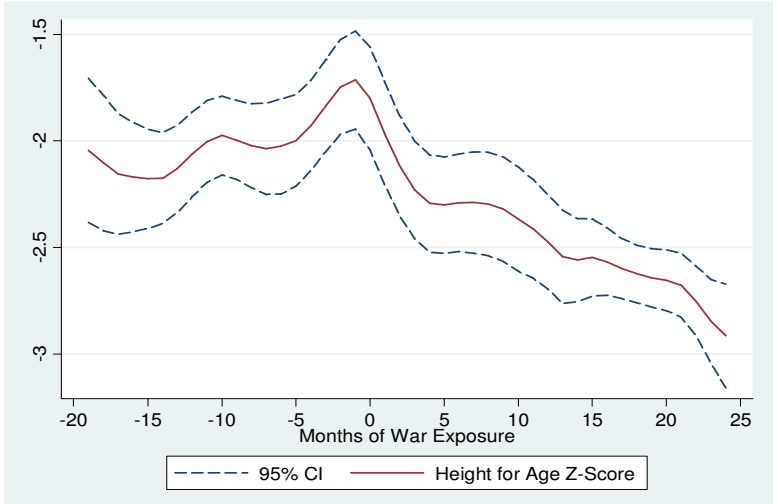

Source: Bundervoet, Verwimp and Akresh (2009).

The adverse effect of the conflict on Burundi's children started well before they reached school age. Linking the timing and spatial intensity of the war to nutritional outcomes, Bundervoet, Verwimp and Akresh (2009) find that children under the age of five who were exposed to the violence were much more likely to be stunted, with a height-for-age of more than 0.5 standard deviations lower compared to non-exposed children (Figure III.24). A body of literature shows that stunting in early childhood is causally linked to worse social and economic outcomes later in life (lower educational attainment, lower wages and productivity, etc.). This means that the war, through adversely affecting nutritional status in childhood, can be expected to have an adverse long-run effect on economic prospects of affected cohorts long after the shooting has stopped.

Burundian children exposed to the war were also more likely to die prematurely, an effect that runs through the war's effect on malnutrition ${ }^{29}$. One year of exposure to the war reduced children's height-for-age by 0.15 standard deviations, and increased the probably of dying by ten percent (and 25 percent for boys). Children in the most-affected areas were most likely to be severely malnourished and most likely to die prematurely.

\footnotetext{
${ }^{29}$ Verwimp, 2012.
} 


\section{Violence and Time Preferences}

Widespread violence substantially increases the risks faced by economic agents. Investment rates typically plummet during large-scale internal conflicts, as uncertainty over the future makes businesses and households refrain from risk and focus on the short term. In a field experiment in Burundi, Voors et al (2012) found that exposure to violence had indeed affected time preferences: people most exposed to the war had shorter time horizons and were less patient, preferring immediate short-run payoffs to higher payoffs in a more distant future. Violent conflict thus makes people focus on short-term gains, foregoing investments that would be lucrative in the longer-run and hurting long-term growth. 


\section{Chapter IV - Governance, Fragility and Persisting Poverty}

\section{Key Messages}

- Weak governance and institutional failures are at the root of poor performance and chronic poverty.

- There has been slow progress in governance following the 2006 end of hostilities, although average levels remain lower than those in Sub Saharan Africa, and while recent political unrest is jeopardizing said governance improvements.

- Burundi needs to build further institutional capacity to make real progress in economic development and poverty reduction.

This chapter reviews the evolution of governance and institutional development in Burundi, and investigates their potential linkages with the deep-rooted poverty. Chronic fragility and a succession of governance failures are likely strongly related to the lack of development and poverty reduction in Burundi, and any progress is unlikely to take place until these binding constraints are addressed. This chapter proceeds as follows. The first section reviews the evolution of the key Governance indicators and its linkages to different episodes of violence and political instability. The second section examines possible correlations between governance, fragility and poverty based on theoretical assumptions and empirical evidence. The chapter concludes highlighting the importance of improving governance in Burundi to avoid violence and promote development.

\section{Institutional and Governance Quality}

Rent-seeking, patronage and regionalism have been the root causes of both the conflict and poor economic performance in Burundi. As a country with limited resources, the public sector is the main source of financial accumulation. Capture of the state since Micombero's coup in 1966 has allowed the small Hima clan from the southern province of Bururi to consolidate power and wealth, providing employment in government and parastatals to clan members. Non-clan members were excluded from political and economic life and the education system, providing a fertile breeding ground for grievances.

During the successive military regimes, public investment was heavily skewed towards the southern province of Bururi (home of the Hima clan) and the capital of Bujumbura. To illustrate, Burundi's fifth Five-Year Plan in the 1980s allocated 98 percent of gross fixed capital formation to a geographical area made up of larger Bujumbura and the southern province of Bururi, out of a total of 15 provinces. Education was likely used to filter entry into the elite: secondary education, a requirement for entry into the public sector, was skewed towards 
Bujumbura and Bururi. ${ }^{30}$ The result of these policies was a civil service largely monopolized by a small clan holding all political and economic power.

Next to foreign aid, the main source of rents for the political elite was the agricultural sector, in particular the export crops, through the use of price controls. Three parastatals controlled almost 100 percent of total exports. Control of producer prices allowed the government to appropriate a large part of the export earnings. ${ }^{31}$ For instance, during the 15 years before adopting a Structural Adjustment Programme in 1986, coffee farmers were paid an average of 40 percent of the world price, the lowest share in the region. ${ }^{32}$ As government enforced the growing of export crops, this translated to a taxation of rural farmers to the benefit of the urban elite.

These circumstances have likely contributed to the slow growth experienced in Burundi since independence. The absence of qualified managers and restrictions on the access to education have hindered economic growth in the country. The 1993 war brought economic collapse, but also ended the exclusionary policies of the past. The end of the war however did not result in a significant economic rebound.

Slow progress in governance after the peace period but overall institutional capacity remains weak

Despite some progress after the end of violence in 2005 , public sector governance in Burundi remains very weak and below SSA averages. Overall, governance indicators improved after 2005. In particular, the World Governance Indicators (WGI) show increased progress in "voice and accountability" and "regulatory framework" (Figure IV.1). ${ }^{33}$ However, Burundi continues to lag behind the Sub-Saharan Africa regional average on most dimensions of governance, as it ranks in the lowest 20 percent in "political stability", "government effectiveness", "rule of law" and "control of corruption". Meanwhile, according to the Ibrahim Index of African Governance (IIAG), Burundi is getting closer to African averages and even outperforming in terms of "Participation and Human Rights" and "Human Development" (Figure IV.2). ${ }^{34}$ As illustrated by both the WGI and the IIAG, Burundi needs to make greater efforts to improve its public sector governance, as it still falls far behind the African average.

\footnotetext{
${ }^{30}$ According to Jackson (2001), Bujumbura and Bururi accounted for 32 percent of secondary school students in the late 1980s, while only accounting for 11 percent of total population. Moreover, fully 60 percent of donor aid to education was allocated to Bururi.

${ }^{31}$ The parastatals were OCIBU (coffee), OTB (tea) and COGERCO (cotton).

${ }^{32}$ Nkuruniza and Ngaruko, 2005.

33 WGI tracks six key dimensions of governance, including "voice and accountability", "political stability", "government effectiveness", "regulatory framework", "control of corruption", and "rule of law". WGI are not absolute measures of governance but a country's relative rank with respect to each indicator.

${ }^{34}$ IIAG provides an annual assessment of the quality of governance in African countries aggregated in four categories.
} 
Figure IV.1: World Governance Indicators (Percentile Rank)

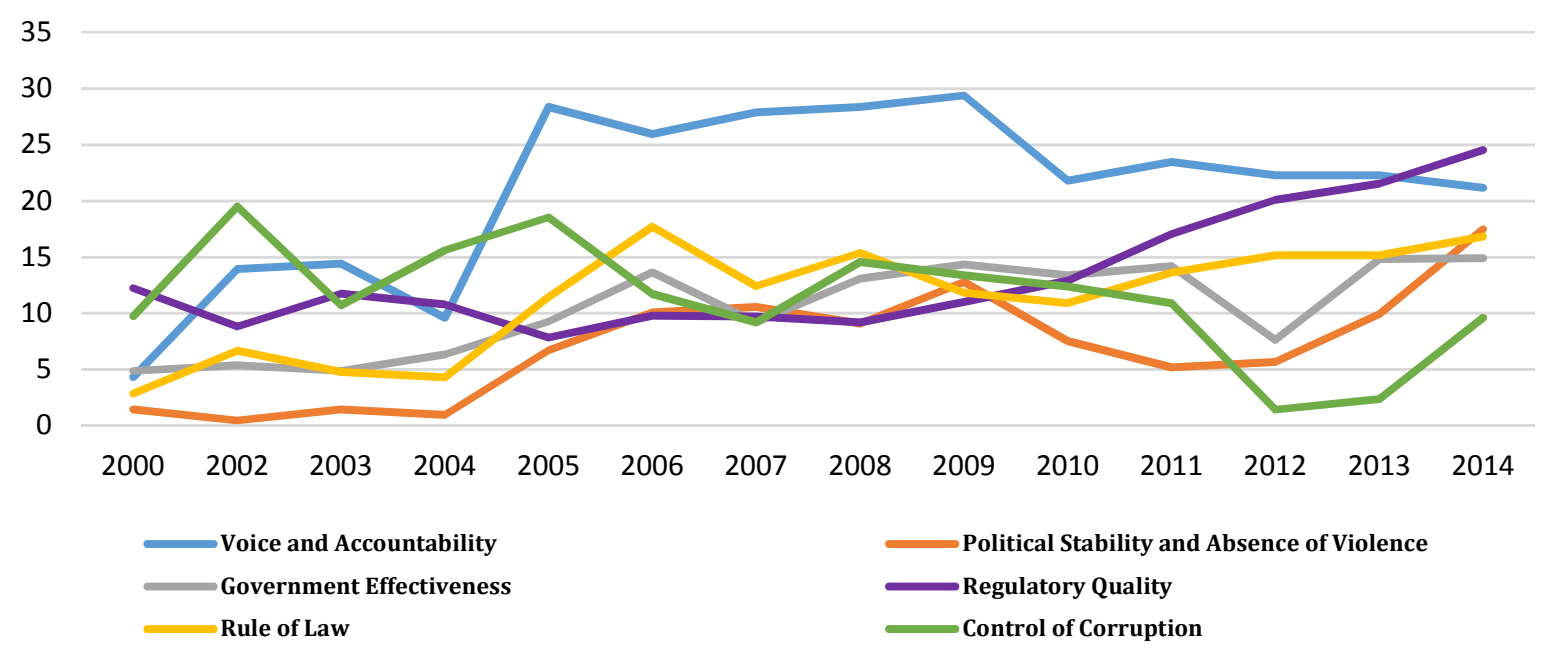

Source: World Governance Indicators

Figure IV.2: IIAG Index (score/100) from 2000 to 2014

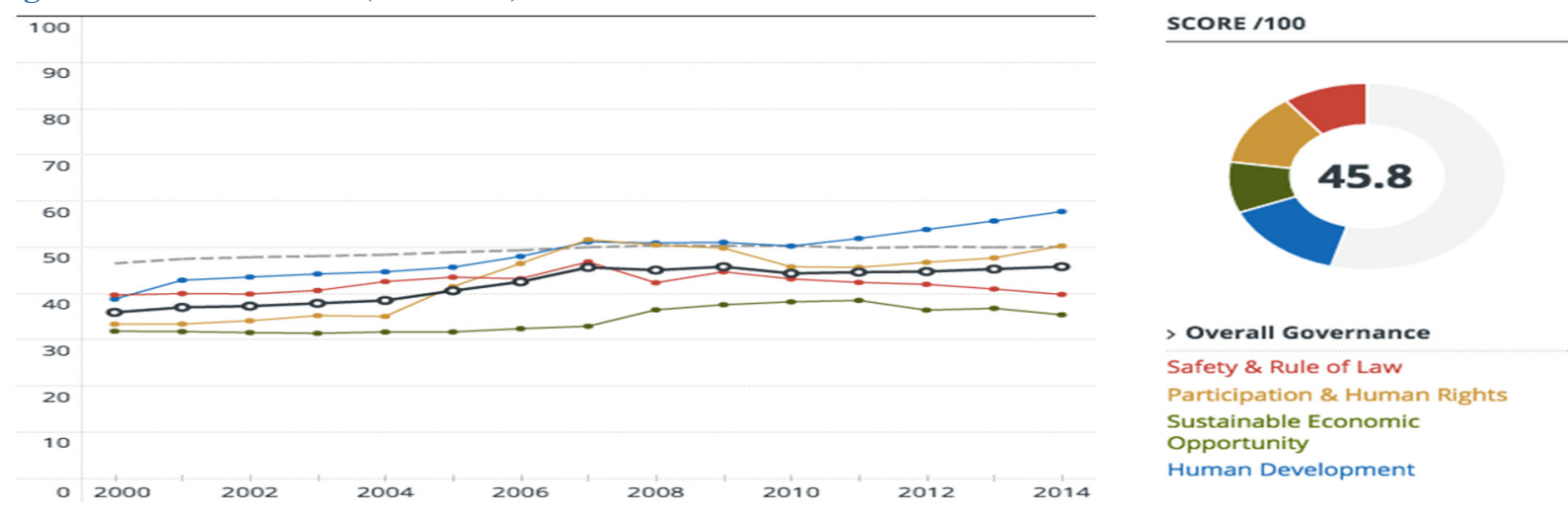

Notes: The gray line represents the African average and the black line overall governance. The other colored lines correspond to the governance indicators as shown on the right. The score on the right side is based on 2014 data. Source: Mo Ibrahim Foundation, IIAG

Quality of public sector management in Burundi is also low compared to Sub Sahara Africa. Though Burundi's score on the Country and Policy Institutional Assessment -a composite indicator of a country's policies and institutional arrangements- is at par with SubSahara Africa (3.3), Burundi is lagging behind on the "Public Sector Management and Institutions" cluster, pointing to weaknesses in governance and public sector capacity. Within this cluster, one dimension that is performing particularly poorly is the "Quality of Public Administration": the extent to which civilian central government staff is structured to design and implement government policy and deliver services effectively (score of 2.5 vs 2.9 in SSA Figure IV.3). Burundi also ranks below its peers on "Property Rights and Rule-Based Governance", an important impediment to private economic activity. 
Figure IV.3: Score on the items of the public sector management and institutions cluster, CPIA, Burundi and SSA

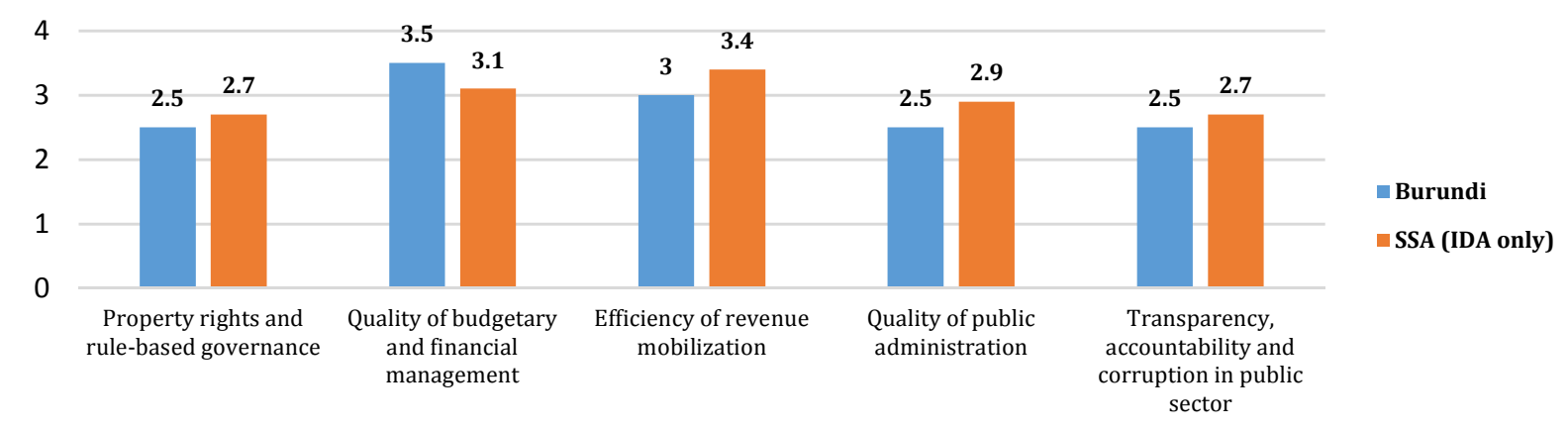

Source: World Development Indicators, 2015.

\section{Box IV.1}

\section{Security and Rule of Law} Identifying Burundi's binding constraint

Limited rule of law and lack of asset security have been identified as key binding constraints to investment and economic activity in Burundi. Wagner (2009) applies the Growth Diagnostic Approach (Hausmann, Rodrik, and Velasco, 2005) to identify the most binding constraint to investment and entrepreneurial activity (and hence growth) in Burundi. Gradually eliminating all potential constraints, Wagner (2009) identifies the limited rule of law and the lack of asset security as the most binding constraint to investment and economic activity. Lack of asset security and the rule of law prevents investors from securing the returns of their investments, which has adverse effects on investment levels through three different channels: (i) an expropriation channel, with investors anticipating that they will not be able to reap their rewards and as a result do not invest; (ii) a collateral channel, in which the high risk of asset destruction leads banks to ask for larger collateral as a protection against default, and (iii) an entrepreneurial migration effect, with businesses and entrepreneurs leaving the country.

\section{Voice and Accountability}

After a sharp increase in 2004, voice and accountably, which entails civil liberties and political rights, has remained stable at relatively higher levels compared to other governance indicators. In 2004, Burundi's political rights rating went up as a result of the agreement of one of two remaining rebel groups to join the government and participate in the political process. It increased further in 2006 following the 2005 national and local elections the first elections since 1993.

But the recent political climate in Burundi has raised concerns over a deterioration of political rights and civil liberties. The deterioration of political rights in the country worsened in 2010, due to increasing confrontations during election campaigns. Continuous clashes between the ruling party and opposition groups and human rights violations were reported, which contributed to further decrease in the political rights indicator (Figure IV.4). The decision of President Nkurunziza to run for a third term also affected the situation. Continued violence in the aftermath of the elections left at least 100 deaths. Following the failed attempted coup of Godefroid Niyombare, most independent media was shut down and a number of opposition figures left the country. 
The gap between regional average and Burundi's level of accountability has been widening over the years. According to Mo Ibrahim Foundation, Burundi scored 20.6 in 2014 for "accountability", the lowest since 2000 and lowest of all sub-aggregate indicators within the IIAG index (Figure IV.5). In the same year it ranked the position $44^{\text {th }}$ out of 54 countries in SubSaharan Africa. The score is mainly explained by increased corruption and weak institutions that failed to hold accountable some of those involved in crimes during the civil war (1993-2006). In addition, the justice system remains subject to political interference, creating a sense of impunity.

Figure IV.4: Civil Liberties and Political Rights ${ }^{35}$

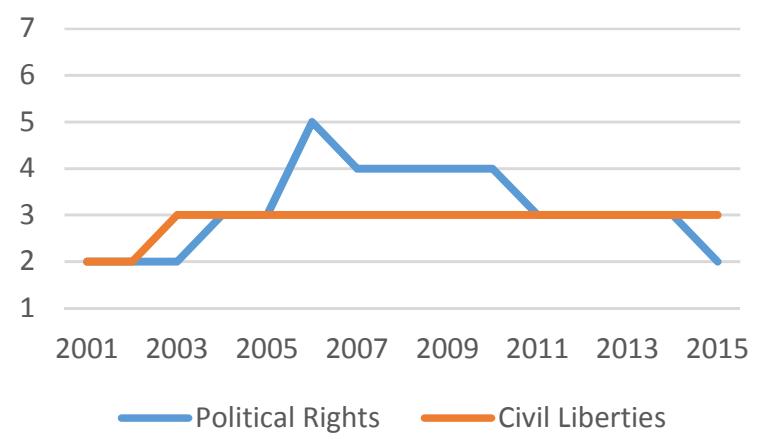

Source: Freedom House (2016)

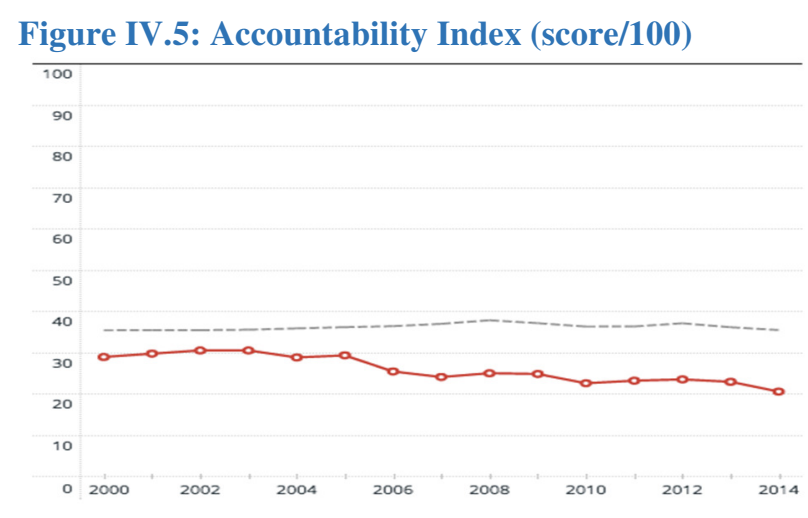

Note: The gray line represents the African average while the red line represents the Burundi average. Source: Mo Ibrahim Foundation, IIAG

\section{Political Stability and Absence of Violence}

Political stability and absence of violence is the worst preforming governance indicators as a result of 12 years of civil war. The civil war that broke out in 1994 following the assassination of president Melchior Ndadayeand sparked bursts of violence that left more than 300,000 deaths during the twelve years of war. After several power-sharing agreements, peace was finally achieved in 2006 when the last rebel group signed a ceasefire deal in Tanzania.

Security and stability improved from 2006, when the last rebel group decided to participate in the political process, until 2010 elections caused increased violence and repression. The decision of the National Liberation Front (FNL) to stop the guerrilla welfare and participate in a democratic government brought relative improvements of security in the country. As seen in Figure IV.6, Burundi's national security subsequently improved sharply. However, the 2010 election was followed by sporadic violence between supporters of the ruling party and opposition groups and further attacks by the FNL, followed by heightened tension with the opposition and increased restrictions on civil and press freedoms, all of which threatened the fragile political state achieved by post-conflict Burundi.

\footnotetext{
${ }^{35}$ Freedom House - rating goes from $1=$ worst to $7=$ best
} 
Figure IV.6: Burundi National Security (left) and Personal Security (right) versus African average

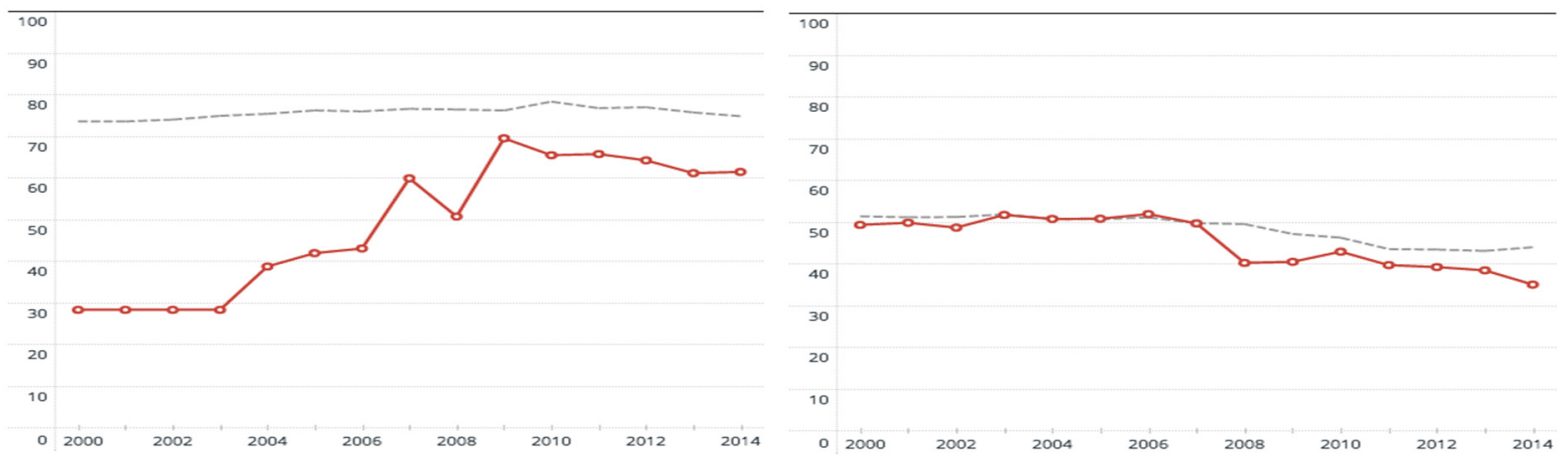

Note: The gray line represents the African average while the red line represents the Burundi average.

Source: Mo Ibrahim Foundation, IIAG

Following 2015 President Nkurunziza's decision to run for a third term, there was a resurgence of violence in the country. There have been a number of protests, as well as clashes between opposition and police forces and overall election violence since the president's announcement. International watchdogs and local NGOs have expressed concern about the increased violence and reported abuses. The Fragile State Index, developed by the think tank Fund for Peace, recently worsened its outlook for Burundi, ranking the country as the $18^{\text {th }}$ most fragile state in the world in 2015.

\section{Government Effectiveness}

Government effectiveness has shown slow and modest increases since 2000 with the exception of a sharp decline in 2012, where it ranked at the bottom of the Global Competitiveness Index. As seen in Figure IV.7, Burundi is at the bottom of the GCI, classified as one of the least competitive countries in the world. The government is mainly accountable to the ruling CNDD-FDD party, and other groups are hardly able to effectively influence policies or legislation.

Access to financing, corruption, and political instability are the drivers of Burundi's low scores in the Global Competitiveness Index. According to the World Economic Forum GCI 2012 report, Burundi did less to promote economic efficiency than any other nation in the world (Figure IV.7). Access to financing and corruption were by far the most problematic factors for doing business; the availability of financial services in Burundi was ranked among the worst in the world. In particular, Burundi suffers from unreliable police services - second worst out of 148 countries - and low scores for ethical behavior in Burundian businesses. The country also faces several challenges in the area of cash-management, public accounting, and external budget control that reduces its credibility to implement reforms and improve quality of services. 
Figure IV.7: GCI score (1-7) of African economies, 2007 compared with 2015

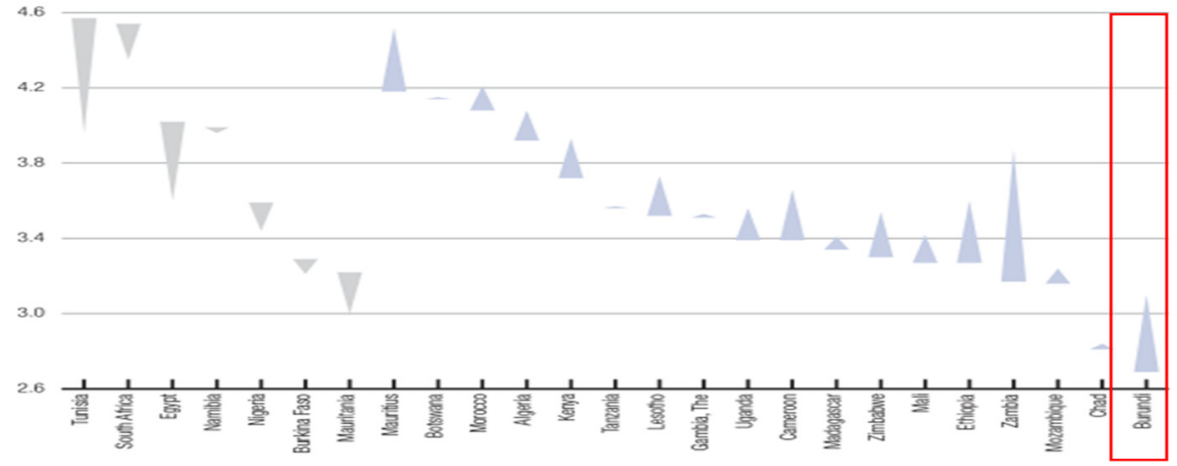

Source: World Economic Forum (2015), The Africa Competitiveness Report 2015.

Despite some improvements in education and health indicators over the last $\mathbf{1 5}$ years, levels and quality remain low. Even though primary and secondary enrolment has improved, the quality of education has declined since 2000, mostly because of the increase in the ratio of pupils to teachers in primary school (+23.5 percent between 2000 and 2014 according to UNESCO). Health, in general, performs better than education. Burundi has been successful in immunization campaigns and reducing child mortality. Nonetheless access to sanitation has not seen significant increments since 2000 and health facilities remain relatively precarious (WHO, 2014).

Figure IV.8: Evolution Education (left) and Health (right) in the IIAG Index

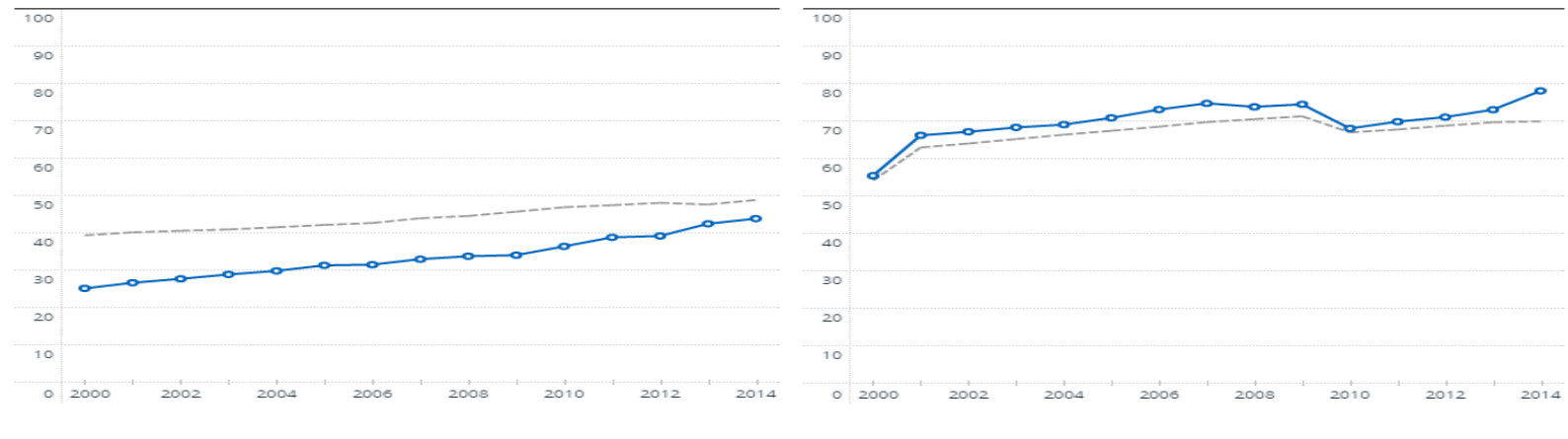

Note: The gray line are SSA averages and the Blue line represents Burundi averages

Source: Mo Ibrahim Foundation, IIAG.

\section{Regulatory Quality}

Regulatory quality started to improve significantly since 2009 due to several reforms that have resulted in a better business environment. According to the 2016 World Bank Doing Business report, in the last seven years Burundi has created new regulations to improve its business and investment environment. In particular, the country has greatly improved in the "starting a business" indicator (Figure IV.9). In 2013, the government made starting a business easier by eliminating requirements to have company documents notarized, to publish information on new companies in a journal, and to register new companies with the Ministry of Trade and Industry. Similarly, in 2014 the government allowed registration with the Ministry of Labour at a one-stop shop and sped up the process of obtaining a registration certificate. The country started 
to make adjustment in tax collection efficiency in 2011, replacing transactions tax with a value added tax. In 2014, the government reduced the corporate income tax rate.

However, access to credit and access to electricity still remain big challenges for "Doing Business" in the country. "Getting credit" has declined since 2013, making this indicator the worst performer (Figure IV.9). This is mainly explained by a weak financial system and political tensions. According to the Doing Business report, there is no fertile ground for investment in Burundi even when new regulations are in place. Electricity also remains a major issue. Even though Burundi eliminated the electricity utility's monopoly on the sale of materials needed for new connections in 2014 and dropped the processing fee for new connections, access to electricity remains difficult due to the poor state of infrastructure in the country. Out of the 14 indicators that IIAG index measures, "Infrastructure" has been the worst performance indicator after "accountability".

Figure IV.9: Doing Business indicators from 2010 to 2015

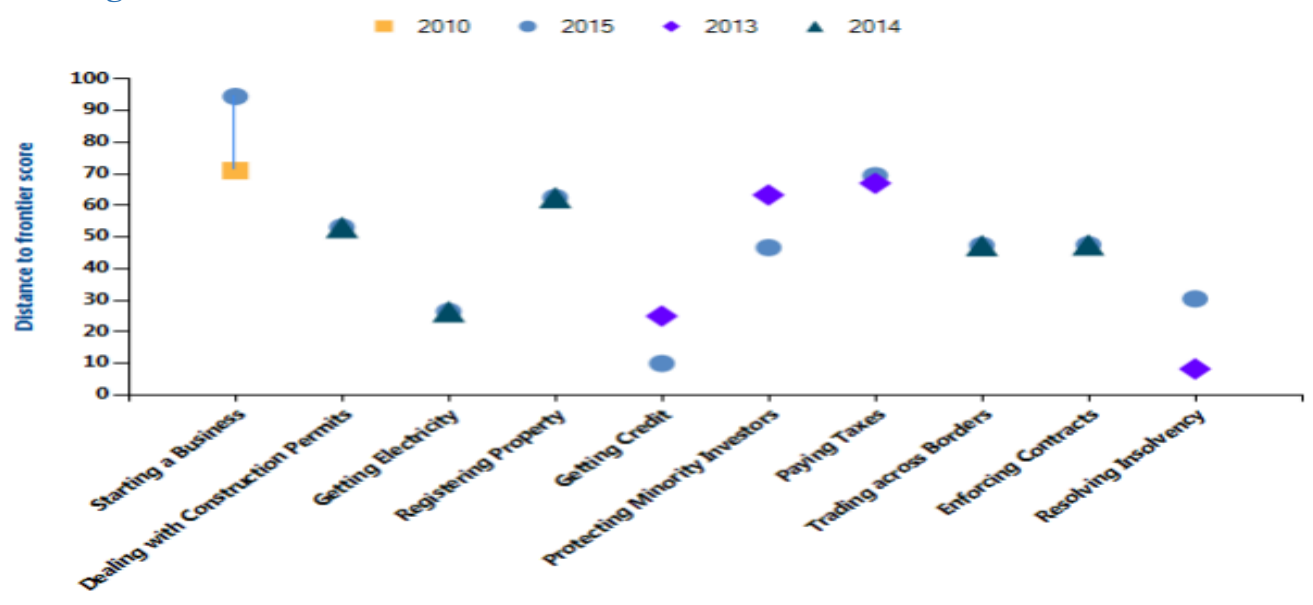

Source: Doing Business Report 2016, World Bank

\section{Rule of Law}

Few Burundians perceive the country's legal system to be fair, transparent or independent. After 2000 Arusha agreements there was high expectations of forming and implementing a transparent truth and reconciliation commission (TRC) that would hold those involved in different crimes during the civil war accountable. The process of drafting the law raised several concerns among civil society organizations and international NGOs, as did the commission's independence and impartiality, the likelihood of popular participation and the prospects for criminal justice (Taylor, 2013). In April 2014, Parliament passed a law creating a new truth and reconciliation commission to provide accountability for abuses committed between 1962 and 2008. The body has yet to begin its work, and many question the viability of the project given its lack of independence and 2015 renewed violence.

Ongoing judicial reform processes have failed to address legal and political barriers to the independence and effectiveness of the judiciary. These reforms included the construction of 
local tribunals and the clearing of backlogged decisions in court. While communities now have greater access to justice, the judiciary still lacks independence from political influence. It has been alleged that the ruling party has gained control of judicial nominations and that they have used the judicial system to legitimize the incarceration of opposition figures (Bouka, 2014). There have also been accusations that the TRC is unfairly balanced towards the ruling party, which could fuel conflict. As it currently stands, the justice system lacks independence and autonomy (IPSTC, 2014).

Figure IV.10: Rule of law score in the IIAG Index (2000-2014)

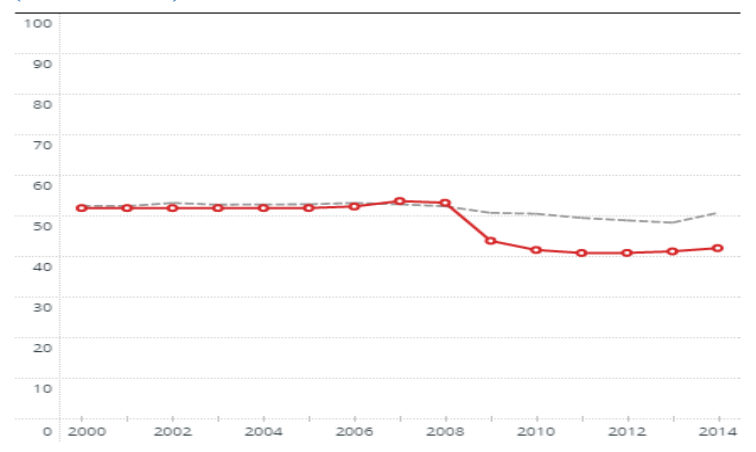

Note: The gray line represents SSA averages and the Red line represents Burundi averages.

Source: Mo Ibrahim Foundation, IIAG.
Figure IV.11: Disaggregated indicators of rule of law (2000-2014)

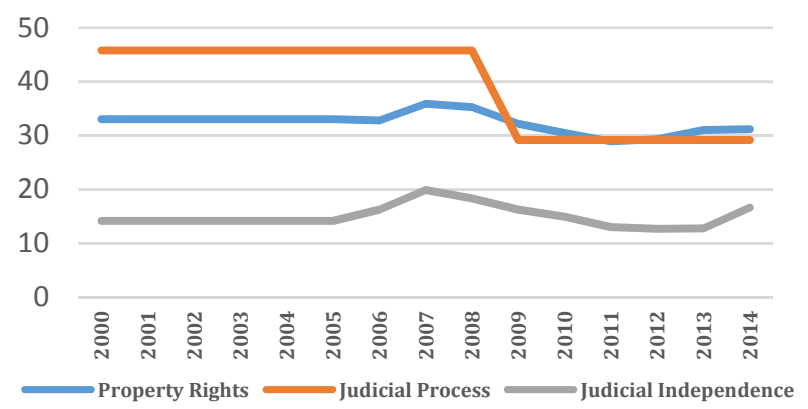

Rule of law in Burundi has further deteriorated after misconduct and irregularities following 2015 unrest. Freedom House has reported the intimidation of judges as well as impunity for police violence following the elections. There have also been accusations that protesters have been denied access to appropriate legal support. According to the United Nations, the death toll from the political unrest had reached more than 400 by the end of 2015 .

\section{Control of Corruption}

Burundi scores relatively low in transparency, accountability and corruption. In 2014 and 2015, Burundi was classified as the sixth most corrupt country in Sub-Saharan Africa, after Angola, Guinea-Bissau, Eritrea, South Sudan and Somalia. Nationally representative polls confirm the perception of high and rising corruption $^{36}: 66$ percent of respondents interviewed in Burundi in 2013 reported corruption had increased in the preceding two years, while seven percent thought it had decreased. People are more focused on the petty corruption they encounter in everyday life - the need to pay bribes to receive basic services, a job, and to obtain justice from the police. They are also worried about corrupted practices of high-level officials of the government. Corruption was perceived to be endemic among the judiciary, police, and public officials and civil servants (Global Corruption Barometer, 2013). The Corruption Perception Index (CPI) from Transparency International also shows a gradual deterioration of checks and

\footnotetext{
36 The latest round of the Global Corruption Barometer interviewed 114,000 persons in 107 countries. In Burundi, a national random sample of 1,000 individuals was interviewed in 2013.
} 
balances against corruption. When the country appeared in the CPI for the first time in 2006, it was ranked 130th out of 159 countries. Its position stabilized during the following two years (130th out of 163 in 2007 and 131st out of 179 in 2008) before declining to 172nd out of 182 countries in 2011. The Afrobarometer, another non-partisan poll that measures citizens' opinions on democracy and governance, confirms the importance of corruption (Figure IV.12). Corruption ranked third regarding the main problems of the country, and was more frequently mentioned than both famine and unemployment. ${ }^{37}$

Figure IV.12: Main problems the government should address identified by respondents (percentage)

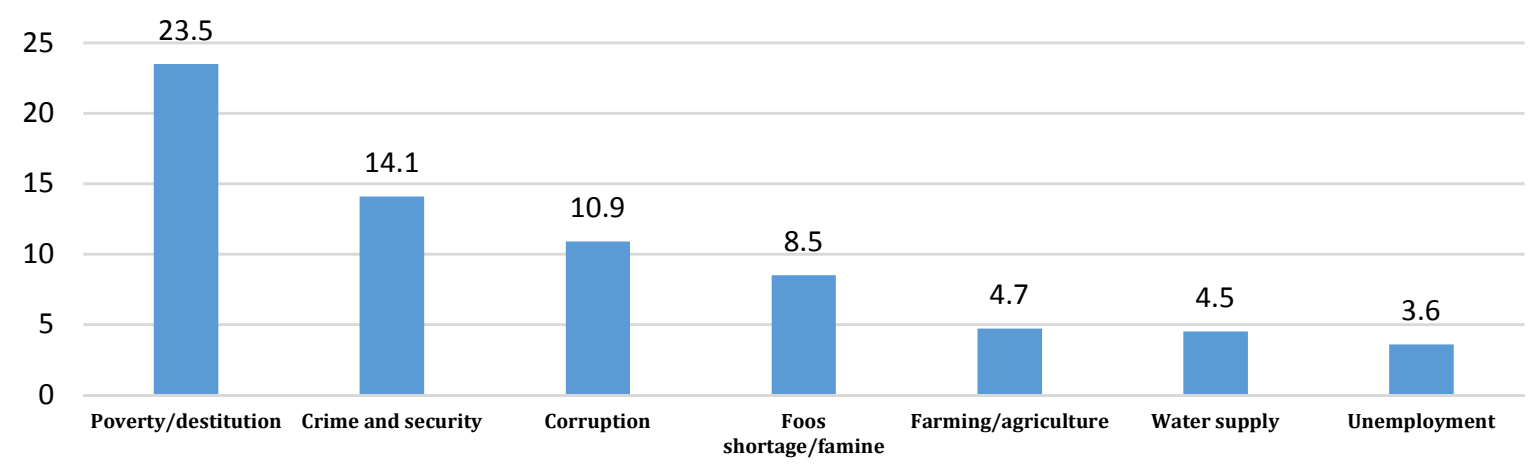

Source: Afrobarometer, 2012.

Since improved political stability in $\mathbf{2 0 0 5}$, the government has made efforts to project an image of intolerance against corruption, but corruption scandals remain frequent. The government made the fight against corruption and economic governance a priority in its 20052010 program, entitled "Priorities for Good Governance and Economic Revival". This program included a series of reforms on governance of the public sector and economy. In September 2006, a strategic framework for growth and fight against poverty was adopted with special emphasis on good governance (ICG, 2012). However, despite these efforts, frequent corruption cases have deteriorated Burundi's relationships with its development partners. The circumstances surrounding the sale of the presidential aircraft in 2006 led the World Bank to request an audit. In 2007, the Inter-petrol scandal broke, in which the public treasury lost more than $\$ 10$ million.

Despite a recent "zero tolerance campaign" launched by President Pierre Nkurunziza in 2011, success in the fight against corruption has remained limited. Again, the president's intentions were to improve Burundi's image in order to attract greater international financial support, which accounts for half of the annual budget of the country (IPSTC 2014). However, shortly after the launch of the campaign, several corruption scandals involving CNDD-FDD dignitaries and state officials led some to question the government's intentions.

37 The 2012 Afrobarometer interview 1,200 respondents in Burundi and was nationally representative. http://afrobarometer.org/countries/burundi-0. 


\section{Impact of Weak Governance on Poverty and Welfare}

\section{There are multiple links between weak institutional capacity, violence and poverty}

Violence is linked through underlying institutional weaknesses and limited welfare levels. Research supports the finding that states that weak institutions and governance are associated with higher risk of violence. Fearon and Walter (2010) tested whether the six indicators from the WGI correlate with risk of civil conflict. They found that countries with good governance are much less likely than their peers to have suffered from civil conflict or high murder rates in 2000-05. In addition, people in countries trapped in recurrent violence and poor governance are more than twice as likely to be malnourished, three times as likely to miss primary school and almost twice as likely to die in infancy as people in other developing countries. They are also more vulnerable to shocks. ${ }^{38}$

Violent conflict and fragility impede social and economic development. Next to the most visible and dramatic human effects, violence and fragility keep people from going about their usual activities, keep children out of school, keep investors out of the country, and stunt development prospects in general. The inexorable link between violence and underdevelopment has been well established: the poorest countries are at the highest risk of violent conflict, and violent conflict tends to further deepen the social and economic malaise in those countries. Violent conflict, or civil war, is indeed "development in reverse." 39

The devastating consequences of fragility on poverty are obvious. The average incidence of extreme poverty in fragile states is 40 percent, more than two and half times that of the global average. ${ }^{40}$ While solid progress on global poverty has been achieved over the past two decades, fragile countries have witnessed little progress. The impact of conflict is illustrated by Africa's dual experience since the mid-1990s: between 1996 and 2012, poverty in non-fragile economies in Africa decreased by 24 percentage points, double the reduction seen in fragile countries. Extreme poverty in fragile countries in Africa now stands at 53 percent, more than 20 percentage points higher than in stable countries (32 percent). ${ }^{41}$

Poverty is on the decline for much of the world, but countries affected by violence, like Burundi, are lagging behind. As a rule of thumb, the WDR 2011 concludes that countries that suffer from recurrent violence lose almost 1 percent in poverty reduction each year. In addition they find that for every three years that a country is affected by major violence, poverty reduction lags behind by 2.7 percent, on average. The report also gathers empirical evidence that indicates that peaceful countries are managing to escape poverty, which is becoming concentrated in countries marked by civil war, ethnic conflict and organized crime. There is also reverse causality between fragility and poverty. Perhaps countries are violent because they are

\footnotetext{
${ }^{38}$ WDR 2011

${ }^{39}$ World Bank, 2003 referenced in WRD 2011.

${ }^{40}$ World Bank, 2014.

${ }^{41}$ World Bank, 2015a.
} 
poor, rather than poor because they are violent. Growth would presumably reduce the incentive to fight. To test the importance of wealth, the authors of the WDR 2011 asked why young people joined gangs and rebel groups in different countries. The biggest share, about two-fifths, cited unemployment as the main reason; only a tenth said belief in the cause.

Figure IV.13: Gap in poverty between countries affected by violence and those not experiencing violence

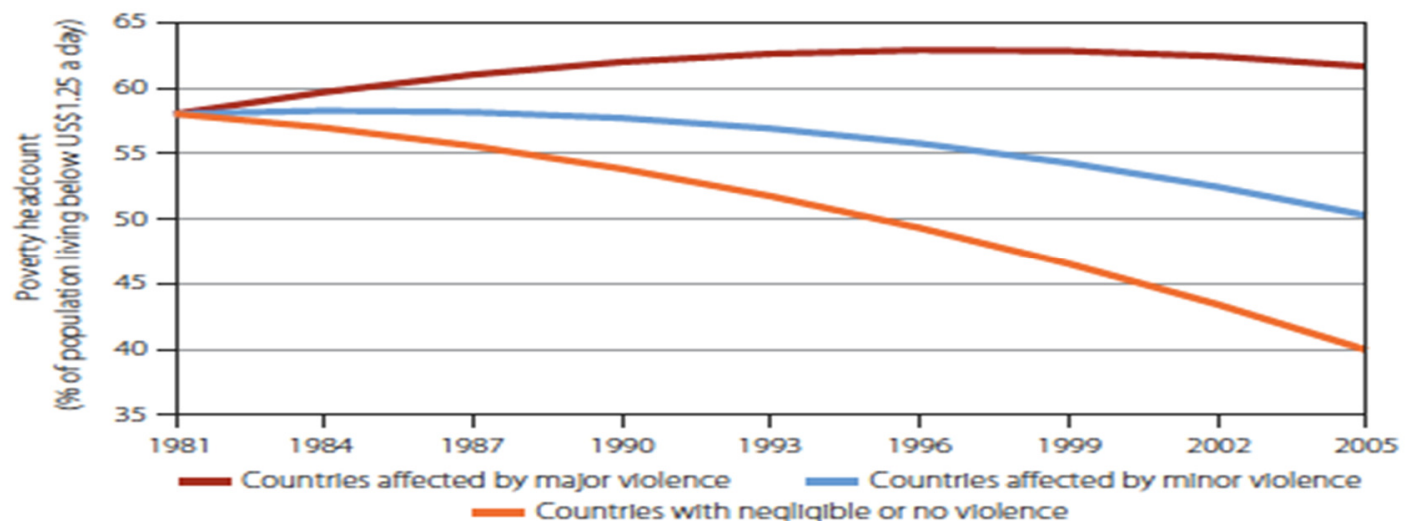

Source: WDR 2011

Interactions between economic and social 'stresses' and a weak institutional capacity to manage them exacerbate conflict and poverty

A scarcity of resources such as land, exacerbated by population pressure, environmental degradation, and inequitable resource allocation leads to poverty and conflict. In Burundi, there is a lack of cultivable land, and both rural unemployment and underemployment are high. Those affected by these constraints are subject to manipulation by outsiders with a vested interest in generating and prolonging civil conflict. Conflict in Burundi is typically presented as purely ethnic, but the unequal distribution of resources and a rural population struggling for subsistence land drives poor governance and fragility. In addition, inefficient farming and stock-raising that promote environmental degradation led to unemployment in the country. ${ }^{42}$ Poor institutional capacities create instability and in turn, disrupt production system, destroying jobs and infrastructure.

Credible policies and institutional capacity give states the power to overcome armed threats and maintain stability. If the country's formal institutions fail to deliver local justice, education or employment opportunities, individuals have greater incentives to turn to non-state groups even if they are violent. Conversely, an accountable government and strong institutions can avoid human right abuses that often fuel grievances and create incentives for violent opposition. In Burundi, agreements among elites to end fighting in 2005 did not result in a relevant transformation of state institutions and better governance outcomes. Given the limited improvements on institutional capacity, Burundi remains vulnerable to the same stresses that

${ }^{42}$ USAID, 2006 
induce violence in the first place. In these circumstances, any stressors that shift the balance of power-such as economic or demographic pressure- risk further violence.

Burundi needs to expand and build on the limited improvements on governance since 2005 to avoid further conflict and promote development

Despite improvements on government's capacity to implement public policies, corruption and overall governance remained weak during the post-war decade, and none of the key risk factors for further conflict have been tackled. As mentioned in the Country Economic Memorandum, corruption and low government capacity have been critical barriers to post-war development in Burundi. The pre-1993 institutional failure characterized by concentration of political and economic power in the hands of an ethno-regional clan has given way to a failure of government to implement policies effectively and provide decent basic services to its citizens. Since 2005, economic growth has been volatile and weak (was below 1 percent for five of the past 10 years) and did not result in any substantial improvements in living standards. Poverty remains massive at about 70 percent in rural areas. ${ }^{43}$ Fertility rates have stayed persistently high at 6.4 children per woman, putting pressure on already strained household budgets, and hunger levels are alarming. ${ }^{44}$ Most youth remain trapped in low productivity agriculture without much perspective for a better life. In addition, many argue that some of the crimes committed during the successive crises have gone unpunished. Overall impunity is high, and the judicial system is widely perceived to be unfair and corrupt. All this is fertile breeding ground for a relapse into conflict.

Quickly restoring people's confidence in government is key given 2015 renewed violence. Although the signs are not promising, avoiding a relapse into conflict ought to be the main priority for the government and all stakeholders. The 1993-2006 civil war had devastating impacts on health, education, and living standards, which are likely to persist in the long run. A relapse into conflict would set Burundi back even further, and would delay yet again the process of development and institution-building that the country needs. Burundi will not be able to experience any sustainable development as long as the conflict risk factors are not addressed and peace and stability are wanting. The government needs to signal good intentions by making credible appointments and policies, and provide some quick results, like new jobs.

\footnotetext{
${ }^{43}$ Republic of Burundi, 2015.

${ }^{44}$ According to the International Food Policy Research Institute (IFPRI), Burundi has the most alarming hunger levels in the world (Global Hunger Index, 2014).
} 


\section{Chapter V - Employment in Formal and Informal Economy}

\section{Key Messages}

- Burundi's economy is almost exclusively informal and heavily concentrated in the agricultural sector.

- The few non-agricultural formal activities of the country are too scarce to have a significant impact over the labor market.

- Young men have initiated the recent move towards non-farming activities, but the effect remains slow.

Burundi lacks the prerequisites for productive transformation and jobs creation. The fragility of the economy and governance and institution weaknesses are holding back private investment and productive economic activity. Consequently, most of the population rely on agriculture and nonagriculture informal jobs and are likely to continue working in these sectors for the foreseeable future. The present and following chapters examine the structure of the labor market and agricultural sector and investigate the main bottlenecks, adding further to governance and institutional failures that are hampering poverty reduction.

The present chapter is built on the 2014 Household Living Conditions Survey (ECVMB 2014) that informs very thoroughly on the state of the labor market in Burundi. The difficulty arises from the distinction between individual workers and units of production or enterprises. As it is the case in most developing countries characterized by a high degree of informality, the frontier is always blurry and many individuals are accounted as self-account enterprises. The analysis presented in the first and second sections of the chapter will make a clear distinction between jobs held by individual workers and UPI - Informal Unit of Production.

The chapter starts by sketching the main features of employment in Burundi. The prevalence of agriculture and informality in the country are the two main features. It then proceeds by examining specifically the state of informal employment in non-farming enterprises. The last section gives an analytical overview of changes in the employment situation and dynamics in Burundi over the past 20 years.

\section{A snapshot of employment in Burundi}

\section{A young, small, and largely unskilled labor force}

Burundi's labor force is young and exceptionally unskilled. In 2014, half of the labor force was between 15 and 34 years old and three quarters was younger than 46 (Figure V.1). Education of the labor force is low: over half of the labor force (56 percent) never went to school, and a mere six percent completed more than primary school (Figure V.2). The fraction of the labor 
force that completed secondary education or more is negligible (1.6 percent). The situation is even direr for women: 93 percent of female labor force participants did not complete primary.

Figure V.1: Burundi's Labor Force by Age (percentage of Total Workforce)

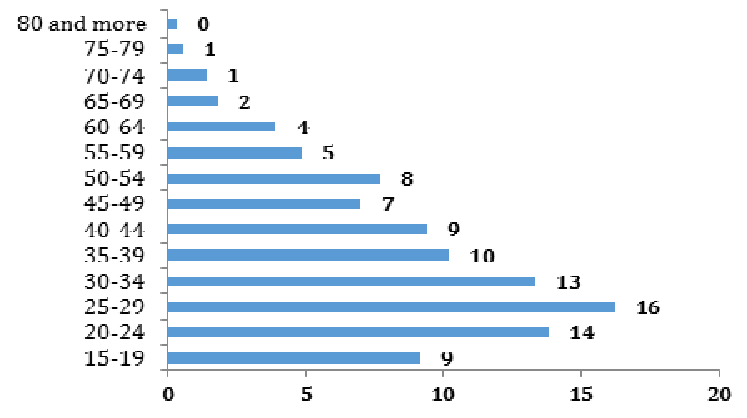

Figure V.2: Burundi's Labor Force by Education Level (percentages)

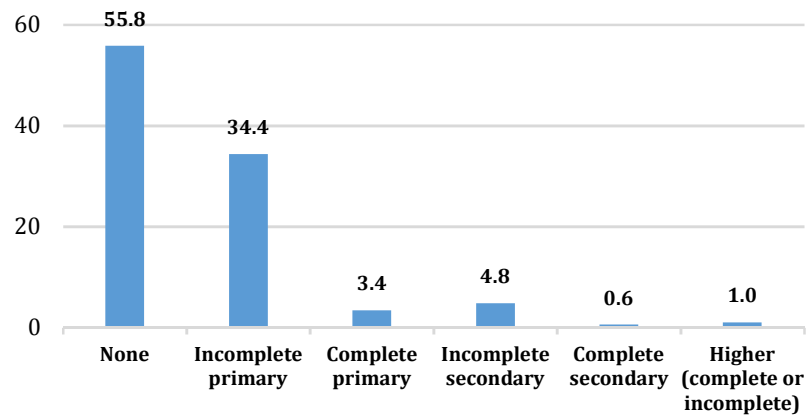

Source: ECVMB, 2013-14.

In relative terms, the labor force in Burundi is small. Only 40 percent of the total population is in the labor force, and the working-age population (15+) accounts for slightly more than half (51.7 percent) of total population. Persistent high fertility levels continuously increase the weight of the non-working age population and can explain the small share of the labor force: the 2010 DHS estimated the total fertility rate at 6.4 children per woman, down only marginally from 6.9 in 1987.

Figure V.3: A snapshot of jobs in Burundi (Number of Workers by Job Category, 2014)

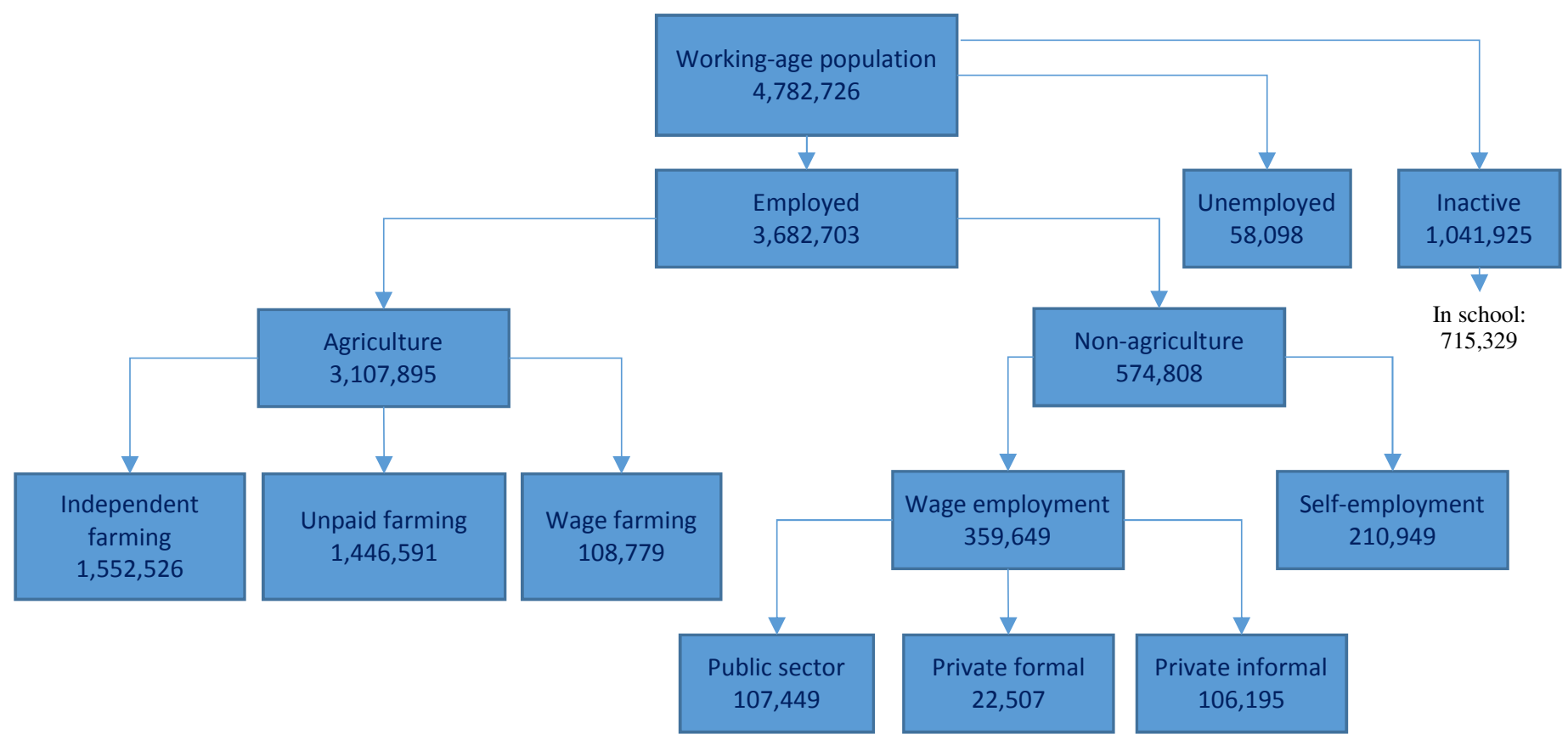

Source: ECVMB, 2013-14. Note: The number of wage workers in the public, private formal and private informal sector does not add up to the total number of wage workers. More than 100,000 wage workers in the private sector do not know whether the business employing them is formal or informal. 


\section{The sectoral composition of the economy shows a high prevalence of agriculture}

The bulk of Burundi's working-age adults are employed in agriculture. Out of the 3.7 million Burundians who were employed during the 2014 ECVMB, 3.1 million had their main job in agriculture, putting agriculture's share of employment at 86.3 percent (Figure V.4). The services sector represented 6.4 percent of employment while trade and industry sectors combined accounted for 7.3 percent of it.

Within agriculture, independent farming and unpaid family farming are the dominant form of employment. Independent farming (people who work on their own farm and who consider themselves the main decision-maker on the farm) and unpaid family farming (people who work as unpaid laborers on their household's farm - mainly women and youth) provide main employment to a roughly similar number of people (about 1.5 million each). Overall, independent farming accounts for 42.2 percent of total employment, while unpaid family farming accounts for 39.3 percent (Figure V.5). Wage farming is relatively rare (at least as main employment), providing main employment to three percent of Burundians.

Figure V.4: Employment Share by Sector (Percentages)

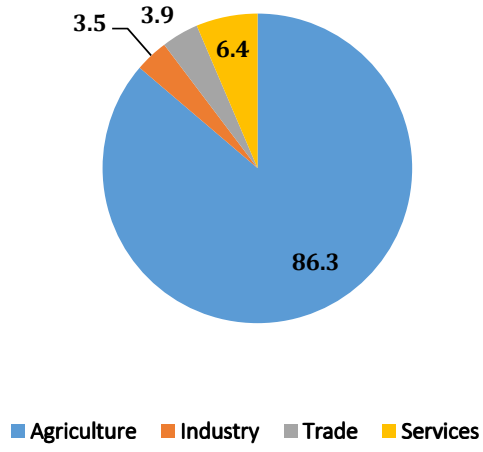

Figure V.5: Employment Share by Job Category (Percentages)

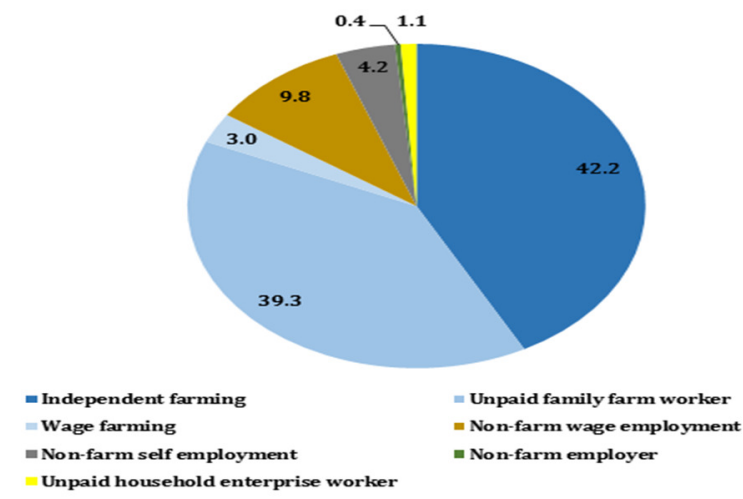

Source: ECVMB, 2013-14.

Approximately 575,000 Burundians - 15 percent of the labor force- have their main employment in the non-farm sector. Wage work is the dominant type of employment in the non-farm sector, accounting for 60 percent of non-farm employment and 10 percent of employment overall (Figure V.5). Non-farm self-employment is the main occupation for four percent of workers, while the fraction of people with a main job as employer (0.4 percent) or unpaid household enterprise worker ( 1 percent) is marginal. The public sector accounts for almost one third of wage employment in the non-farm sector. The private formal sector is negligible, providing main employment to a mere 22,500 workers ( 0.6 percent of overall 
employment). The private informal sector provides wage employment to approximately 106,000 workers. ${ }^{45}$

As in most low-income agrarian countries, unemployment in Burundi is low. In the week preceding the survey, only 1.6 percent of the labor force was not employed and actively looking for a job. Given the dominance of agriculture, underemployment seems to be a key issue, but the survey does not allow calculating the underemployment rate. ${ }^{46}$

\section{Women and youth are particularly disadvantaged}

Women in Burundi are almost exclusively employed in agriculture. While the share of men and women in the informal sector is similar (93.8 percent and 97.5 percent respectively), strong discrepancies exist between genders regarding the nature and status of employment. Over 92 percent of women work the fields as their main occupation, compared to 75 percent of men (Figure V.6), and less than four percent has a wage job in the non-farm sector (Table V.1). Even within agriculture, women are overrepresented in the less desirable occupations: two thirds of women have their main job in unpaid family farming, compared to nine percent of men. Women are less likely than men to be independent farmers (to be the "boss" of a family farm) and also less likely to be self-employed outside agriculture.

Table V.1: Employment by Gender and Employment Status (Employment share by job category, 2014)

\begin{tabular}{llll}
\hline \hline Type of employment & Overall & Men & Women \\
\hline Agriculture & 84.5 & 75.3 & 92.1 \\
Independent farming & 42.2 & 61.8 & 26.1 \\
Unpaid family farm worker & 39.3 & 9.3 & 64.1 \\
Wage farming & 3.0 & 4.2 & 1.9 \\
\hline Non-agriculture & 15.5 & 24.7 & 7.9 \\
Non-farm wage employment & 9.8 & 17.1 & 3.7 \\
Non-farm self-employment & 4.2 & 6.3 & 2.4 \\
Non-farm employer & 0.4 & 0.8 & 0.1 \\
Unpaid household enterprise & 1.1 & 0.5 & 1.7 \\
worker & & & \\
\hline \hline
\end{tabular}

Source: ECVMB, 2013-14.
Figure V.6: Employment by Gender and Sector (Percentages)

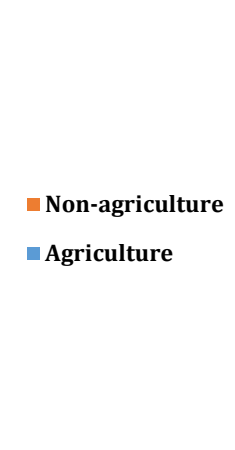

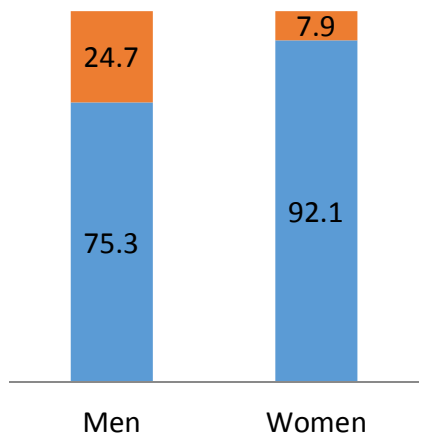

Youths in Burundi are surprisingly similar to their parents. The fraction of youths (15-30) in Burundi with a main job in agriculture (83 percent) is not substantially lower than the fraction of "older" workers (85 percent), hinting at stagnation and inertia in the "labor market" (Table V.2). In comparison, 37 percent of the youths in Rwanda have their main jobs in the non-farm sector. Unpaid work on the family farm is the main employer for youths in Burundi, highlighting the dire economic situation of young workers.

\footnotetext{
${ }^{45}$ The private formal sector is defined as businesses that pay taxes, have a tax identification number (NIF), and are registered in the Business Register. The informal private sector is defined as businesses that do not have a NIF and are not registered in the Business Register.

${ }^{46}$ According to the ILO, a person is considered underemployed if s/he (a) is employed, (b) during a reference period, was willing to work additional hours, and (c) during the reference period, was working fewer hours than the nationally-defined threshold. While the survey recorded actual hours worked, it did not record whether the person was willing to work more.
} 
Table V.2: Employment by Age Category and Employment Status (Employment share by job category, 2014)

\begin{tabular}{lcc}
\hline \hline Type of employment & Older & Youth (15-30) \\
\hline Agriculture & 85.3 & 83.3 \\
Independent farming & 52.5 & 25.8 \\
Unpaid family farm worker & 30.4 & 53.6 \\
Wage farming & 2.4 & 3.9 \\
\hline Non-agriculture & 14.8 & 16.7 \\
Non-farm wage employment & 9.0 & 11.0 \\
Non-farm self-employment & 4.4 & 3.8 \\
Non-farm employer & 0.5 & 0.3 \\
Unpaid household enterprise worker & 0.9 & 1.6 \\
\hline \hline
\end{tabular}

Source: ECVMB, 2013-14.
Figure V.7: Employment by Age Category (Percentages)

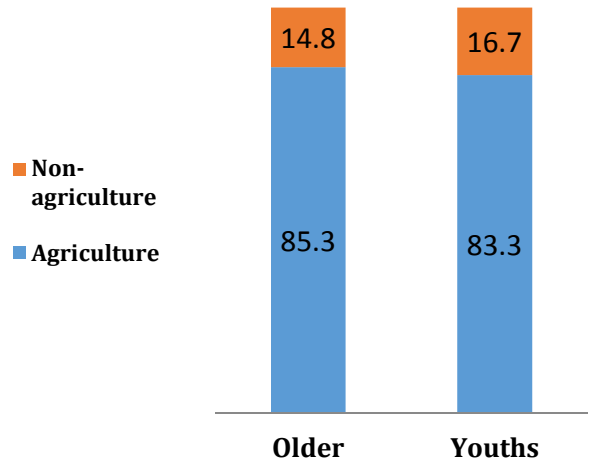

Overall, women and youth are overrepresented in lower status and unpaid employment. Respectively, women and youth carry out 90 and 57 percent of unpaid jobs. In contrast, the public sector -arguably the most attractive sector in Burundi- employs substantially more men than women (Figure V.8). As shown by Figure V.9, women in agriculture are severely disadvantaged compared to men regarding the status of employment. While only 9 percent of Burundi's male workers are employment as unpaid family workers, this status concerns 64 percent of all the working women in the country. The situation of the youths compared to older workers is comparable. The share of youths - that is age 15-30 - working as unpaid family farm workers stands at 54 percent while such an employment status only concerns 30 percent of the older workers.

Figure V.8: Nature of Employment by Gender (Percentage)

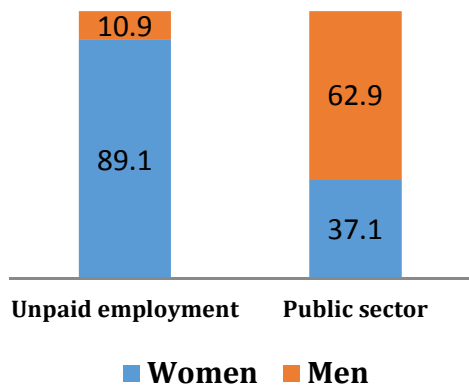

Figure V.9: Employment by Employment Status, Gender and Age Category (Percentage)

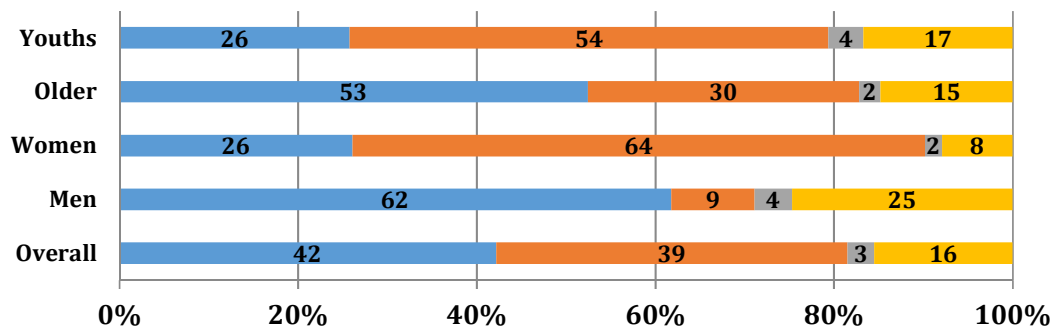

- Independent farming $\square$ Unpaid family farm worker $\backsim$ Wage farming $\backsim$ Non Agriculture

Source: ECVMB, 2013-14.

\section{Non-agricultural workers are more likely to have several jobs}

Only a relatively small percentage of workers in Burundi (7 percent) have more than one job. Workers with a main job outside agriculture are almost three times more likely to have a secondary job compare to agricultural workers. Workers engaged in unpaid family farming- 
mostly women- are least likely to have several jobs, while self-employed workers and employers in the non-farm sector are most likely to have secondary jobs. Men (12 percent) are significantly more likely to have secondary jobs than women (three percent).

Workers with several jobs tend to diversify. Of all agricultural workers who have a secondary job, 84 percent have a secondary job in the non-farm sector, mainly in self-employment (56 percent). Workers with a main job in non-farming are more likely to have their secondary job in farming (64 percent -Figure V.10), mainly independent farming (50 percent).

Table V.3: Share of workers with a secondary job in and outside of agriculture (percentage)

\begin{tabular}{cc}
\hline Main employment & $\begin{array}{c}\text { \% of workers with } \\
\text { several jobs }\end{array}$ \\
\hline Agriculture & 5.9 \\
Independent farming & 8.9 \\
Unpaid family farm worker & 2.5 \\
Wage farming & 7.6 \\
\hline Non-agriculture & 15.1 \\
Non-farm wage employment & 13 \\
Non-farm self-employment & 20.5 \\
Non-farm employer & 33.9 \\
Unpaid household enterprise worker & 7.3 \\
\hline Total & 7.3 \\
\hline \hline
\end{tabular}

Source: ECVMB, 2013-14. World Bank staff calculations.
Figure V.10: Nature of Secondary Job (percentage)

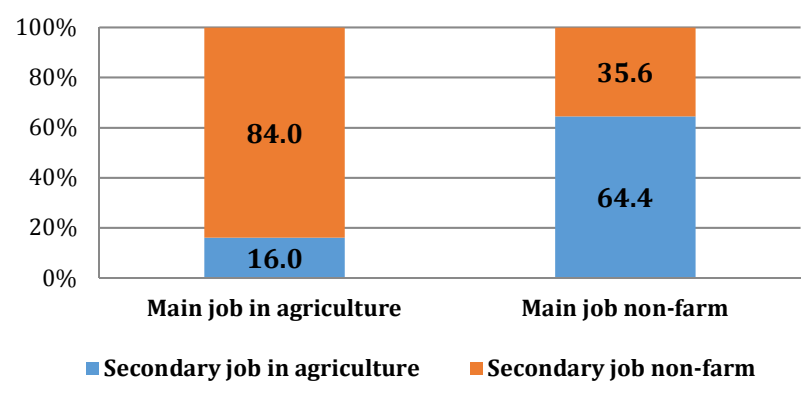

Farm workers are on average older and less educated, but there are considerable variations across employment categories

Next to being more likely to be female, farm workers are older and less educated compared to workers in the non-farm sector. At 37, farm workers are on average three years older than non-farm workers. Farmers are largely uneducated: over 60 percent never went to school, and 95 percent did not complete primary education (Figure V.11). Although workers outside agriculture are more educated, their education levels are also low: two-thirds of non-farm workers did not complete primary school, and a mere eight percent completed secondary school or more.

Figure V.11: Farm workers are largely uneducated (Share of workers by educational attainment, farm and non-farm)

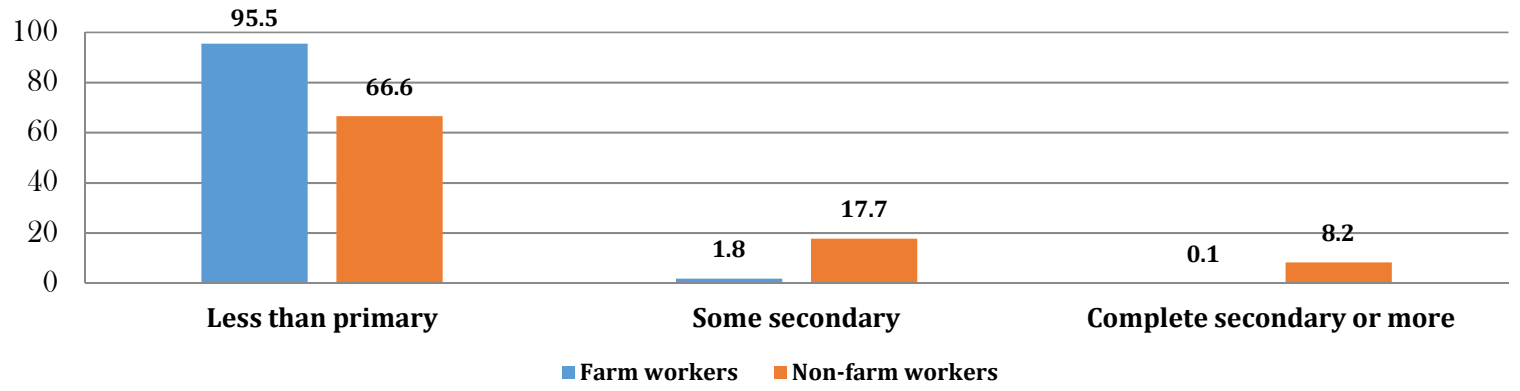

Source: ECVMB, 2014. World Bank staff calculations 
The different characteristics of farm and non-farm workers mask considerable variation across specific employment categories. While independent farmers are by far the oldest type of workers (42 years), unpaid family farmers and wage farmers are on average younger than workers in the non-farm sector (underscoring the precarious employment condition of rural youths). Women are heavily underrepresented in the non-farm sector (except for the category of "unpaid family workers"), highlighting again the disadvantaged employment position of women (Table V.4). In particular, only 20 percent of non-farm wage jobs -usually among the best employment categories in low-income African countries- are held by women. There is also substantial variation in education: while farm workers are on average less educated than nonfarm workers, those in non-agricultural self-employment are not discernibly more educated than farmers. Wage employees in the non-farm sector and -to a lesser extent- employers are the only ones with relatively high education levels (although educational attainment remains low in absolute terms).

Table V.4: Worker characteristics by employment category (percentage)

\begin{tabular}{lccccc}
\hline \hline Type of employment & $\begin{array}{c}\text { Age } \\
\text { (years) }\end{array}$ & Female & Urban & $\begin{array}{c}\text { Incomplete } \\
\text { primary or less }\end{array}$ & $\begin{array}{c}\text { More than } \\
\text { primary }\end{array}$ \\
\hline Independent farming & 42.2 & 33.9 & 2.4 & 95.6 & 1.8 \\
Unpaid family farm worker & 31.7 & 89.3 & 1.8 & 95.5 & 2.0 \\
Wage farming & 31.8 & 35.4 & 8.4 & 94.3 & 1.3 \\
Non-farm wage employment & 33.3 & 20.9 & 43.3 & 58.1 & 34.7 \\
Non-farm self-employment & 36.7 & 31.4 & 36.2 & 80.0 & 1.3 \\
Non-farm employer & 35.1 & 20.2 & 43.2 & 64.3 & 10.1 \\
Unpaid household enterprise worker & 29.9 & 82.1 & 16.3 & 92.4 & 6.8 \\
\hline \hline
\end{tabular}

Source: ECVMB, 2013-14. World Bank staff calculations.

Within the non-farm wage employment category, there is a large difference between public and private sector workers. Public sector workers are on average older (39 years compared to 31 in the private sector) and substantially more educated (70 percent completed secondary or more, compared to 10 percent for private sector workers). Women are also better represented in the public sector: 37 percent of public sector employees are women, compared to only 14 percent in the private sector.

\section{Informal employment is prevalent across all sectors}

Informal workers dominate across all sectors, accounting for 95.8 percent of the total number of jobs. Informality is almost the norm in agriculture with 99.4 percent of the agricultural jobs reported as informal (Figure V.12). The industrial and trade sectors are also heavily dominated by informal employment with respectively 86.1 and 91.4 percent of jobs reported as informal. The situation is more balanced regarding the service sector with 44.2 percent of the jobs reported as formal employment. 
Figure V.12: Formal and Informal Employment by Sector (percentage)

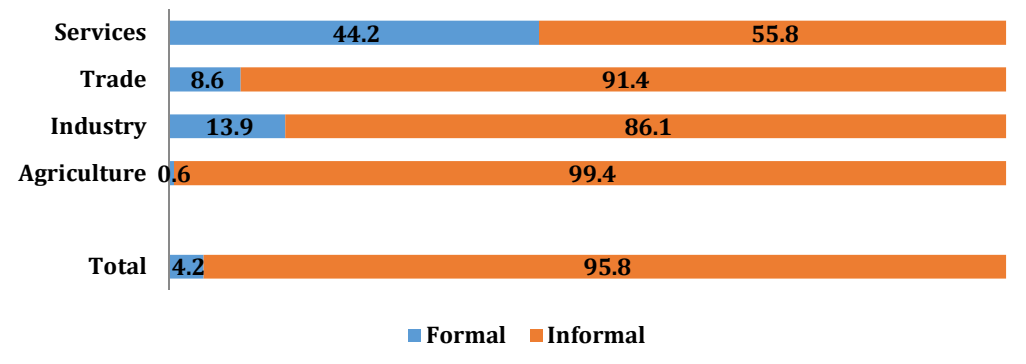

Figure V.13: Formal and Informal

Enterprises (percentage)

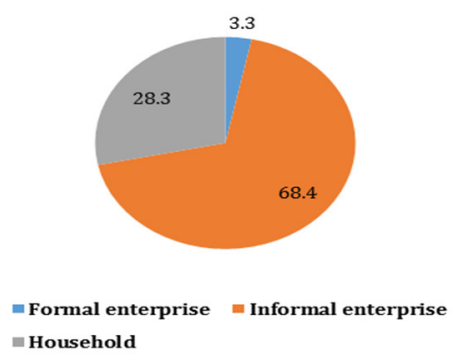

Source: ECVMB, 2013-14. World Bank staff calculations

Overall, agricultural informal employment dominates, while services account for the majority of formal employment. With 99.4 percent of agricultural jobs accounted as informal, the dominance of agriculture over Burundi's economy, and its large size in absolute numbers of agricultural workers, translates into 89.5 percent of informal workers are in the agricultural sector. For the same reason, 12.8 percent of formal jobs are taking place in the agricultural sector (Figure V.13). Furthermore, formal employment is heavily dominated by services, which account for 67.7 percent of the total formal employment. However, the impact of the service sector should be considered in light of its small share in Burundi's total employment - the services sector only accounts for 6.4 percent of Burundi's employment.

Figure V.14: Sectoral Composition of Formal and Informal Employment (percentage)

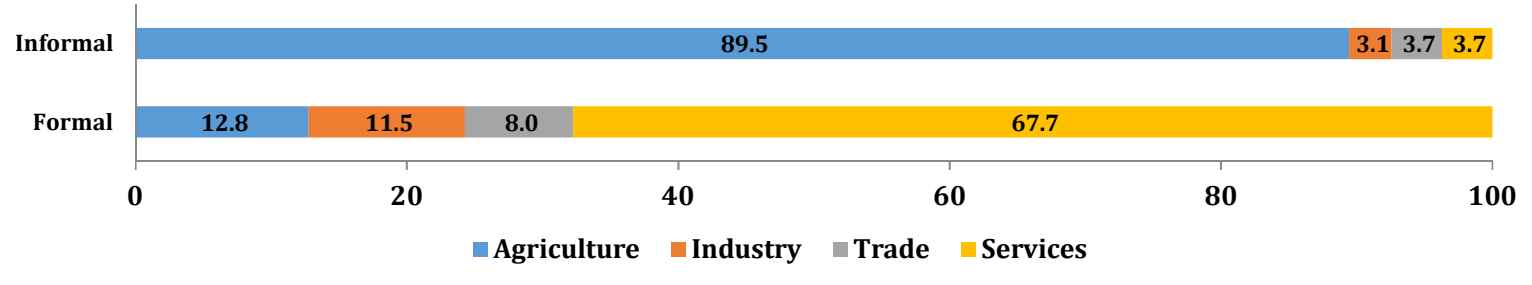

Source: ECVMB, 2014. World Bank staff calculations

Informality is also high at the enterprise level with estimates showing that informal enterprises undertake the major part of job creation. 68.4 percent of the jobs available in Burundi depended from informal unit of production (UPI). Jobs undertaken in private household (e.g. paid domestic workers, unpaid household family worker, etc.) accounted for 28.3 percent. Not surprisingly given the prevalence of informal jobs in Burundi, the share of formal enterprises is very small, standing at a low 3.3 percent (Figure V.13).

In the same vein as per individuals, the norm is informal agricultural units of production. As shown by Table V.5, 85.8 percent of Burundi's enterprises are in the agricultural sector. Most of them take the form of informal sector enterprises or household employment. The natural consequence of those forms of unit of employment is the prevalence of own-account workers and contributing family workers status in the agricultural sector. The non-agricultural sector remains limited with only 13.2 percent of Burundi's enterprises, in which formality remains almost inexistent - representing 3.4 percent of the existing jobs and 3 percent of the enterprises. 
Table V.5: Employment by Type of Worker and Production Unit (Percentage of total workforce employed)

\begin{tabular}{|c|c|c|c|c|c|c|c|}
\hline & \multicolumn{3}{|c|}{ Agriculture } & \multicolumn{3}{|c|}{ Non-Agriculture } & \multirow[b]{2}{*}{$\begin{array}{c}\text { Total } \\
\text { employed }\end{array}$} \\
\hline & $\begin{array}{c}\text { Formal } \\
\text { sector } \\
\text { enterprises }\end{array}$ & $\begin{array}{c}\text { Informal } \\
\text { sector } \\
\text { enterprises }\end{array}$ & Household & $\begin{array}{c}\text { Formal } \\
\text { sector } \\
\text { enterprise }\end{array}$ & $\begin{array}{l}\text { Informal } \\
\text { sector } \\
\text { enterprise }\end{array}$ & Household & \\
\hline Employees & 0,2 & 2,8 & 0,4 & 3,0 & 3,9 & 1,7 & 11,8 \\
\hline Formal job & 0,1 & 0,2 & 0,0 & 2,5 & 0,8 & 0,0 & 3,7 \\
\hline Informal job & 0,1 & 2,6 & 0,4 & 0,4 & 3,0 & 1,6 & 8,1 \\
\hline Employers & 0,0 & 0,2 & 0,1 & 0,0 & 0,4 & 0,0 & 0,7 \\
\hline Own-account workers & 0,0 & 17,7 & 25,3 & 0,0 & 3,7 & 0,2 & 46,8 \\
\hline Contributing family workers & 0,1 & 39,5 & 0,6 & 0,0 & 0,3 & 0,1 & 40,6 \\
\hline Total employed persons & 0,3 & 60,1 & 26,4 & 3,0 & 8,3 & 1,9 & 100,0 \\
\hline
\end{tabular}

Source: ECVMB, 2014. World Bank staff calculations

Workers who held jobs in formal enterprises were more or less equally distributed between urban and rural areas. As shown by Figure V.15, rural workers accounts for 52.3 percent of formal employment while Bujumbura-based jobs accounted for 31.9 percent of formal employment and other urban centers' employment represented 15.7 percent of formal employment. The distribution is more dispersed when we consider formal sector enterprises as the unit of analysis instead of individual jobs. 57.7 percent of formal enterprises are found in rural areas while only 26.3 percent are based in Bujumbura. These discrepancies are mostly explained by the relative size of formal enterprises in rural and urban areas. Formal units tend to employ more workers in urban areas, decreasing the relative share of urban areas in the distribution of the formal sector compared to individuals.

Figure V.15: Geographic Distribution of Formal and Informal Workers (percentage)

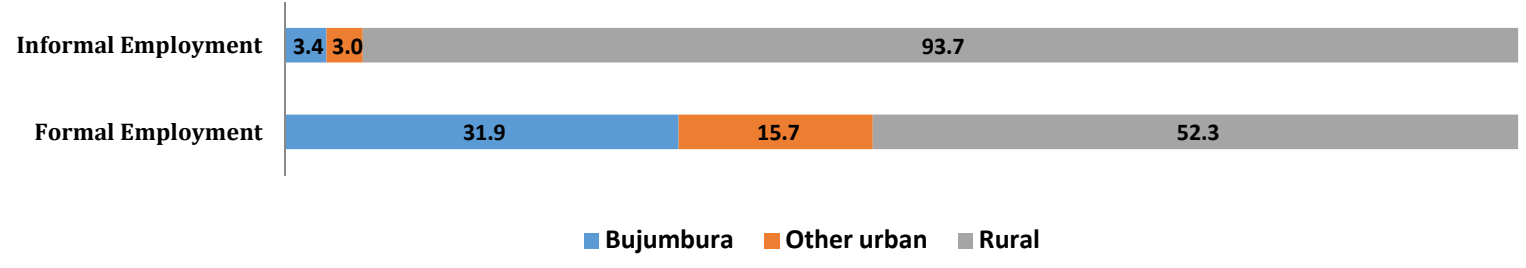

Source: ECVMB, 2014. World Bank staff calculations

\section{Informal non-farming enterprises}

Agricultural employment is often characterized by informal employment arrangement. Such a pattern has been highlighted in the previous sections of the document. Therefore, a high incidence of total informal employment as it is the case in Burundi - 95.8 percent of jobs are informal-might simply reflect the prevalence of informal agricultural employment. In this section we will focus on the non-agricultural informal sector.

\section{Workers in informal non-farm enterprises are mainly young men with low or no education}

The non-farming informal labor force is very young, both in rural and urban areas. By age category, age group with the highest prevalence was 25-29, accounting for 19.8 percent of the total informal employment (Table V.6). Similar to most developing economies and to Burundi's 
neighbors, the informal labor force is concentrated among the 20-44 years, accounting for 72.8 percent of the total informal labor force. Interestingly, informal employment increases as age increases from age 14-19 until a peak at 25-29. Beyond this age group, informal employment start to slowly decline as age increases. The pattern is similar both in rural and urban areas except that the rural peak occurs later at 30-34 years. For urban areas, age group 30-34 has the highest prevalence by far at 23.9 percent (Figure V.16).

Table V.6: Non-Farming Informal Employment by Age Group and Urban/Rural (percentage)

\begin{tabular}{cccc}
\hline \hline $\begin{array}{c}\text { Age } \\
\text { Group }\end{array}$ & Urban & Rural & Total \\
\hline $14-19$ & 5,5 & 7,3 & 6,8 \\
$20-24$ & 17,7 & 12,6 & 13,8 \\
$25-29$ & 23,9 & 18,5 & 19,8 \\
$30-34$ & 13,4 & 19,9 & 18,3 \\
$35-39$ & 11,9 & 11,2 & 11,4 \\
$40-44$ & 8,6 & 9,7 & 9,4 \\
$45-49$ & 5,4 & 6,2 & 6,0 \\
$50-54$ & 6,2 & 5,9 & 5,9 \\
$55-59$ & 3,4 & 2,8 & 2,9 \\
$60-64$ & 1,9 & 4,1 & 3,6 \\
$65-69$ & 0,6 & 0,3 & 0,4 \\
$70-74$ & 0,1 & 0,4 & 0,3 \\
$75-79$ & 0,7 & 0,5 & 0,6 \\
$80-84$ & 0,5 & 0,6 & 0,5 \\
Total & 100,0 & 100,0 & 100,0 \\
\hline \hline
\end{tabular}

Figure V.16: Non-Farming Informal Employment by Age Group and Urban/Rural

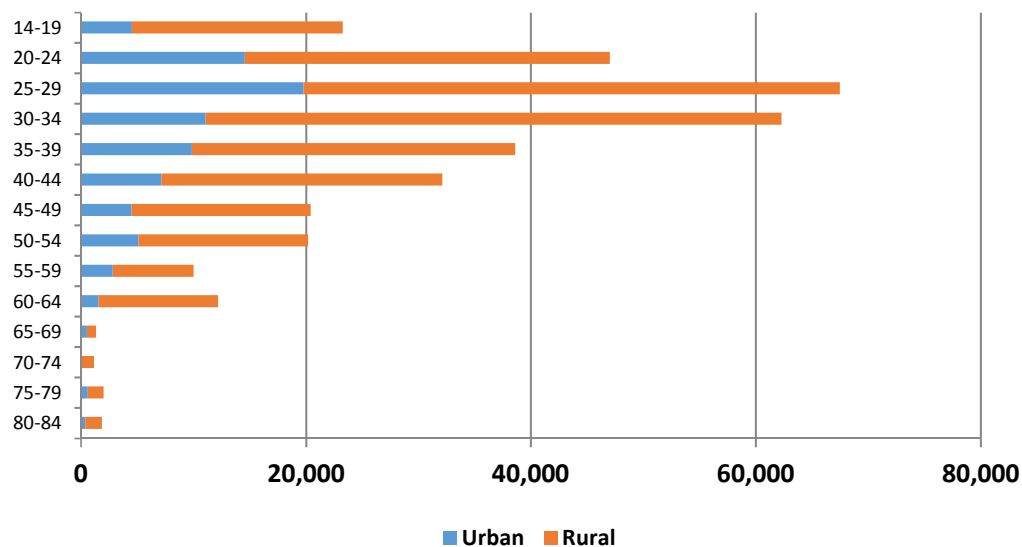

Source: ECVMB, 2014. World Bank Source: ECVMB, 2014. World Bank staff calculations staff calculations

The non-farming informal labor force is heavily dominated by men in all group categories, accounting for 70.7 percent of the non-farming informal workforce. This prevalence is particularly visible in all age categories (Figure V.17). The age category 35-39 stands as an outlier with a high rate of women informal employment at 40.5 percent. While no general pattern seems to emerge from the cross-observation of non-farming informal employment by age and gender, the balance between men and women in the youngest age categories (namely 14-19, 2024, and 25-29) slowly improves. Women's share in informal employment for age category 14-19 and 20-24 respectively reaches 45 percent and 35 percent.

Figure V.17: Non-Farming Informal Employment by Age Group and Gender (Percentages)

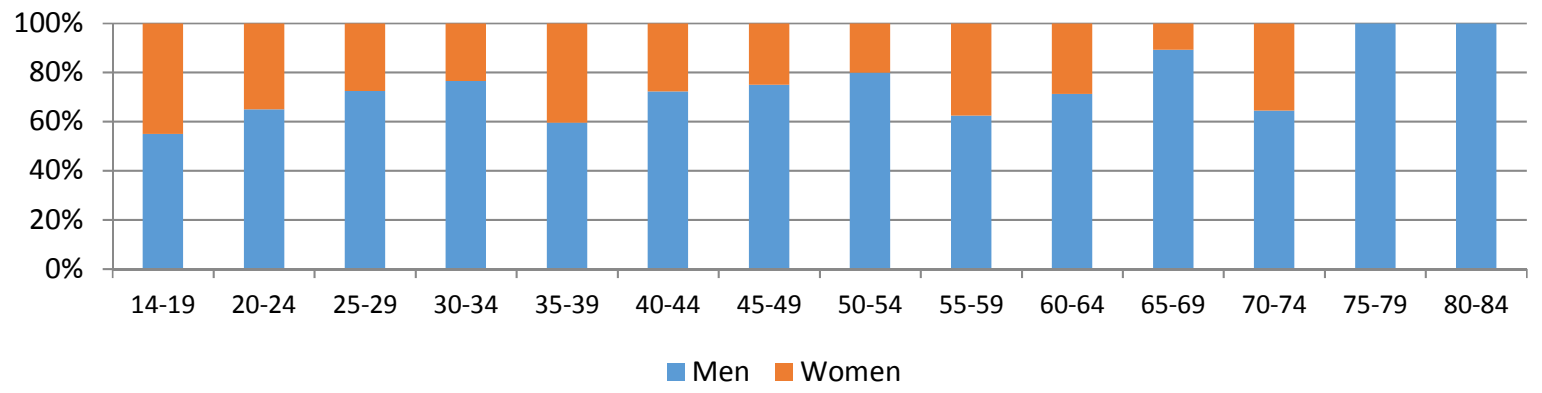

Source: ECVMB, 2014. World Bank staff calculations 
Non-farming informal employment is largely associated with low levels of education. As shown in Table V.7, the majority of workers holding non-farming informal jobs have limited or no education at all. Most of them have not completed basic education (76.7 percent) and the share of non-farming informal workers that have not gone beyond primary education represents almost the entire informal workforce ( 96.3 percent). These observations also hold when we look at the level of education by gender. However, women in the non-farming informal sector tend to have higher levels of education since only 21.7 percent of women had no education (compared to 31.7 percent for men). Conversely, 2.6 percent of women had secondary education, compared to only 1.5 percent of men.

\begin{tabular}{|c|c|c|c|}
\hline Type of Education & Men & Women & Total \\
\hline No education & 31,7 & 21,7 & 28,8 \\
\hline Not complete primary & 47,1 & 49,7 & 47,9 \\
\hline Primary & 17,6 & 24,4 & 19,6 \\
\hline Middle & 2,1 & 1,7 & 2,0 \\
\hline Secondary & 1,5 & 2,6 & 1,8 \\
\hline Total & 100,0 & 100,0 & 100,0 \\
\hline
\end{tabular}

Source: ECVMB, 2014. World Bank staff calculations

\section{Informal non-farm enterprises mainly operate in rural areas and the trade sector}

Excluding agricultural activities, the main non-farming informal employment is focused on the trade sector and rural areas (Figure V.18). An overwhelming majority of non-agricultural informal units of production (UPI) are found in rural areas with 74.6 percent of informal activities located outside Bujumbura and other urban centers (Table V.8). The capital Bujumbura concentrates 16.5 percent of the non-agricultural informal activities, while other urban centers represents only 9 percent of the informal activity, which is mainly explained by the small absolute size of those other urban areas.

Figure V.18: Non-farming UPI by Sector (percentage)

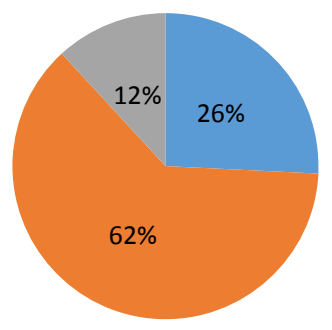

Source: ECVMB, 2013-14. World Bank staff calculations
Table V.8: Non-farming UPI by Sector and Geographical Area (percentage)

\begin{tabular}{cccc}
\hline \hline & Bujumbura & Urban & Rural \\
\hline Industry & 7,0 & 4,7 & 88,3 \\
Trade & 18,2 & 10,4 & 71,5 \\
Services & 28,2 & 10,8 & 61,0 \\
Total & $\mathbf{1 6 , 5}$ & $\mathbf{9 , 0}$ & $\mathbf{7 4 , 6}$ \\
\hline \hline
\end{tabular}

Non-farming informal employment is concentrated in wholesale and retail, manufacturing, and accommodation and restaurants. The weight of rural areas versus urban centers is further 
confirmed by Table V.9, which presents the geographical repartition of informal jobs by economic activity. Three specific areas of economic activities represent the bulk of the informal employment: wholesale and retail (52.3 percent), manufacturing (23.3 percent), and accommodation and restaurants (9.8 percent). Combined, those three sub-sectors represent 85 percent of the non-agricultural informal employment. The urban/rural pattern is similar in all the industries in the informal sector. Typically, 69.8 percent of the informal wholesale and retail jobs and 80.6 percent of the informal accommodation and restaurants jobs are located in rural areas. This figure rises to 89.4 percent for informal manufacturing jobs.

Table V.9: Non-farming Informal Employment by Industry, Geographical Area, and Gender (Percentages)

\begin{tabular}{|c|c|c|c|c|c|c|}
\hline \multirow[b]{2}{*}{ Industry } & \multicolumn{3}{|c|}{ Area } & \multicolumn{2}{|c|}{ Gender } & \multirow{2}{*}{$\begin{array}{c}\text { Non-farming } \\
\text { Informal } \\
\text { Employment }\end{array}$} \\
\hline & Bujumbura & Urban & Rural & Men & Women & \\
\hline Agriculture, forestry, and fishing & 18,7 & 10,5 & 70,8 & 0,6 & 0,4 & 0,5 \\
\hline Mining and quarrying & 10,4 & 3,5 & 86,1 & 2,6 & 0,0 & 1,8 \\
\hline Manufacturing & 6,1 & 4,5 & 89,4 & 25,3 & 18,6 & 23,3 \\
\hline Electricity, gas, and water supply & 0,0 & 0,0 & 100,0 & 0,3 & 0,0 & 0,2 \\
\hline Construction & 63,8 & 36,2 & 0,0 & 0,4 & 0,0 & 0,3 \\
\hline Wholesale and retail trade & 19,1 & 11,1 & 69,8 & 46,1 & 67,1 & 52,3 \\
\hline Transportation and storage & 34,1 & 7,5 & 58,4 & 5,6 & 0,1 & 4,0 \\
\hline Accommodation and restaurants & 13,2 & 6,2 & 80,6 & 9,7 & 10,0 & 9,8 \\
\hline Information and communication & 1,9 & 21,6 & 76,6 & 0,8 & 0,0 & 0,6 \\
\hline Real estate activities & 0,0 & 100,0 & 0,0 & 0,0 & 0,0 & 0,0 \\
\hline Professional, sci & 45,1 & 6,0 & 48,9 & 3,3 & 0,1 & 2,4 \\
\hline Administrative and defense & 0,0 & 9,8 & 90,2 & 0,7 & 0,0 & 0,5 \\
\hline Education & 0,0 & 100,0 & 0,0 & 0,0 & 0,4 & 0,1 \\
\hline Human health and social work activities & 59,4 & 40,6 & 0,0 & 0,1 & 0,3 & 0,1 \\
\hline Arts, entertainment & 0,0 & 100,0 & 0,0 & 0,0 & 0,0 & 0,0 \\
\hline Other service activities & 21,3 & 9,0 & 69,7 & 4,3 & 2,3 & 3,7 \\
\hline Activities of households & 0,0 & 38,3 & 61,7 & 0,2 & 0,7 & 0,3 \\
\hline Total & 16,5 & 9,0 & 74,6 & 100,0 & 100,0 & 100,0 \\
\hline
\end{tabular}

Source: ECVMB, 2014. World Bank staff calculations

\section{Size of non-farming informal enterprises}

Non-farming informal units of production tend to be small, particularly in Bujumbura. 74 percent of Bujumbura's non-farming UPI only account for one employee (Table V.10). While non-farming UPI of 3 or more employees in the capital only represent a share of 14 percent. The situation is similar in rural and other urban areas of Burundi, with a large prevalence of oneemployee non-farming UPI. Such a feature highlights the fact that many Burundi's workers are registered as own-account worker. 
Table V.10: Size of UPI by Geographical Location

(percentage)

\begin{tabular}{lrrrr}
\hline \hline & Bujumbura & \multicolumn{1}{c}{ Urban } & Rural & \multicolumn{2}{c}{ Total } \\
\hline 1 & 74 & 44 & 56 & 57 \\
2 & 12 & 20 & 21 & 19 \\
3 & 9 & 17 & 11 & 12 \\
$4+$ & 6 & 19 & 12 & 12 \\
Total & 100 & 100 & 100 & 100 \\
\hline \hline
\end{tabular}

Source: ECVMB, 2014. World Bank staff calculations

\section{Employment status of non-farming informal workers}

Non-agricultural informal workers are mostly found to be own-account workers, followed by wage employees. Own-account work is the most prevalent form of employment across all non-agricultural informal sectors, accounting for 64.1 percent of the jobs (Figure V.19). This is not surprising given the small size of non-farming informal enterprises. Jobs of employee (for the non-agricultural informal sector) were also quite common, accounting for 13.2 percent of the non-agricultural informal jobs available in Burundi. Surprisingly, employers also represented a significant share of the informal jobs with 9.1 percent of the respondents defining themselves as the boss of their own multi-employee business. This was followed by unpaid family workers $(9.5$ percent), associate ( 2.8 percent), paid apprentice ( 0.9 percent), and apprentices and interns $(0.4$ percent).

Most of non-agricultural informal employment is located in rural areas, which confirms the rural concentration of non-farming UPIs. In the four main categories of informal employment - namely own-account worker, employee, unpaid family worker, and employermore than 75 percent of the jobs are located in rural settings (Figure V.20). Some urban/rural variations can be observed. While the status of own-account worker is the most important one, accounting for 64.1 percent of the non-agricultural informal jobs, it is particularly important in Bujumbura where it accounts for 75 percent of the total informal employment. Conversely, in other urban centers and in rural areas, this status only concerns respectively 57.5 and 62.9 percent of the informal employment. There, other forms of informal employment are more significant, in particular unpaid family workers that represent 15.2 percent of the informal workforce in other urban centers, and employees that account for 14.1 percent of the rural nonagricultural informal workforce (Table V.11). 
Figure V.19: Distribution of Non-farming Informal Employment by Employment Status (Percentage)
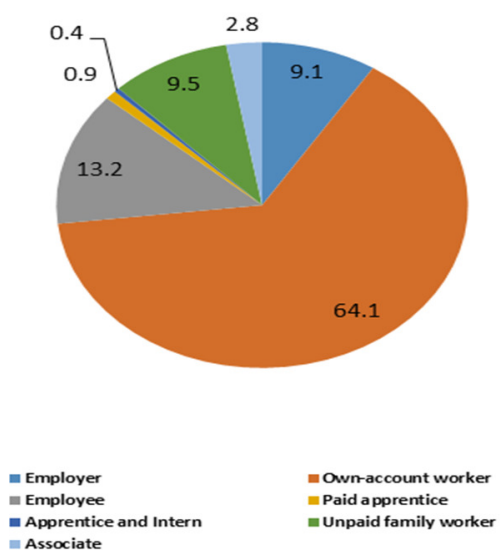

Figure V.20: Distribution of Non-farming Informal Employment by Employment Status and Geographical Area (Percentage)

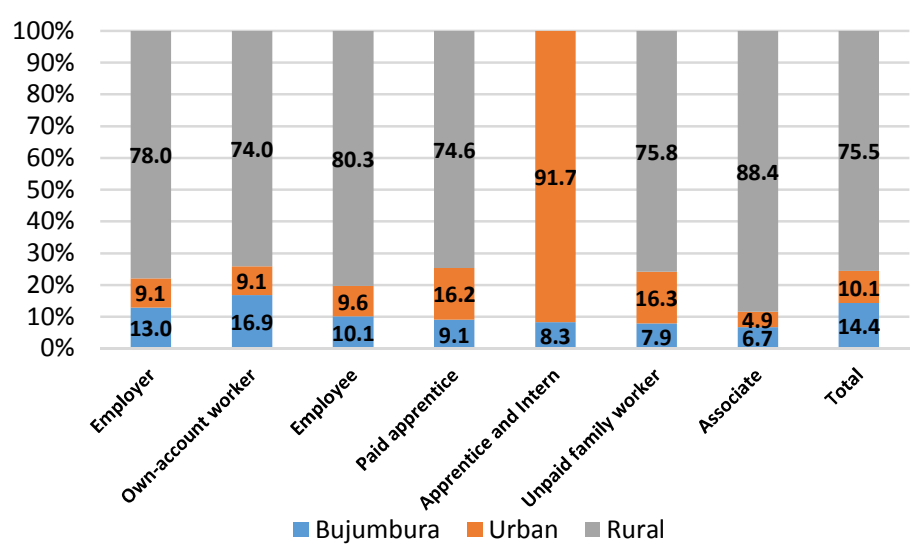

Source: ECVMB, 2014. World Bank staff calculations

Table V.11: Non-farming Informal Employment by Employment Status and Geographical Area (Percentage)

\begin{tabular}{lrrr}
\hline \hline Employment Status & Bujumbura & Urban & Rural \\
\hline Employer & 8,2 & 8,1 & 9,4 \\
Own-account worker & 75,2 & 57,5 & 62,9 \\
Employee & 9,3 & 12,5 & 14,1 \\
Paid apprentice & 0,6 & 1,4 & 0,9 \\
Apprentice and Intern & 0,2 & 3,9 & 0,0 \\
Unpaid family worker & 5,2 & 15,2 & 9,5 \\
Associate & 1,3 & 1,4 & 3,3 \\
Total & 100,0 & 100,0 & 100,0 \\
\hline \hline
\end{tabular}

Source: ECVMB, 2014. World Bank staff calculations

Not surprisingly given the prevalence of own-account workers in the informal sector of Burundi, the dominant form of contract is the self-contract or workers considered as head of UPI. As shown in Figure V.21, the category head of UPI accounts for 72.3 percent of the non-agricultural informal employment. It is followed by verbal agreement and absence of contract that account respectively for 12.3 percent and 13.1 percent of the informal sector. Written contracts, whether they are limited in time or not, are very rare and only apply to 2.3 percent of the informal jobs.

Within the non-farming informal sector, women suffer the most from the lack of written official documents regarding their employment status. While the share of women in the category head of UPI (i.e. self-contracting) only accounts for 29.3 percent, they represent more than half of the non-contracted informal workers (51.3 percent). In the safest category - written contract with limited and unlimited duration - the women's share respectively falls at 9.4 percent and 3.1 percent compared to men (Figure V.22). 
Figure V.21: Informal Employment by Form of

Contract (Percentages)

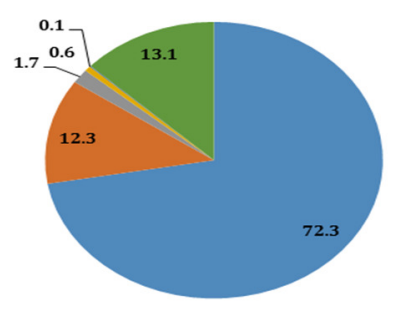

$=$ Head of UPI

- Written contract (limited duration)
On trial

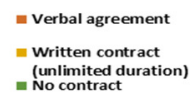

Figure V.22: Informal Employment by Form of Contract and Gender (Percentages)

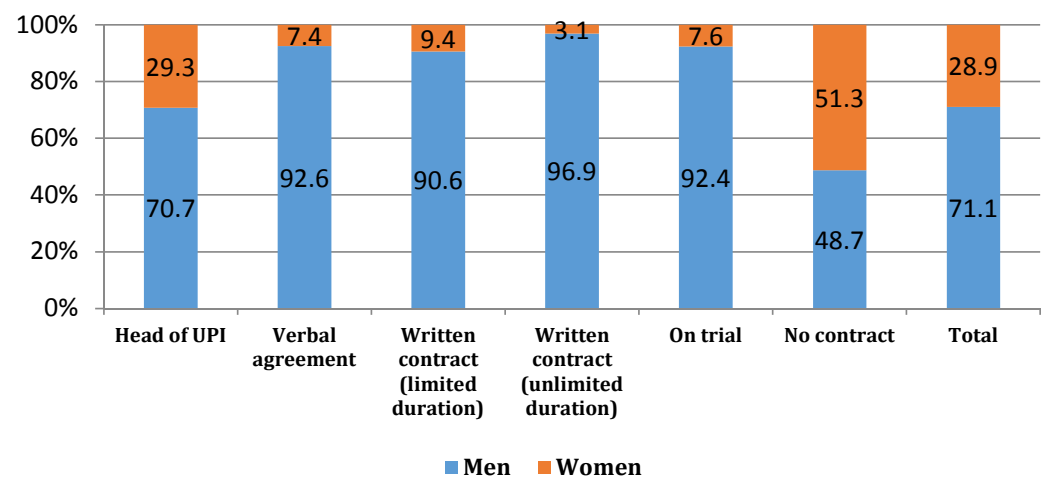

Source: ECVMB, 2013-14. World Bank staff calculations

\section{Difficult working conditions}

Workers with formal employment earn significantly higher income, while discrepancies between agricultural and non-agricultural jobs are important. As shown by Table V.12, workers in the non-agricultural sectors of the economy earn significantly higher yearly income, whether they are employed by formal or informal enterprises. Non-agricultural informal workers earn twice the amount of agricultural workers while non-agricultural formal workers earn more than five times the income of agricultural workers. While incomes in the agricultural sector are similar across both formal and informal employment, important discrepancies exist within the non-agricultural sectors. Employees and own-account workers that work in formal employment earn twice the amount received by non-agricultural informal employees.

Table V.12: Average Yearly Income by Type of Worker, Economic Sector, and Nature of Employment (Thousands FBU)

\begin{tabular}{lcccc}
\hline \hline & \multicolumn{2}{c}{ Non-Agriculture } & \multicolumn{2}{c}{ Agriculture } \\
& Formal & Informal & Formal & Informal \\
\hline Employee & 1483,1 & 701,0 & 387,3 & 315,5 \\
Employer & 3353,3 & 705,9 & & 242,5 \\
Own-account worker & 1218,5 & 559,2 & 230,6 & 210,5 \\
Paid family worker & & 158,7 & & 124,9 \\
\hline \hline
\end{tabular}

Source: ECVMB, 2014. World Bank staff calculations

The overwhelming majority of workers from the non-farming informal sector receive income under the form of profit. Figure V.23 shows that most workers holding a non-farming informal job receive an income based on the profits generated by their activities (72 percent). This observation is consistent with the prevalence of own-account workers whose income represent the entire profit earned from their informal occupation. More formal forms of income such as monthly wages and daily/hourly wages remain limited, accounting for 8 percent and 2.7 percent respectively. The share of informal workers that do not perceive any form of income is 
quite significant and represents 8.6 percent of the total informal workforce. Similarly, a large part of the informal workers only receive irregular payment ( 7 percent), meaning that those workers are contracted on a one-time basis and receive a flat payment for a specific task performed.

Gender disparity regarding income is significant in the non-farming informal sector, with a majority of women often left with no income or only in nature. While men are prevalent in forms of payment that are more stable such as monthly wages (94.8 percent) and daily/hourly wages (86.1 percent), the profit form of payment - the most common one-follows the same profile as the gender distribution of informal jobs with 70.3 percent of profit-sharing payments accruing to men and 29.7 percent of it to women (Figure V.24). However, women are disproportionately disadvantaged in regards to less secured and unequal forms of payment. 55.7 percent of the informal workers paid in nature are women. The women's share rises to 57.8 percent in the case of the absence of any form of income. Those figures stems from the prevalence of women involved in non-farming informal activities without any form of contract. Because many women often carry tasks related to the main economic activity of the household, the income generated generally accrues to the male head of household, leaving women without any proper form of payment.

Figure V.23: Informal Employment by Nature of Payment (percentage)

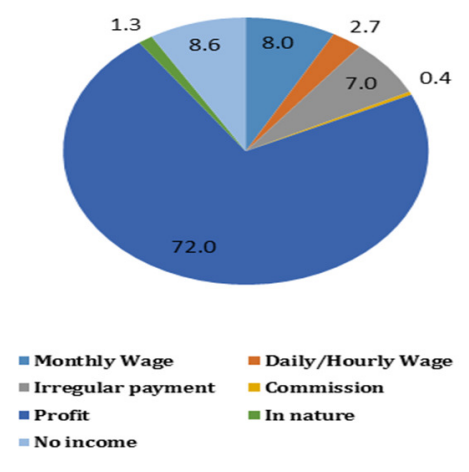

Figure V.24: Informal Employment by Nature of Payment and Gender (Percentages)

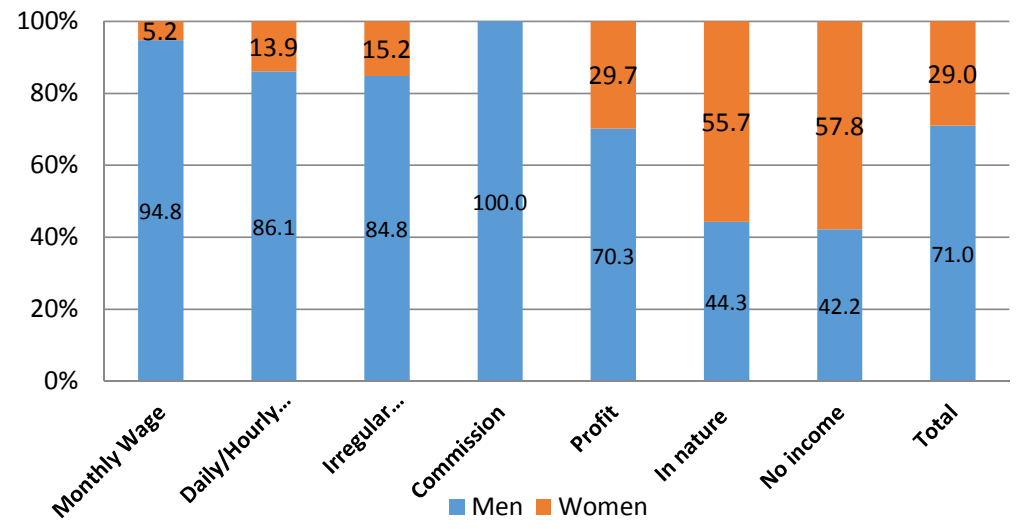

Source: ECVMB, 2014. World Bank staff calculations

The non-farming informal workforce in Burundi is characterized by an overwhelming lack of social benefits and social protection. In particular, informal workers do not perceive any leave protection or social security. Only 11.5 percent of the non-agricultural informal workforce receives bonuses under the form of profit sharing while only 9.3 percent obtain in-kind benefits. Other forms of benefits within the informal workforce are almost inexistent. Less than 5 percent of informal workers benefit from paid sick leave, paid annual leave, and end-of-the-year premium. 


\section{Employment dynamics, 1998-2014}

Examining employment dynamics in Burundi is complicated by the lack of comparable data (Box V.1). Nevertheless, in this section, we will use data from the 2008 Population and Housing Census (PHC) and the 1998 Priority Survey (PS) to explore how employment in Burundi changed over the past 15 years. While the employment sections of the 1998 PS and the 2008 PHC differ from the one in the ECVMB, we have attempted to create similar variables and indicators across the three surveys. Due to data limitations, we focus only on the main job.

\section{8-2008: Wartime stagnation}

Between 1998 and 2008, the employment landscape in Burundi was characterized by complete inertia. The share of workers with a main job in agriculture stagnated at a high level (over 90 percent), and accordingly, the share of workers in the non-farm sector remained constant and low (Table V.13). Within the non-farm sector, the employment share of services increased modestly (and statistically significantly) between 1998 and 2008, while that of industry decreased insignificantly (Figure V.25). The 1998-2008 period largely coincides with Burundi's internal conflict (the last rebel group signed a peace agreement in 2009), which may explain the observed stagnation.

Table V.13: Employment status since 1998

(percentage)

\begin{tabular}{llll}
\hline \hline Type of employment & 1998 & 2008 & 2014 \\
\hline Agriculture & 92.3 & 91.4 & 84.5 \\
Independent farming & 44.2 & 90.1 & 42.2 \\
Unpaid family farm worker & 47.4 & & 39.3 \\
Wage farming & 0.7 & 1.3 & 3.0 \\
\hline Non-agriculture & 7.7 & 8.6 & 15.5 \\
Non-farm wage employment & 4.7 & 4.4 & 9.8 \\
Non-farm self-employment & 2.5 & 3.7 & 4.2 \\
Non-farm employer & 0.1 & 0.1 & 0.4 \\
Unpaid household enterprise worker & 0.4 & 0.4 & 1.1 \\
\hline \hline
\end{tabular}

Source: PS, 1998; PHC, 2008; ECVMB, 2014. World Bank staff calculations.
Figure V.25: Secondary and Tertiary sectors employment share between 1998 and 2008 (percentage)

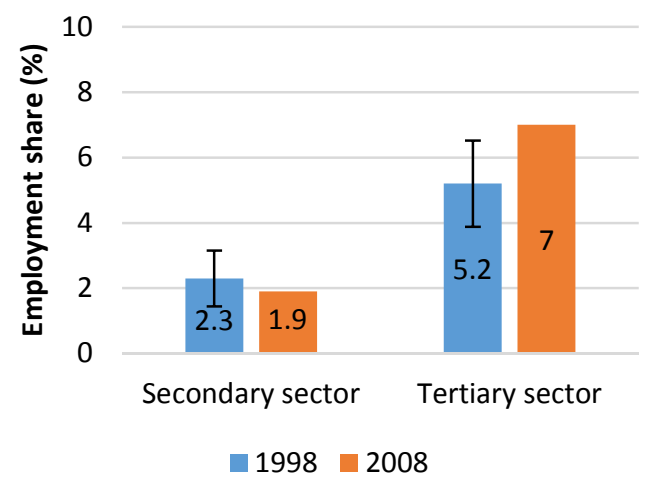

Primary sector not shown for the sake of readability.

\section{8-2014: A move towards non-farm employment}

Between 2008 and 2014, the share of workers with a main occupation outside agriculture increased from a low base. In 2014, about 16 percent of Burundian workers had their main occupation in the non-farm sector, up from 9 percent in 2008 (Table V.13). Wage employment experienced the strongest increase: 10 percent of workers had their main job in non-farm wage employment in 2014, compared to less than five percent in 2008. Other types of non-farm employment increased modestly (Table V.13). 


\section{Box III.1}

\section{What are Burundi's non-farming wage-workers doing?}

\section{Government, domestic services, and construction}

Although the share of workers with a wage job in the non-farm sector remains small, it has more than doubled since 2008 (Table V.13). How does non-farm wage employment look like in Burundi? The public sector largely dominates, accounting for 30 percent of overall non-farm wage employment (Figure V.26). Domestic services (guards, cooks, nannies,...) account for 15 percent of wage employment, followed by construction (13 percent), hotels, restaurants and trade (10 percent), and transport (eight percent). Together, the five subsectors account for three quarters of total non-farm wage employment.

Figure V.26: Government, domestic services and construction account for the bulk of wage employment outside farming (Share of total non-farm wage employment by subsector, 2014)

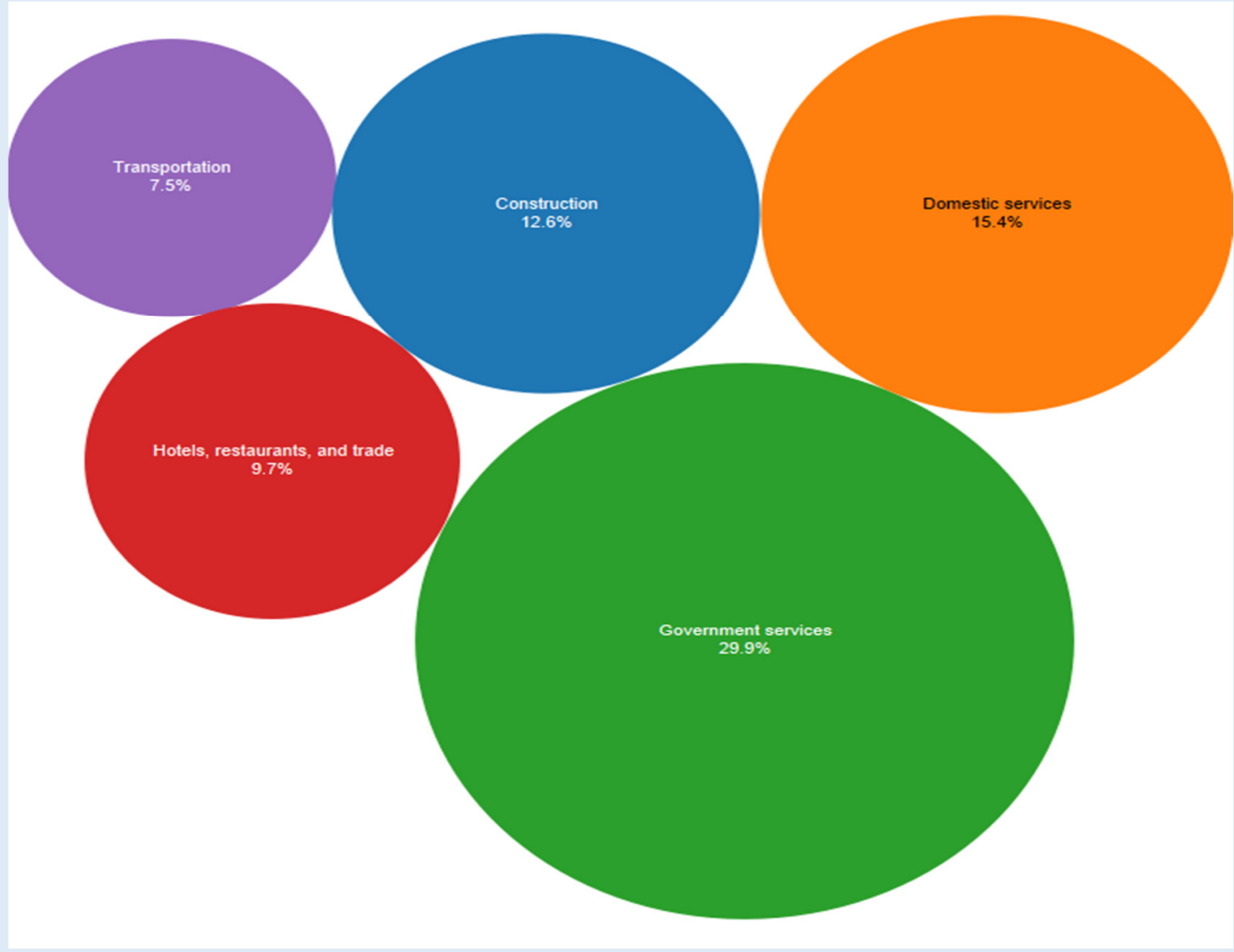

Source: ECVMB; 2014

The move to non-farm employment happened to workers of all ages but was most significant for the youth. Figure V.27 follows each five-year cohort of workers between 2008 and 2013 (when the bulk of the fieldwork for the ECVMB was conducted). The starting point of each line shows the share of workers in a cohort with a main occupation outside farming in 2008, while the ending point of the line shows the share of that same cohort with a main non-farm occupation in 2013. For each cohort, the share of workers with a non-farm main occupation is higher in 2013 than in 2008, and the increase is particularly steep for the younger workers (steeper lines in Figure V.27). In 2008 for instance, 10 percent of workers aged 25-29 had their 
main occupation outside farming (third line in Figure V.27). Five years later, when those same workers were now aged 30-34, 20 percent had their main occupation in the non-farm sector.

Figure V.27: Share of workers with non-farming jobs by age group

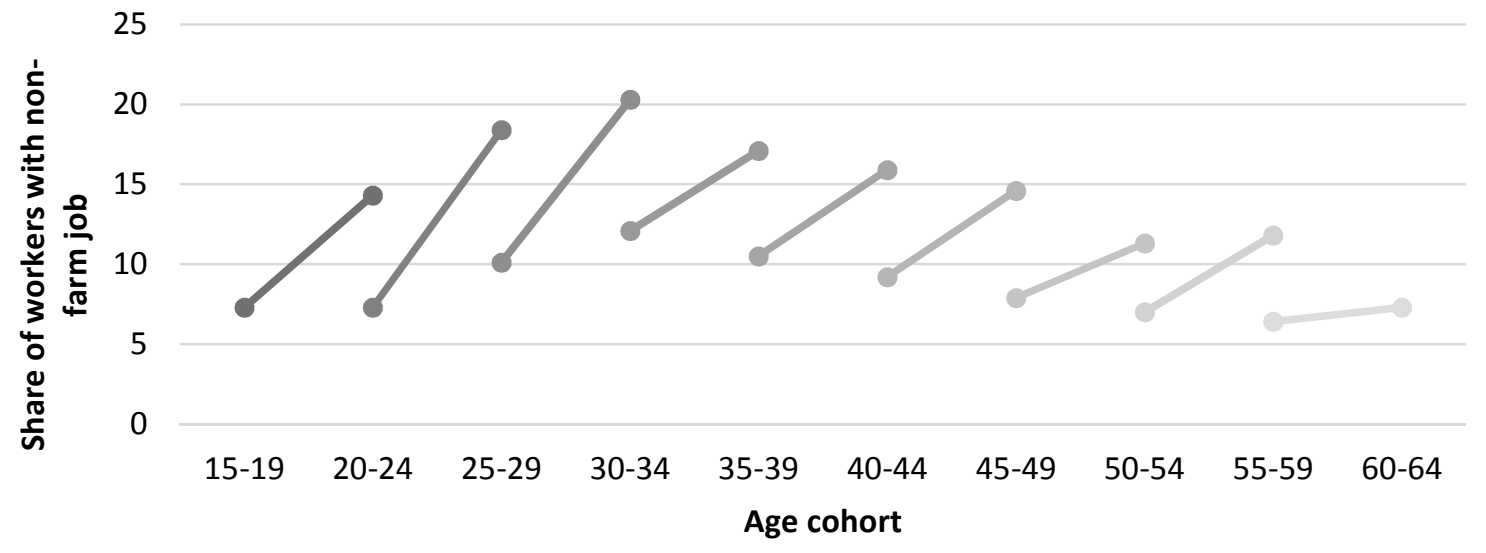

Source: ECVMB; 2014

The move to non-farm employment was largely restricted to men. The share of men with a main occupation outside agriculture doubled between 2008 (13 percent) and 2011 (25 percent), while the share of women outside agriculture increased modestly by three percentage points (Table V.14). In 2014, over 90 percent of women still had their main employment on the farm, compared to 75 percent of men. Men were particularly likely to move to wage employment: 17 percent of men had their main job in non-farm wage employment in 2014, up from seven percent in 2008.

Table V.14: Employment status between 2008 and 2014 by gender (percentage)
Figure V. 28: Secondary and Tertiary sectors employment share between 2008 and 2014 (percentage)

\begin{tabular}{ccccc}
\hline \hline \multirow{2}{*}{ Type of employment } & \multicolumn{2}{c}{ Women } & \multicolumn{2}{c}{ Men } \\
& 2008 & 2014 & 2008 & 2014 \\
\hline Agriculture & 95.4 & 92.0 & 87.2 & 75.3 \\
Independent farming & 94.5 & 26.1 & 85.4 & 61.8 \\
Unpaid family farm worker & & 64.0 & & 9.3 \\
Wage farming & 0.9 & 1.9 & 1.8 & 4.2 \\
\hline Non-agriculture & 4.7 & 8.0 & 12.9 & 24.7 \\
Non-farm wage employment & 2.3 & 3.7 & 6.8 & 17.1 \\
Non-farm self-employment & 2.0 & 2.4 & 5.5 & 6.3 \\
Non-farm employer & 0.1 & 0.2 & 0.2 & 0.8 \\
Unpaid household enterprise worker & 0.3 & 1.7 & 0.4 & 0.5 \\
\hline \hline
\end{tabular}

15

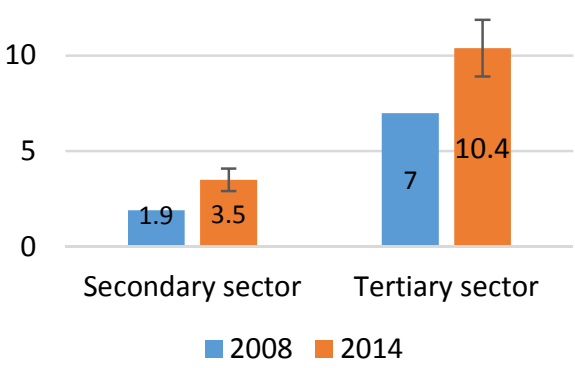

Source: PS, 1998; PHC, 2008; ECVMB, 2014. World Bank staff calculations.

Since 2008, the employment share of the secondary and tertiary sector increased significantly. Employment in industry rose sharply from a low base but remains low at less than four percent (Figure V.28). The service sector provides main employment to about 10 percent of 
workers, a 50 percent increase since 2008. In line with this, employment in agriculture declined in relative terms but remains high at almost 86 percent.

\section{Modest intergenerational mobility in occupation}

Although youth in Burundi are largely doing similar occupations as their parents, young workers have nevertheless led the recent trend towards non-farm employment (Figure V.27). The ECVMB questionnaire includes information on the occupational status of workers' parents (based on current workers' responses), enabling an exploration of intergenerational occupation mobility. In this subsection, we look at the relation between the occupation of young workers (15-30) and that of their parents.

Overall, there has been some occupational mobility between father and son, though the direction is mixed. About 24 percent of young workers with a father in independent farming work in the non-farm sector (Figure V.29), which can be considered as upward mobility given the higher earnings in this sector (documented in the next section). However, over half of youth whose father works or worked for wages in the non-farm sector currently work in agriculture, which can on average be considered as downward mobility (Figure V.29). ${ }^{47}$ Overall, 73 percent of male youth works in the same sector (farm or non-farm) as their father.

Figure V.29: Occupation of son by occupation of father, 2014 (percentage)

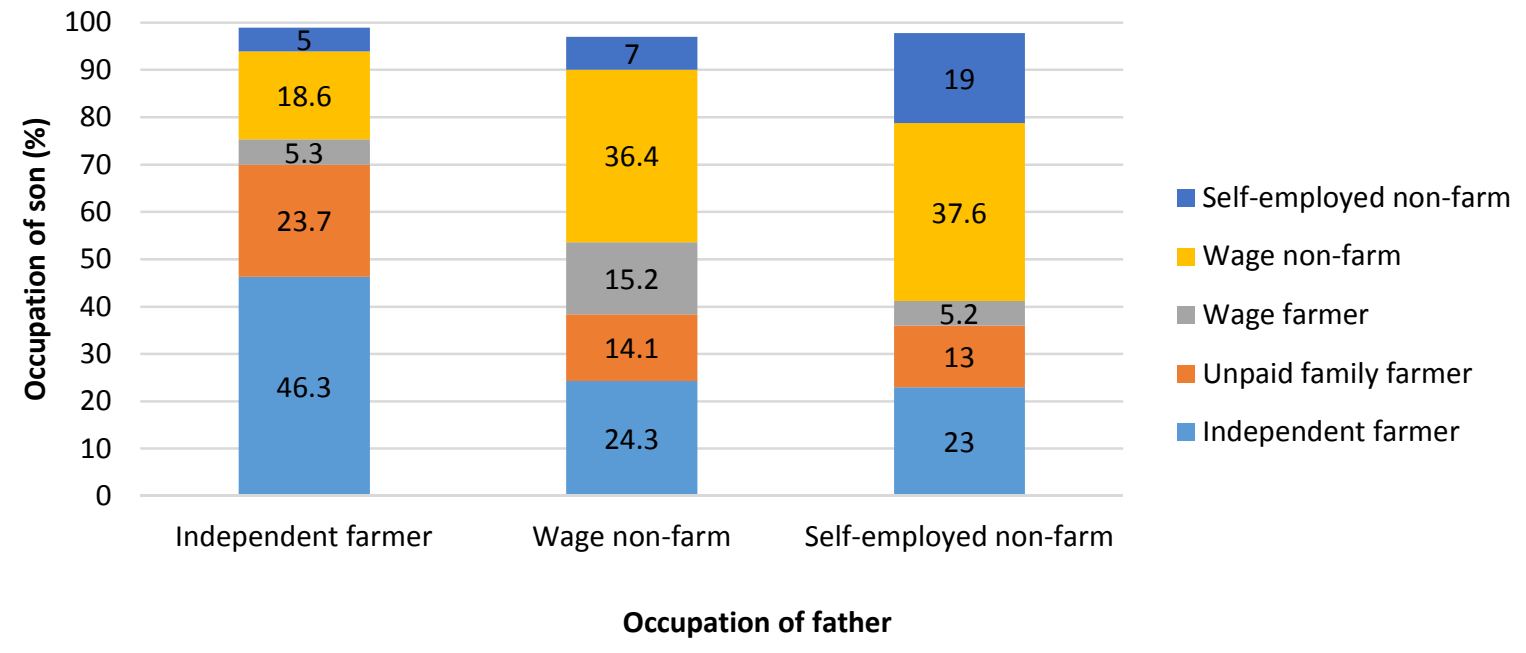

Source: ECVMB, 2013-14. World Bank staff calculations.

Controlling for other factors, there is a strong persistence in occupation within agriculture but not outside. Young men with a farming father seem to have 29 percentage points more chances to be an independent farmer, controlling for differences in age, education level, and location. In contrast, occupations are a lot less persistent in the non-farm sector: male youths

\footnotetext{
${ }^{47}$ It is of course possible that certain youth have large farms and earn more than in the non-farm sector. These would however be exceptions.
} 
whose father works in the non-farm sector are not discernibly more likely to also work in the non-farm sector.

Occupational mobility across generations is even lower for women. About 94 percent of young women (15-30) with a farming mother are also employed in farming, mainly as unpaid family farm workers (Figure V.30). Even when their mother is employed in the non-farm sector, daughters have a largely similar chance of working in the non-farm sector or as unpaid labor on the family farm. Overall, 92 percent of young women work in the same sector as their mother, and relatively more of them are employed as unpaid farmers. Occupational persistence is high: controlling for other factors, female youth with a mother in independent farming are 27 percentage points more likely to be an independent farmer themselves, female youth with a mother in unpaid family farming are 23 percentage points more likely to be an unpaid farmer themselves, and young women whose mother works in the non-farm sector are more likely to be in the non-farm sector themselves, although this effect is far from significant (due to the small share of women actually working outside agriculture).

Figure V.30: Occupation of daughter by occupation of mother, 2014 (percentage)

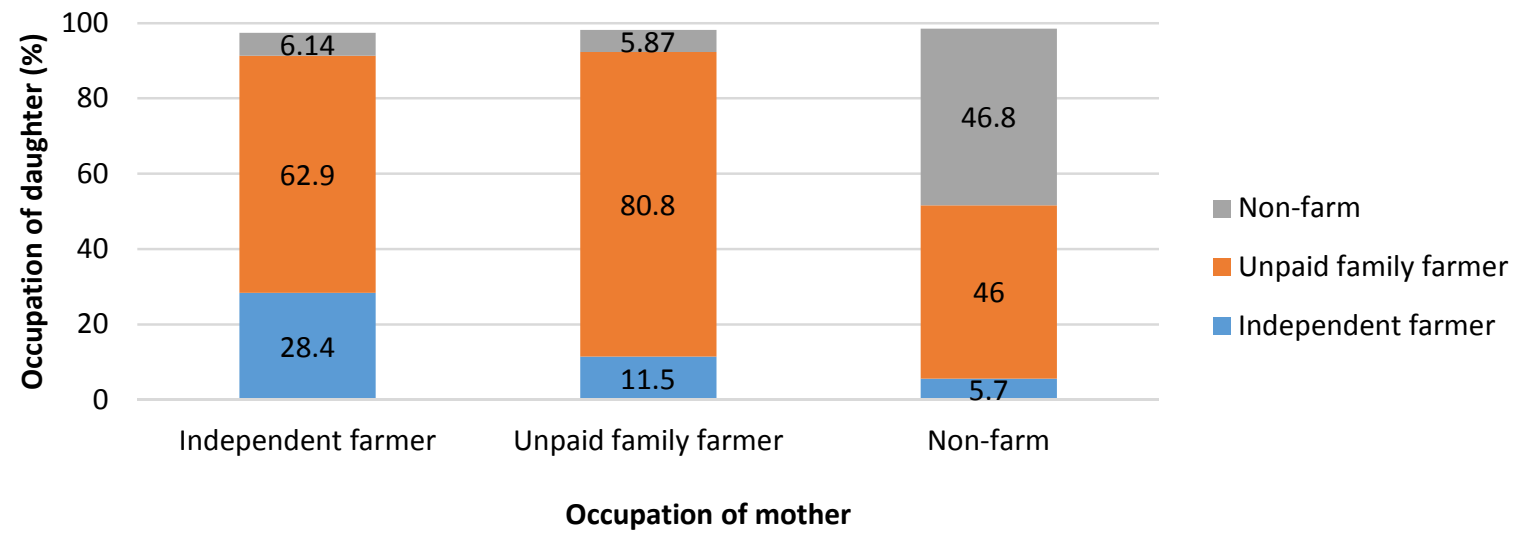

Source: ECVMB, 2014. World Bank staff calculations

\section{Earnings of wage employees}

Data on earnings are available for only a small fraction of workers. The ECVMB survey only asked questions on earnings to people who reported having a tangible compensation for their work, hereby excluding unpaid farm and non-farm workers (whom represent over 40 percent of total employment - Table V.13). The earnings question was asked to about 9,000 workers, more than 5,000 of whom refused to reply. Overall, there are earnings data on about 3,500 persons: 2,000 respondents gave an exact figure, while about 1,500 gave a range. Table V.15 summarizes response rates by employment category. Given the high non-response rates, this section will only present earnings of wage employees (both in the farm and non-farm sector). 
Table V.15: Share of workers with earnings data by employment status (percentage)

\begin{tabular}{lcccc}
\hline \hline Type of employment & $\begin{array}{c}\text { No } \\
\text { earnings }\end{array}$ & $\begin{array}{c}\text { Earnings in } \\
\text { tranches }\end{array}$ & $\begin{array}{c}\text { Direct } \\
\text { estimation }\end{array}$ & Total \\
\hline Agriculture & & & & \\
Independent farming & 91.6 & 5.7 & 2.8 & 4,861 \\
Unpaid family farm worker & 94.2 & 5.0 & 0.8 & 4,396 \\
Wage farming & 19.1 & 37.8 & 43.1 & 379 \\
\hline Non-agriculture & & & & \\
Non-farm wage employment & 18.1 & 22.1 & 59.8 & 2,349 \\
Non-farm self-employment & 51.5 & 27.6 & 20.9 & 794 \\
Non-farm employer & 38.5 & 29.2 & 32.3 & 96 \\
Unpaid household enterprise worker & 80.4 & 12.3 & 7.3 & 178 \\
\hline \hline
\end{tabular}

Source: ECVMB, 2014. World Bank staff calculations.

Overall, earnings of wage employees in Burundi are low. Median earnings (salary plus benefits) of non-farm wage employees amounted to 480,000 BIF per year in 2014, corresponding to US\$ 780 in purchasing power parity terms and US\$ 314 using the official exchange rate. ${ }^{48}$ At 300,000 BIF per year, earnings of agricultural wage employees are substantially lower. In the non-farm sector, female wage employees earn substantially more (double) than male employees, a finding -though at odds with the common empirical pattern in Africa- that can be explained by the higher education of women in non-farm wage employment. ${ }^{49}$

There is substantial variation in earnings across sector of employment, economic sector, and education. ${ }^{\mathbf{5 0}}$ As in many low-income countries in Africa, public sector employees have the highest earnings (BIF 1.2 million), followed by employees of the formal private sector (BIF 720,000). Employees in the informal non-farm sector have the lowest earnings (BIF 360,000), though they are still higher than earnings of agricultural wage employees. Most of the difference in earnings between public and formal private sector employees can be explained by differences in endowments: public sector employees are on average better educated and older, explaining their higher earnings. The earnings differential between the formal and informal private sector is explained by differences in endowments too, in particular better education in the formal sector. ${ }^{51}$

\footnotetext{
48 This is based on the 2011 PPP exchange rate of US $\$ 1=$ BIF 615.73 and the average 2014 official exchange rate of US $\$ 1=\mathrm{BIF}$ 1530.31 .

4956 percent of women who are wage employed in the non-farm sector attained incomplete upper secondary education or more. For men, this is only 21 percent.

${ }^{50}$ The median earnings presented in the table are however based on small samples.

51 This is based on Oaxaca-Blinder decompositions of earnings differences between the public and formal private sector, and between the formal and informal private sector. For both decompositions, the explained part of the difference is statistically significant while the unexplained part is not. See Annex.
} 
Table V.16: Median annual earnings of non-farm employees, by location, sector, and education

\begin{tabular}{lrr}
\hline \hline & $\begin{array}{r}\text { Annual median } \\
\text { earnings (BIF) }\end{array}$ & $\mathrm{N}$ \\
\hline Urban & 720,000 & 1477 \\
Rural & 360,000 & 447 \\
\hline Sector of employment & & \\
Public sector & $1,200,000$ & 694 \\
Formal private sector (nonfarm) & 720,000 & 127 \\
Informal private sector (nonfarm) & 360,000 & 433 \\
\hline Sector of economic activity & & \\
Secondary sector & 360,000 & 287 \\
Tertiary sector & 600,000 & 1540 \\
\hline Education & 300,000 & 348 \\
None & 300,000 & 614 \\
Incomplete primary & 480,000 & 121 \\
Complete primary & $1,164,000$ & 127 \\
Incomplete secondary & $1,350,000$ & 517 \\
Complete secondary & $3,000,000$ & 197 \\
Higher, complete or incomplete & & \\
\hline \hline
\end{tabular}

Figure V.31: Median annual earnings for private sector employees, by establishment size (in BIF)

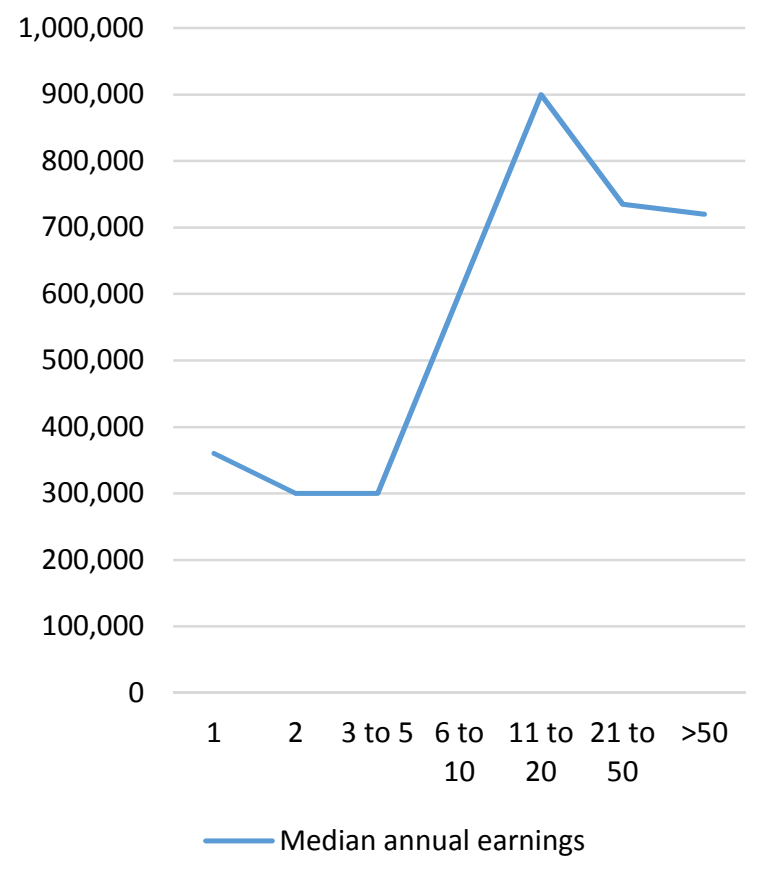

Source: ECVMB, 2013-14. World Bank staff calculations.

Private sector employees tend to earn more the bigger the establishment they work in. Wage employees in establishments with up to five employees earn about BIF 300,000 per year (median), compared to BIF 600,000 for employees in establishments with six to 10 employees and BIF 900,000 in those with 11 to 20 employees. The positive effect of firm size holds even when controlling for education, economic sector, and demographic characteristics of workers: all else equal, private sector employees earn more the larger the firm is.

\section{(Un)employment in the "modern" labor market}

This section examines in more detail the nature of the "modern" labor market in Burundi. As a proxy for the modern labor market, this analysis focuses only on persons who attained at least incomplete upper secondary education. Given the low educational attainment of Burundi's workforce, this reduces the sample from 13,399 (the size of the labor force in the sample) to 1,206. People in this reduced sample are somewhat younger than the average (median age of 32 compared to 33 overall) and more likely to be male (59 percent are male, compared to 45 percent of the overall employed). Most of workers in the reduced sample are wage employed in the nonfarm sector ( 83 percent), unsurprising given that we filtered on education. 93 percent of the individuals in the sample work outside farming.

As typical in low-income countries, unemployment is low at the national level but high among the better educated. A mere 1.6 percent of Burundi's labor force is unemployed, but 
this increases to 20 percent in the higher-educated sample. ${ }^{52}$ The unemployed are young (median age of 25), have never had a job before ( 86 percent) and the majority lives in the capital of Bujumbura (54 percent). About one-quarter of the unemployed do not take any specific action to look for a job, while another quarter reports to have contacted the Ministry of Civil Service to obtain a public sector job. Newspaper and radio ads (16 percent) and personal relationships (13 percent) are other frequent means through which unemployed people are hoping to obtain a job.

Most of the higher-educated unemployed are looking for a wage job, preferably in the public sector. About 80 percent of the unemployed are looking for wage employment, and more than half aim to be employed in the public administration (Figure V.32 and Figure V.33). Large private enterprises are the second most-wanted employer, unsurprising given the positive relation between firm size and earnings (Figure V.31).

Figure V.32: Type of employment the unemployed higher-educated look for (percentage)

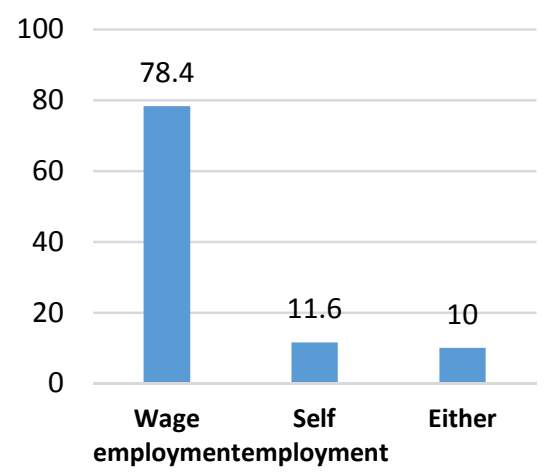

Figure V.33: Type of employer the unemployed higher-educated look for (percentage)

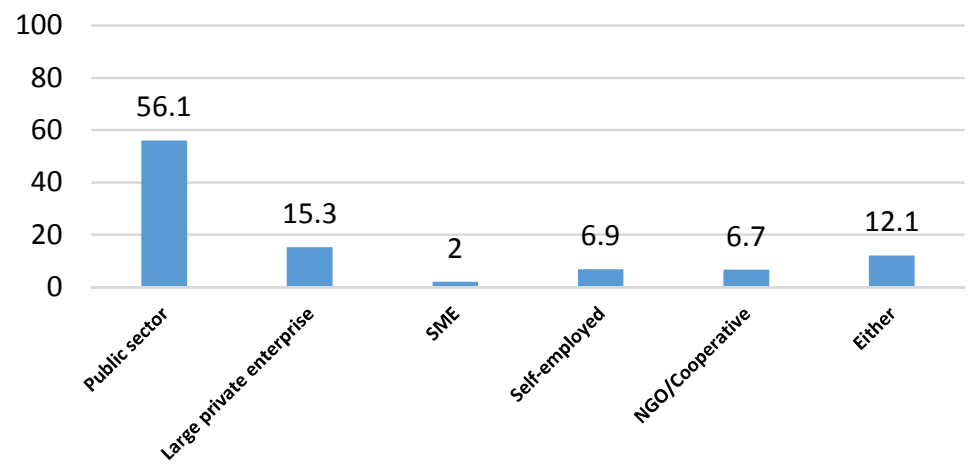

Source: ECVMB, 2014. World Bank staff calculations.

Of the higher-educated workers who are employed, most of them work in the public sector. 48 percent of workers are employed in government services while an additional 15 percent are employed in public enterprises and parastatals (Figure V.34). About one-fourth is employed in private businesses, and 8 percent is nevertheless in farming. The weight of the public sector is higher among educated women: over 70 percent of women with at least incomplete upper secondary education work in the public sector, compared to 57 percent of men.

Figure V.34: Employment of higher-educated workers (percentage)

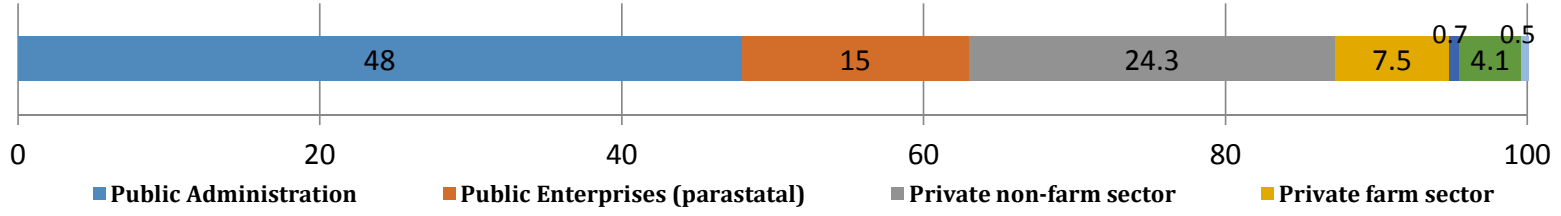

Source: ECVMB, 2014. World Bank staff calculations.

${ }^{52}$ As a reminder, we label a worker as "educated" if s/he attained at least incomplete upper secondary education. 
The modern labor market seems relatively inert. A mere 18 percent of workers in the educated sample has ever had a different employer than the current one, and this drops to 14 percent for workers in the public sector. 78 percent of educated workers wish to either stay in the same job in the future (69.4 percent) or obtain another job in the same enterprise or ministry (7.9 percent). Focusing on the public sector, over 82 percent of workers aim to stay put. The overall picture is one of inertia, where the lucky few to actually get a job in the formal sector have no intention nor incentive to leave -especially in the privileged public sector- and the higher educated unemployed appear to be waiting for a job in the public sector. 


\section{Chapter VI - Agricultural Situation in Burundi}

\section{Key Messages}

- Farmers operate on land plots of small sizes in hilly areas, facing serious erosion problems.

- Agriculture is predominantly traditional, with low productivity and little use of quality inputs and modern production means.

- While there are some diversifications in crops production, diversification outside agriculture remains very low.

- There are inefficiencies in labor allocation at the plot level driven by constraints in credit, labor and insurance markets.

Achieving the ambitious goals of eradicating extreme poverty will imply focusing on farmers, and boosting agricultural productivity, especially for a country like Burundi. In this context, the authorities' commitment to accelerate agricultural growth in Burundi has resulted in more financial resources injected in the agricultural sector, especially since the PRPS II. The Government and partners increased financing from \$92 million in 2012 to \$130 million in 2013.

The required knowledge that is needed to reform the agricultural policy in Burundi is still lacking. Little evidence is available on the typical farmer, in terms of their socio-demographic characteristics, their activities, their productivity level, accessibility to extension services, commercialization, and other constraints that they faces. The purpose of this chapter is to fill this gap by providing the relevant descriptive statistics of farmers in Burundi.

Despite the importance of agriculture in Burundi, reliable basic statistical data on the sector was lacking up until very recently. The country has never conducted a General Census of Agriculture from which a good sampling frame can be obtained. The opportunity to conduct a General Census of Population and Habitat (RGPH) in 2008 facilitated the possibility to undertake annual agrarian surveys, with the idea of improving planning and budgeting decisions in agriculture and livestock. In this context, the government and development partners launched in November 2011 a series of National Agricultural Surveys (ENAB), which cover all agricultural seasons and apply the same survey sampling methodology. The main outcomes are twofold: (i) collecting the data required to determine farming typologies (size, household composition, type of crops / speculations, acreage per farm, etc.) and support better evidence-based planning of agricultural policies and programs; (ii) collecting data on yields and production.

In this chapter, two rounds of the Enquête Nationale Agricole du Burundi (ENAB) for the periods 2011/12 and 2012/13 are used to provide a detailed profile of a typical farmer in Burundi with a focus on gender, regional and welfare disparities. The first section will provide an extensive account of the agricultural sector in Burundi, which is critical given that over 80 
percent of the labor force works in agriculture-related activities. The second section will focus on food production and productivity. The ENAB survey captures detailed data on production levels and size of plots and farm, which allow to accurately measuring yields. The ENAB survey did not focus on main cash crop (coffee, cocoa, tea, etc.). Therefore, all these crops are almost absent in the analysis, which will instead focus on staple food (maize, rice, cassava, etc.). The surveys also collect information on assets ownership and consumption levels that allow the analysis of farmers' welfare. In the last section of this chapter, the analysis will focus on bottlenecks and constraints that prevent Burundi's agriculture from reaching the necessary levels to ensure a proper development of the country. In particular, the section will explore the existing constraints related to access to finance and services, access to inputs, and the implementation of anti-erosion schemes.

\section{Snapshot of Agricultural Sector in Burundi's Economy}

\section{Burundi's farmers are generally young and have low education}

The farming community in Burundi is constituted of a young population with limited education. Overall, 57.9 percent of Burundi's farming population is less than 19 years old, and nearly 85 percent is younger than 39 years old (Figure VI.1). This extremely young population remains largely uneducated since more than half of the surveyed population (namely 53.8 percent) cannot read and/or write in Kirundi, the main language of Burundi (Figure VI.2). In addition, 76.2 percent of the population cannot read and/or write in other languages. Such low level of education is a barrier for technology penetration and use of modern inputs.

Figure VI.1: Burundi’s Farming Population by Age (Percentage)

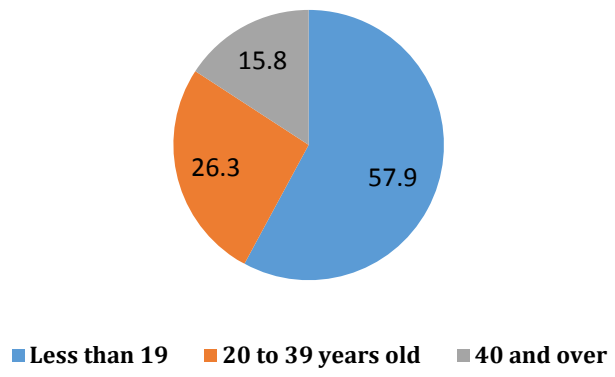

Source: WB estimations based on ENAB 2012-13
Figure VI.2: Farming Population by Literacy in Kirundi (Percentage)

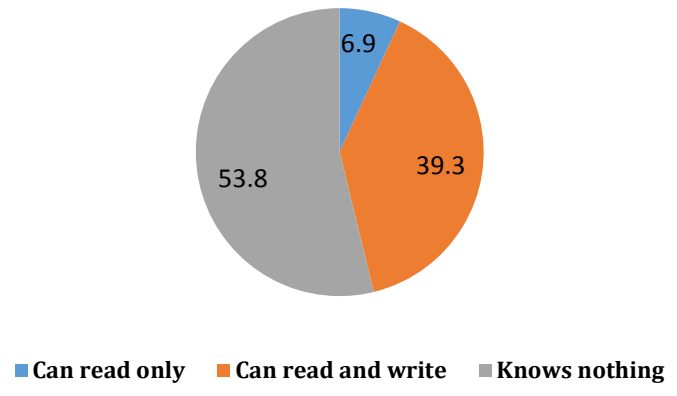

Low education attainment is negatively correlated to welfare and asset distribution, particularly regarding the education level of households' heads. While literacy is more or less the same for individuals in terms of welfare distribution, differences are larger when looking at assets distribution. In 2013, 43 percent of individuals in the richest quintile by asset cannot read and/or write in Kirundi, but 64.9 of individuals in the poorest quintile by asset are in the same situation (Figure VI.3). However, the situation appears more critical when looking at the 
education level of the heads of households, both in terms of welfare and asset distribution. Concerning welfare distribution, 69.1 percent of households' heads of the poorest welfare quintile were illiterate in Kirundi in 2013, while only 39.8 percent of households' heads in the richest welfare quintile were. This asymmetry increases when considering the asset distribution, with 62.6 percent households' heads of the poorest asset quintile identified as illiterate in Kirundi, while only 20.3 percent of households' heads of the richest asset quintile were also illiterate in said language (Figure VI.4). It is worth mentioning that welfare groups are based on the information on assets and consumption in ENAB surveys and therefore different from the welfare groups constructed in ECVMB 2013-14 of previous chapters.

Figure VI.3: Farming Population by Literacy in Kirundi and Asset Quintile (Percentage)

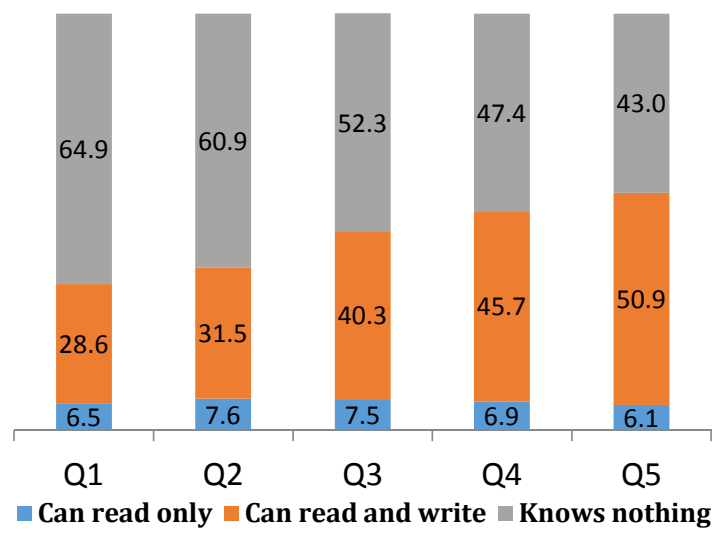

Figure VI.4: Heads of Households by Literacy in Kirundi and Asset Quintile (Percentage)

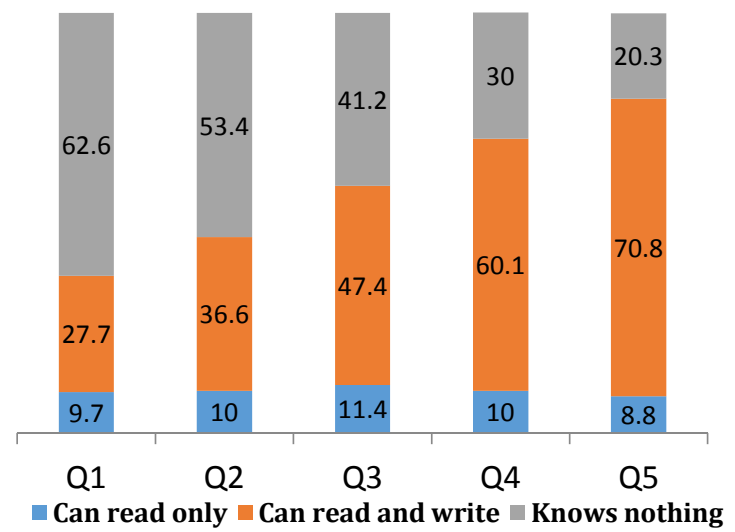

Source: WB estimations based on ENAB 2012-13

Agricultural population tends to live in large households who tend to be poorer. The average household size as estimated by the ENAB survey is 5.1 individuals per household. However, large discrepancies exist across the welfare distribution. In 2013, about 10 percent of the population in the lowest welfare quintile lives in households of less than 3 individuals while 24 percent of those at the richest quintiles live in households of similar small sizes. The spread between quintiles increases as the size of the household increases - farmers living in households of more than 5 individuals accounted for 66.3 percent of the poorest quintile and 42.2 percent of the richest one, while farmers living in households of more than 8 individuals accounted for 25.3 percent of the poorest quintile but only 11 percent of the richest one. For agricultural households, a larger size means easy access to almost free family labor. However, a larger household does not imply more land to farm. Instead it can lead to many individuals from the same household relying on the same small plots and limited food production. A larger family also implies more challenges, especially for the head that has to cater for everyone, thus increasing the likelihood of being poor. 
Figure VI.5: Farming Population by Size of Household and Welfare Quintile (Percentage)

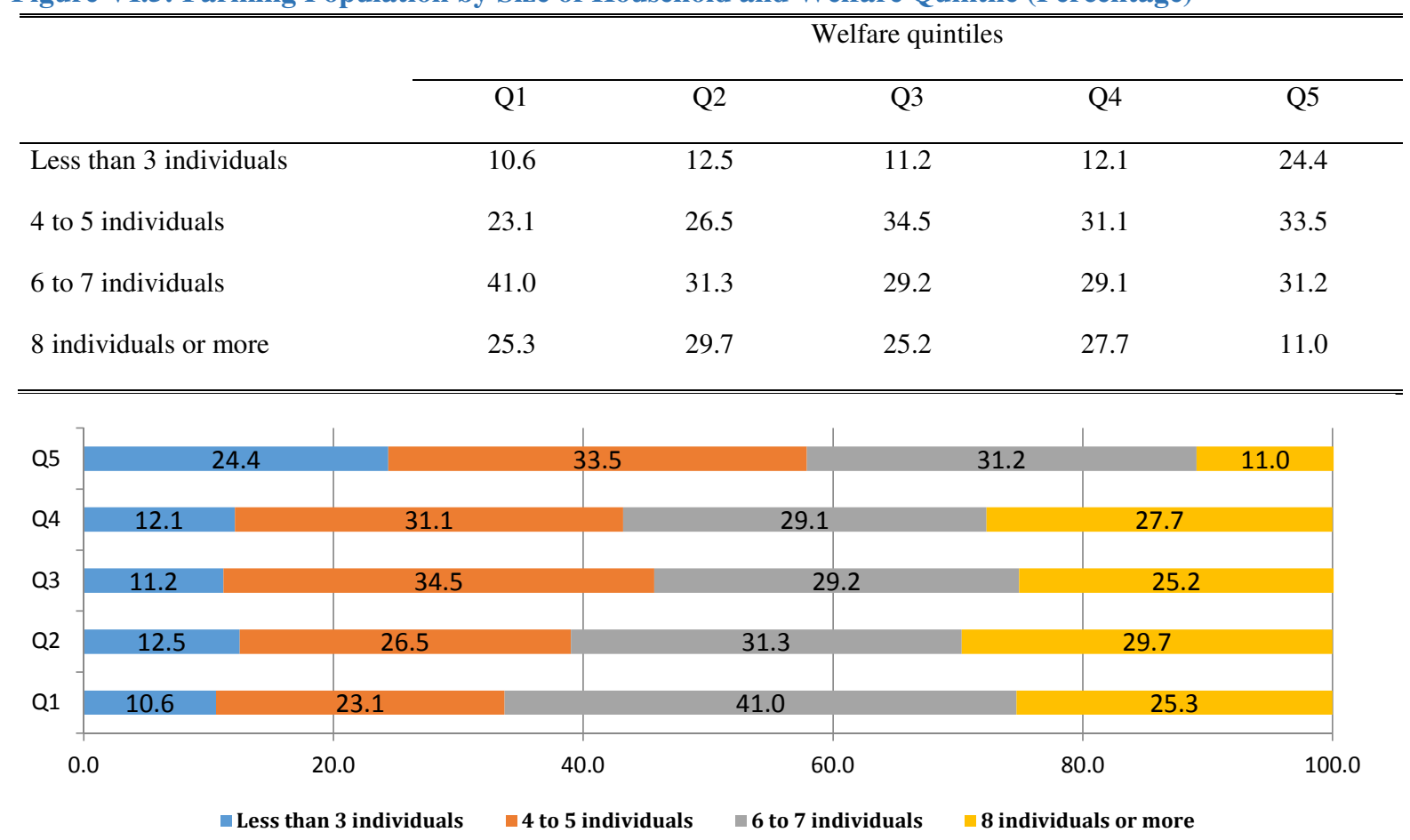

Source: WB estimations based on ENAB 2012-2013

In addition, very few farmers belong to a farmers' association/organization, which prevents the sharing of knowledge and good practices. In 2012/13, only 3 percent of farmers were members of an association/organization, down from 6 percent in 2011/12.

\section{Land plots are generally located inside the community in hilly areas and are of small size}

The majority of farms are located inside the community, limiting the commuting time necessary to reach the farm. In 2013, 63.1 percent of farms were located inside the community, with non-significant differences across gender and welfare distribution but important discrepancies across provinces. For instance, 85.2 percent of the farms in the provinces of Buyogoma are located inside the community while the same figure is only 35.5 percent in the Bugesera province (Figure VI.6). The overall consequence is that workers' commuting time to the farm - mostly by foot - remains limited and estimated on average at 13 minutes, with a commuting time slightly higher for non-poor. While individuals in the richest quintile will spend 15 minutes to reach the farm, a person in the poorest quintile will spend 11 minutes. The province of Imbo stands out with a high walking time to reach the farm. Those leaving in that area spend 25 minutes on average to reach their farm, reflecting the fact that half of the province's farms are located outside the community (maps of natural regions and administrative regions are provided at the end of the document). 
Figure VI.6: Location of Farms by Province (Percentage)

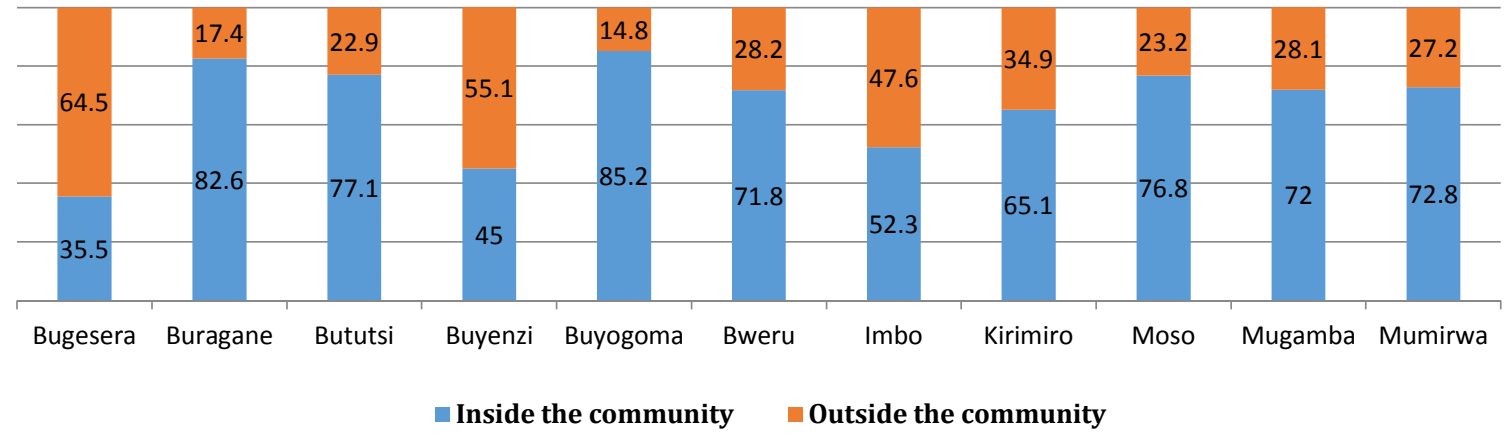

Source: WB estimations based on ENAB 2012-2013

With the majority of farms located in hilly areas - mostly hill-flanked -, erosion stands as a critical problem. Most of Burundi is a hilly plateau covered by forested mountainous slopes. As a consequence, the majority of farms are located either on hill flanks (55 percent), hill feet (17 percent), and hilltop (13 percent). A non-negligible 16 percent of farms are located in plain or in marsh, but it mostly reflects the topologies of Imbo, Moso, and Buyogoma provinces that are flat areas (Table VI.1). Conversely, the majority of Burundi's provinces are almost exclusively composed of hilly farms, which creates significant challenges in terms of erosion and the design of schemes addressing the degradation of hill-flanked plots. Given the landscape, and the type of soil, erosion control can prove important for sustainability and productivity.

Table VI.1: Relief of the Farms by Province (Percentage)

\begin{tabular}{|c|c|c|c|c|c|c|c|c|c|c|c|c|}
\hline & Bugesera & Buragane & Bututsi & Buyenzi & Buyogoma & Bweru & Imbo & Kirimiro & Moso & Mugamba & Mumirwa & Burundi \\
\hline Hilltop & 8,8 & 5,2 & 2,3 & 15,7 & 9,7 & 21,1 & 6,3 & 11,7 & 7,8 & 25,3 & 10,6 & 12,8 \\
\hline $\begin{array}{l}\text { Hill } \\
\text { flank }\end{array}$ & 57,3 & 72,7 & 66,6 & 57,9 & 45,5 & 52,8 & 34,5 & 60,8 & 30,1 & 49,5 & 66,9 & 54,5 \\
\hline Hill feet & 18,4 & 13,2 & 14,8 & 18,9 & 21,4 & 15,7 & 8,5 & 15 & 21,4 & 14,7 & 18,4 & 16,8 \\
\hline Plain & 5,6 & 1,3 & 2,2 & 2,3 & 12,1 & 6,8 & 46,2 & 1,2 & 35,8 & 0,8 & 0,4 & 8,2 \\
\hline Marsh & 9,9 & 7,7 & 14,1 & 5,3 & 11,2 & 3,5 & 4,6 & 11,4 & 4,9 & 9,8 & 3,8 & 7,8 \\
\hline
\end{tabular}

Source: WB estimations based on ENAB 2012-2013

Despite improvements overtime, the average size of a plot owned by individuals remain very small, which furthers gender, welfare, and regional discrepancies. The ENAB survey estimates suggest that the average plot size increased to 914 square meters in 2012/13, up from 740 square meters in 2011/12 (Figure VI.7). Despite this improvement, the average plot size is still less than a tenth of a hectare ( 0.0914 hectare). The average size of a plot owned by men is slightly higher than the one owned by women (938 against 835 square meters in 2012/13). Similarly, the average plot size of the poor is smaller compared to the average plot size of the non-poor. In 2012/13 for example, the plot size of the poorest quintile was 835 square meters, 
compared to 941 square meters for the richest quintile. Geographical discrepancies are the most striking. For instance, in the province of Moso the average plot size is 1,946 square meters, as most of the farms' parcels are located in plain areas and therefore prone to be larger. In comparison, the average plot size in the Buragane province is much smaller attaining 617 square meters only.

Differences across provinces and welfare quintiles are even higher at the farm and household level. If we combine all the plots for a given household and therefore consider farms size at the household level, it still appears that farm size is small in Burundi. On average, in $2012 / 13$, the farm owned by a household represented slightly less than half of a hectare $(4,616$ square meters - approximately 0.46 hectare). As it was the case at the plot level, the total size own by the non-poor is higher than the total size own by the poor (Figure VI.8). If we consider the asset quintile, the total size for the richest quintile (6,394 square meters) was 2.2 times bigger than the size for the poorest quintile (2,961 square meters). The biggest total size owned by households is found in Mugamba, Moso, Bututsi, Buyogoma, and Buragane, respectively. Overall, the fact that the total size of the farm is smaller than one hectare will potentially yield serious challenges in terms of economies of scales and technology adoption.

Figure VI.7: Average Plot Size by Province (Squared meter)

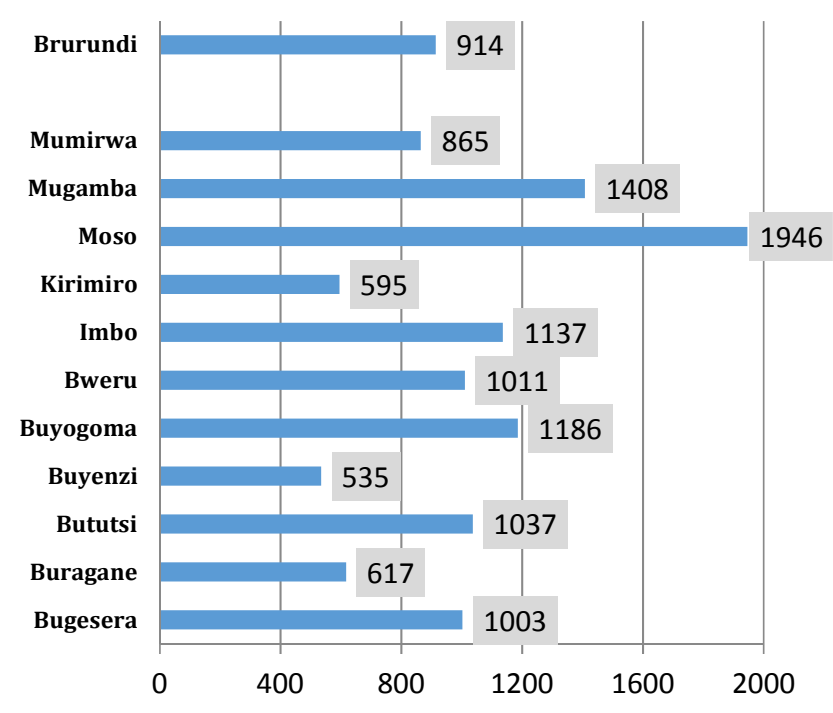

Source: WB estimations based on ENAB 2012-2013
Figure VI.8: Farm Size by Welfare Quintile and Asset Quintile (Squared meter)

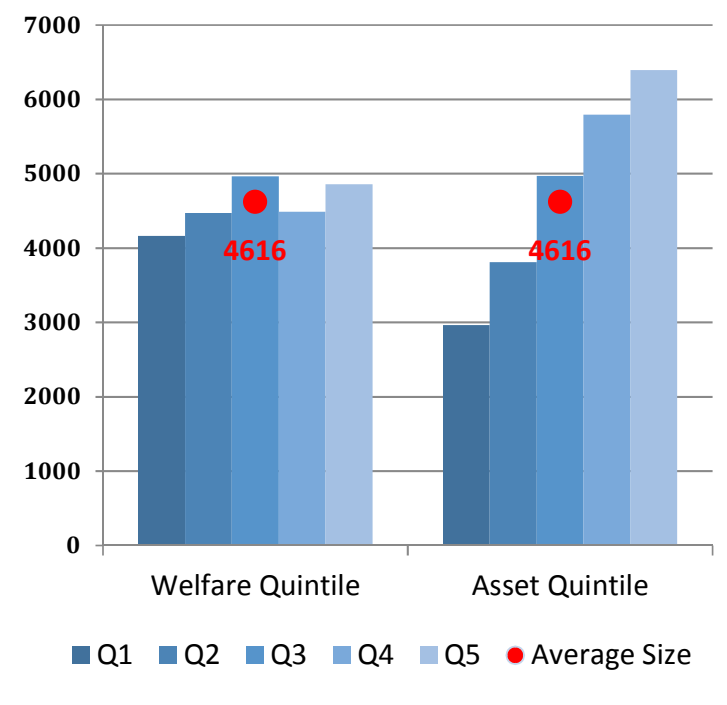

Source: WB estimations based on ENAB 2012-2013

Farmed land is traditionally transmitted through inheritance while commercial transactions remain limited. In Burundi, inheritance is the main channel through which people acquire land (Figure VI.9). A bit more than two third of Burundi's farms were acquired by inheritance (69.3 percent in 2013). Purchase of land is a distant second, with 18.5 percent of farms being declared as acquired through a commercial transaction. Fixed rent, free use, and gift 
are limited practices ( 3 to 7 percent of farms), while sharecropping is not significant (about 1 percent of farms only in 2012 and 1013). Inheritance is slightly more predominant among women and the poor. Conversely, male and the non-poor are more likely to purchase the land for farming. There are important regional differences on ownership right. Unlike in other provinces, inheritance is less important and occurs in less than half times in Imbo and Moso, with respectively 33.7 percent and 49.6 percent of the farms of these provinces being inherited.

Figure VI.9: Ownership rights, 2012/13 (percentage)

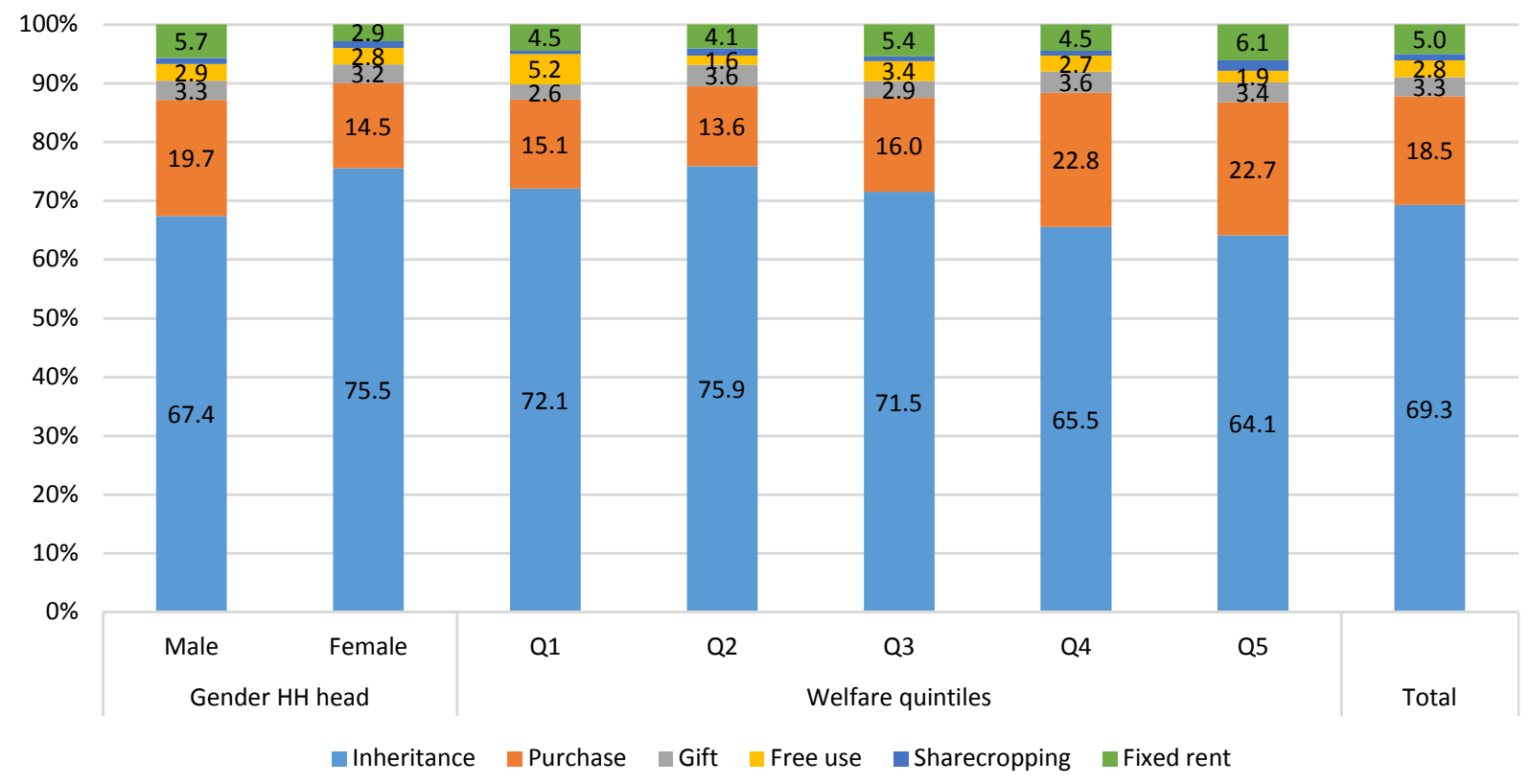

Source: WB estimations based on ENAB 2012-2013

\section{Agriculture is predominantly traditional with little use of quality inputs}

Agriculture in Burundi relies exclusively on traditional, farming practices, without any form of animal traction or mechanization. Neither animal traction nor modern mechanization exists in Burundi. Farmers use a diverse range of tools that are owned by the household with very low technology involved. Tools owned and used by farmers include hoe, tin, machete, basket, axe, and mortar, each of those being owned by at least 50 percent of Burundi's households. As pointed earlier, the average farm size is very small, which does not provide the necessary room for mechanization. Moreover, the low levels of education of households' heads, and the critical lack of financial resources prevent households from acquiring the necessary assets to develop towards systematic mechanization or animal traction.

Use of enhanced seeds remains very limited, with rice as the only exception. Penetration of improved seeds is still very low in Burundi with less than 5 percent of the plots planted with improved seeds. Less than 3 percent of the plots planted with bean, maize, Irish potato, cassava, and banana use improved seeds. Rice is the only crop that stands out since 10 percent of the plots growing rice were planted with improved seeds in 2012/13, up from 3.3 percent in 2011/12 
(Figure VI.10). However, the figure shows important major regional discrepancies, with the Moso and Imbo provinces accounting for almost all the improvement observed. Efforts in these provinces to mainstream the use of improved rice seeds led to a sharp increase of the share of plots planted with improved rice seeds between 2011 and 2013, from 13.4 to 49.1 percent in the Imbo province, and from 5.1 to 15.4 percent in the Moso province.

Figure VI.10: Share of Plots Planted with Improved Seeds by Crop (Percentage)

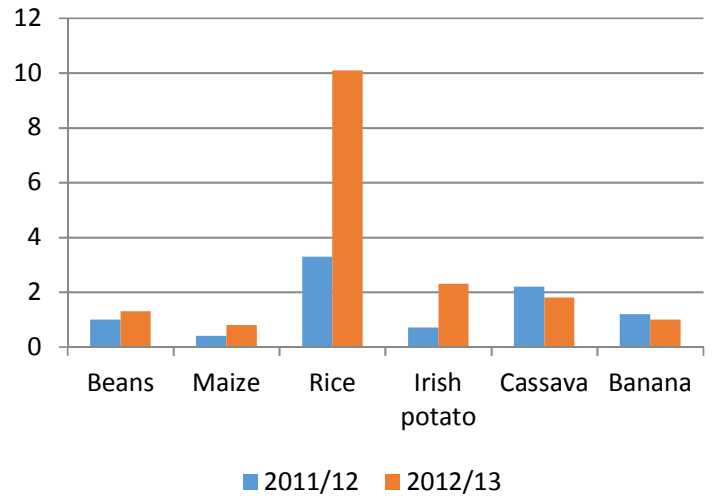

Figure VI.11: Share of Households and Plots using Chemical Fertilizers (Percentage)

Share of Households using Chemical Fertilizers

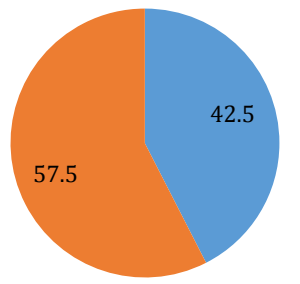

Share of Plots planted with Chemical Fertilizers

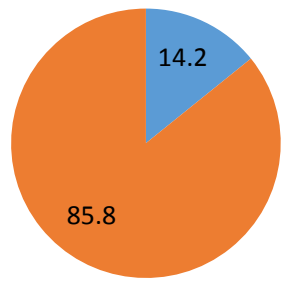

Source: WB estimations based on ENAB 2012-2013

At the same time, the current situation shows weak diffusion and use of chemical fertilizers, with specific crops targeted. The use of chemical fertilizers seems to improve over time with 42.5 percent of households using them in 2013 (Figure VI.11). In particular, provinces such as Kirimiro and Bututsi have a respective rate of households using chemical fertilizers of 92.9 and 76.6 percent. However, those promising figures at the household level hinder a weak diffusion and rate of usage at the plot level. In 2012/13, only 14.2 percent of the plots had been sprayed with chemical fertilizers, down from 19.8 percent in 2011/12. In certain provinces, such as Bweru and Buyogoma, only 3.1 and 4.1 percent of the plots respectively receive chemical fertilizers. The discrepancy between the rate of households using chemical fertilizers and the same rate at the plot level suggests that while two fifth of Burundi's households use chemical fertilizers, they only do so on a limited subset of the plots they own, mostly depending on the type of crops being grown. Indeed, in 2013, 44.7 percent of the plots planted with industrial crops received chemical fertilizers. Conversely, the figure was down to 6.7, 7.9, and 10.2 percent of the plots planted respectively with fruits, oleaginous, and bananas.

\section{Food Production: Characteristics and Performances}

\section{Burundi produces a mix of food crops across three different seasons}

Burundi's main agricultural activities entail rain-fed crop, truck farming, and livestock. All famers are engaged in rain-fed crop (Figure VI.12). Truck farming, livestock, and forestry are also very important activities in rural areas with respectively 53.8, 69.2, and 34.4 percent of 
households involved in them. While differences across welfare and gender are not significant, we notice important discrepancies across provinces. Truck farming is a prominent agricultural activity in Bututsi, Buyogama, and Kirimiro, concerning more than 70 percent of rural households of these provinces. Livestock is fairly widespread and well balanced across provinces. Forestry activities are concentrated in two provinces: Bututsi and Mugamba (Figure VI.13).

Figure VI.12: Farming activity by gender and welfare quintile (percentage of households)

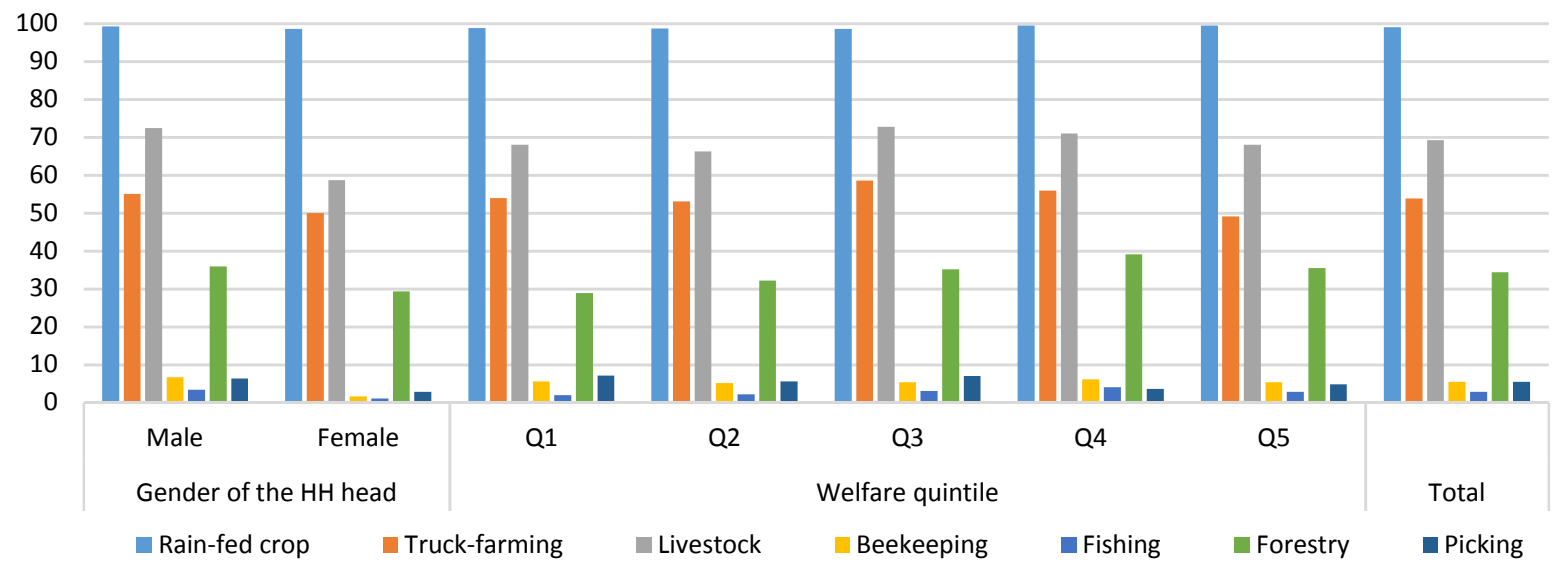

Source: WB estimations based on ENAB 2012-2013

Figure VI.13: Farming activity by provinces (percentage of households)

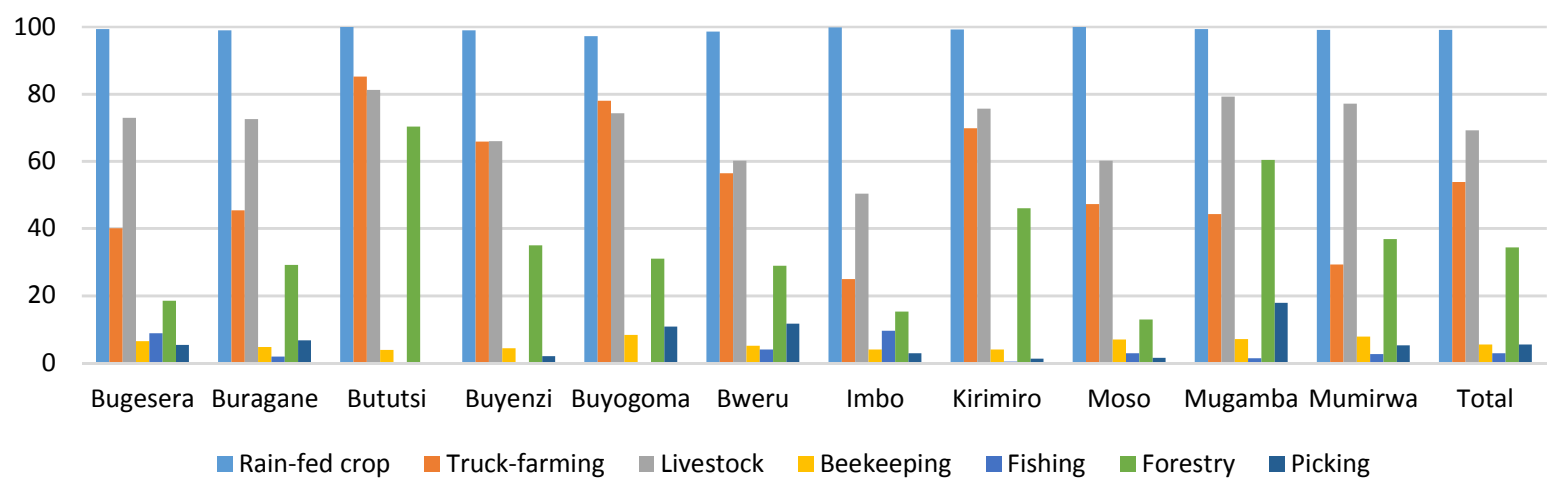

Source: WB estimations based on ENAB 2012-2013

Maize, cassava, banana, beans, and sweet potato are by far the main crops that are cultivated by farmers in Burundi. At national level, five crops stands out and are more likely to be cultivated by farmers - namely maize, cassava, banana, beans, and sweet potato (Figure VI.14). At least eight out of ten households cultivate each of these five crops. Other nonnegligible crops that are produced in Burundi include taro, Irish potato, pea, sorghum, rice, avocado, and peanuts. Beyond the five crops that are cultivated across the board, there are some 
crops that are specifics for some provinces. For example, the incidence of Irish potato cultivation is high in Bututsi and Mugamba, while sunflower and taro are mainly cultivated in Bugesera.

Figure VI.14: Crop prevalence in households (percentage of households using the crop)

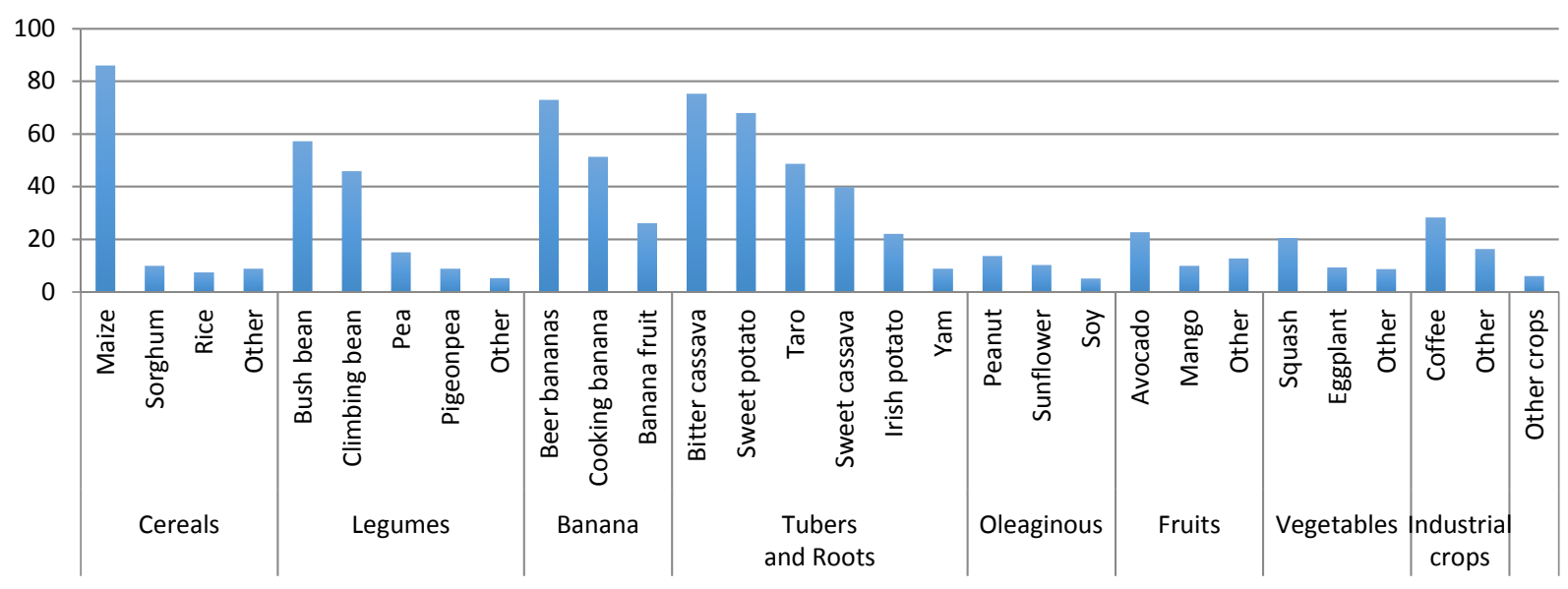

Source: WB estimations based on ENAB 2011/12 and ENAB 2012/13

The agro-ecological conditions of Burundi allow farmers to cultivate food crops three times per agricultural year, with differentiated food crop incidence by agricultural seasons. The bulk of yearly national food production stems from food crops grown in the agricultural season B that spans mid-February to mid-June. It supplied respectively 42.3 percent and 40.5 percent of yearly national food productions in 2012 and 2013, respectively (Figure VI.15). From midNovember to mid-February, the agricultural season A supplied yearly national food productions in proportions of 33.8 percent in 2012 and 32.5 percent in 2013. The agricultural season C (midJune to mid-November) remains the smallest national food crop supplier, but its share improved substantially compared to what was observed in previous years.

Figure VI.15: Share of Food Production by Season and Type of Crop (Percentage)

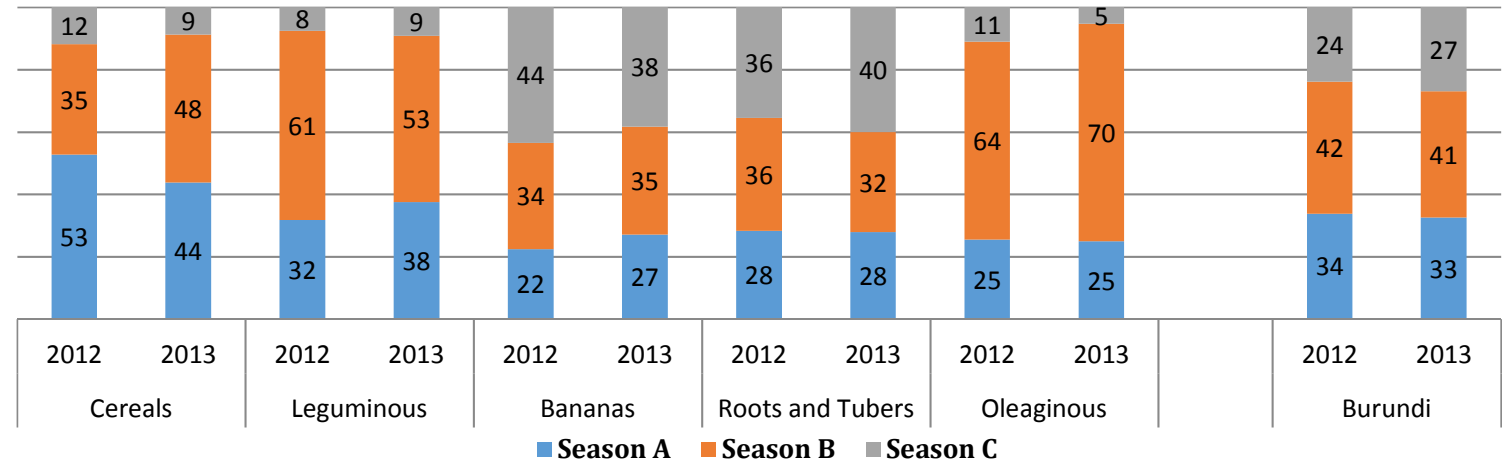

Source: WB estimations based on ENAB 2011-2012 and ENAB 2012-2013 
In each agricultural season, Burundian farmers can produce different mix of rain-fed crops. In terms of crops, maize and cereals is mainly produced in Season A, while cassava and banana are cultivated all year long (Figure VI.15). Beans are mainly produced in Season A and Season B. More specifically, cereals have continued to be produced prominently during the agricultural season A, which contributed to 52.7 percent of the total national production of cereals in 2012 and to 43.8 percent of the total national production of cereals in 2013. The national production of leguminous crops (measured in cereals equivalent $-\mathrm{CE}$ ) and the national production of oleaginous crops produce in the agricultural seasons $\mathrm{B}$, reached 60.7 percent in 2012 and 53.3 percent in 2013 for the former crops, and 63.6 percent in 2012 and 69.8 percent in 2013 for the latter crops. The annual production of bananas and the annual production of roots $\&$ tubers came mainly from the agricultural seasons B and C. For the former crops, the received proportions were 34.1 percent (season B) and 43.5 percent (season C) in 2012 and 34.7 percent (season B) and 38.3 percent (season C) in 2013. For the latter crops, the received proportions were 36.3 percent (season B) and 35.5 percent (season C) in 2012 and 32.1 percent (season B) and 40.1 percent (season C) in 2013.

Food production seems to be specialized by regions in rural Burundi. Cereals and oleaginous were produced notably in the Centre Eastern region, representing, in 2013, 43.7 percent of Burundi's national cereals production and 45.4 percent of the national oleaginous production. The agricultural year 2012 saw similar leading position for the Centre Eastern region, supplying 37.2 percent of the national production of cereals and 50.5 percent of the national production of oleaginous. The Northern region dominates the production of leguminous and bananas, contributing to 48.5 percent of the 2013 national production of leguminous and 47.5 percent of the 2013 national productions of bananas. These proportions were in progression by 8-12 percent compared to 2012. As for roots \& tubers, the Northern region (yearly average of 34.7 percent) and the Centre Eastern region (yearly average of 32.4 percent) showed the largest contributions to national productions in 2012 and 2013.

Crops are usually combined with others at the farm level. Only a third of the cultivated land is allocated to a single crop (Figure VI.16). About the quarter of land is allocated to two crops. A fifth of the land is allocated to three crops. A non-negligible part is attributed to four crops or more. There are some differences across regions.

Figure VI.16: Number of crops per farm by gender and welfare quintiles (percent of households)

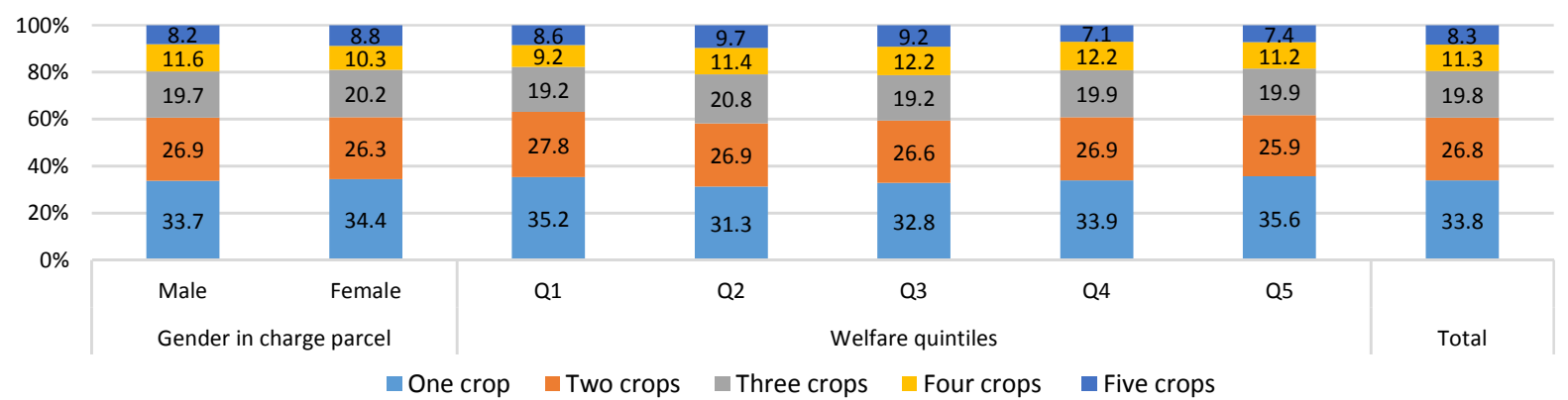

Source: WB estimations based on ENAB 2012-2013 
Figure VI.17: Number of crops per farm by provinces (percent of households)

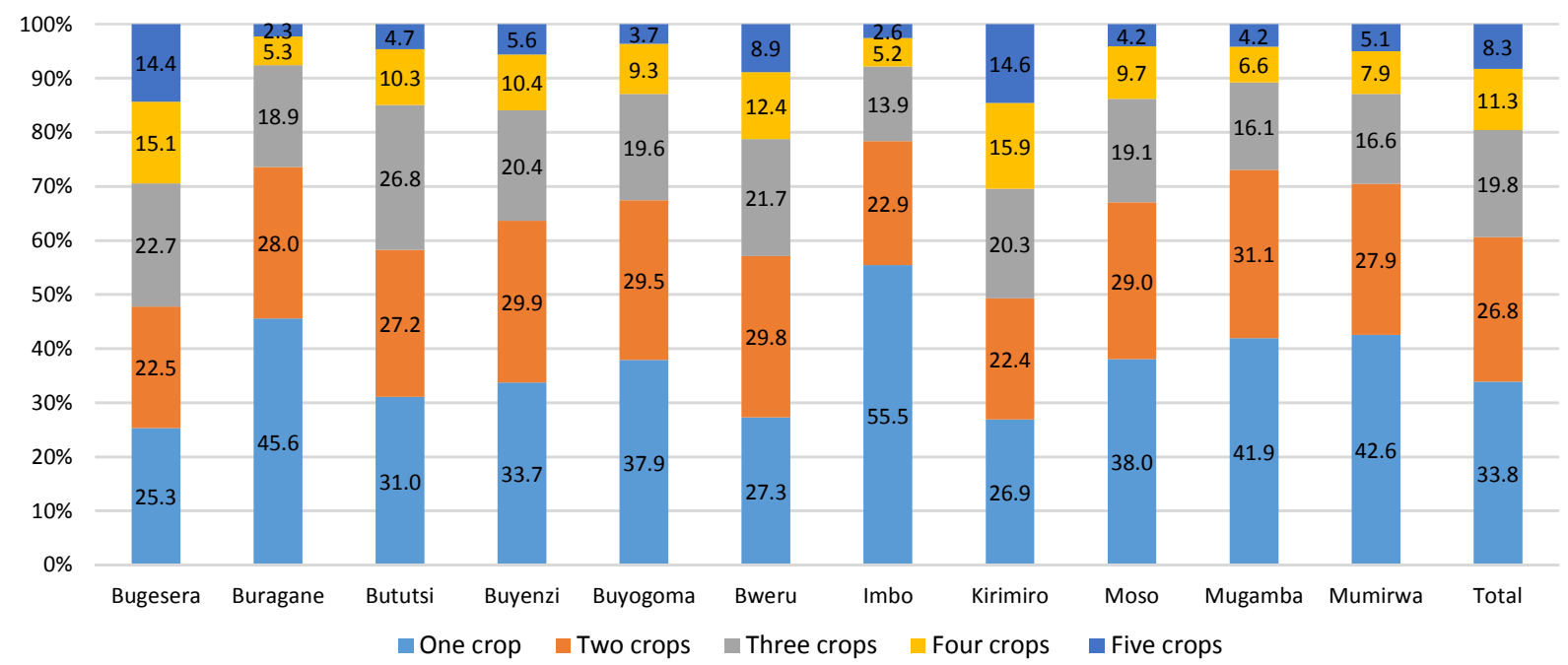

Source: WB estimations based on ENAB 2012-2013

Diversification out of agriculture remains scarce leaving farmers vulnerable to adverse climatic conditions and price shocks. The vast majority of households only relied on agriculture as their sole income source. Yet, experiences in other Sub-Sahara African countries (Uganda for example) suggest that diversification out of agriculture is important for farmers to smooth their consumption and to be less vulnerable to weather and price shocks (Ruth Hill and Carolina, 2016). In Burundi, 90.2 of agricultural households have no income outside of the agricultural sector. The likelihood to have alternative sources of income outside agriculture increases with welfare, both in terms of income and assets. This suggest two things: (i) the poor are so poor that they don't have the necessary endowment to venture out of the traditional agriculture system; and (ii) having a secondary income source can protect against shocks that can affect agricultural production (weather, prices, etc.), thus helping maintaining a level of wellbeing.

For those who diversify, transfers and trade/sales side-activities are the second most important source of livelihoods. For those who venture out of agriculture for additional income, "other" is the most predominant income source (Figure VI.18), which might include among other transfers (4.9 percent of total households). Following diversification activities are sales/trade (3.7 percent) and handcraft (1.3 percent). Bututsi and Moso are the provinces with the lowest tentative of diversification out of agriculture with respectively 94.5 and 93.1 percent of these provinces' households without secondary sources of income (Figure VI.19). On the opposite, Mumirwa is the province with the highest rate of diversification out of agriculture. Only 7.9 percent of Mumirwa's rural households have no additional sources of income while 6.9 percent of them benefit from "other" sources and 4 per cent from sales/trade activities. 
Figure VI.18: Diversification out of agriculture by gender and welfare quintiles (percentage of households)

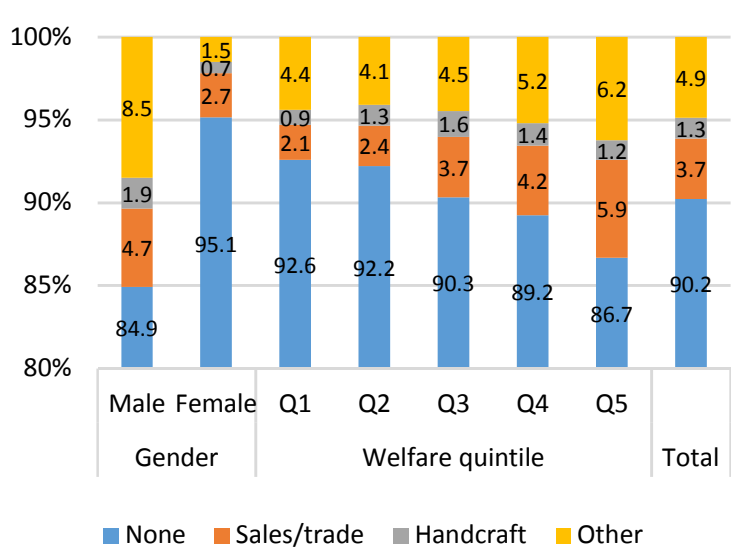

Source: WB estimations based on ENAB 2012-2013
Figure VI.19: Diversification out of agriculture by provinces (percentage of households

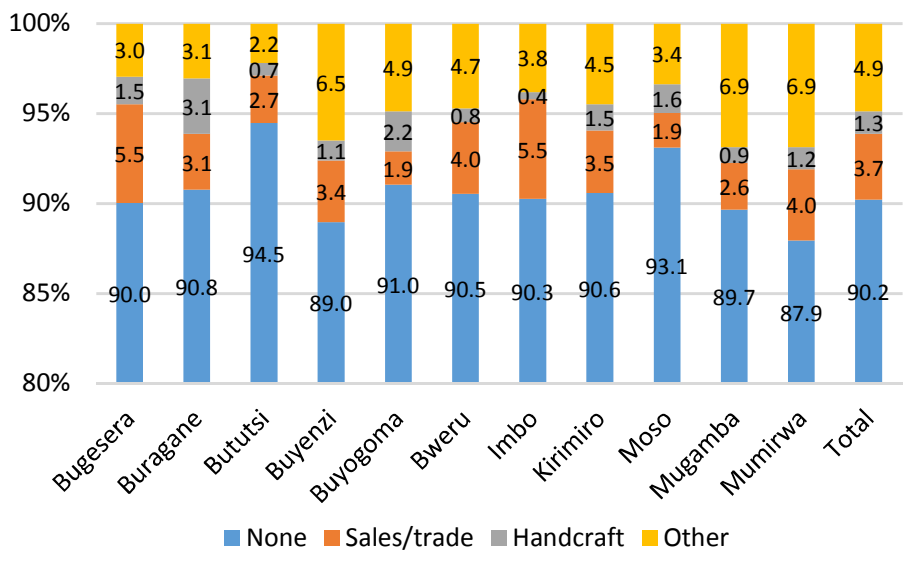

Source: WB estimations based on ENAB 2012-2013

\section{Some gains in food productivity, though levels remain low}

Between 2012 and 2013, the Burundi food production increased by 21.1 percent, which may have slightly helped families to improve their daily lives. In 2013, food production reached 1.43 million cereal equivalent (CE) metric tons (MT), up from CE 1,18 million metric tons in 2012 (Table VI.2). As a result, household food production averaged CE 919 kilograms $(\mathrm{kg})$ in 2013, making up a progress of CE $154 \mathrm{~kg}$ from the previous year, i.e., a year-on-year increase of 20.2 percent. Households living in the South of Burundi experienced the largest food production gains countrywide, with an increase of 33.9 percent in annual average food production, whereas households living in the other regions could achieve food production gains of 17-20 percent only. However, during the two years analyzed, the Centre Eastern region and Northern region were the regions in which household food production was the largest among the four regions, averaging CE $1009 \mathrm{~kg}$ and CE $971 \mathrm{~kg}$ per household in 2013 and CE $845 \mathrm{~kg}$ and CE $832 \mathrm{~kg}$ per household in 2012, respectively.

Table VI.2: Food Production by Type of Crop (CE metric tons)

\begin{tabular}{lrrr}
\hline \hline & 2012 & 2013 & $\Delta(\%)$ \\
\hline Cereals & 260,289 & 274,049 & $5.3 \%$ \\
Leguminous & 288,549 & 281,719 & $-2.4 \%$ \\
Bananas & 135,667 & 259,435 & $91.2 \%$ \\
Roots and tubers & 474,204 & 584,686 & $23.3 \%$ \\
Oleaginous & 22,689 & 30,700 & $35.3 \%$ \\
Total & $1,181,398$ & $1,430,589$ & $21.1 \%$ \\
\hline \hline
\end{tabular}

Source: WB Estimations from ENAB 2011-2012 and ENAB 2012-2013

The productivity of most Burundi's food crops increased between 2012 and 2013, up from low base. In particular, productivity of bananas and roots \& tubers has increased across 
the different seasons, despite shocks and adverse conditions. The productivity of (beer, cooking, fruits) bananas improved steadily since the agricultural season A of 2012, without strong disturbances that could be expected in the Burundian context of salient agricultural seasonality and diseases susceptible to affect banana productivity (Figure VI.20). On a seasonal average, banana yield - measured as quantity produced of bananas divided by specific land planted to bananas - increased by 28 percent per agricultural season. This allowed the country to reach a productivity level of $3.485 \mathrm{MT} /$ ha in the agricultural season C of 2013.

Figure VI.20: Food crop yields dynamics from 2012 A to 2013 C (MT/ha)

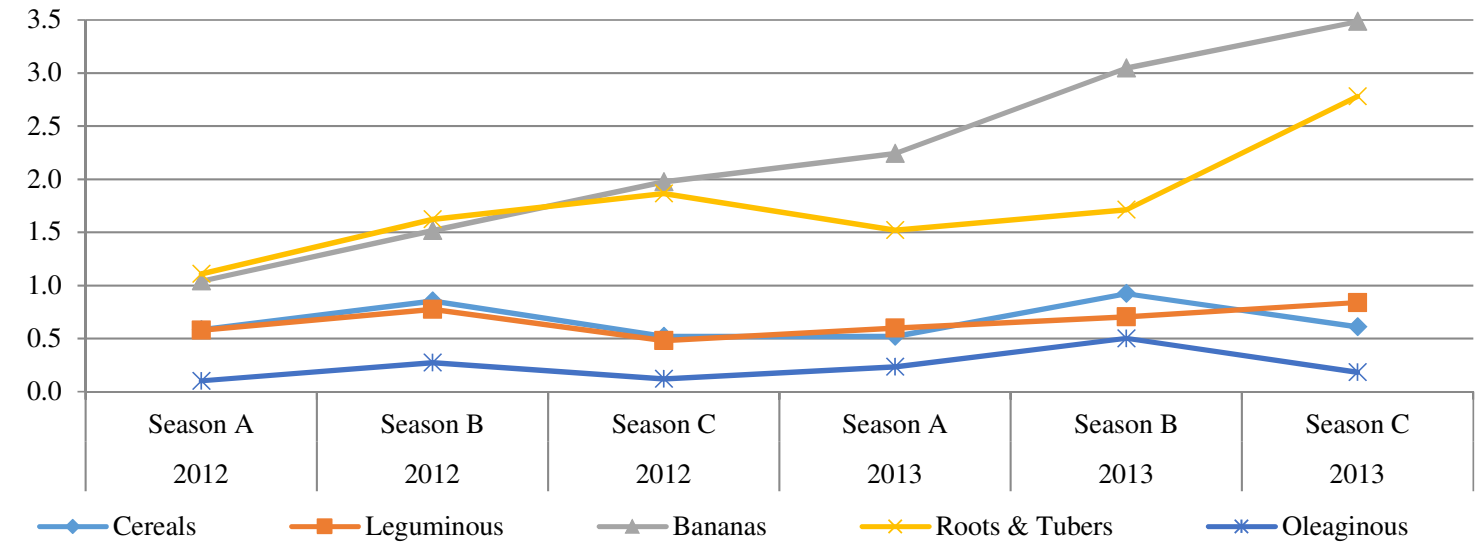

Source: WB estimations based on ENAB 2011-2012 and ENAB 2012-2013 surveys

Roots \& tubers yields suffered from important shocks but still show an improvement since 2012. Our estimations suggest that the yields of roots \& tubers, the other key perennial food plants in Burundi, might have been affected recently by more severe shocks. These yields followed a trend similar to that of the yields of bananas up until the agricultural season C of 2012 (Figure VI.20). The sharp productivity drop that occurred in the agricultural season A of 2013 stemmed essentially from the negative impact of devastating diseases, including the cassava severe mosaic and the cassava brown streak virus (CBSV). The worrying presence of the latter disease was detected in 2011, raising concerns on cassava yields in the years ahead if appropriate actions were not taken. The Ministry of Agriculture and Livestock (MINAGRIE) assessed that nine provinces out of sixteen were infected by the CBSV in early 2013. In this context, it can be hypothesized that the distribution of nearly 16 million improved and resistant cassava seeds / cuttings in early 2013 to rural farmers in the Centre Eastern region and the Northern region contributed to the rapid recovery of cassava productivity since the agricultural season C of 2013. Clearly, it is the combination of coordinated efforts such as the one abovementioned that permitted a 24-percent productivity growth per agricultural season for roots \& tubers in Burundi, mitigating the harmful impact of shocks. The Centre Eastern and Northern regions, which used to be in the top-three regions with yields above seasonal averages in 2012 and before, could manage to produce in 2013 more than the average of season B (1.713 MT/ha) and more than the average of season $\mathrm{C}$ (2.780 MT/ha). The Western region experienced the highest roots \& tubers productivity outcomes in the six agricultural seasons examined. 
Yields of leguminous, cereals, and oleaginous show only a weak improvement over time with a high sensitivity to shocks and unpredictable events. The average leguminous yield of the three agricultural seasons in 2013 was $0.713 \mathrm{MT} /$ ha whereas it equaled $0.611 \mathrm{MT} / \mathrm{ha}$ in 2012, giving rise to an increase of 16.8 percent. This progress is still very insufficient to achieve the minimum yield standards of for example Rwanda whereby leguminous yields varied between $0.730 \mathrm{MT} / \mathrm{ha}$ and $1.000 \mathrm{MT} / \mathrm{ha}$ during the same years. The 16-perfent increase cannot hide the fact that the base productivity is extremely low. Cereals yields recorded the lowest progress out of all food crops examined, averaging 10.3 percent growth rate per agricultural season. However, there seem to be rooms to achieve better productivity levels. Cereals yields decreased by 10.7 percent between agricultural season A of 2012 (0.581 MT/ha) and agricultural season A of 2013 (0.519 MT/ha). In contrast, not only the yields of cereals improved significantly between the two agricultural seasons B (8.1 percent) and the two agricultural seasons $C$ (17.7 percent), but they were also globally higher than what was seen in agricultural seasons A. With respect to cereals, it is likely that something worth understanding better happened during seasons B and seasons C, which may explain the presence of both faster yield growth rates and higher yield levels. To draw lessons to improve the production of cereals in Burundi, perhaps the performance in the Western and Southern regions would be a useful inspiration. The former one is a region whereby cereals yields regularly exceeded $1.000 \mathrm{MT} / \mathrm{ha}$, while the latter one is a region whereby cereals yields is very close to $1.000 \mathrm{MT} / \mathrm{ha}$.

However, yields in the main crop categories remain low in Burundi, particularly compared to regional peers. The ENAB survey captures yields in a very robust way. For each sample plot, the enumerator chose randomly an area of 4 square meters or 25 square meters and that area is harvested and the quantity is weighted. Yields of various types of crops remain low in Burundi compared to neighboring countries (Table VI.3). For instance, Burundi's average yield in banana production is estimated at $6.7 \mathrm{~T} / \mathrm{ha}$ compared to Kenya's average that stands at $24 \mathrm{~T} / \mathrm{ha}$, even though Burundi outperform other neighbors. However, when we consider yields in potatoes, rice, and cassava, Burundi badly trail behind its peers. The country's yield in cassava stands at 8.9 T/ha compared to $12.9 \mathrm{~T} /$ ha for Kenya, $14.9 \mathrm{~T} / \mathrm{ha}$ for Rwanda, and $11.5 \mathrm{~T} / \mathrm{ha}$ for Uganda. Similarly, in potatoes crops, Burundi's yield is only of $3.1 \mathrm{~T} /$ ha compared to $20.3 \mathrm{~T} / \mathrm{ha}$ in Kenya, 14.2 T/ha in Rwanda, and 7.3 T/ha in Tanzania.

Table VI.3: Food Crop Yields (selection) in East African Community (2012, Tons per Hectare - T/ha)

\begin{tabular}{lcccccc}
\hline \hline & Beans, dry & Bananas & Cassava & Maize & Potatoes & Rice, paddy \\
\hline Burundi & 0.6 & 6.7 & 8.9 & 1.2 & 3.1 & 2.1 \\
Kenya & 0.6 & 24.0 & 12.9 & 1.7 & 20.3 & 4.9 \\
Rwanda & 0.9 & 1.6 & 14.9 & 2.3 & 14.2 & 5.7 \\
Uganda & 0.4 & 4.4 & 11.5 & 2.5 & 7.1 & 2.3 \\
Tanzania & 0.9 & 5.7 & 5.7 & 1.2 & 7.3 & 2.2 \\
\hline \hline
\end{tabular}

Source: FOASTAT 2013.

Advisory services and access to modern inputs will be key steps to help farmers in maximizing their potential and in catching up with best performers. For most type of crops, 
yields remains constant between 2011/12 and 2012/13 (Table VI.4). The only exceptions are for fruits, other crops, and vegetables. Between 2011/12 and 2012/13, yield for fruits and others crop went down. The yield for fruits decreased by more than 2 ton/ha, down to 6.1 ton/ha from 8.5 ton/ha. In the opposite, there was a sharp improvement in the productivity for vegetables. The yield for vegetables increased from 6.4 ton/ha to 8 ton/ha.

Table VI.4: Food Yields by Type of Crop and Year (in Tons per Hectare - T/ha)

\begin{tabular}{cccccccccc}
\hline \hline & Cereals & $\begin{array}{c}\text { Legumino } \\
\text { us }\end{array}$ & Banana & $\begin{array}{c}\text { Tubers/roo } \\
\text { ts }\end{array}$ & $\begin{array}{c}\text { Oleaginou } \\
\text { s }\end{array}$ & Fruits & Vegetables & $\begin{array}{c}\text { Industrial } \\
\text { crops }\end{array}$ & $\begin{array}{c}\text { Other } \\
\text { crops }\end{array}$ \\
\hline $2011 / 12$ & 1,7 & 1,4 & 5,9 & 5,5 & 0,9 & 8,5 & 6,4 & 4,0 & 3,6 \\
$2012 / 13$ & 1,4 & 1,2 & 6,3 & 5,4 & 0,9 & 6,1 & 8,0 & 8,7 & 2,2 \\
\hline
\end{tabular}

Source: WB Estimations from ENAB 2011-2012 and ENAB 2012-2013

There are important regional differences of productivity across specific crops. Mugamba is by far the most productive region for cereals, producing around 3 ton/ha in 2012/13. Bututsi, Buyenzi and Imbo provinces also perform relatively well in terms of cereal production (more than 2 ton/ha for these three regions). Conversely, the provinces of Bugesera and Bweru have the lowest productivity in cereals. The yields in these provinces are barely higher than half the national average. In addition to its dominant position in cereal production, Mugamba is the region with the highest productivity for banana and oleaginous. On the other hand, Bugesera appears to be the region with lowest productivity for many types of crops.

As a consequence of the difference in land size and yields across gender, welfare and regions, the national production of various crops is concentrated among small population groups. More than 87 percent of the production of banana, oleaginous, fruits and vegetables is done by men. For fruit for example, almost all the production (99 percent) is done by men. The two wealthiest quintiles account for a bigger share of the national production for all type of crops. These two quintiles produce 81 percent of fruits production. The corresponding figures are 57, 62 and 66 percent for cereals, leguminous and oleaginous respectively. There are also impressive concentration by region. For example, Imbo, Kirimiro, and Moso account for 64 percent of cereals production. Bugesera accounts for 32 percent of the banana production; Imbo accounts for 33 percent of oleaginous production; Kirimiro accounts for 81 percent of fruits production; and Mumirwa accounts for 42 percent of vegetables production.

\section{Bottlenecks and Existing Constraints}

\section{Low access to finance and services}

In Burundi, banks and microfinance institutions seldom finance agricultural activities. This is because they see agriculture and livestock too risky due to inter alia price and climatic shocks, terribly lacking professionalism as most farmers have no managerial education or training, and not offering sufficient guaranty to secure repayment in case of default as land - i.e. the main asset of farmers - is not considered as a secured and liquid enough collateral. In this context, 
about 90 percent of rural households are excluded from the formal banking system, being bound to rely on low capacity informal financing (e.g., mutual aid associations, etc.) or self-financing essentially for those households selling cash crops.

As a consequence, financial services in Burundi are not accessible to the farmers. Only 2 percent of farmers said that they were able to receive a loan during the last 3 years. In 2012/13, access to credit was slightly higher in Bugesera, Buyogoma, and Imbo compared to other provinces, but yet remains very limited. As extensively demonstrated in the literature, financial constraint is often the main limitation faced by farmers when they try to shift to a higher level and more productive technology. The absence of competitive financial institution, which mobilizes savings and provides credit to farmers at good conditions, undermines agricultural productivity and rural revenues. Many small landholders would like to take full advantage of high food market prices (bananas, potatoes, dry beans, vegetables, fruits) prevailing in urban centers, but they remain deeply limited in their capacity to finance disproportionately improved seeds and expensive fertilizers, including manure and limestone amendment.

The coverage of extension and advisory services is very low in rural areas of Burundi. In 2012/13, only 2.3 percent of farmers had benefited from advisory services. This is down from 4 percent in 2011/12. These numbers are quite low, and suggest a very low coverage of extension and advisory services. Yet in a context where agriculture is still very traditional, advisory services, along with access to credit, are a minimum requirement if the goal is to support the farmers in shifting to a different and more modern practice. In some provinces - namely Buragane, Imbo and Moso - extension services are nonexistent. In the provinces with the highest rates of coverage, such as Mugamba and Mumirwa, the extent of extension and advisory services remains very low with close to only 5 percent of farmers benefiting from such services in $2012 / 13$.

As far as geographic coverage of the country is considered, the government and NGOs seem to have divided responsibilities across the country. For most provinces, either the government or NGOs/projects provide advisory services (Figure VI.22). In 2012/13, government's advisory services were mainly concentrated in Bututsi, Buyogoma, Kirimiro, Mugamba and Mumirwa provinces. In the meantime, NGOs/projects interventions were concentrated in Bugesera, Buyenzi and Bweru. As pointed out in the national agricultural strategy (Ministry of Agriculture, 2008), agro-processing businesses are heavily concentrated in these provinces. These NGOs and projects are organizing and supporting farmers in various ways in order to insure the availability in quantity and quality of inputs for their transformation units. Government and NGO/projects seem to be targeting different groups of farmers. Clearly, the overall likelihood of benefitting from advisory service is the same for both male and female (Figure VI.21). But female are more likely to benefit from the support of NGO/projects while male are slightly more likely to benefit from the government's advisory services. Moreover, $\mathrm{NGO}$ /projects seems to do better in reaching out to the extreme poor. 
Figure VI.21: Provider of advisory services by gender and welfare quintile (percentage of households)

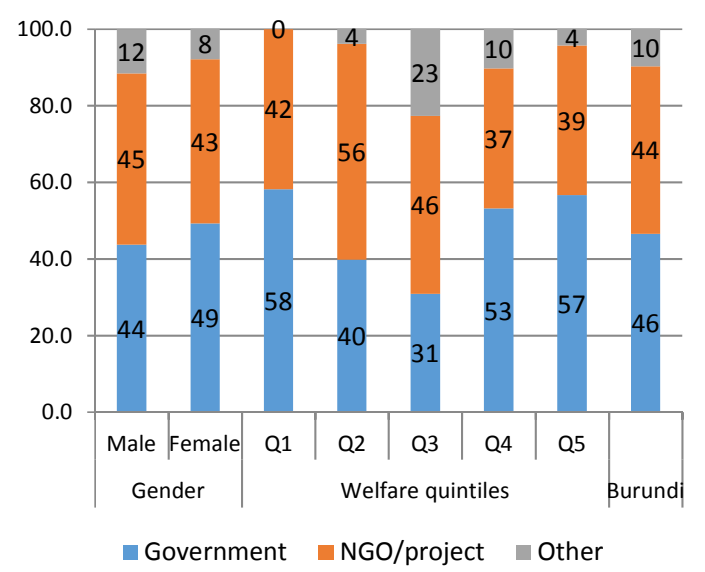

Figure VI.22: Provider of advisory services by provinces (percentage of households)

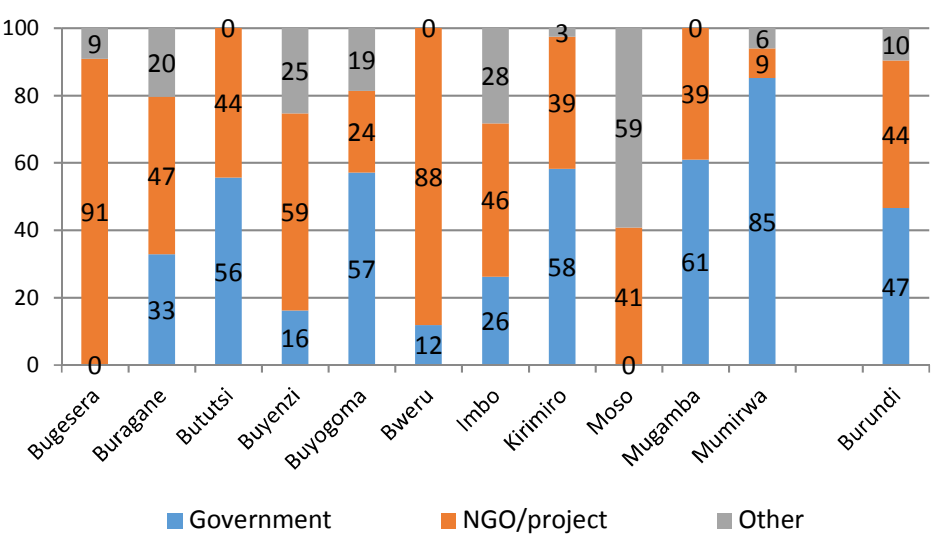

Source: WB estimations based on ENAB 2012-2013.

The ongoing reform of land ownership might provide farmers with valuable collateral that could be used to seek financial credit and loans. In recent years, the incidence of land-led conflicts has grown fast resulting from high population growth, massive return of refugees, and its corollary of heightened human activities. To maximize the benefit of land ownership in rural areas, participants in the 2014 "Etats Généraux de l'Agriculture et de l'Elevage du Burundi" agreed that the banking system should now endeavor to provide credits to agro-pastoral farmers based on their sole capital asset possession, namely land. They also recommended that the communal land titling / certification institutions, created with the 2011 Land Code, accelerate the ongoing process of land titling / certification to provide formal land titles to landholders. Down the road, this challenging reform should lead to more land transactions in rural areas because land certificates will bring in the actual land market security, transparency, and reliability.

\section{Low access to inputs}

Although the diffusion of chemical fertilizers remains limited, the situation has improved over the last few years, presumably explaining at least part of the period's aggregate food production increase. As mentioned previously, 42.5 percent of Burundi's households use chemical fertilizers. In the Burundi context, access and use of fertilizers have become perhaps one of the most significant impediments to improved yields and productivity in the agricultural and livestock sector. With an increase of 76.0 percent in the (revealed) demand for fertilizers between 2012 and 2013 (Table VI.5), the country's authorities assisted by development partners are clearly showing commitment to promote the use of modern fertilizers by farmers in Burundi's rural areas. For instance, the government launched the National Fertilizer Subsidy Program launched in August 2012. As a result of this encouraging progress, the volumes of modern fertilizers applied in cultivated plots by farm households moved from an average of 10.2 $\mathrm{kg} / \mathrm{ha}$ in 2012 to an average of $18.4 \mathrm{~kg} / \mathrm{ha}$ in 2013 . This is above the average of $8 \mathrm{~kg} / \mathrm{ha}$ per 
year in Sub-Saharan Africa in 2006, but still largely below for instance the World's average of $93 \mathrm{~kg} /$ ha a year.

Table VI.5: Fertilizer's Use by Agricultural Season and by Type of Fertilizer (metric tons)

\begin{tabular}{|c|c|c|c|c|c|c|c|}
\hline & NPK & Urea & DAP & KCL & "Chaux" & All fertilizers & $\begin{array}{l}\text { Fertilizer application } \\
(\mathrm{kg} / \mathrm{ha})\end{array}$ \\
\hline \multicolumn{8}{|l|}{2012} \\
\hline Season A & 548 & 1,027 & 2,711 & 56 & 0 & 4,342 & 10.2 \\
\hline Season B & 290 & 936 & 6,076 & 156 & 79 & 7,537 & 16.9 \\
\hline Season C & 125 & 354 & 869 & 19 & 0 & 1,366 & 3.6 \\
\hline \multirow{2}{*}{ Total } & 963 & 2,317 & 9,656 & 230 & 79 & 13,245 & \multirow{2}{*}{10.2} \\
\hline & 7.3 & 17.5 & 72.9 & 1.7 & 0.6 & 100 & \\
\hline \multicolumn{8}{|l|}{2013} \\
\hline Season A & 310 & 887 & 9,542 & 110 & 0 & 10,849 & 25.3 \\
\hline Season B & 315 & 1,554 & 6,164 & 141 & 1,247 & 9,421 & 21.1 \\
\hline Season C & 101 & 663 & 1,023 & 2 & 1,247 & 3,036 & 8.7 \\
\hline \multirow{2}{*}{ Total } & 725 & 3,104 & 16,729 & 253 & 2,494 & 23,306 & \multirow{2}{*}{18.4} \\
\hline & 3.1 & 13.3 & 71.8 & 1.1 & 10.7 & 100 & \\
\hline
\end{tabular}

Source: WB estimations based on ENAB 2011-2012 and ENAB 2012-2013.

The Burundi regional authorities and development partners particularly concentrate their efforts to improve access of households to fertilizers on the use of DAP. DAP is a chemical fertilizer that represents about 71-73 percent of the total consumption of chemical fertilizers per annum in Burundi (71.8 percent in 2013 - Table VI.5). Examining the incidence of household users of DAP in the agricultural seasons A and the agricultural seasons B (the two largest contributors to yearly food productions) in parallel with the level of household total food production per year, we can identify a possible positive correlation between the two variables for the four regions analyzed separately (Figure VI.23). The differentiated levels and growth dynamics in the incidence of fertilizer use by regions recommend probably specific actions in terms of supply-side extension services, access to finance to acquire inter alia fertilizers, and capacity building to develop managerial skills and understanding of the benefits of soil amendment based on chemical fertilization approaches.

Figure VI.23: Household's Output and Share of Household's Plots Treated with DAP Fertilizer by Region and Year (Kilograms and Percentage of household's plots)

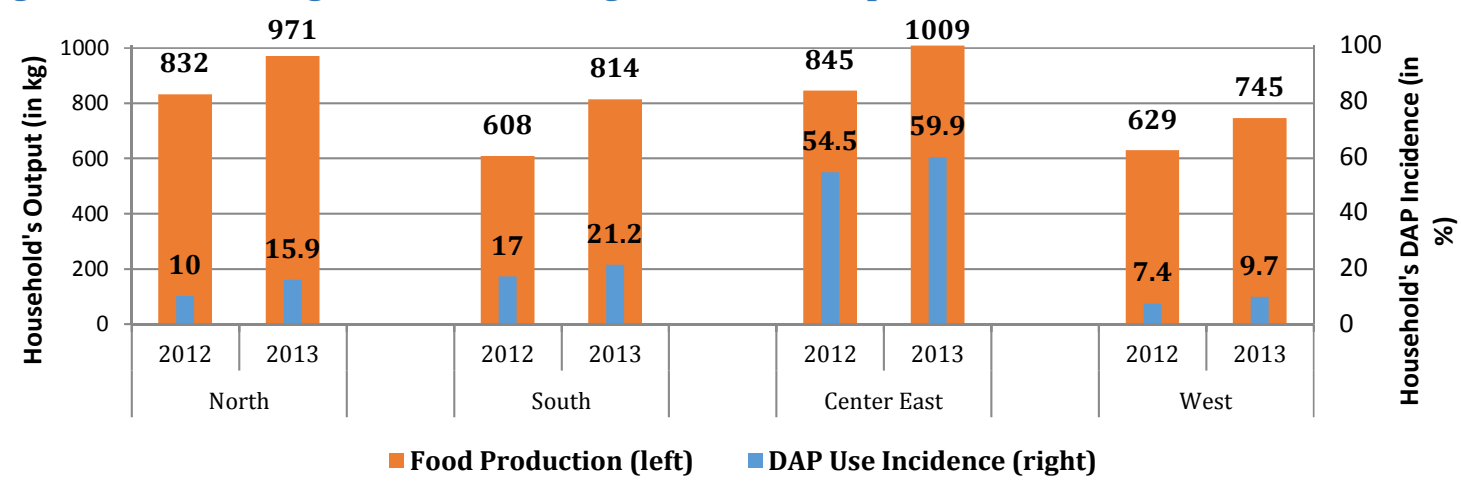

Source: WB estimations based on ENAB 2011-2012 and ENAB 2012-2013. 
The diffusion and level of use of fertilizers increased significantly in three out of Burundi's four regions and bolstered a sharp rise in food production. On the regional front, the situation suggests that the three regions experiencing the largest incidence of farm household users of fertilizers achieved the largest food production levels per farm household in 2013 compared to 2012. Between 2012 and 2013, the share of farm households using chemical fertilizers in season A and B respectively went up from 51.1 to 57.1 percent and from 64.4 to 65.5 percent. In the meantime, annual food production in the Centre East region rose from CE $845 \mathrm{~kg}$ per household in 2012 to CE $1009 \mathrm{~kg}$ per household in 2013. Similar trends occurred in the Northern and Southern region. Thus, annual food production per household in the Northern region improved significantly (CE $971 \mathrm{~kg}$ in 2013 against CE $832 \mathrm{~kg}$ in 2012), while the incidence of household users of fertilizers increased rather importantly between the two agricultural of both seasons A and B. Similar trends were observed in the Southern region. Contrasting with these patterns, the Western region not only experienced a decline in the incidence of household users of fertilizers between the two agricultural seasons A but also remained the region with the lowest incidence levels, except in the agricultural season C of 2013 - which represents the lowest contribution in Burundi's total food production. This region obtained the lowest total food production per household in 2013, reaching CE $745 \mathrm{~kg}$.

However, with three out of four regions showing very low prevalence (7-22 percent) of rural household users of DAP fertilizer, it is legitimate to question the effectiveness of existing research \& extension services in Burundi. In this regard, it is worth noticing that only 6-8 percent of farm households have (at least once) benefitted from research \& extension services in 2012 and 2013, except during the agricultural season A of 2012 where about 12 percent of farm households received such research \& extension services, irrespective of the service providers. Despite its high prevalence (54-60 percent) of household users of DAP, the Centre Eastern region showed no obvious singularity in terms of the incidence of household beneficiaries of research \& extension services compared to the rest of the regions. Therefore, the high prevalence of household users of DAP in this region stems probably from the relatively high deficit of its soil in nutrients (less fertile), which commands large number of households to resort to chemical fertilizers. More facility to use chemical fertilizers almost routinely and rather massively can be perhaps explained by the favorable dispositions that household heads are endowed with in the Centre Eastern region, namely: (i) they were the (second or third) best in terms of literacy rates (57-61 percent), (ii) they comprised the highest proportion of female heads (23-26 percent), and (iii) they were the (first or second) best in terms of membership in producer organizations (9-15 percent).

\section{Limited implementation of anti-erosion schemes}

Burundi's agricultural lands are exposed to intense and rapid erosion, although very limited schemes are designed and implemented to prevent and slow this phenomenon. As 
explained earlier in the document, the majority of cultivated plots are located in the hillsides, thereby being more exposed to erosion phenomena. Yet the farmers in Burundi are doing very little to protect their soil against erosion. In 2012/13 only one out of five plots were equipped with an erosion control mechanism. The most common erosion control method is contour line with hedge (hurdle). In 2012/13, anti-erosive ditches (gaps) without hedge (hurdle) were used by a significant proportion of farmers to protect their land against erosion, especially in Bututsi and Bweru provinces. The data also suggests that those who received the land as a gift or inherited the land are more likely to act against erosion (Figure VI.24). This implies among other that either the land that is given away (gift of inheritance) is in a very poor state, or people have some sentimental value attached to it and therefore care a bit more about issues related to degradation. Given the landscape, and the type of soil, erosion control can prove important for sustainability and productivity. The promotion of anti-erosion schemes is critical to help Burundian rural households better manage the risk of productivity losses due to erosion and other damages linked to environmental shocks.

Figure VI.24: Erosion-control method by ways the land was received (percentage of farms)

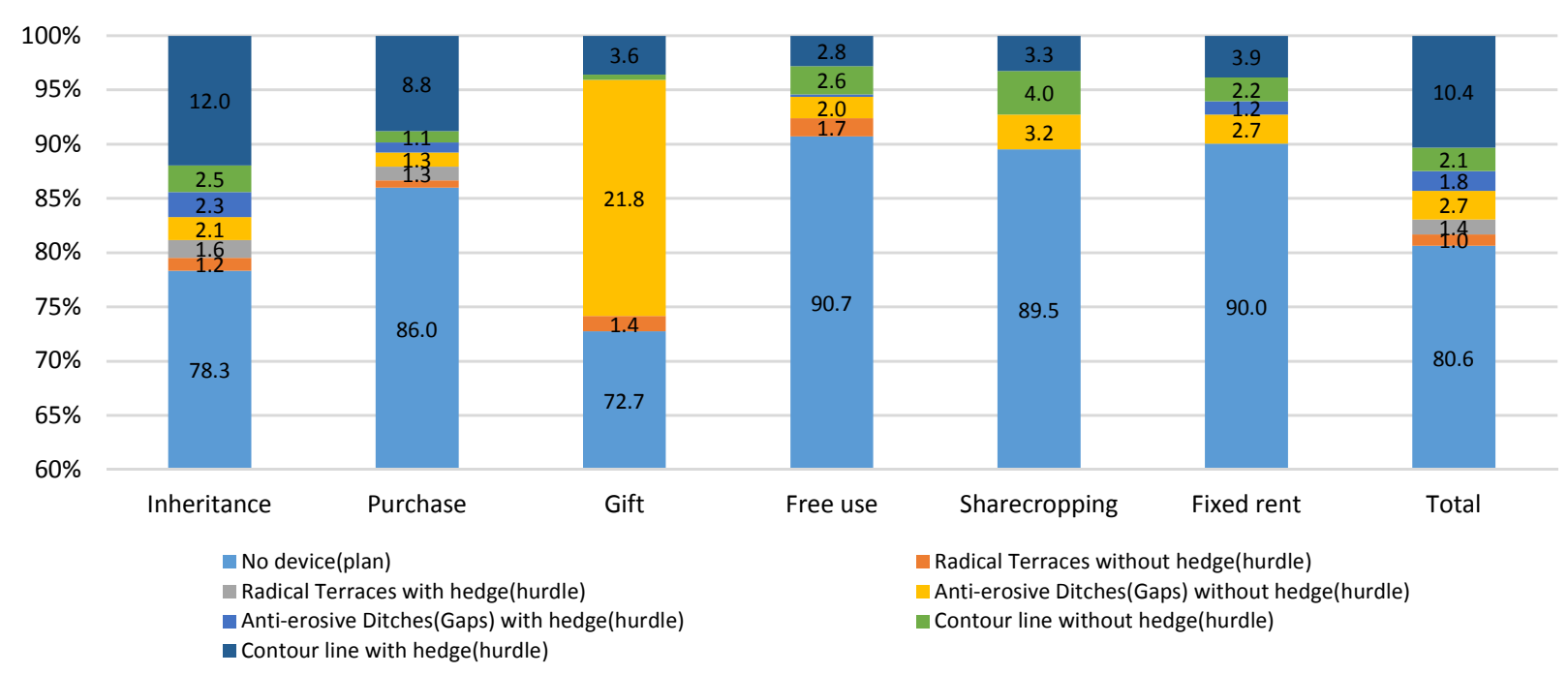

Source: WB estimations based on ENAB 2012-2013. Note: The scale starts at 60 percent.

The implementation of anti-erosion schemes seems to lead to an increase of average food production. Wherever the promotion of anti-erosion schemes has progressed with for instance the construction of plot protecting hedges, it is very likely that this has helped Burundian rural households better manage the risk of productivity losses due to erosion and other damages linked to environmental shocks. One possible indication of the existence of any positive externalities due to anti-erosion schemes in rural Burundi can be perhaps found out by analyzing the distribution of food yields by existence or not of any anti-erosion schemes in cultivated plots. As shown by Figure VI.25, average food production per hectare tended to reach its biggest levels whenever food crops were cultivated in plots endowed with anti-erosion schemes compared to the alternative of no such scheme at all. 
Figure VI.25: Food yields of plots by erosion schemes (kg/ha)

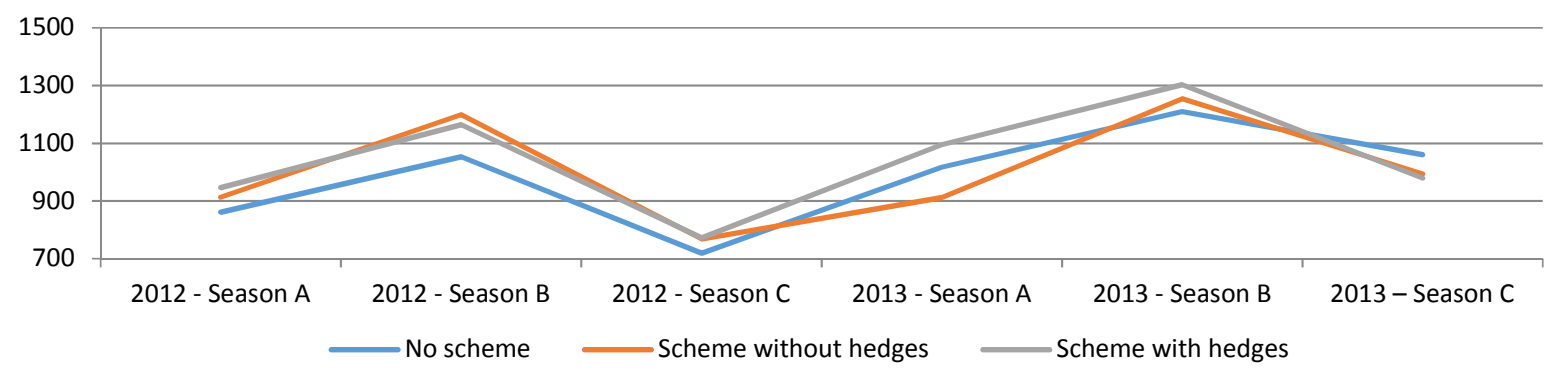

Source: WB estimations based on ENAB 2011-2012 and ENAB 2012-2013.

However, in provinces exposed to abnormal and frequent soil losses and landslides due to heavy rainfalls, anti-erosion schemes are promoted, albeit insufficiently. For example, the mountainous - hence prone to erosion - region of Mumiwra managed to protect only 10 percent of plots by anti-erosion schemes in 2012. Similarly, despite high risks of large soil losses as well in the Buragane and South Moso areas, the incidence of anti-erosion schemes is respectively 21.4 percent and 14 percent, still very low incidence. This is way below 59.2 percent and 51.2 percent shown in Bututsi and Mugamba provinces, respectively. In rural areas with high erosion risks, the government has promoted inter alia anti-erosion schemes to improve resilience to climatic shocks. For instance, in the Imbo province, efforts to better manage floods and water torrents have consisted in building a hydro-agricultural facility that will soon be operational.

\section{Inefficiencies in labor allocation at the plot level driven by constraints in the credit, labor and insurance markets}

The low performance of agriculture can be driven by both intra- and inter-household inefficiencies. When markets and households are subject to imperfections, the allocation of resources between and within households is inefficient (or Pareto-suboptimal), leading to deviations with respect to the first-best optimum. These deviations can be driven by interhousehold inefficiencies, intra-household inefficiencies or both. Inter-household efficiency is based on the idea that in presence of complete market structure, households take their production decisions as if they were risk-neutral profit-maximizing firms. The marginal productivity of inputs will be a function solely of plot characteristics and prices. In contrast, when factor demands are a function of household characteristics, marginal productivities are not equated across households and production is inefficient. Testing for inter-household inefficiencies allows to test for the presence of market imperfections. Intra-household efficiency is observed when the allocation of factor inputs across plots controlled by different household members is optimal. This means that the characteristics of the individual who takes production decisions on the plot (such as gender) do not affect factor allocation at the plot level, once plot-specific attributes have been appropriately dealt with. 
The analysis of the sources of agricultural inefficiencies in Burundi reveals the presence of both market imperfections and inefficient allocation of resources within the household. The findings are based on the study of Arcand et al. (2016), which examines whether the sources of inefficiency in Burundi agriculture have intra- or inter-household origins, by testing both hypotheses simultaneously. ${ }^{53}$ The empirical analysis considers six principle crops, representing the major crops in terms of the number of plots cultivated and for which detailed variables on the plot characteristics (including the topography of the plot, presence of anti-erosion infrastructure, and so forth) are available. These are: bush beans, climbing beans, maize, bitter cassava, beer bananas and sweet potatoes. Given the extremely labor-intensive nature of agriculture in Burundi, the analysis focus on inefficiencies in labor input. The key variable in testing for the efficiency of labor allocation within the household is the gender of the person who is in charge of the plot, as more than one fifth of the plots are under the control of a woman. Intra-household efficiency is achieved when the gender of the individual who manages a given plot does not affect plot-level labor demand, while inter-household efficiency is achieved when labor demands by households is independent of their characteristics. The results reveal the presence of both, inefficiencies in resources allocation within and between households.

The inefficient allocation of agricultural labor resources is driven by three major constraints related to credit, labor and insurance markets. The results of the analysis of the sources of inefficiency in Burundian agriculture reveal three main findings. First, a combination of credit market constraints and imperfections in the labor market leading to households not being able to hire sufficient labor, on plots cropped to maize and bitter cassava, and inducing major misallocation of hired labor between households. Second, a binding credit market constraint combined with insurance market failure leads to a severe misallocation of female family labor on plots where climbing beans are cultivated: this leads to both inter- and intrahousehold inefficiencies. Third, there is a major misallocation of family labor inputs driven by the gender of the person who manages a plot of land, which obtains for five out of the six main crops considered. On plots managed by women, excessive use is made of female family labor with respect to the first-best optimum, while insufficient use is made of male family labor, with the converse obtaining on plots managed by men: this results in departures from the Pareto optimum in terms of the intra-household allocation of male and female family labor.

\footnotetext{
53 Arcand, Jean-Louis, Aurélien Beko, Nadia Belhaj Hassine Belghith, and Béatrice d'Hombres. "Searching for the Sources of Inefficiency in Burundian Agriculture." (2016).
} 


\section{Chapter VII - Environmental Degradation, Climate Change, and Poverty}

\section{Key Messages}

- Change in wealth per capita was continuously negative over 15 years, driven notably by population growth and deforestation

- Burundians are heavily dependent on land and forest resources for their livelihood

- Climate variability and soil erosion worsen Burundi's socio-economic situation, and particularly affect the poorest

- Investing on land restoration is greatly needed, as infrastructure or agricultural projects relying on fragile lands cannot fully succeed.

\section{Change in Wealth per capita and natural capital depletion}

Burundi's endowment in natural resources-abundant rainfall, a dense river network, arable land and ability to harness its marshlands and lakes-is key to its agricultural productivity and socio-economic development. Nevertheless, post-conflict fragility, extreme population density and overwhelming reliance on the agricultural sector, all overlaid on a geomorphologically sensitive land mass, have simultaneously caused and aggravated environmental degradation.

Arguably, Burundi's wealth has not been managed sustainably over the past fifteen years. Wealth is defined in this document as the sum of gross savings, depreciation of physical capital, human capital formation, natural capital depletion, and adjusted population. In economies with growing population, and especially in developing countries that aspire to higher material standards of living for their citizens, sustainable development requires not just increasing wealth but also increasing per capita wealth ${ }^{54}$. This requires enough accumulation of capital to overcome population growth. Burundi has witnessed a depletion of wealth per capita over the past years (WDI, 2016): change in wealth per capita was continuously negative from 1995 to 2010, going from -\$151 in 1995 (or -60.1 percent of GDP per capita) to -\$145 in 2010 (or -79.5 percent of GDP per capita $)^{55}$. Although some progress in absolute terms occurred from 1995 to 2010, change in wealth per capita is in fact worsening over the same period as share of GDP, due to a much lower GDP p.c. in 2010 (\$182.1) than in 1995 (\$251.6). These figures greatly contrast with the negative change in wealth, estimated at -18.7 percent of GDP per capita, in Sub-Saharan Africa in 2010. The country's ability to sustain production and welfare is therefore undermined.

\footnotetext{
${ }^{54}$ The Changing Wealth of Nations: Measuring Sustainable Development in the New Millennium, The World Bank

55 all in 2010 US\$
} 
This wealth depletion is notably driven by population growth and natural capital depletion - mostly due to deforestation -, with a loss equivalent to -48.5 percent and -29.9 percent respectively in 2010 in terms of GDP per capita (Figure VII.1). ${ }^{56}$

Figure VII.1: Change in wealth per capita components ( $\%$ of GDP per capita), 2010

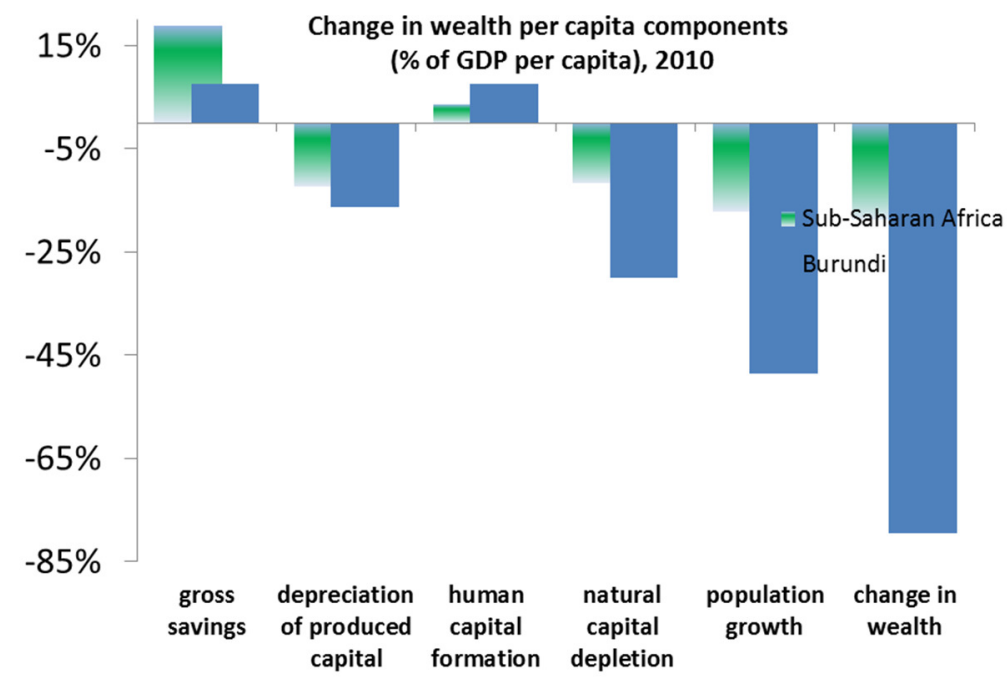

Source: authors' calculations and WDI, 2016

The impacts on Burundi's natural capital were particularly severe from 2005 to 2008, with a loss in terms of GDP per capita equivalent to 8.3 percentage points (Figure VII.2). Forest degradation is mostly responsible for this natural capital depletion. Net forest depletion went from $\$ 54.8$ p.c. in 2005 to $\$ 71.7$ p.c. in 2008, representing a 30.8 percent increase. In particular, depreciation of natural capital in 2010 was attributed to net forest depletion (97 percent) and mineral depletion (3 percent).

Figure VII.2: Evolution of Burundi's change in wealth and natural capital depletion, in \% of GDP per capita, 1995-2010

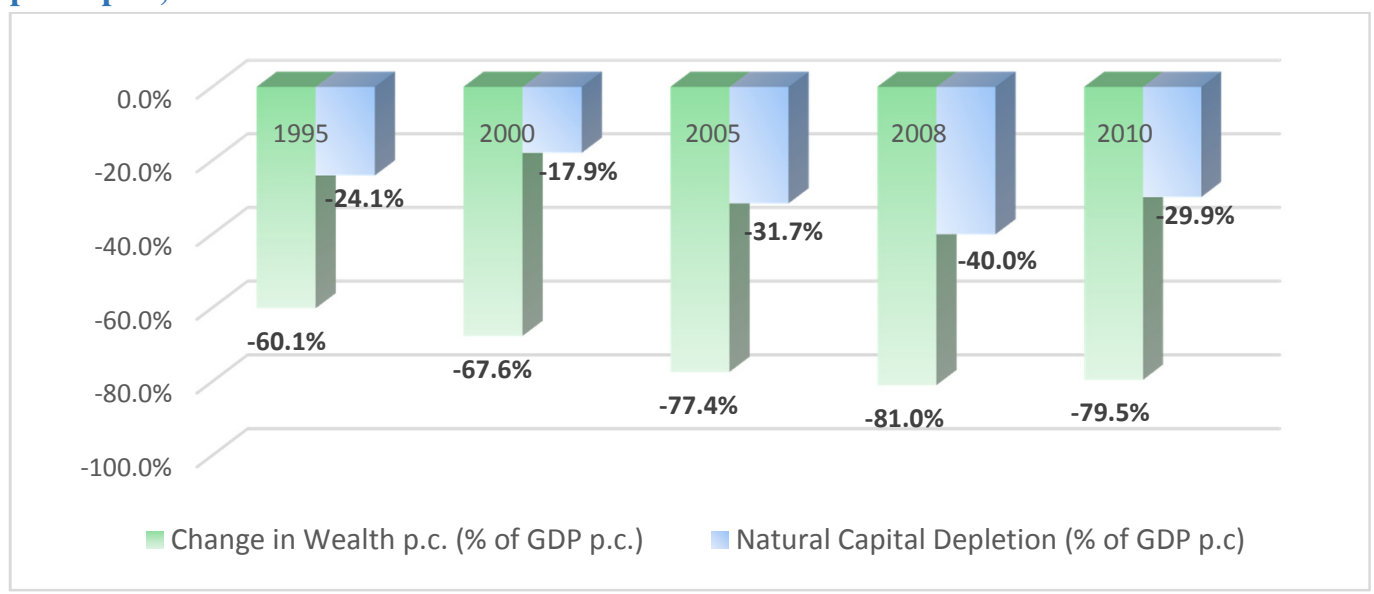

Source: WDI, 2016

\footnotetext{
${ }^{56}$ It should be noted that the parameters used to calculate natural capital depletion are currently limited, as they only include forests, mining and energy, and exclude soil erosion or water pollution.
} 
Moreover, currently available macroeconomic data confirm that Burundi' Adjusted Net Savings are negatively affected by natural capital depletion and pollution damages. Figure VII.3 shows the calculation of Adjusted Net Savings (ANS) for Burundi in 2013, where gross national saving is 17.8 percent of Gross National Income (GNI). After adjusting for the consumption of fixed capital (minus 14.7 percent), education expenditures (plus 5.2 percent), depletion of natural resources (minus 15.6 percent), and pollution damages (minus 1.3 percent), Burundi's adjusted net saving are about minus 8.6 percent of GNI.

Figure VII.3: Burundi Adjusted Net Savings, 2013

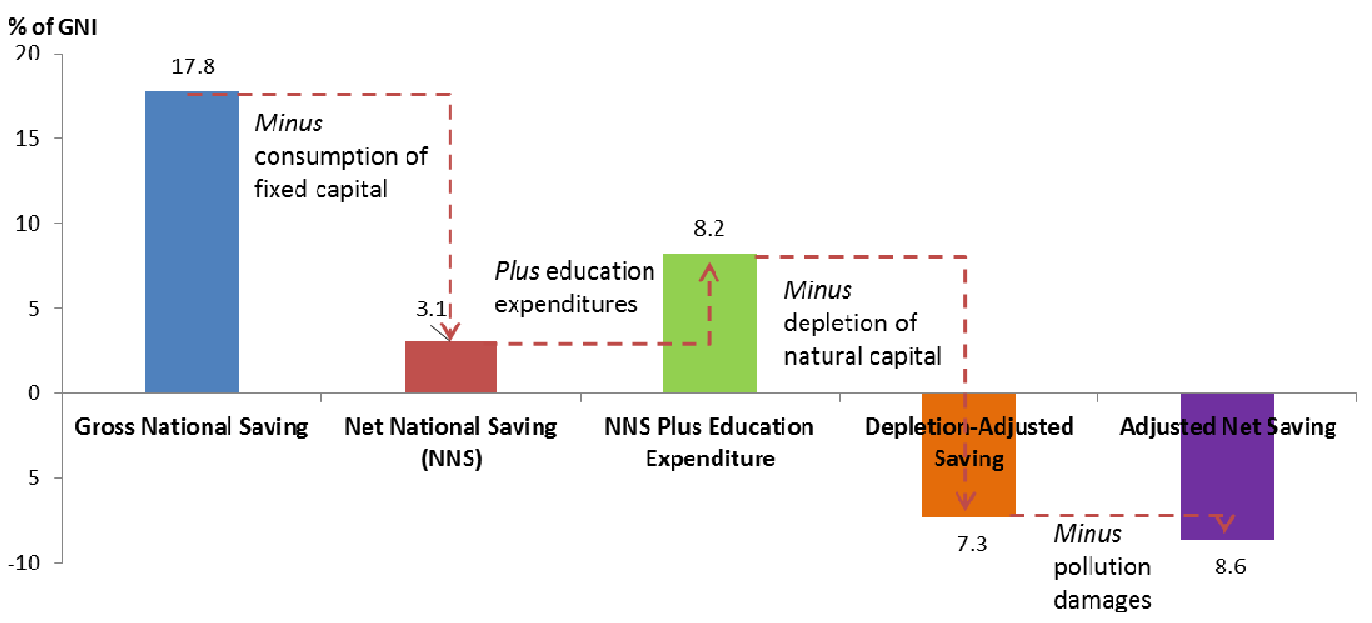

Source: Forthcoming World Development Indicators 2016, World Bank

\section{Deforestation, land degradation and poverty}

Forests are an essential part of the average Burundian's life for two major reasons. First, forests provide timber and non-timber resources for households. The most significant of timber uses is wood energy. Like many developing nations, Burundi is strongly dependent upon fuelwood and charcoal for energy: more than 95 percent of the energy consumed by households is provided by wood. This is due to wood's ready availability and the lack of cheaper alternatives-electricity and gas are very expensive and often inaccessible to people in rural areas. ${ }^{57}$ Wood is also highly sought for construction and carpentry (bricks, woodwork and tile), in the baking of bricks used to dry tea and tobacco leaves, and in the smoking of fish. ${ }^{58}$ Nontimber forest products include plants, fungi, and animal products used in traditional medicine; fodder trees and shrubs; and tannins, gum and saps that can be used for industrial purposes. ${ }^{59}$ Second, forests provide ecosystem services. Without these services other natural resources are negatively impacted, which can lead to potentially catastrophic environmental, economic and social consequences. Forests maintain an integral function in regulating the water cycle, protecting watersheds, reducing soil erosion, preventing siltation and pollution, and helping preserve biodiversity.

\footnotetext{
${ }^{57}$ MEEATU (2011).

${ }^{58}$ Ibid

${ }^{59}$ Marc Rwabahungu, Deo Niyonkuru et Libère Bukobero (2013).
} 
Forests play a pivotal role in Burundi's national economy. Forest and agro-forest resources contribute around three percent to Burundi's $\mathrm{GDP}^{60}$ and six percent to national employment. ${ }^{61}$ Electricity production depends on the health of forests and their ability to regulate the flow of water into hydroelectric dams, such as the one at Rwegura, which provides 50 percent of Burundi's electricity needs. Fuelwood allows the country to decrease the amount of hydrocarbons that it would otherwise import from abroad, with adverse effects on the national balance of payments. ${ }^{62}$ Burundi's forests, which host a wide array of flora and fauna-including a chimpanzee corridor that connects Tanzania and Rwanda and a RAMSAR site ${ }^{63}$ — can be developed for eco-tourism purposes. Tourism currently accounts for three percent of GDP and 2.4 percent of jobs, though these numbers are likely to drop in the wake of the 2015 sociopolitical security crisis. ${ }^{64}$

However, in spite of their manifest and critical benefits, Burundi's forests have been significantly degraded over the past several decades. Natural forest used to cover 30-50 percent of the country, but human pressure has vastly reduced national forest cover. ${ }^{65}$ There is approximately $152,000-183,700$ ha of forest remaining in the country, none of which is considered intact forest. ${ }^{66}$ Previously forested land has mainly been changed for other land use purposes, leaving little natural forest to remain. Deforestation and forest degradation have been mainly concentrated in the most densely populated areas. ${ }^{67}$ During the conflict period of the 1990s, Burundi may have experienced a deforestation rate as high as nine percent, the highest in the world at that time, a testimony to the heavy damage that war caused on Burundi's natural bounty. ${ }^{68}$ Recently, from 2000 to 2011, Burundi saw an average rate of deforestation of 1.4 percent, which is almost three times higher than the Sub-Saharan Africa average (0.5 percent) and the second highest among neighboring countries after Uganda ${ }^{69}$ (see Figure VII.4). As mentioned, Burundi's forest cover today stands at 6.6 percent as compared to an average of 27.7 percent in Sub-Saharan Africa. ${ }^{70,71}$

\footnotetext{
${ }^{60}$ Global Forest Watch, Burundi Country Profile, 2016

${ }^{61}$ Republic of Burundi (2013). Note Conceptuelle sur l'Environnement et la Gestion des Ressources Naturelles.

${ }^{62}$ Ibid

${ }^{63}$ Under the Ramsar Convention, a Ramsar site is a site placed on the List of Wetlands of International Importance

${ }^{64}$ Republic of Burundi (2013).

${ }^{65}$ USAID/REDSO, 2003 quoted in USAID. (2010).

${ }^{66}$ Burundi R-PP (2013); World Bank. (2015). The Little Green Data Book 2015.

${ }^{67}$ MEEATU. 2013. Burundi R-PP. Bujumbura: Government of Burundi.

${ }^{68}$ Athman et al., 2006 quoted in USAID. (2010).

${ }^{69}$ World Bank. 2015. World Development Indicators 2015. Washington, DC: World Bank.

${ }^{70}$ Ibid

${ }^{71}$ World Bank. 2015. The Little Green Data Book 2015.
} 
Figure VII.4 Deforestation over the 2000-2011 period in selected countries, in average annual \%

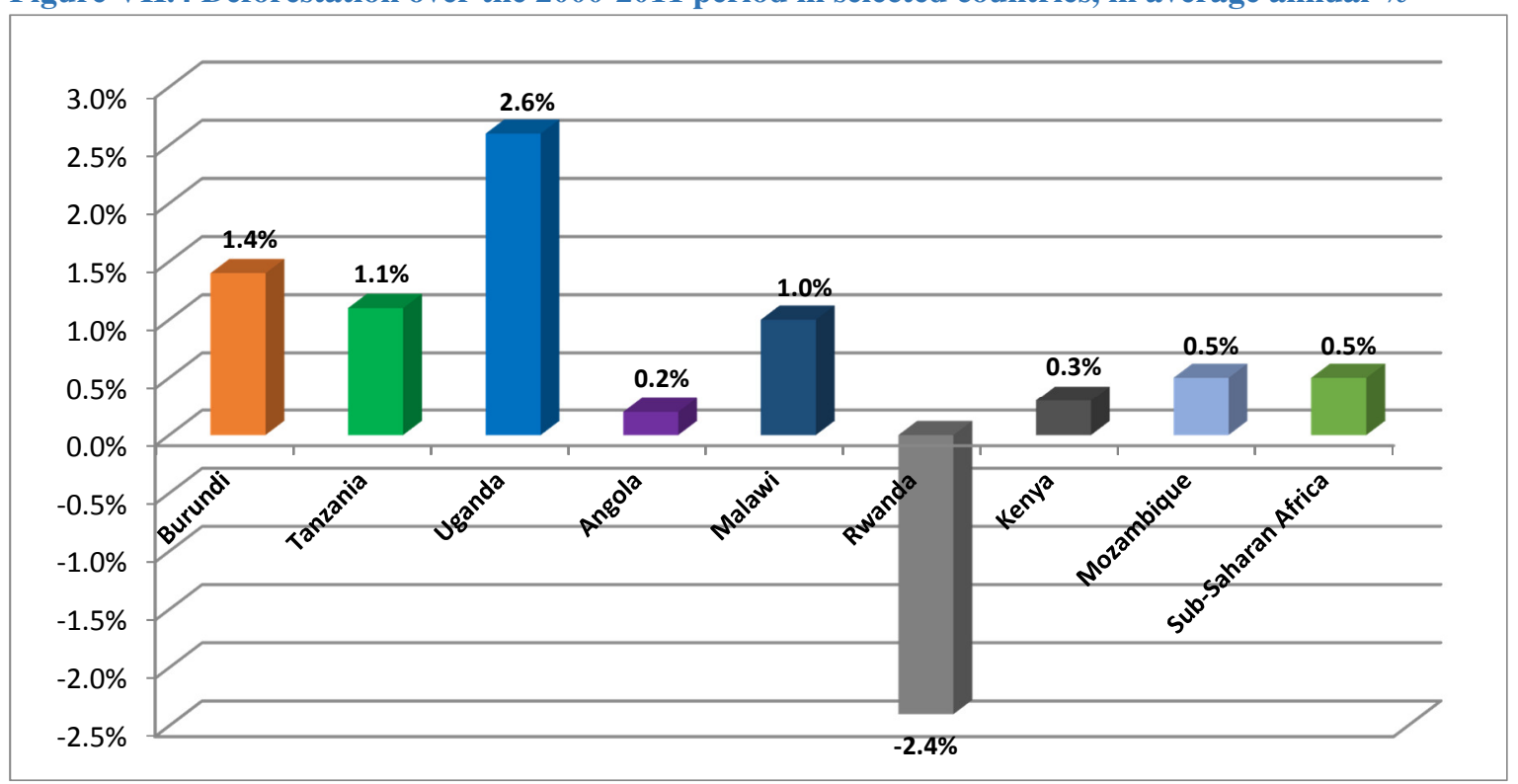

Source: The Little Green Data Book, World Bank, 2015

Note: A negative deforestation rate means that on average, the forest cover gains are greater than the losses

The degradation of forest resources encourages erosion, leading to the loss of soil fertility and endemic species, and increased climate variability. Afromontane forests in Burundi used to occupy an area of 104,000 ha. However, due to pressures on the country's forest resources, they have been reduced to an area of 55,000 hectares, including Kibira National Park. ${ }^{72}$ Unfortunately, anthropogenic impacts to vegetative cover during the crisis of the 1990s left a lasting mark on Kibira's ability to provision ecosystem services. This destruction led to massive flood-related damages on the Imbo plain several years later in 2010, with flooding across the Rusizi plain, including widespread damage to Bujumbura International Airport. ${ }^{73}$

The effects of land degradation are also pervasive in Burundi. Over one-third of Burundi's land, 38 percent is considered very highly or highly degraded (Figure VII.5). Erosion of topsoil results in decreased agro-pastoral productivity, as well as changes in the biological, physical, chemical and hydrological makeup of the earth. This is particularly acute in the steep sloped areas of Mumirwa, the Congo Nile ridge, and the highest points of the Central Plateau. ${ }^{74}$ The drastic reduction of areas of vegetation and their density leads to a lower quality of plant resources. It also increases carbon emissions that contribute to climate change, reduces carbon sequestration potential (which can be converted into carbon financing), and transforms natural habitats, leading to a decrease in genetic stock and biodiversity.

\footnotetext{
${ }^{72}$ MEEATU (2011).

${ }^{73}$ MEEATU (2013).

${ }^{74}$ MEEATU (2011).
} 
Figure VII.5 Land Degradation in Burundi by Severity Classification, 2014.

Land Degradation by Classification, 2014

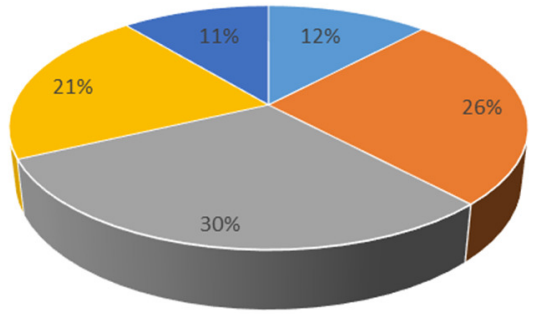

" Very high " High " Medium " Low "Very low

Source: $\mathrm{MESA}^{75}$

Land degradation threatens to weaken an economy already hobbled by more than a decade of political crisis and primary sector dependency. Poverty headcounts are generally higher in regions of the country marred by excessive land degradation. With continually declining productivity, environmentally unsustainable practices can be linked to the persistence of poverty in Burundi's hinterland. Eight of the most impoverished provinces (Muyinga, Ruyigi, Gitega, Cankuzo, Kayanza, Kirundo, Karusi, Rutana) as well as their corresponding communes are also identified as being among the most heavily environmentally degraded in the country (Figure VII.7).

Figure VII.6 Land degradation levels (Low, Medium, Figure VII.7 Poverty rates by communes in High, Very High) in Burundi, 2014 Burundi, in \%, data from 2008 and 2014
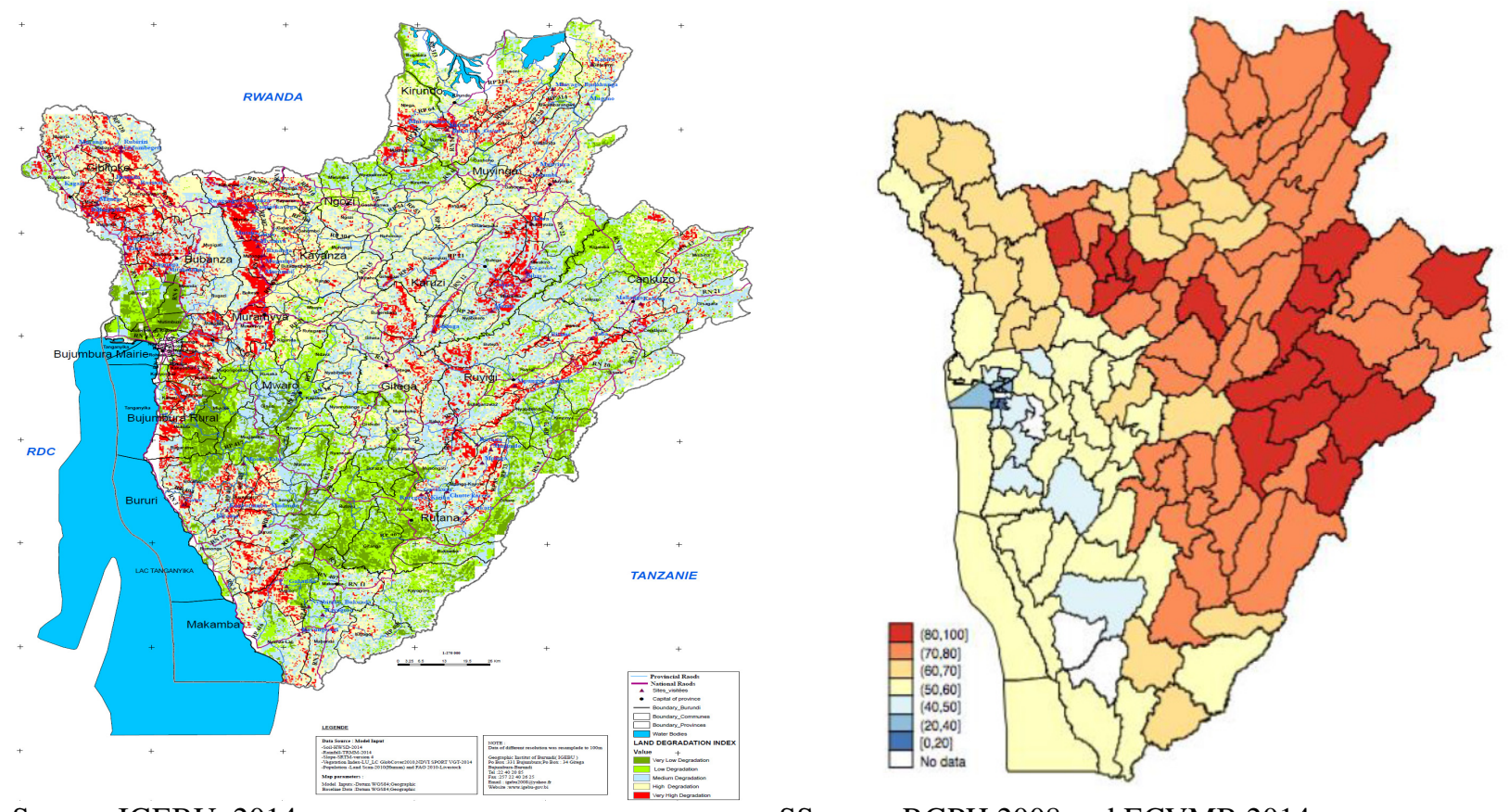

Source: IGEBU, 2014

SSource: RGPH 2008 and ECVMB 2014

\footnotetext{
${ }^{75}$ MESA. 2014. LAND DEGRADATION ASSESSMENT USING Earth Observation Data in IGAD Region, Bulletin IV: Sep 2014 - March 2015. Regional Centre for Mapping of Resources for Development: Nairobi.
} 
Indirect effects of land degradation on the economy, while difficult to measure, are nonetheless highly important. First, the siltation of waterways and dams and its impact on water flow has resulted in the loss of kilowatt hours in a country that is already electricity impoverished. The link between land degradation and natural disasters that occasion damage to homes and public and private infrastructure, especially trade, industry and transportation, has deeper effects than those that can be measured quantitatively, such as the trauma of losing one's livelihood and personal possessions. Finally there are ecosystem health impacts related to land degradation, including the loss of carbon sinks and its effect on air quality and climate change, as well as the loss of biodiversity and the unknown ramifications that this can instigate. ${ }^{76}$

Overall, the eastern and northern regions are the most vulnerable to shocks due to the combination of high levels of deforestation and soil erosion, combined with of widespread poverty. There appears to be a link between deforestation and soil erosion, and poverty headcount rates in Burundi. Most provinces in the Northeast of Burundi seem to exhibit mediumto-high poverty levels combined with high tree cover loss and soil erosion. In particular, rapid deforestation and high poverty are found in the provinces of Cankuzo, Ruyigi and Kayanza (Figure VII.8). The relationship between soil erosion and poverty follows similar geographical patterns. However, soil erosion levels are higher compared to deforestation levels: for instance, while Cankuzo has a medium level of tree cover loss combined with a high poverty rate, the same province present a high level of soil erosion combined again with a high poverty rate (Figure VII.9).

Figure VII.8 Tree forest loss and poverty headcount rate (high, medium and low) in Burundi

Figure VII.9 Soil erosion and poverty headcount rate (high, medium and low) in Burundi

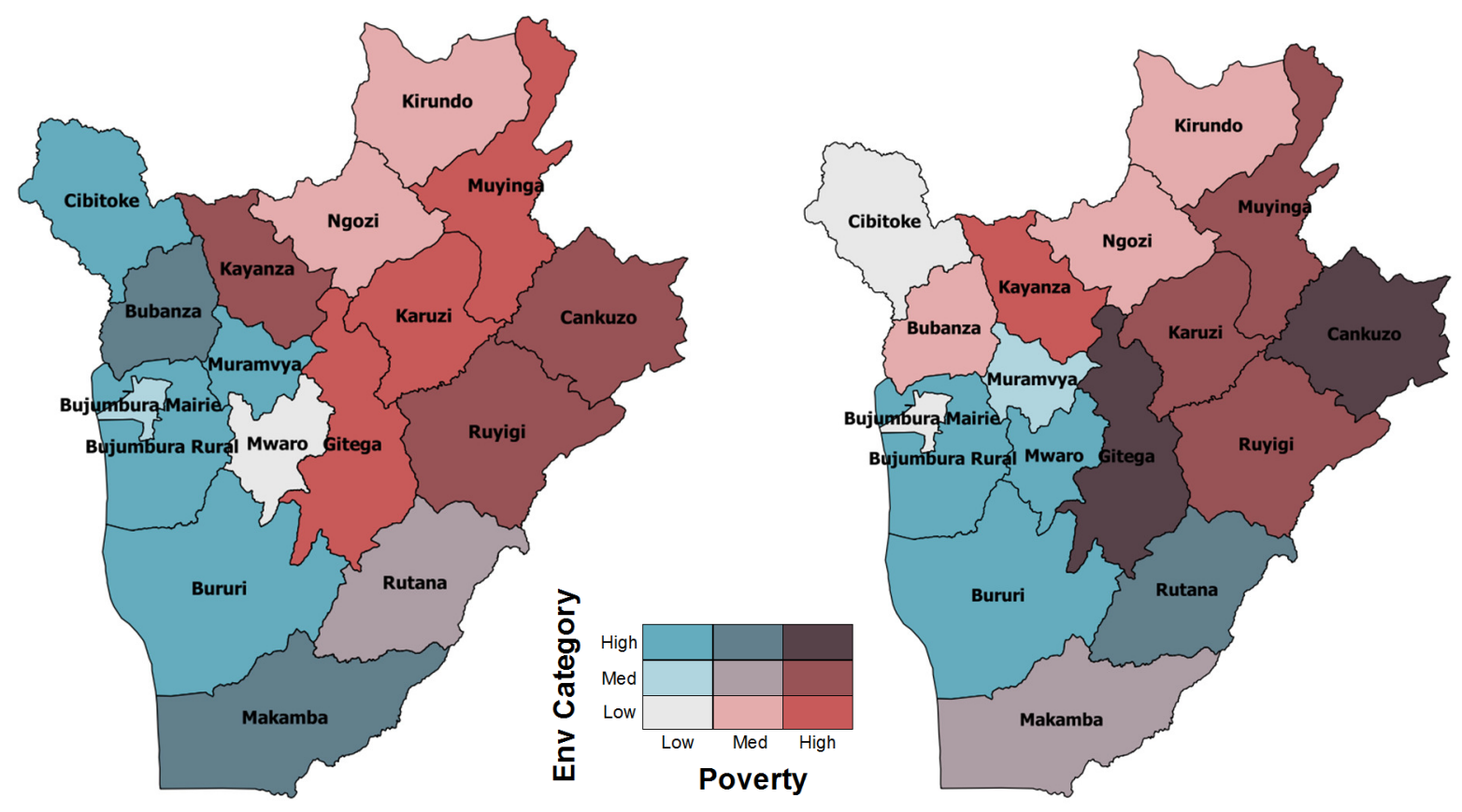

${ }^{76}$ MEEATU (2011). 
Source: World Bank, Climate Change Policy Team. Authors' calculation based on data from Hansen et al., 2013 and Naipal et al., 2015.

Notes: Figures the province-level overlay of poverty and environmental maps based on the following categories (calculated as three terciles, with equal number of provinces in each category): Poverty - Low $=<53 \%$, Medium $=53-67 \%$, High $=>67 \%$ based on poverty headcount rate; Tree Cover - Low $=<17.8 \%$, Medium $=17.8-22.15 \%$ High $=>22.15 \%$ based on share of tree cover; Tree cover loss $-<0.43$, Medium $=0.43-0.79$ High $=>0.79$ based on share of forest area affected by tree cover loss; Land degradation - Low $=<10$, Medium $=10-34.1 \mathrm{High}=>34.1$ based on yearly average of soil erosion rates from RUSLE model.

Finally, it should be noted that Burundi is also exposed to climate change. Studies conducted for the initial national communication on climate change and the evolution of climate parameters in Burundi through 2050, based on the general circulation model, show that the average annual temperature will increase by $1^{\circ} \mathrm{C}$ to $3^{\circ} \mathrm{C}$. Rainfall will rise by around 10 percent, and the precipitation regime will be disrupted such that there will only be two seasons remaining, each lasting six months: a rainy season from November to April, followed by a dry season.

Moreover, since September 2015, Burundi has been severely affected by the El Niño climate phenomenon. The rainy season (from September to December) was extremely heavy due to sea surface temperature increases in the West Equatorial part of the Indian Ocean - and brought about dangerous floods in Burundi's most vulnerable zones. The situation is already particularly worrisome in the Bubanza and Rutana provinces - notably on the Karambira and Nyekarange hills - where torrential rains that led to sliding caused the death of 3 persons and damaged 1,000 hectares of fields in June 2015. In September 2015, the Mitakataka, Gahongore, Buramata, Gihungwe, Rugunga, Kagwema, and Kizina hills were impacted and caused the death of one person as well as damaged crops and more than 680 houses. It was observed that due to El Niño, the rainy season extended until the first quarter of 2016, which brought about the destruction of more than 14,000 houses in the country as of March 2016, according to assessments carried out by the authorities with support from the Red Cross ${ }^{77}$. The 2016 Season A (from September to January) is especially threatened by heavy rainfalls induced by El Niño, which might affect yields and food security nationally. It should also be noted that the Cibitoke province registered more than 100 cases of cholera in September $2015 .^{78}$

\footnotetext{
${ }^{77}$ IOM (2016).

${ }^{78}$ Plan de Réponse Catastrophe Naturelle: Innondation (El Nino 2015), Government of Burundi, 2015
} 
Figure VII.10 Map of flood risks (high, medium and low) in Burundi
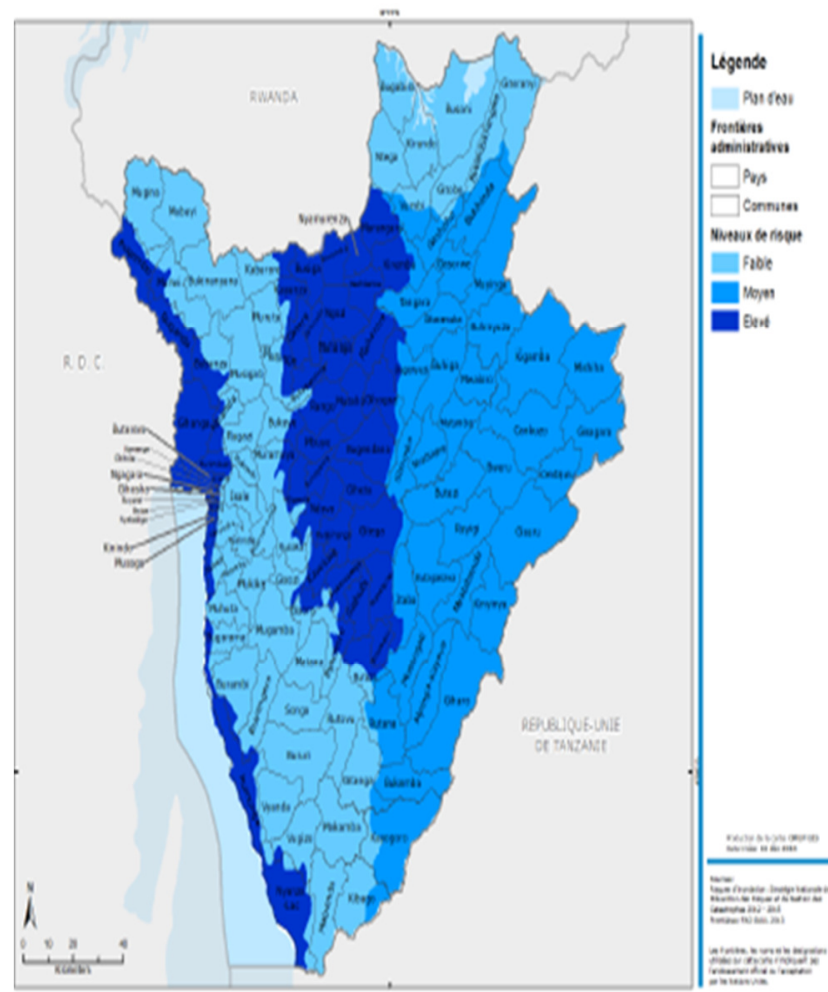

Source: PAM-ICA 2015

Rural household livelihoods have been affected by two main shocks related to natural hazards: droughts and hail-related damages. 53.4 percent of rural farmers were impacted by droughts and shortfalls in water supplies between June 2007 and June 2008. The aforementioned eight impoverished provinces and their corresponding communes are particularly impacted by droughts. Hail-related damages notably affected over 11 percent of the rural population. In 2012, key informants at the commune level indicated that their respective hills were degraded mostly by these shocks, i.e., water/rainfall deficits and droughts (25.4 percent), and hail (15.2 percent). Some provinces have been intensely impacted by different shocks. In Bujumbura rural the majority of complaints about the shocks affecting household livelihoods revolved around rainfall shortfalls and droughts (33.9 percent) and erosion (15.5 percent). The other affected provinces include Muramvya in the Centre East, Bubanza and Cibitoke in the West, and Ngozi and Kayanza in the North. 


\section{Burundi's Geographic Regions}


Administrative regions

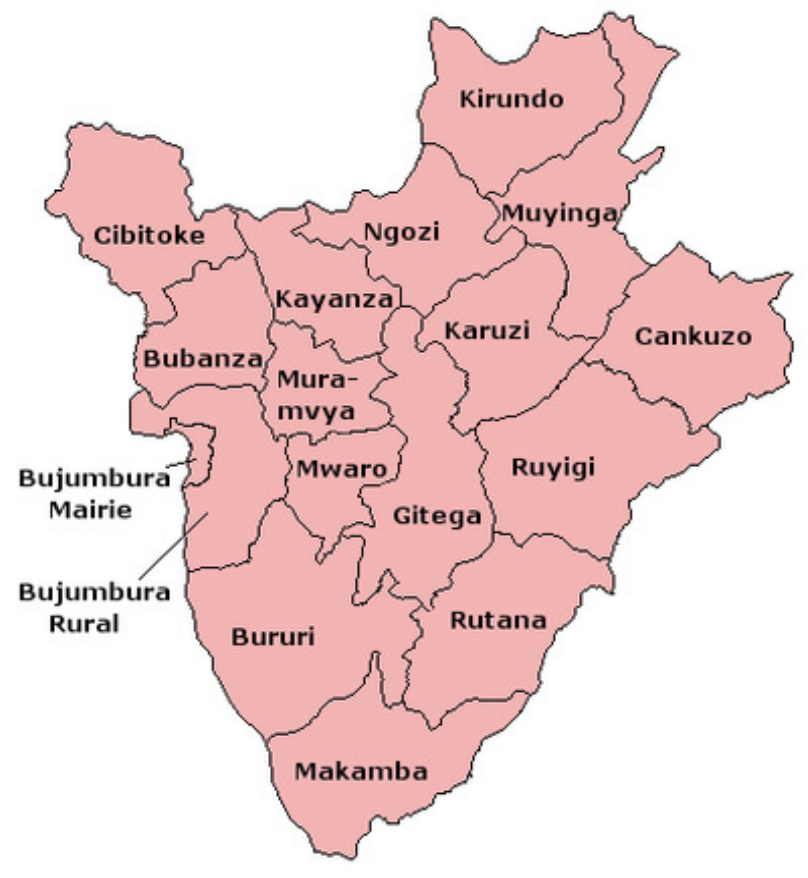

Natural regions

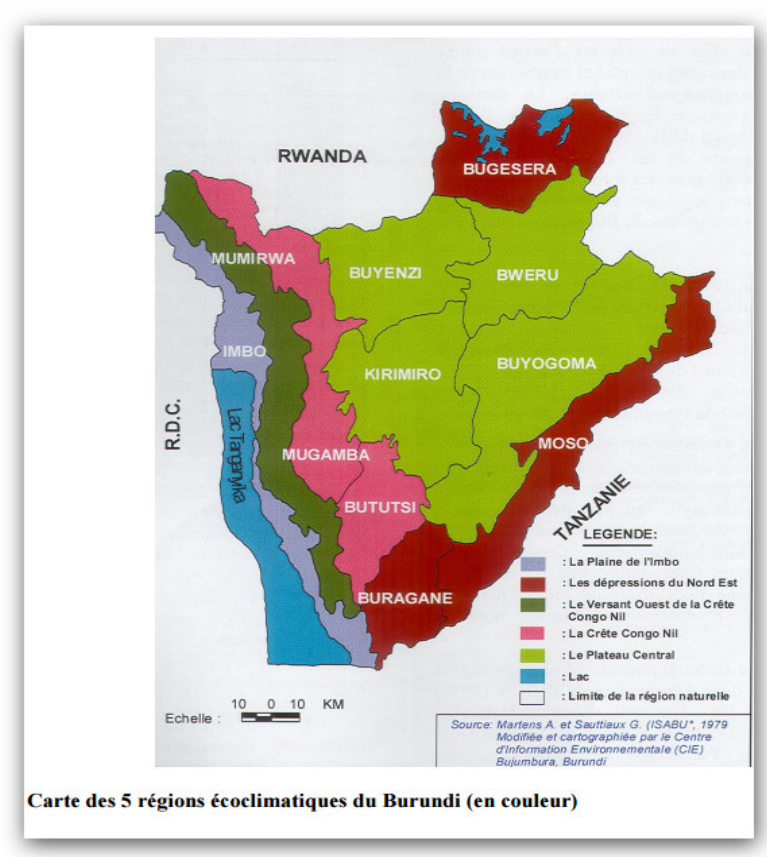

Découpage des provinces du Burundi en fonction des régions naturelles en 1992

\begin{tabular}{|c|c|c|c|c|c|c|c|c|c|c|c|c|}
\hline Province & Bugesera & $\begin{array}{c}\text { Buragan } \\
\mathrm{e}\end{array}$ & Bututsi & Buyenzi & $\begin{array}{c}\text { Buyogo } \\
\text { ma }\end{array}$ & Bweru & Imbo & Kirimiro & Moso & $\begin{array}{c}\text { Mugamb } \\
\text { a }\end{array}$ & $\begin{array}{c}\text { Mumirw } \\
\text { a }\end{array}$ & $\begin{array}{l}\text { Admin } \\
\text { region }\end{array}$ \\
\hline Bubanza & & & & & & & $\mathbf{x}$ & & & $\mathrm{x}$ & $\mathrm{x}$ & West \\
\hline $\begin{array}{l}\text { Bujumbu } \\
\text { ra rural }\end{array}$ & & & & & & & $\mathbf{x}$ & & & $\mathrm{x}$ & $\mathbf{x}$ & West \\
\hline Bururi & & & $\mathbf{x}$ & & & & $\mathrm{x}$ & & & $\mathrm{x}$ & $\mathrm{x}$ & South \\
\hline Cankuzo & & & & & $\mathrm{x}$ & & & & $\mathrm{x}$ & & & $\begin{array}{l}\text { Center } \\
\text { East }\end{array}$ \\
\hline Cibitoke & & & & & & & $\mathbf{x}$ & & & $\mathrm{x}$ & $\mathbf{x}$ & West \\
\hline Gitega & & & $\mathrm{x}$ & & $\mathrm{x}$ & & & $\mathbf{x}$ & & & & $\begin{array}{l}\text { Center } \\
\text { East }\end{array}$ \\
\hline Karuzi & & & & $\mathrm{x}$ & $\mathrm{x}$ & $\mathbf{x}$ & & $\mathbf{x}$ & & & & $\begin{array}{l}\text { Center } \\
\text { East }\end{array}$ \\
\hline Kayanza & & & & $\mathbf{x}$ & & & & $\mathrm{x}$ & & $\mathrm{x}$ & & North \\
\hline Kirundo & $\mathbf{x}$ & & & & & $\mathrm{x}$ & & & & & & North \\
\hline $\begin{array}{l}\text { Makamb } \\
\text { a }\end{array}$ & & $\mathbf{x}$ & $\mathrm{x}$ & & & & $\mathrm{x}$ & & $\mathrm{x}$ & & $\mathrm{x}$ & South \\
\hline $\begin{array}{l}\text { Muramv } \\
\text { ya }\end{array}$ & & & & & & & & $\mathbf{x}$ & & $\mathrm{x}$ & $\mathrm{x}$ & $\begin{array}{l}\text { Center } \\
\text { East }\end{array}$ \\
\hline Muyinga & $\mathrm{x}$ & & & & & $\mathbf{x}$ & & & & & & North \\
\hline Mwaro & & & $\mathrm{x}$ & & & & & $\mathbf{x}$ & & $\mathrm{x}$ & & $\begin{array}{l}\text { Center } \\
\text { East }\end{array}$ \\
\hline Ngozi & & & & $\mathbf{x}$ & & $\mathrm{x}$ & & & & & & North \\
\hline Rutana & & $\mathrm{x}$ & & & $\mathrm{x}$ & & & $\mathrm{x}$ & $\mathbf{x}$ & & & South \\
\hline Ruyigi & & & & & $\mathbf{x}$ & & & & $\mathbf{x}$ & & & $\begin{array}{l}\text { Center } \\
\text { East }\end{array}$ \\
\hline
\end{tabular}




\section{References}

Afrobarometer. (2016). "Escalating political crisis belies Burundians' strong support for democracy." Afrobaromenter.

Akresh, R., Bundervoet, T., Verwimp, P. (2009). "Health and Civil War in Rural Burundi." Journal of Human Resources, University of Wisconsin Press, vol. 44(2), 536-563.

Arcand, J.L, Beko. A., Hassine, N.B., Hombres, B. (2016). "Searching for the Sources of Inefficiency in Burundian Agriculture."

Baghdadli, I., Harborne, B., and Rajadel, T. (2008). "Breaking the Cycle: A Strategy for Conflict-Sensitive Rural Growth in Burundi." The World Bank. Washington D.C.

Basdevant, O. (2009). "How Can Burundi Raise Its Growth Rate? The Impact of Civil Conflict and State Intervention on Burundi's Growth Performance." IMF Working Paper, WP/09/11.

Beegle, K., De Weerdt, J., Friedman, J., and Gibson, J. (2012). "Methods of Household Consumption Measurement through Surveys: Experimental Results from Tanzania." Journal of Development Economics, 98 (1): 3-18.

Benjamin, D. (1992). "Household Composition, Labor Markets, and Labor Demand: Testing for Separation in Agricultural Household Models." Econometrica, Vol. 60, No. 2, pp. 287-322.

Bouka , Y. (2014). "Central Africa Report, Status and dynamics of the political situation in Burundi." ISS Nairobi.

Bundervoet, T. (2010). Assets, Activity Choices, and Civil War: Evidence from Burundi. World Development, 38(7), 955-965.

Campbell et al. (2014). "Independent External Evaluation." UN Peace building Fund Project.

Chrétien, J.P. (1997). “Le Défi de l’Ethnisme: Rwanda et Burundi: 1990-1996.” Karthala. Paris.

Chrétien, J.P. (2000). "L'Afrique des Grands Lacs. Deux mille ans d'histoire. Collection L'Afrique des grands lacs." Champs Histoire. Paris.

Chrétien, J.P., Mukuri, M. (2000). "Burundi, la Fracture Identitaire. Logiques de Violence et Certitudes 'Ethniques', (1993-1996).” Karthala. Paris.

Christiaensen, L., Lanjouw, P., Luoto, J., Stifel, D. (2012). "Small area estimation-based prediction methods to track poverty: validation and applications." Journal of Economic Inequality, 10, 267-297.

Cowell, F.A., Jenkins, S.P. (1995). "How much inequality can we explain? A methodology and an application to the USA." Economic Journal, 105, 421-430.

DiNardo, J., Fortin, N.M., Lemieux, T. (1996). "Labor Market Institutions and the Distribution of Wages, 1973-1992: A Semiparametric Approach.” Econometrica, Vol. 64, No. 5. (Sep., 1996), pp. 1001-1044. 
Dobbs, R., J. Oppenheim, A. Kendall, F. Thompson, M. Bratt, and F. van der Marel. (2013). "Reverse the Curse: Maximizing the Potential of Resource-Driven Economies." McKinsey Global Institute Report. McKinsey \& Company.

Elbers, C., Lanjouw, J.O., Lanjouw, P. (2003). "Micro-level estimation of poverty and inequality." Econometrica, 71(1), 355-364.

Firpo, S., Fortin, N. M., Lemieux, T. (2009). "Unconditional Quantile Regressions." Econometrica, 77 (3), 953-973.

Firpo, S., Fortin, N. M., Lemieux, T. (2010). "Decomposition Methods in Economics." National Bureau of Economic Research, WP 16045.

Freedom House. (2016). "Freedom in the World 2016". Freedom House.

GCB. (2013). “Global Corruption Barometer 2013: Report.” Transparency International.

GOB. (2003), "Evaluation des Récoltes, des Approvisionnements Alimentaires et de la Situation Nutritionnelle - Saison A.” GOB, WFP, UNICEF, FAO. Official Document, Janvier 2003. Bujumbura: Ministère de l'Agriculture et de l'Elevage.

Hausman, J.A., Taylor, E. (1981). "Panel Data and Unobservable Individual Effects." Econometrica, Vol. 49, No. 6 (Nov., 1981), 1377-1398.

Hausmann, R., Rodrik, D., Velasco, V. (2005). "Growth Diagnostics." John F. Kennedy School of Government, Harvard University. Cambridge, Massachusetts.

Hixon, K. (2015). "Despite Responsibility to Protect, the International Community Is Failing Burundi." Freedom House.

ICG. (2012). "Burundi: A Deepening Corruption Crisis." International Crisis Group.

IMF. (2007). "Burundi: Poverty Reduction Strategy Paper.” International Monetary Fund. IMF Country Report No. 07/46.

International Peace Support Training Centre. (2014). "Governance Instability in Burundi: Is Burundi Vulnerable to Internal Implosion?” IPSTC. Kenya.

IOM. (2016). "Displacement Tracking in Burundi." International Organization for Migration.

Jackson, T. (2001), “L'Egalite d'accès à l'éducation: un impératif pour la paix au Burundi”, International Alert.

Jolliffe, D. (2001). "Measuring Absolute and Relative Poverty: The Sensitivity of Estimated Household Consumption to Survey Design." Journal of Economic and Social Measurement Volume 27 (Numbers 1-2): 1-23.

Lemarchand, R. (1994). "Burundi: Ethnocide as Discourse and Practice." Cambridge University Press. Cambridge.

Lewbel, A. (2012). "Using Heteroskedasticity to Identify and Estimate Mismeasured and Endogenous Regressor Models." Journal of Business \& Economic Statistics, vol. 30(1), pages 67-80. 
Machado, J.A.F., Mata, J. (2005). "Counterfactual decomposition of changes in wage distributions using quantile regression." Journal of Applied Econometrics, Volume 20, Issue 4, pages 445-465, May/June 2005.

MEEATU (2013). "Plan régional de mise en œuvre de la Stratégie Nationale et Plan d'Action sur la Biodiversité en zones écologiques de Mumirwa et de la crête Congo-Nil." Government of Burundi. Bujumbura.

MEETAU. (2011). "Étude sur les coûts de l'inaction contre la dégradation des sols au Burundi." Government of Burundi. Bujumbura.

Mercier, M. et al. (2015). "The Long-Term Effects of Conflict on Welfare: Evidence from Burundi." Households in Conflict Network. HiCN Working Paper 198.

Mo Ibrahim Foundation. (2015). "Ibrahim Index of African Governance. Country Insights Burundi." Mo Ibrahim Foundation.

Ndikumana, L. (2005). "Distributional conflict, the state, and peace-building in Burundi." The Round Table, 94(381): 413-427.

Ngaruko, F. and Nkurunziza, J. (2000). "An Economic Interpretation of Conflict in Burundi." Journal of African Economies 9(3): 370-409.

Ngaruko, F., Nkurunziza, J. (2005). "Why has Burundi grown so slowly? The political economy of redistribution”. In: Ndulu, B., O’Connell, S., Azam, J.P., Bates, R., Fosu, A., Gunning, J.W., and Njinkeu, D. (Eds.). The Political Economy of Economic Growth in Africa, 19602000. Cambridge University Press.

Nillesen, E., Verwimp, P. (2010a). "Grievance, Commodity Prices and Rainfall : A Village-level Analysis of Rebel Recruitment in Burundi." MICROCON Research Working Paper 11.

Nillesen, E., Verwimp, P. (2010b). "A Phoenix in Flames? Portfolio Choice and Violence in Civil War in Rural Burundi.” MICROCON Research Working Paper 25.

Republic of Burundi (2013). "Note Conceptuelle sur l'Environnement et la Gestion des Ressources Naturelles." Government of Burundi. Bujumbura.

Republic of Burundi. (2013). "Rapport d'Aide Publique au Développement Edition 2012-2013." National Committee of Aid Coordination (CNCA).

Reyntjens, F. (2001). "Again at the Crossroads - Rwanda and Burundi, 2000-2001." Nordiska Afrikainstitutet, Current African Issues, No.24.

Rubin, D.B. (1987). "Multiple Imputation for Nonresponse in Surveys.” John Wiley \& Sons, Inc. New York.

Rwabahungu, M., Niyonkuru, D., Bukobero, L. (2013). "Dégradation et prédation des boisements communaux avant, pendant et après la guerre au Burundi”, Vertigo - la revue électronique en sciences de l'environnement, Hors-série 17 
Schwab, K. (2012). “The Global Competitiveness Report 2012-2013.” World Economic Forum.

Taylor, D. (2013). "We Have No Influence: International Discourse and the Instrumentalisation of Transitional Justice in Burundi", Department of Criminal Law and Criminology, Faculty of Law, Maastricht University, the Netherlands.

Udry, C. (1999). "Efficiency and Market Structure: Testing for Profit Maximization in African Agriculture in Trade, Growth and Development." Essays in Honor of Professor T.N. Srinivasan, ed. by G. Ranis, and L. K. Raut. Elsevier Science. Amsterdam, The Netherlands.

USAID. (2006). "The Link between Land, Environment, Employment, and Conflict in Burundi." United States Agency for International Development.

USAID. (2010). "Burundi Environmental Threats and Opportunities Assessment (ETOA)." USAID. Washington, DC.

Verwimp, P. (2012). Undernutrition, subsequent risk of mortality and civil war in Burundi. Economics and Human Biology, 10(3), 221-31.

Verwimp, P., Bundervoet, T. (2009). "Civil War and the Welfare of Extended Households: Evidence from Longitudinal Data from Burundi." Households in Conflict Network. HiCN Working Papers 70.

Verwimp, P., Muñoz-Mora, J.C. (2012). "Returning Home After Civil War: Food security, nutrition and poverty among Burundian households." Households in Conflict Network. HiCN Working Paper 123.

Verwimp, P., Van Bavel, J. (2013). "Schooling, Violent Conflict, and Gender in Burundi." The World Bank Policy Research Working Paper 6418.

Voors, M. J., Nillesen, E. E. M., Verwimp, P., Bulte, E. H., Lensink, R., \& Van Soest, D. P. (2012). "Violent Conflict and Behavior." American Economic Review, 102(452), 941-964.

Wagner, R. (2009). "What is the weakest link for entrepreneurial activity in Burundi?"

WFP. (2014). “Analyse Globale de la Sécurité Alimentaire, de la Nutrition et de la Vulnérabilité au Burundi." World Food Program.

World Bank. (2003). "Breaking the Conflict Trap." The World Bank.

World Bank. (2011). "World Development Report 2011. Conflict, Security and Development." The International Bank for Reconstruction and Development / The World Bank.

World Bank. (2012). "Doing Business in a more Transparent World." World Bank and International Financial Corporation.

World Bank. (2013). "Doing Business 2013: Smarter Regulations for Small and Medium-Size Enterprises. Economic Profile 2013, Burundi." The International Bank for Reconstruction and Development / The World Bank. 
World Bank. (2013). "Republic of Burundi Burundi Public Expenditure Review." The International Bank for Reconstruction and Development / The World Bank.

World Bank. (2015). "Burundi - Strengthening Institutional Capacity for Government Effectiveness Project." The International Bank for Reconstruction and Development / The World Bank. Project Appraisal Document.

World Bank. (2015). "Burundi Vulnerability Assessment." The World Bank Report No: AUS6966.

World Bank. (2015). “The Little Green Data Book 2015.” The World Bank. Washington, DC.

World Bank. (2015a). "Poverty in a Rising Africa: Overview." The World Bank. Washington, DC.

World Bank. (2015b). "A Measured Approach to Ending Poverty and Boosting Shared Prosperity. Concepts, Data, and the Twin Goals.” The World Bank. Washington, DC.

World Bank. (2015c). "Ending Poverty and Sharing Prosperity: Global Monitoring report 2014/15." The World Bank. Washington, DC.

World Bank. (2016). "Doing Business 2016: Measuring Regulatory Quality and Efficiency. Economic Profile 2016, Burundi." The International Bank for Reconstruction and Development / The World Bank.

World Economic Forum. (2015). “Africa Competitiveness Report 2015." World Economic Forum / The World Bank / OECD.

World Health Organization. (2014). "Country Cooperation Strategy at a glance: Burundi.” World Health Organization. 


\section{Appendices}

\section{Appendix I - Poverty Estimation Data and Methodology}

This appendix covers technical issues in the design, implementation and poverty estimation methodology of the surveys with a focus on data quality. These issues have been mentioned in the body of the report, but are elaborated here.

\section{Calculation of the Household Consumption/Expenditure Indicator}

The 2013/14 household consumption/expenditure indicator is estimated as an aggregation of food and non-food expenditure data collected using both diary and recall approaches through specific survey modules. The estimation work exploits a total of 21 modules directly linked to food and non-food data. The estimated household consumption indicator is the sum of the estimated household food expenditure indicator and the estimated household non-food expenditure indicator.

\section{Food consumption/expenditure:}

Food data and indicators are first drawn from the CQ03 module, which is a diary-based module that collects daily current expenditures of eligible household members assigned to this task and subsequently registered in household diaries. It contains daily current expenditures undertaken over a 9-day period in which households are visited 4 times by interviewers to inspect and validate registered expenditures prior to the corresponding record in the CQ03 module. Second, food data and indicators are drawn from the CQ04 module, which is a classical recall-based module destined to capture important (bulky) or exceptional food expenditures carried out over a 12-month period. Note that food expenditures made for parades and ceremonies (celebrations) are not included in the estimation of the household food consumption indicator.

The household food indicator is estimated by combining food data from respective diary and recall modules. First, diary-based food data are merged with 12-month recall period food data, using the following merging variables: household identifier, product item or service code (COICOP), harmonized measurement unit of product or service, frequency of renewal of product or service, place where the purchase is made, and the origin of the product or service. Then, within each household, the final list of food expenditures to be further aggregated is defined according to a simple rule, namely: (i) if the food product or service originates solely in the diary-based module (not purchased in the 12-month recall-based data file), we include it in the list directly; (ii) if the food product or service originates solely in the recall-based module (not purchased in the diary-based data file), we include it in the list directly; (iii) if the food product or service originates in both diary-based module and recall-based module, we retain it in the diary-based module only if they follow a more reasonable distribution. 


\section{Non-food consumption/expenditure:}

Non-food data and related estimated indicators are of both from diary and recall modules, with several recall periods for the later (Table). A simple 3-step approach is used to estimate the nonfood consumption/expenditure indicator:

First, identical non-food products or services (as per their COICOP codes) collected with different recall periods are merged to form unified recall-based non-food datasets, based on differentiated merging variables. The twelve household final consumption/expenditure categories were collected through the diary approach, which was completed by recall-based data collected through different recall modules/periods (Table 1. A-1 ). Except "housing, water, electricity, gas and other fuels" and "education", all non-food data modules had to be merged before being aggregated/combined to obtain those unified recall datasets. Prior to proceeding to this merging step, monthly non-food indicators are calculated using the respective recall periods of the nonfood datasets that have to be combined. Similar to the estimation of food consumption indicators, a decision has to be made with regard to non-food products or services collected simultaneously in the two non-food datasets that are merged. The monthly non-food indicator retained is the one displaying a somewhat more reasonable distribution. For non-food products or services originated only in one of the two merged datasets, inclusion in the household list of final nonfood products or services is made.

Table 1. A-1: Consumption/expenditure data collection approaches

\begin{tabular}{|c|c|c|c|c|c|}
\hline & \multirow{2}{*}{ Household final consumption functions } & \multirow{2}{*}{ Diary } & \multicolumn{3}{|c|}{ Recall (month) } \\
\hline & & & 12 & 6 & 3 \\
\hline 1 & Food and non-alcoholic beverages & $\mathrm{X}$ & $\mathrm{X}$ & & \\
\hline 2 & Alcoholic beverages, tobacco and narcotics & $\mathrm{X}$ & $\mathrm{X}$ & & \\
\hline 3 & Clothing and footwear & $\mathrm{X}$ & $\mathrm{X}$ & $\mathrm{X}$ & \\
\hline 4 & Housing, water, electricity, gas and other fuels & $\mathrm{X}$ & & $\mathrm{X}$ & \\
\hline 5 & $\begin{array}{l}\text { Furnishings, household equipment and routine } \\
\text { household maintenance }\end{array}$ & $\mathrm{X}$ & $\mathrm{X}$ & $\mathrm{X}$ & \\
\hline 6 & Health & $\mathrm{X}$ & $\mathrm{X}$ & & $\mathrm{X}$ \\
\hline 7 & Transport & $\mathrm{X}$ & $\mathrm{X}$ & & $X$ \\
\hline 8 & Communication & $\mathrm{X}$ & $\mathrm{X}$ & & $\mathrm{X}$ \\
\hline 9 & Recreation and culture & $\mathrm{X}$ & $\mathrm{X}$ & $\mathrm{X}$ & \\
\hline 10 & Education & $\mathrm{X}$ & $\mathrm{X}$ & & \\
\hline 11 & Restaurants and hotels & $\mathrm{X}$ & $\mathrm{X}$ & & $\mathrm{X}$ \\
\hline 12 & Miscellaneous goods and services & $\mathrm{X}$ & $\mathrm{X}$ & $\mathrm{X}$ & \\
\hline
\end{tabular}


Source: ECVMB 2014 interviewers' manual.

The second step consists in analyzing the distributions of monthly non-food consumption/expenditure obtained from the two different recall-based non-food datasets that are merged. The final outcome of this said data selection/cleaning process follows:

- Clothing and footwear: 89 products or services matched perfectly, from which we retained the monthly non-food consumption based on the 6-month recall period.

- Furnishings, household equipment and routine household maintenance: 13 products or services matched perfectly, from which we retained the monthly non-food consumption based on the 6-month recall period.

- Health: There were not products or services matched in the two merged non-food datasets.

- Transport: 95 products or services matched perfectly, from which we retained the monthly non-food consumption based on the 3-month recall period.

- Communication: There were not products or services matched in the two merged nonfood datasets.

- Recreation and culture: There were not products or services matched in the two merged non-food datasets.

- Restaurants and hotels: 3 products or services matched perfectly, from which we retained the monthly non-food consumption based on the 3-month recall period.

- Miscellaneous goods and services: There were not products or services matched in the two merged non-food datasets.

The third step of the non-food estimation process consists in forming combined diary-recall nonfood datasets for each of the 10 household final consumption/expenditure functions related to non-food. Here again, we apply the same selection/cleaning rule for non-food products or services that matched, which gives the following specific outcome:

- Clothing and footwear: 466 products or services matched perfectly, from which we retained the monthly non-food consumption using the recall-based estimation.

- Housing, water, electricity, gas and other fuels: 2343 products or services matched perfectly, from which we retained the monthly non-food consumption using the recallbased estimation.

- Furnishings, household equipment and routine household maintenance: 4603 products or services matched perfectly, from which we retained the monthly non-food consumption from the recall-based dataset.

- Health: 364 products or services matched perfectly, from which we retained the monthly non-food consumption from the recall-based dataset.

- Transport: 935 products or services matched perfectly, from which we retained the monthly non-food consumption from the diary-based dataset.

- Communication: 1131 products or services matched perfectly, from which we retained the monthly non-food consumption from the recall-based dataset.

- Recreation and culture: 615 products or services matched perfectly, from which we retained the monthly non-food consumption from the recall-based dataset.

- Education: There were not products or services matched in the two merged non-food 
datasets.

- Restaurants and hotels: 4 products or services matched perfectly, from which we retained the monthly non-food consumption from the recall-based dataset.

- Miscellaneous goods and services: 795 products or services matched perfectly, from which we retained the monthly non-food consumption from the recall-based dataset.

- Other miscellaneous goods and services: 230 products or services matched perfectly, from which we retained the monthly non-food consumption from the recall-based dataset.

\section{Potential Quality Issues Plaguing Quality of Consumption/Expenditure Estimations}

Expenditure questionnaires from 4 enumeration areas (zones de dénombrement - ZDs) were reviewed. The 9-day diaries filled in by members of the households were compared to the questionnaires filled in by the interviewers from the diaries. Potential quality problems were found.

\section{Non-standard units of measure:}

There are several non-standard units of measure included in the expenditures questionnaires. The equivalents for these measures in standard units are not known.

\section{Daily expenditures:}

During Phase 3 of the survey, daily expenditures are collected using a 9-day diary. Eligible individuals include includes household members that are 15 year-old or above and have a source of revenue. This includes young household individuals who receive money from someone else if these they can decide how to spend the money. For members not eligible for a diary, their expenditures are included in the diaries of the eligible members.

A review of questionnaires from four ZDs in Bujumbura urban and Bujumbura rural showed several potential areas of problems.

- Not all eligible members agree to fill in the diary. When this happens, it is unclear whether all daily expenditures in the household are collected. If the spouse of the household head reports expenditures, it is likely that most of the food expenditures are recorded for the household. However, other incidental expenditures, such as telephone recharge cards, transportation costs, and food eaten outside by other members may not be recorded. This will result in an under-estimation of household daily expenditures, but it is not possible to estimate the magnitude of the missing expenditures.

- Some individuals who do not meet the eligibility criteria for diary are coded as eligible for a diary.

- The information in the diaries does not always match the information that has been recorded in the questionnaire:

- In some cases, items not found in the diary are included in the questionnaire. It is likely that in these cases, the interviewer asked the respondent if he or she remembered any additional expenditure and those were added. 
- In other cases, the value of the expenditure is different in the questionnaire than that recorded in the diary. This could, again, be a correction made in cooperation with the respondent, but it could also be a mistake in copying answer into the questionnaire. Any note was found to know why some changes occurred in the questionnaires that were reviewed.

- After copying the total amount spent from the diary to the questionnaire, the interviewer collected additional information from the respondent regarding the unit of measure and number items purchased. For example, if a diary reports purchasing 1500 Francs of rice, after recording the total, the interviewer asks the informant for the quantity purchased, the unit of measure, and the unit price. There are many records where the quantity purchased times the unit price does not equal the total price paid. However, there is no way to know where the error is.

- According to the manual for Phase 1, domestics are not considered members of the household. However, there have been a few cases where domestics received a diary to record purchases. There is nothing in the manual for Phase 3 that says a domestic cannot complete a diary.

- There are numerous instances where the daily expenditures questionnaire indicates that a member of the household agreed to fill in a diary. However, when the questionnaire is filled in, there are no diary entries for that person. The supervisor should have noted this and either changed the code indicating that the person agreed to "No" or made some other note on the questionnaire that explained the situation.

- In the limited number of questionnaires that were reviewed, only men purchased phone minutes. The retrospective questionnaire collects expenditures on communications over the last 12 months and includes the collection of phone minutes. In those questionnaires, the assignment of expenditures for the last 12 months on phone minutes were all for men. This indicates that men routinely purchase phone minutes. However, when no males in the household completed a diary, there is no information on phone minutes purchased during the last 9 days. When males complete a diary, phone minutes are in their diaries.

There were no notes on the questionnaires from either interviewers or supervisors that explained the changes between the diaries and the questionnaires.

\section{Retrospective expenditures:}

The questionnaire defines the categories of goods are to be collected for the 12,6 or 3 month time period (Table). Respondents are then asked if they have purchased any of these items during a particular time period. The added value of this questionnaire is that the information is collected by individual, not at the household level. This allows for gender analysis on non-food expenditures.

However, there are potential collection errors in retrospective expenditures.

- There are no standard questions to obtain the information. The questionnaire has several columns with a heading that determines the information to be included in the column. The manual includes some suggestions on how to ask the information, but it is uncertain how the information was collected. COICOP categories for each section are included on 
the left side of the page. The list of codes was used as a guide for the items that are to be included on the corresponding section of the questionnaire. There is potential for errors and omissions because the interviewers were not provided with the wording of the questions they ask, and because they had to calculate expenditures on the fly (see below).

- The instructions in the Interviewer Manual dated October 2013 call for the interviewer to calculate expenditures during the interview rather than recording what the informant reports. For example, information on the amount paid for rent, water, electricity, gas and other fuels is collected for the last 6 months. Interviewers are instructed "for a monthly rent, ask the amount of the rent and multiply by 6". In another example, "for the purchase of bath soap, ask how many times per week or month the household makes this purchase on average and how much the household pays each time and then calculate how much the expenditure was for the last 6 months." The interviewer has to do this with every purchase while in the household, and thus it must be done quickly so that the respondent does not lose interest in the survey or decide to stop the interview. Hence, the information reported in the questionnaire is the number calculated by the interviewer.

- Few households recorded paying rent, which is quite surprising for the ZD in Bujumbura "Mairie".

\section{Respondent fatigue:}

There are some problems related to the implementation of the diary surveys. A strong pattern of respondent's fatigue is found as the number of transactions declined over the course of the diary. In addition, the number of transactions seems to increase only when the enumerators visit the household, as they go every other day (Figure 1. A-1).

Figure 1. A-1: Number of transactions recorded since households receive the diary

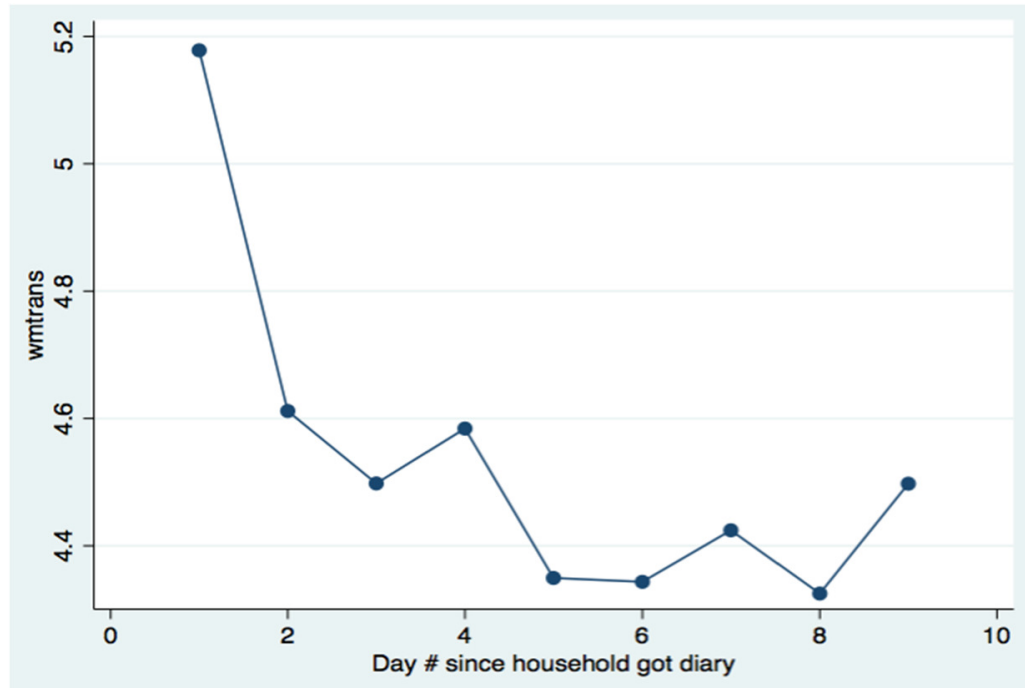

Source: ECVMB 2013/14 


\section{The 2014 Household Budget Consumption Survey in Burundi (ECVMB) - Alternative Methods of Estimation of Poverty Indicators in Burundi}

\begin{tabular}{|c|c|}
\hline ISTEEBU through AFRISTAT & World Bank Group \\
\hline \multicolumn{2}{|c|}{ Household consumption / expenditure (no difference) } \\
\hline $\begin{array}{l}\text { The household consumption / expenditure indicator } \\
\text { is made up of (i) food consumption / expenditure } \\
\text { (either purchased in markets or self-produced and } \\
\text { consumed) and (ii) non-food consumption / } \\
\text { expenditure (either purchased in markets or self- } \\
\text { produced and consumed). }\end{array}$ & $\begin{array}{l}\text { The household consumption / expenditure indicator } \\
\text { is made up of (i) food consumption / expenditure } \\
\text { (either purchased in markets or self-produced and } \\
\text { consumed) and (ii) non-food consumption / } \\
\text { expenditure (either purchased in markets or self- } \\
\text { produced and consumed). }\end{array}$ \\
\hline \multicolumn{2}{|c|}{ Excluded from household consumption / expenditure (difference) } \\
\hline $\begin{array}{l}\text { Are not included in the household consumption, } \\
\text { expenditures made during parades; expenditures } \\
\text { related to very large goods and services (e.g., } \\
\text { automobiles, bicycles, motorcycles, etc.), transfers } \\
\text { paid / gifts given by households to other } \\
\text { households, the costs / fees linked to taxes, } \\
\text { investment expenses (e.g., real estate, land, etc.). }\end{array}$ & $\begin{array}{l}\text { Are not included in the household consumption, } \\
\text { expenditures made during parades, holidays and } \\
\text { ceremonies; expenditures related to very large } \\
\text { goods and services (e.g., automobiles, bicycles, } \\
\text { motorcycles, etc.), transfers paid / gifts given by } \\
\text { households to other households, the costs / fees } \\
\text { linked to taxes, investment expenses (e.g., real } \\
\text { estate, land, etc.). }\end{array}$ \\
\hline \multicolumn{2}{|c|}{ Price indices to deflate household consumption (difference) } \\
\hline $\begin{array}{l}\text { Fisher price indices are calculated to control for } \\
\text { spatial differences in the cost of living of provinces } \\
\text { (survey strata), with Bujumbura the capital taken as } \\
\text { the base province. }\end{array}$ & $\begin{array}{l}\text { Fisher price indices are calculated to control for } \\
\text { spatial differences in the cost of living of residence } \\
\text { areas (rural, urban, Bujumbura the capital), with } \\
\text { national prices taken as the base. }\end{array}$ \\
\hline \multicolumn{2}{|c|}{ Adult-equivalent household consumption (difference) } \\
\hline $\begin{array}{l}\text { Use of specific equivalent scales to } F A O \text {, which are } \\
\text { advised by the WHO, to estimate the adult- } \\
\text { equivalent household size. }\end{array}$ & $\begin{array}{l}\text { Use of specific equivalent scales to World Bank to } \\
\text { estimate the adult-equivalent household size. }\end{array}$ \\
\hline \multicolumn{2}{|c|}{ Source of caloric equivalent values (difference) } \\
\hline $\begin{array}{l}\text { Most caloric values are drawn from caloric food } \\
\text { tables developed by FAO, which provide the } \\
\text { caloric equivalents of most food products } \\
\text { consumed by African households. These caloric } \\
\text { equivalents reflect the caloric value per } 100 \text { grams } \\
\text { or } 100 \text { milliliters of edible food / beverage } \\
\text { products. }\end{array}$ & $\begin{array}{l}\text { Most caloric values are drawn from caloric food } \\
\text { tables developed by FAO, which provide the } \\
\text { caloric equivalents of most food products } \\
\text { consumed by African households. These caloric } \\
\text { equivalents reflect the caloric value per } 100 \text { grams } \\
\text { or } 100 \text { milliliters of edible food / beverage } \\
\text { products. But, missing values are completed using } \\
\text { caloric equivalent values from African tables. }\end{array}$ \\
\hline \multicolumn{2}{|c|}{ Estimation of poverty lines (no difference) } \\
\hline $\begin{array}{l}\text { Use of cost of basic needs (CBN) approach to } \\
\text { estimating food poverty line with the following } \\
\text { characteristics: (i) a food basket is determined, } \\
\text { which contains } 46 \text { food items representing } 82 \\
\text { percent of national food consumption / expenditure; } \\
\text { (ii) calculation of the quantities of consumed } \\
\text { products in standard units (kg or liter), per adult- } \\
\text { equivalent and per day, for the } 46 \text { items; (iii) } \\
\text { conversion of each product consumed in calories; }\end{array}$ & $\begin{array}{l}\text { The same CBN approach is used, with slight } \\
\text { variance. }\end{array}$ \\
\hline
\end{tabular}




\begin{tabular}{|l|l|}
\hline (iv) using the prices collected in markets, & \\
calculating the expenditure amounts for these & \\
products, which permit to achieve the daily 2,100 & \\
Kcal per head. Food and non-food poverty lines are & \\
then generated as usually done in the CBN & \\
approach, relying on the Ravallion works & \\
(especially for the non-food poverty line). & \\
\hline
\end{tabular}




\section{Appendix II - The Unconditional Quantile Regression Method}

The unconditional quantile regression approach used to investigate the underlying causes of inequality within Burundi households, in the third section of the first chapter, is based on the estimation of the Recentered Infuence Function (RIF) for different quantiles of the consumption distribution. An ordinary least squares (OLS) regression model of the following form is then estimated to evaluate the impact of the different households attributes on their consumption levels:

$$
R I F\left(y, Q_{\theta}\right)=X \beta+\varepsilon
$$

where $y$ is log real per capita monthly household consumption, and $\operatorname{RIF}\left(y, Q_{\theta}\right)$ is the RIF of the $\theta$ th quantile of $y$ estimated by computing the sample quantile $Q_{\theta}$ and estimating the density of $y$ at that point by kernel method:

$R I F\left(y, Q_{\theta}\right)=Q_{\theta}+\left(\theta-I\left\{y \leq Q_{\theta}\right\}\right) / f_{Y}\left(Q_{\theta}\right), f_{Y}$ is the marginal density function of $y$ and $I$ is an indicator function. RIF can be estimated by replacing $Q_{\theta}$ by $\theta^{\text {th }}$ sample quantile and estimating $f_{Y}$ by kernel density. ${ }^{79}$

$X$ is the regressors matrix including the households demographic characteristics, the education, occupation and sector of work of the head, assets ownership, access the basic services and geographic location. $\beta$ is the regression coefficient vector and $\varepsilon$ is the error term.

\section{The Analysis of the Sources of Spatial Inequality}

The sources of inequality between rural and urban areas, and between the Western and rest of the regions, are analyzed using the Recentered Influence Function (RIF) regression method. The procedure allows to understand how the difference in the distributions of observed household characteristics between the locations contribute to the welfare gap and how the marginal effects of these characteristics vary across the entire distribution.

Popular approaches used in the decomposition of distributional statistics and the analysis of the sources of inequality include the standard Oaxaca-Blinder decomposition method, the reweighting procedure of DiNardo, Fortin, and Lemieux (1996) and the quantile-based decomposition approach of Machado and Mata (2005). The main drawback of the OaxacaBlinder technique is that it applies the decomposition to only the mean welfare differences between two population sub-groups and yields an incomplete representation of the inequality sources. The other conventional methods extend the decomposition beyond the mean and permit the analysis of the entire distribution, nevertheless they all share the same shortcoming in that they involve a number of assumptions and computational difficulties (Fortin et al., 2010).

\footnotetext{
${ }^{79}$ For more details see Firpo, Fortin and Lemieux (2009).
} 
The RIF regression approach recently proposed by Firpo, Fortin and Lemieux $(2009,2010)$ addresses these shortcomings and provides a simple regression-based procedure for performing a detailed decomposition of different distributional statistics such as quantiles, variance and Gini coefficient. The RIF-regression model is called unconditional quantile regression when applied to the quantiles. The technique consists of decomposing the welfare gaps at various quantiles of the unconditional distribution into differences in households' endowment characteristics such as education, age, employment etc., and differences in the returns to these characteristics. These components are then further decomposed to identify the specific attributes, which contribute to the widening welfare gap.

We apply the RIF unconditional quantile regression to examine the rural-urban as well as the Western-rest of the regions welfare differentials at various points of the consumption distribution. The procedure is carried out in two stages. The first stage consists of estimating unconditional quantile regressions on log real per capita monthly household consumption for rural and urban (Western and rest of the regions) households, then constructing a counterfactual distribution that would prevail if rural (rest of the regions) households have received the returns that pertained to urban (Western) area. The comparison of the counterfactual and empirical distributions allows to estimate the part of the welfare gap attributable to households characteristics differentials, the endowment effect, and the part explained by differences in returns to characteristics, the return effect. The second stage involves dividing the endowment and return components into the contribution of each specific characteristic variable.

The method can be easily implemented as a standard linear regression of the form of Equation (1).

The regressors in this model include seven groups of variables: (1) the household demographic and general characteristics variables including household size, the proportion of household members aged below fourteen years and the proportion of those aged over 65 years, and the gender of the household head; (2) the household human capital measured by the education level of the head and of his spouse. ${ }^{80}$ The inclusion of education level of the spouse is motivated by capturing the influence she may have in household decision making; (3) the household head employment sector recoded as a categorical variable: (i) Agriculture \& fishing; (ii) Construction \& mining; (iii) Service sector; (iv) Public administration, education \& health; (v) Small businesses; (vi) Other sectors; (4) Household head other attributes, which include a dummy variable indicating whether the head is over 65 years old and his marital status; (5) Assets ownership including the area of land owned, dummy variables indicating respectively whether the household owns big and small livestocks, poultry, transportation means, cell phone, durables and small appliances, and dummies capturing the housing conditions; (6) access to basic services measured by categorical variables indicating the sources of cooking fuel, drinking water, sanitation and access to electricity; (7) external factors to the household capturing the community characteristics and geographic location fixed effects.

\footnotetext{
${ }^{80}$ The experience of the head was not significant in any equation, thus we excluded it.
} 
We estimate model (1) for the $10^{\text {th }}$ to $90^{\text {th }}$ quantiles and use the unconditional quantile regression estimates to decompose the rural-urban inequality, as well as the Western-rest of the regions, inequality into a component attributable to differences in the distribution of characteristics and a component due to differences in the distribution of returns as follows:

$$
\hat{Q}_{\theta}^{i}-\hat{Q}_{\theta}^{i^{\prime}}=\left\{\hat{Q}_{\theta}^{i}-\hat{Q}_{\theta}^{*}\right\}+\left\{\hat{Q}_{\theta}^{*}-\hat{Q}_{\theta}^{i^{\prime}}\right\}=\left(\bar{X}^{i}-\bar{X}^{i^{\prime}}\right) \hat{\beta}_{\theta}{ }^{i}+\bar{X}^{i^{\prime}}\left(\hat{\beta}_{\theta}{ }^{i}-\hat{\beta}_{\theta}^{i^{\prime}}\right)
$$

where $\hat{Q}_{\theta}$ is the $\theta^{\text {th }}$ unconditional quantile of log real per capita monthly household consumption, $\bar{X}$ represents the vector of covariate averages and $\hat{\beta}_{\theta}$ the estimate of the unconditional quantile partial effect. Superscripts $i, i$, and * designate respectively the urban (or Western), rural (or rest of the regions) and counterfactual values.

$\hat{Q}_{\theta}^{*}=X^{i^{\prime}} \hat{\beta}^{i}$ is the counterfactual quantile of the unconditional counterfactual distribution which represents the distribution of welfare that would have prevailed for group $i$ ' (rural/rest of the regions households) if they have received group $i$ (urban/Western households) returns to their characteristics. $^{81}$

The first term on the right-hand side of equation (2) represents the contribution of the differences in distributions of household characteristics to inequality at the $\theta^{\text {th }}$ unconditional quantile, denoted endowment effect. The second term of the right-hand side of the equation represents the inequality due to differences (or discrimination) in returns to the household characteristics at the $\theta^{\text {th }}$ unconditional quantile,

The endowment and return effects can be further decomposed into the contribution of individual specific households characteristics (or group of some characteristics) as follows:

$$
\hat{Q}_{\theta}^{i}-\hat{Q}_{\theta}^{*}=\sum_{k}\left(\bar{X}_{k}{ }^{i}-\bar{X}_{k}{ }^{\prime}\right) \hat{\beta}_{\theta, k}{ }^{i} \quad \text { and } \quad \hat{Q}_{\theta}^{*}-\hat{Q}_{\theta}^{i^{\prime}}=\sum_{k} \bar{X}_{k}^{i^{\prime}}\left(\hat{\beta}_{\theta, k}{ }^{i}-\hat{\beta}_{\theta, k}{ }^{i^{\prime}}\right) \quad k: 1 \ldots K
$$

where $k$ designates the individual specific household characteristics.

\footnotetext{
${ }^{81}$ The decomposition results may vary with the choice of the counterfactual distribution. For example, if the counterfactual used is the distribution that would have prevailed for group $i$ if they have received group $i$ ' returns we would obtain different results. The choice of the counterfactual in this analysis is motivated by the aim of emphasising household groups living in disadvantaged areas.
} 


\section{Appendix III - Inefficiency on the Burundian Agriculture}

\section{Method}

In a plot-level version of the test for separation, the equation being estimated on agronomic data is given by:

$$
Y_{i h}=X_{i h} \alpha+Z_{h} \gamma+\varepsilon_{i h}
$$

where $Y_{i h}$ is labor usage on plot $i$, cultivated by household $h$ (for the time being, we eschew variation over time), $\quad X_{i h}$ is a matrix of plot characteristics, $Z_{h}$ is a matrix of household characteristics, and $\mathcal{E}_{i h}$ is a disturbance term that satisfies the usual Gauss-Markov assumptions. Separation is then associated with a simple $F$-test on the exclusion restriction that $\gamma=0$. In one of the best-known versions of the test for separation (Benjamin, 1992), $Z_{h}$ is household size. In our plot-level Burundian data, there is an additional, intermediate level of aggregation, between the plot and the household levels, known as the champ (field). In this case, equation (basic equation) can be rewritten with an additional index as:

$$
Y_{i c h}=X_{i c h} \alpha+Z_{h} \gamma+\varepsilon_{i c h},
$$

where $c$ indexes fields.

The main problem associated with this procedure is that the disturbance term $\mathcal{E}_{i c h}$ can be decomposed into a nested error components structure given by:

$$
\varepsilon_{i c h}=\mu_{h}+\lambda_{c h}+\eta_{i c h}
$$

where $\mu_{h}$ is a shock common to all plots (and all fields) cultivated by a given household, $\lambda_{c h}$ is a field effect common to all plots within a given field, and $\eta_{i c h}$ is a disturbance term that satisfies the usual assumptions. This is a standard panel data framework, with one dimension being given by plots, the second by fields, and the third by households. Although $\lambda_{c h}$ (and thus $\mu_{h}$ ) can be accounted for by a within procedure which transforms variables into deviations with respect to their field-specific means, this procedure "throws the baby out with the bathwater" since it also partials out $Z_{h}$. Field-specific random effects (the variance components estimator) are usually not an option, since it is likely that $\operatorname{cov}\left[\lambda_{c h}, X_{i c h}\right] \neq 0$ and $\operatorname{cov}\left[\lambda_{c h}, Z_{h}\right] \neq 0$, and the appropriate Hausman test will therefore reject. Therefore the pooling (OLS) estimate of $\gamma_{\text {will }}$ be biased with, in the scalar case:

$$
\operatorname{plim} \widehat{\gamma}_{\text {pooling }}=\gamma+\frac{\operatorname{cov}\left[\lambda_{c h}, \hat{e}_{i h t}\right]}{\sigma_{e}^{2}},
$$


where $\sigma_{e}^{2}$ is the variance of the residual $\hat{e}_{i h t}$ from the auxiliary regression of household size $Z_{h}$ on $X_{i h t}$. If $\operatorname{cov}\left[\lambda_{c h}, \hat{e}_{i c h}\right] \neq 0$, as is likely in the context of what is essentially a labor demand equation, then all standard tests of separation based on the pooling estimator are biased towards rejecting the null-hypothesis of complete markets, when the true value of $\gamma$ is zero. One may therefore reject the null not because market structure is necessarily incomplete, but simply because of a banal problem of unobservable household-level heterogeneity. Conversely, assume that the population value of $\gamma$ is positive (say, because, labor markets are imperfect and labor usage is therefore an increasing function of household size), but that $\operatorname{cov}\left[\lambda_{c h}, \hat{e}_{i c h}\right]<0$. In the case of a factor demand equation, the second hypothesis is likely to be the case. Then standard tests of the separation hypothesis could fail to reject the null, if these two effects cancel out.

The problem, which is similar in spirit to that of consistently estimating the returns to education using panel data when schooling is correlated with the individual effects, can be solved using the Hausman-Taylor (1981, henceforth, HT) IV estimator, which here permits one to control for unobservable field-specific effects that are correlated with $Z_{h}$, while allowing one to identify $\gamma$.

Intuitively, the "internal" HT instruments are given by dividing the plot-specific covariates $X_{i c h}$ into two subsets, one of which, denoted by $X_{1 i c h}$ is assumed to be uncorrelated with $\lambda_{h}$, while the other (denoted by $X_{2 i c h}$ ) is allowed to be correlated with $\lambda_{h}$. The HT instruments are then given by $X_{1 \bullet c h}$, which denotes the field-specific means of $X_{1 i c h}$. Our work builds on previous applications of the HT estimator to the problem of understanding differences in productivity among farms using two-dimensional (farm $h_{\text {-time period }} t$ ) panel datasets. To the best of our knowledge, however, the HT estimator has not been used in the context of the debate concerning the separation hypothesis, and has not been applied to plot-level data.

Now consider extending our basic empirical model to include a simple test for the presence of intra-household deviations with respect to Pareto optimality. In this case, using Udry's (1996) version of the test, the augmented specification is given by:

$$
Y_{i c h}=X_{i c h} \alpha+Z_{h} \gamma+G_{i c h} \beta+\lambda_{c h}+\eta_{i c h}
$$


where $G_{i c h}$ is the gender of the individual who manages plot $i$, and where we subsume the household-specific effects under $\lambda_{c h}$, which of course controls for both field- and householdspecific unobservables. Once again, there is a problem of correlated unobservables. If we perform the within-field transformation, we can test for deviations with respect to intra-

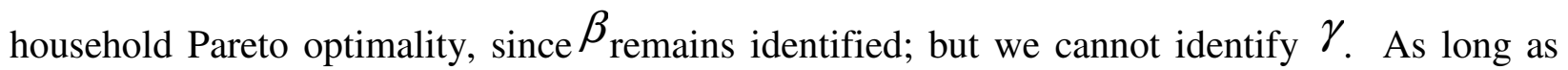
$\operatorname{cov}\left[G_{i c h}-G_{\bullet c h}, \eta_{i c h}\right]=0$, this procedure will yield consistent estimates of $\beta$.

To test both hypotheses simultaneously while controlling for unobservable characteristics at the lowest level of aggregation that is possible through covariance transformations, our proposed solution is therefore to use the HT procedure where the "internal" instruments are given by $X_{1 \bullet c h}$. There remains the problem that it may not be the case that:

$$
\operatorname{cov}\left[G_{i c h}-G_{\bullet c h}, \eta_{i c h}\right]=0 .
$$

For example, female household members may be allotted plots that are of lower quality along some unobservable dimension that is not accounted for by the field-specific effects, even after controlling for what will be an extremely rich set of plot-specific covariates. Standard (excluded) instrumental variables (IV) procedures, in which one would simply instrument for $G_{i c h}$ are not usually implementable. This is because admissible exogenous IVs that would be correlated with $G_{i c h}$ but are orthogonal to $\eta_{i c h}$ and usually not available or, if they initially seem to be, should probably already be included in $X_{i c h}$ for theoretical reasons. In our empirical results below, we circumvent the absence of admissible excluded instruments by applying a recent estimator, due to Lewbel (2012), which uses heteroskedasticity as an identification strategy. This allows us to construct two sets of internal instruments, one based on the HT procedure, the other based on heteroskedasticity, through which to simultaneously test for the presence of inter- and intra-household deviations with respect to Pareto optimality.

\section{Restrictions and Data}

First, we let $Z_{h}$ be household size. This variable is likely to be correlated with $\lambda_{c h}$ in the presence, for example, of unobservable health shocks to working household members.

Second, we consider the amount of land cultivated by the household on other plots. As noted by Udry (1999), a significant negative coefficient can provide indication of a binding working capital constraint, as it implies that inputs are diluted on a given plot as the area farmed on other plots increases. It can also provide evidence in favor of missing insurance markets. Under the maintained hypothesis of a Pareto-optimal intra-household allocation, these first two exclusions 
restrictions will therefore allow us to test for failure of the separation property at the interhousehold level.

Third, and specifically at the plot-level, we will implement Udry's (1996) exclusion restriction concerning the gender of the person in charge of the plot, using $G_{i c h}$. This will allow us to test for the presence of deviations with respect to Pareto-efficiency at the intra-household level. Note that our second exclusion restriction (the amount of land cultivated by the household on other plots) is actually linked to a test for both inter- and intra-household Pareto optimality. While a significant negative coefficient associated with this variable is sometimes linked, as mentioned earlier, with the debate surrounding the inverse farm size/productivity relationship, at least two other interpretations are possible.

On the one hand a statistically significant coefficient associated with this variable (once fieldspecific unobservables are controlled for) implies that the marginal productivity of the labor input in question is not equated across plots cultivated by a given household, since the variable in question is, by construction, plot-specific. A failure in the insurance market or a working capital constraint can therefore lead to the intra-household allocation of resources being inefficient. On the other, if one relaxes the assumption of a Pareto-optimal intra-household model, and by analogy with the plot-specific variable given by the gender of the individual who manages the plot, such a finding would also be consistent with an inefficient intra-household allocation of resources stemming from other causes.

The data allow us to distinguish between three types of labor inputs $\left(L_{i}^{M}, L_{i}^{F}, H_{i}\right)$ on each plot: family and hired labor, where family labor is then further divided into its male and female components. Average family labor input per plot (expressed in persons) is equal to 2.761 for male family labor $\left(L_{i}^{M}\right), 5.218$ for female family labor $\left(L_{i}^{F}\right)$, and 1.213 for hired labor $\left(H_{i}\right)$. The average total labor input (which includes the relatively unimportant mutual labor input) is equal to 9.747 persons. The corresponding figures are 149, 311, 36 and 519, in persons per hectare terms, respectively. This highlights the extremely labor-intensive nature of agriculture in Burundi, and therefore the interest of testing for the presence of inter- and intra-household inefficiencies using labor input measures. The key variable in terms of our test of the Pareto efficiency of the intra-household allocation of labor is the gender of the person who is in charge of the plot: roughly 21 percent of plots are under the control of a woman.

The data include a rich description of plot characteristics (apart from the gender of the person in charge of the plot), which we group under four headings. First, there is the topography of the plot: whether it is on the top, on the hillside or at the bottom of the hill, as well as the altitude at which the plot is located. Second, is the anti-erosion infrastructure present on the plot: whether the plot is terraced, with or without hedges, and whether the plot has an anti-erosion ditch, with or without a hedge. Third, there is the physical position of the plot with respect to the location of the household's dwelling: in between the dwellings of the village, or in the bush, with or without a campsite. Fourth, there is the human capital (measured by whether he/she can read) of the person in charge of plot, which may directly affect plot productivity). For the purposes of HT 
estimation, we classify all of these plot characteristics as $X_{2 i c h}$ variables, apart from the altitude of the plot (which, once the topography, anti-erosion, and plot location variables are controlled for should be uncorrelated with respect to $\lambda_{c h}$ ) and the human capital of the person in charge of the plot, which are assumed to be orthogonal with respect to field-specific unobservables. The third $X_{\text {lich }}$ variable is given by the season dummy. Recall that these three variables, expressed in field-specific mean form, will allow us to identify the effect of household size in our three labor demand equations, while controlling for field-specific unobservables. ${ }^{82}$

\section{Results of the Analysis}

Our empirical results for the full sample labor demand equations -for male family, female family and hired labor, which do not disaggregate by crop, are presented in tables 4, 5 and 6 . For comparison purposes, column (1) in each table reports the pooling results that, for the reasons stated earlier, are likely to be inconsistent because of field-specific unobservables that are correlated with the covariates. Column (2) presents the within-field results, which, when all covariates are uncorrelated with plot-specific unobservables ( $\eta_{i c h}$ ), will give us consistent estimates of the plot specific exclusion restrictions associated with the gender of the person in charge of the plot, and the log surface of all other plots cultivated by the household, but do not allow one to identify the effect of household size. Column (3) presents the Hausman-Taylor estimates which, under the same assumption concerning the lack of correlation of $\eta_{i c h}$ with the plot-specific covariates, and the assumption that our three $X_{\text {lich }}$ variables are indeed orthogonal with respect to field-specific heterogeneity $\lambda_{c h}$, do provide us with an estimate of the effect of household size. Finally, column (4) reports the Hausman-Taylor-Lewbel (henceforth, HTL) estimates, which allow the gender of the person in charge of the plot to be correlated with $\eta_{i c h}$ : these are our preferred estimates.

\footnotetext{
${ }^{82}$ The variations in input (and output) prices $\left(\frac{w}{p_{k}}\right)$ is accounted for by the field-specific effects.
} 
Table 4: Plot-level male family labor demand equations: pooling, within-field, HausmanTaylor and Hausman-Taylor-Lewbel results. Dependent variable is log male family labor per $m^{2}$. Standard errors are clustered at the household level. All specifications control for the degree of multiple cropping and a seasonal dummy. In the Hausman-Taylor specification, the $X_{1 i c h}$ variables are the altitude of the plot, the dummy variable which indicates whether the person in charge of the plot can read and the seasonal dummy, and are assumed to be uncorrelated with field-specific unobservables; all other plot-specific covariates are classified as belonging to $X_{2 i c h}$ and are allowed to be correlated with fieldspecific unobservables. In the Hausman-Taylor-Lewbel specification, the HT instruments are the same, but the person in charge of the plot being female is allowed to be correlated with plot-specific unobservables, and is identified using Lewbel's heteroskedasticity-based instrumental variables, based on all remaining $X_{i c h}$ covariates.

\begin{tabular}{lcccc}
\hline \hline & \multicolumn{4}{c}{ Estimator } \\
\cline { 2 - 5 } & Pooling & Within & HT & HTL \\
& $(1)$ & $(2)$ & $(3)$ & $(4)$ \\
\hline Log(household size) & $0.122^{* * *}$ & & $0.683^{*}$ & 0.436 \\
& $(0.033)$ & & $(0.375)$ & $(0.319)$ \\
Log(plot surface in $\left.m^{2}\right)$ & $-0.911^{* * *}$ & $-0.904^{* * *}$ & $-0.910^{* * *}$ & $-0.906^{* * *}$ \\
& $(0.010)$ & $(0.012)$ & $(0.013)$ & $(0.012)$ \\
Log(surface of other plots in $\left.m^{2}\right)$ & $0.159^{* * *}$ & 0.170 & -0.060 & 0.078 \\
& $(0.057)$ & $(0.292)$ & $(0.375)$ & $(0.314)$ \\
Person in charge of plot is female & $-0.942^{* * *}$ & $-0.308^{* * *}$ & $-0.311^{* * *}$ & $-0.333^{* * *}$ \\
& $(0.037)$ & $(0.065)$ & $(0.064)$ & $(0.064)$ \\
Person in charge of plot can read & $-0.088^{* * *}$ & -0.027 & -0.024 & 0.003 \\
& $(0.033)$ & $(0.054)$ & $(0.054)$ & $(0.050)$ \\
Altitude of plot & -0.0001 & -0.0002 & -0.0001 & -0.0001 \\
& $(0.0001)$ & $(0.0002)$ & $(0.0001)$ & $(0.0001)$ \\
Plot is on top of hill & $-0.071^{*}$ & -0.039 & -0.037 & -0.030 \\
Plot is at bottom of hill & $(0.039)$ & $(0.037)$ & $(0.036)$ & $(0.037)$ \\
& -0.008 & -0.020 & -0.019 & -0.018 \\
Terraces with hedges & $(0.027)$ & $(0.029)$ & $(0.029)$ & $(0.029)$ \\
& $0.141^{* *}$ & -0.010 & -0.005 & 0.023 \\
Anti-erosion ditches without hedges & $(0.067)$ & $(0.047)$ & $(0.047)$ & $(0.050)$ \\
& -0.026 & -0.043 & -0.042 & -0.029 \\
Anti-erosion ditches with hedges & $(0.073)$ & $(0.068)$ & $(0.067)$ & $(0.068)$ \\
& -0.033 & 0.046 & 0.045 & 0.049 \\
Plot is between dwellings & $(0.033)$ & $(0.030)$ & $(0.030)$ & $(0.030)$ \\
& $0.072^{* * *}$ & $-0.059^{* *}$ & $-0.059^{* *}$ & $-0.060^{* *}$ \\
Plot is in the bush with a campsite & $(0.026)$ & $(0.028)$ & $(0.028)$ & $(0.028)$ \\
& $-0.090^{*}$ & $0.130^{* *}$ & $0.1355^{* *}$ & $0.135^{* *}$ \\
& $(0.050)$ & $(0.057)$ & $(0.057)$ & $(0.057)$ \\
\hline Observations & 29,486 & 29,486 & 29,486 & 29,486 \\
Adjusted $\mathrm{R}^{2}$ & 0.529 & 0.152 & & \\
\hline \hline Note: & & & ${ }^{*} \mathrm{p}<0.1 ;{ }^{* *} \mathrm{p}<0.05 ;{ }^{* * *} \mathrm{p}<0.01$ \\
& & &
\end{tabular}


Table 5: Plot-level female family labor demand equations: pooling, within-field, Hausman-Taylor and Hausman-Taylor-Lewbel results. Dependent variable is log female family labor per $m^{2}$. Standard errors are clustered at the household level. All specifications control for the degree of multiple cropping and a seasonal dummy. In the Hausman-Taylor specification, the $X_{1 i c h}$ variables are the altitude of the plot, the dummy variable which indicates whether the person in charge of the plot can read and the seasonal dummy, and are assumed to be uncorrelated with field-specific unobservables; all other plot-specific covariates are classified as belonging to $X_{2 i c h}$ and are allowed to be correlated with field-specific unobservables. In the Hausman-Taylor-Lewbel specification, the HT instruments are the same, but the person in charge of the plot being female is allowed to be correlated with plot-specific unobservables, and is identified using Lewbel's heteroskedasticity-based instrumental variables, based on all remaining $X_{i c h}$ covariates.

\begin{tabular}{|c|c|c|c|c|}
\hline & \multicolumn{4}{|c|}{ Estimator } \\
\hline & $\begin{array}{c}\text { Pooling } \\
\text { (1) }\end{array}$ & $\begin{array}{c}\text { Within } \\
(2)\end{array}$ & $\begin{array}{l}\mathrm{HT} \\
(3) \\
\end{array}$ & $\begin{array}{c}\text { HTL } \\
(4)\end{array}$ \\
\hline Log(household size) & $\begin{array}{l}0.312^{* * *} \\
(0.029)\end{array}$ & & $\begin{array}{c}0.196 \\
(0.266)\end{array}$ & $\begin{array}{c}0.341 \\
(0.236)\end{array}$ \\
\hline $\log \left(\right.$ plot surface in $\left.m^{2}\right)$ & $\begin{array}{c}-0.983^{* * *} \\
(0.008)\end{array}$ & $\begin{array}{c}-0.950^{* * *} \\
(0.009)\end{array}$ & $\begin{array}{l}-0.980^{* * *} \\
(0.010)\end{array}$ & $\begin{array}{l}-0.973^{* * *} \\
(0.010)\end{array}$ \\
\hline $\log \left(\right.$ surface of other plots in $\left.m^{2}\right)$ & $\begin{array}{c}-0.105^{* * *} \\
(0.039)\end{array}$ & $\begin{array}{c}0.337 \\
(0.239)\end{array}$ & $\begin{array}{c}-0.794^{* * *} \\
(0.293)\end{array}$ & $\begin{array}{c}-0.599^{* *} \\
(0.246)\end{array}$ \\
\hline Person in charge of plot is female & $\begin{array}{l}0.203^{* * *} \\
(0.030)\end{array}$ & $\begin{array}{l}0.220^{* * *} \\
(0.044)\end{array}$ & $\begin{array}{l}0.221^{* * *} \\
(0.043)\end{array}$ & $\begin{array}{l}0.216^{* * *} \\
(0.044)\end{array}$ \\
\hline Person in charge of plot can read & $\begin{array}{c}-0.062^{* * *} \\
(0.024)\end{array}$ & $\begin{array}{c}0.003 \\
(0.037)\end{array}$ & $\begin{array}{c}-0.003 \\
(0.037)\end{array}$ & $\begin{array}{c}-0.039 \\
(0.036)\end{array}$ \\
\hline Altitude of plot & $\begin{array}{l}0.0002^{* * *} \\
(0.0001)\end{array}$ & $\begin{array}{c}-0.00004 \\
(0.0002)\end{array}$ & $\begin{array}{c}0.0001 \\
(0.0001)\end{array}$ & $\begin{array}{c}0.0001^{*} \\
(0.0001)\end{array}$ \\
\hline Plot is on top of hill & $\begin{array}{c}-0.045 \\
(0.028)\end{array}$ & $\begin{array}{c}-0.040 \\
(0.032)\end{array}$ & $\begin{array}{c}-0.045 \\
(0.030)\end{array}$ & $\begin{array}{c}-0.034 \\
(0.031)\end{array}$ \\
\hline Plot is at bottom of hill & $\begin{array}{c}0.058^{* * *} \\
(0.019)\end{array}$ & $\begin{array}{c}0.026 \\
(0.023)\end{array}$ & $\begin{array}{c}0.022 \\
(0.023)\end{array}$ & $\begin{array}{c}0.021 \\
(0.023)\end{array}$ \\
\hline Terraces with hedges & $\begin{array}{c}0.012 \\
(0.036)\end{array}$ & $\begin{array}{c}0.002 \\
(0.037)\end{array}$ & $\begin{array}{c}0.006 \\
(0.036)\end{array}$ & $\begin{array}{c}0.014 \\
(0.040)\end{array}$ \\
\hline Anti-erosion ditches without hedges & $\begin{array}{c}0.091^{*} \\
(0.048)\end{array}$ & $\begin{array}{c}-0.003 \\
(0.052)\end{array}$ & $\begin{array}{c}0.011 \\
(0.050)\end{array}$ & $\begin{array}{c}0.021 \\
(0.051)\end{array}$ \\
\hline Anti-erosion ditches with hedges & $\begin{array}{c}-0.050^{* *} \\
(0.025)\end{array}$ & $\begin{array}{r}0.042^{*} \\
(0.023)\end{array}$ & $\begin{array}{l}0.047^{* *} \\
(0.023)\end{array}$ & $\begin{array}{l}0.048^{* *} \\
(0.023)\end{array}$ \\
\hline Plot is between dwellings & $\begin{array}{c}-0.002 \\
(0.018)\end{array}$ & $\begin{array}{c}-0.044^{* *} \\
(0.022)\end{array}$ & $\begin{array}{c}-0.045^{* *} \\
(0.021)\end{array}$ & $\begin{array}{c}-0.047^{* *} \\
(0.021)\end{array}$ \\
\hline Plot is in the bush with a campsite & $\begin{array}{r}-0.063^{*} \\
(0.037)\end{array}$ & $\begin{array}{l}0.119^{* * *} \\
(0.041)\end{array}$ & $\begin{array}{l}0.124^{* * *} \\
(0.041)\end{array}$ & $\begin{array}{l}0.122^{* *} \\
(0.041)\end{array}$ \\
\hline $\begin{array}{l}\text { Observations } \\
\text { Adjusted } R^{2}\end{array}$ & $\begin{array}{c}29,486 \\
0.665\end{array}$ & $\begin{array}{c}29,486 \\
0.199\end{array}$ & 29,486 & 29,486 \\
\hline
\end{tabular}


Table 6: Plot-level hired labor demand equations: pooling, within-field, Hausman-Taylor and Hausman-Taylor-Lewbel results. Dependent variable is log hired labor per $m^{2}$. Standard errors are clustered at the household level. All specifications control for the degree of multiple cropping and a seasonal dummy. In the Hausman-Taylor specification, the $X_{1 i c h}$ variables are the altitude of the plot, the dummy variable which indicates whether the person in charge of the plot can read and the seasonal dummy, and are assumed to be uncorrelated with field-specific unobservables; all other plot-specific covariates are classified as belonging to $X_{2 i c h}$ and are allowed to be correlated with field-specific unobservables. In the Hausman-Taylor-Lewbel specification, the HT instruments are the same, but the person in charge of the plot being female is allowed to be correlated with plot-specific unobservables, and is identified using Lewbel's heteroskedasticity-based instrumental variables, based on all remaining $X_{i c h}$ covariates.

\begin{tabular}{|c|c|c|c|c|}
\hline & \multicolumn{4}{|c|}{ Estimator } \\
\hline & $\begin{array}{c}\text { Pooling } \\
(1)\end{array}$ & $\begin{array}{c}\text { Within } \\
(2)\end{array}$ & $\begin{array}{l}\mathrm{HT} \\
(3) \\
\end{array}$ & $\begin{array}{c}\text { HTL } \\
(4) \\
\end{array}$ \\
\hline Log(household size) & $\begin{array}{c}-0.043 \\
(0.029)\end{array}$ & & $\begin{array}{l}1.658^{* * *} \\
(0.385)\end{array}$ & $\begin{array}{c}0.652^{* *} \\
(0.282)\end{array}$ \\
\hline $\log \left(\right.$ plot surface in $\left.m^{2}\right)$ & $\begin{array}{c}-0.742^{* * *} \\
(0.009)\end{array}$ & $\begin{array}{l}-0.883^{* * *} \\
(0.013)\end{array}$ & $\begin{array}{c}-0.833^{* * *} \\
(0.016)\end{array}$ & $\begin{array}{c}-0.793^{* * *} \\
(0.014)\end{array}$ \\
\hline $\log \left(\right.$ surface of other plots in $\left.m^{2}\right)$ & $\begin{array}{l}0.286^{* * *} \\
(0.056)\end{array}$ & $\begin{array}{c}-3.066^{* * *} \\
(0.463)\end{array}$ & $\begin{array}{c}-1.169^{* *} \\
(0.491)\end{array}$ & $\begin{array}{c}0.112 \\
(0.348)\end{array}$ \\
\hline Person in charge of plot is female & $\begin{array}{c}0.060^{*} \\
(0.032)\end{array}$ & $\begin{array}{c}-0.025 \\
(0.045)\end{array}$ & $\begin{array}{c}-0.054 \\
(0.044)\end{array}$ & $\begin{array}{c}-0.065 \\
(0.046)\end{array}$ \\
\hline Person in charge of plot can read & $\begin{array}{l}0.192^{* * *} \\
(0.025)\end{array}$ & $\begin{array}{c}-0.025 \\
(0.031)\end{array}$ & $\begin{array}{c}-0.013 \\
(0.031)\end{array}$ & $\begin{array}{r}0.070^{*} \\
(0.037)\end{array}$ \\
\hline Altitude of plot & $\begin{array}{c}0.0001 \\
(0.0001)\end{array}$ & $\begin{array}{c}-0.0001 \\
(0.0002)\end{array}$ & $\begin{array}{r}-0.0003^{*} \\
(0.0001)\end{array}$ & $\begin{array}{c}0.00001 \\
(0.0001)\end{array}$ \\
\hline Plot is on top of hill & $\begin{array}{c}0.041 \\
(0.032)\end{array}$ & $\begin{array}{c}0.018 \\
(0.037)\end{array}$ & $\begin{array}{c}0.034 \\
(0.037)\end{array}$ & $\begin{array}{c}0.013 \\
(0.038)\end{array}$ \\
\hline Plot is at bottom of hill & $\begin{array}{l}0.056^{* *} \\
(0.023)\end{array}$ & $\begin{array}{r}0.053^{*} \\
(0.027)\end{array}$ & $\begin{array}{r}0.051^{*} \\
(0.028)\end{array}$ & $\begin{array}{r}0.053^{*} \\
(0.028)\end{array}$ \\
\hline Terraces with hedges & $\begin{array}{l}0.224^{* *} \\
(0.092)\end{array}$ & $\begin{array}{c}-0.049 \\
(0.053)\end{array}$ & $\begin{array}{c}-0.041 \\
(0.054)\end{array}$ & $\begin{array}{c}-0.011 \\
(0.057)\end{array}$ \\
\hline Anti-erosion ditches without hedges & $\begin{array}{l}0.125^{* *} \\
(0.054)\end{array}$ & $\begin{array}{c}0.104^{*} \\
(0.053)\end{array}$ & $\begin{array}{l}0.106^{* *} \\
(0.054)\end{array}$ & $\begin{array}{l}0.113^{* *} \\
(0.054)\end{array}$ \\
\hline Anti-erosion ditches with hedges & $\begin{array}{l}0.154^{* * *} \\
(0.031)\end{array}$ & $\begin{array}{c}0.031 \\
(0.026)\end{array}$ & $\begin{array}{c}0.026 \\
(0.026)\end{array}$ & $\begin{array}{c}0.038 \\
(0.027)\end{array}$ \\
\hline Plot is between dwellings & $\begin{array}{c}-0.193^{* * *} \\
(0.019)\end{array}$ & $\begin{array}{c}-0.016 \\
(0.022)\end{array}$ & $\begin{array}{c}-0.011 \\
(0.022)\end{array}$ & $\begin{array}{c}-0.017 \\
(0.022)\end{array}$ \\
\hline Plot is in the bush with a campsite & $\begin{array}{l}0.338^{* * *} \\
(0.052) \\
\end{array}$ & $\begin{array}{l}0.179^{* * *} \\
(0.058) \\
\end{array}$ & $\begin{array}{l}0.191^{* * *} \\
(0.059) \\
\end{array}$ & $\begin{array}{l}0.191^{* * *} \\
(0.059)\end{array}$ \\
\hline $\begin{array}{l}\text { Observations } \\
\text { Adjusted } \mathrm{R}^{2}\end{array}$ & $\begin{array}{c}29,486 \\
0.401\end{array}$ & $\begin{array}{c}29,486 \\
0.160\end{array}$ & 29,486 & 29,486 \\
\hline
\end{tabular}

As noted in the introduction, as well as in the discussion of our exclusion restrictions, it is likely that $Z_{h}$ is correlated with $\lambda_{c h}$, rendering the results presented in the first column of Tables 4, 5 and 6 suspect. This is confirmed by the appropriate Hausman tests, which compare a field fixed effects specification with the corresponding field random effects specification: for all three types of labor, the Hausman test rejects, with an extremely low $p$-value in all cases. The bias identified in equation (bias) is therefore manifestly present in conventional tests of the nullhypothesis of complete markets using this panel dataset, given that one strongly rejects the null of the absence of correlation between our exclusion restrictions and $\lambda_{c h}$. If one were to base one's conclusions on the pooling results, only one out of total of nine exclusion restrictions (three exclusion restrictions time 3 different labor demand equations) does not reject: log household size in the hired labor demand equation. 
The within-field results, and the difference with their pooling brethren, are therefore already instructive. As illustrated in Figures 1,2 and 3, which present kernel density estimates of the distribution of log labor input per square meter for the level and within-field versions of the variables, transforming variables into the deviations with respect to the field-specific means removes a great deal of residual variance.

Figure 1: Kernel densities, in levels and within-field, of plot-level male family labor usage.

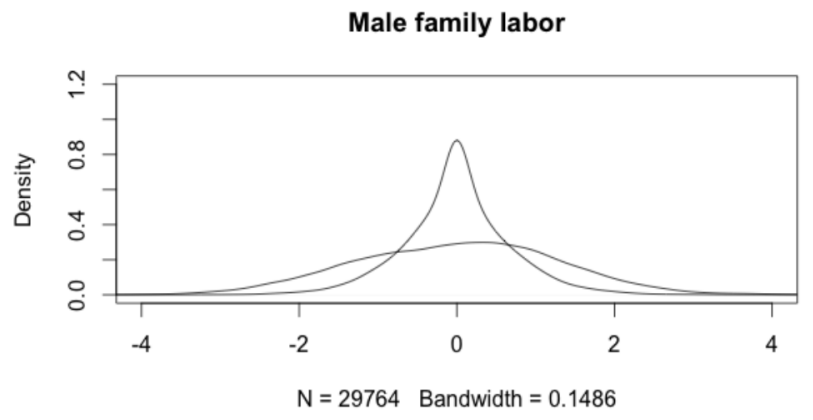

Figure 2: Kernel densities, in levels and within-field, of plot-level female family labor usage.

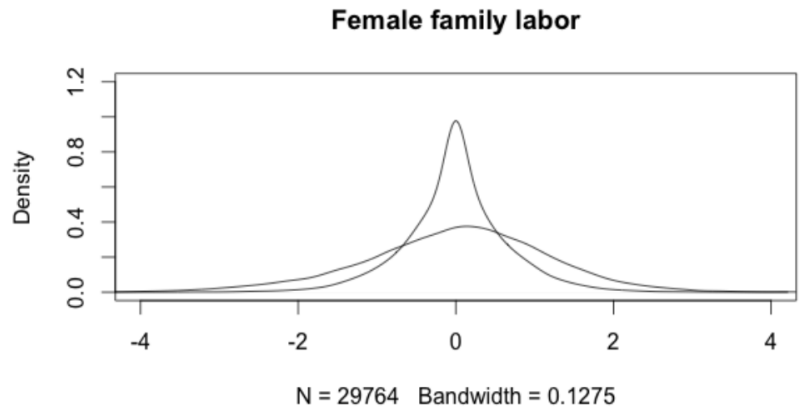

Figure 3: Kernel densities, in levels and within-field, of plot-level hired labor usage.

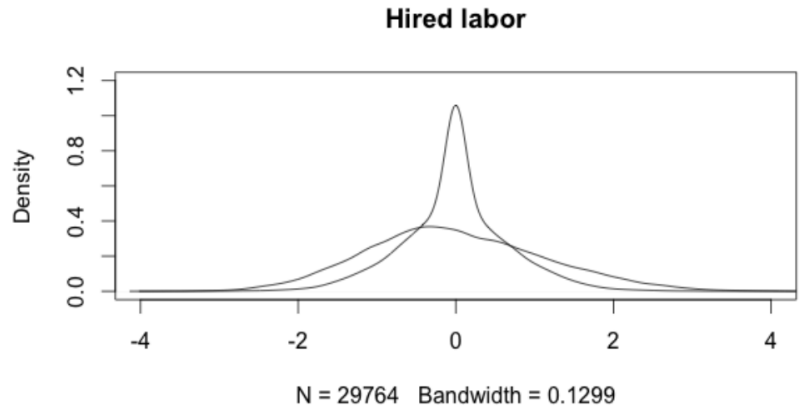

Three aspects of the within-field results are worth noting. First, the surface of other plots farmed by the household, which is statistically significant in the pooling specification for male family 
labor, becomes statistically indistinguishable from zero in the within-field results. The same happens in the female family labor equation. In contrast, the corresponding (negative) coefficient is multiplied by ten in the within-field hired labor equation, and remains statistically significant. Second, the coefficient associated with the plot gender dummy is divided by three but remains both negative and estimated very precisely in the male family labor equation when one moves from the pooling to the within-field estimates. In the female family labor equation, the corresponding associated with the plot gender dummy remains highly significant and virtually unchanged in magnitude. In contrast, in the hired labor equation, the plot gender dummy goes from being positive and marginally significant to being statistically equal to zero. Third, the coefficient associated with log plot surface is always negative, is estimated very precisely, and displays almost no change between the pooling and within-field estimates: this constancy of the coefficient associated with plot size remains true across all of our four econometric specifications.

Moving to column three and HT estimation allows us to ascertain whether the pattern in the pooling estimates in which the separability null in terms of household size was rejected for the two family labor equations, and was not for the hired labor equation, survives controlling for field-specific correlated unobservables: it does not. Indeed, it is reversed: once field-specific correlated unobservables are purged through the HT procedure, the null of no effect of family size is no longer rejected in the female labor demand equation, and is only marginally rejected in the male family labor equation, while (in contrast to the pooling results) it is now strongly rejected in the hired labor equation. These results highlight the value of controlling for correlated field-specific heterogeneity through the HT estimator, and therefore allowing one to estimate the impact of household size.

Finally, we turn to our preferred specification, given by the HTL estimates. In the female family labor demand equation of Table 4, household size is still positive (as in the basic HT results), but statistically indistinguishable from zero. This remains true in the male family labor equation of Table 5. In contrast, and while it diminishes in magnitude with respect to the basic HT specification, the coefficient associated with household size remain statistically different from zero at the 5 percent level of confidence in the hired labor equation of Table 6 . In quantitative terms, a 20 percent increase in household size (i.e. the addition of roughly one household member at the sample mean) is associated with an increase of 13 percent increase in hired labor use per square meter.

This may be taken as evidence of a binding credit constraint in conjunction with labor market imperfections --in that households cannot hire in the desired amount of labor-- that imply that the marginal productivity of hired labor is not equated between households. It is also consistent with the lack of a statistically significant effect of household size in the male and female family labor equations. Intuitively, the increase in household size must increase the shadow value of the credit constraint more than it increases the shadow value of the hiring constraint. Note also that this pattern of violations of the separation null on the basis of household size is not consistent with an explanation based on a credit constraint alone or marketing constraints, because in both these cases both family and hired labor should be statistically significant functions of household 
size. Thus, when we interpret the exclusion restriction based on using household size as our $Z_{h}$, credit market constraints combined with labor market imperfections on the demand side would appear to be prime suspects.

As with the HT results, the coefficient associated with the surface of other plots remains statistically insignificant in the HTL specification, in the male family labor demand equation. In the female family labor demand equation, again as with the HT specification, the surface area of other plots cultivated by the household has a statistically significant and negative impact: an increase of 10 percent in the area of other plots is associated with a 6 percent decrease in female labor input intensity. On the other hand (and contrary to the basic HT results), the total surface of other plots cultivated by the household has no statistically discernible effect on hired labor usage. The statistically significant and quantitatively large effect of this variable on female family labor intensity suggests, as mentioned earlier, either a binding credit constraint or insurance market failure, in which the most important labor input (female family labor, at 311 persons per hectare, displays twice the intensity, 149, of male family labor) is progressively diluted across a larger total surface area that is cultivated, with the other two labor input intensities remaining unchanged. Recall also, since the surface area of other plots is a plotspecific variable, that these two market failures also result in a significant deviation with respect to Pareto optimality of the intra-household allocation of labor between plots.

Finally we turn to our basic test of intra-household Pareto optimality, based on the gender of the person in charge of the plot. In the male family labor equation, the coefficient associated with this variable remains essentially unchanged (as does its standard error) with respect to the HT results, and is negative and estimated very precisely. The point estimate suggests that plots controlled by women use 33 percent less male family labor per square meter than plots that are controlled by men, ceteris paribus. In parallel, if one considers the HTL results for the female family labor equation reported in Table 5, plots controlled by women use 22 percent more female family labor than plots controlled by men, ceteris paribus. The HTL specification for the hired labor equation presented in Table 6 , for its part, shows that there is no difference between maleand female-controlled plots in terms of their usage of hired labor per square meter. As with results for Burkina Faso, reported by Udry (1996), these last results are a powerful indictment of a unitary household model that assumes intra-household Pareto optimality.

\section{Disaggregated results for the six major crops}

In Tables 7 to 12, we report HTL estimates of the three labor demand equations, disaggregated according to the six principle crops in terms of the number of plots cultivated: bush beans, climbing beans, maize, bitter cassava, beer bananas and sweet potatoes. Subsample sizes vary between 2,713 plots for beer bananas and 6,644 plots for maize. As one would expect, there is some heterogeneity in the pattern of the violations of our exclusion restrictions by crop. 
Table 7: BUSH BEANS. Plot-level labor demand equations: Hausman-Taylor-Lewbel results. Dependent variable is $\log$ labor per $\mathrm{m}^{2}$. Standard errors are clustered at the household level. All specifications control for the degree of multiple cropping and a seasonal dummy. In the Hausman-Taylor-Lewbel specification, the $X_{1 i c h}$ variables are the altitude of the plot, the dummy variable which indicates whether the person in charge of the plot can read and the seasonal dummy, and are assumed to be uncorrelated with fieldspecific unobservables; all other plot-specific covariates are classified as belonging to $X_{2 i c h}$ and are allowed to be correlated with field-specific unobservables. The person in charge of the plot being female is allowed to be correlated with plot-specific unobservables, and is identified using Lewbel's heteroskedasticity-based instrumental variables, based on all remaining $X_{i c h}$ covariates.

\begin{tabular}{|c|c|c|c|}
\hline & \multicolumn{3}{|c|}{ Bush beans } \\
\hline & $\begin{array}{l}\text { Male family labor } \\
\text { (1) }\end{array}$ & $\begin{array}{l}\text { Female family labor } \\
\qquad(2)\end{array}$ & $\begin{array}{c}\text { Hired labor } \\
\quad(3)\end{array}$ \\
\hline Log(household size) & $\begin{array}{c}0.350 \\
(0.463)\end{array}$ & $\begin{array}{c}0.146 \\
(0.267)\end{array}$ & $\begin{array}{c}0.512 \\
(0.484)\end{array}$ \\
\hline $\log \left(\right.$ plot surface in $\left.m^{2}\right)$ & $\begin{array}{l}-0.908^{* * *} \\
(0.034)\end{array}$ & $\begin{array}{l}-0.896^{* * *} \\
(0.019)\end{array}$ & $\begin{array}{c}-0.751^{* * *} \\
(0.038)\end{array}$ \\
\hline $\log \left(\right.$ surface of other plots in $\left.m^{2}\right)$ & $\begin{array}{r}-0.567 \\
(0.529)\end{array}$ & $\begin{array}{c}-0.065 \\
(0.253)\end{array}$ & $\begin{array}{c}0.752 \\
(0.550)\end{array}$ \\
\hline Person in charge of plot is female & $\begin{array}{l}-0.509^{* * *} \\
(0.187)\end{array}$ & $\begin{array}{l}0.311^{* *} \\
(0.122)\end{array}$ & $\begin{array}{c}-0.012 \\
(0.151)\end{array}$ \\
\hline Person in charge of plot can read & $\begin{array}{c}0.071 \\
(0.105)\end{array}$ & $\begin{array}{c}0.017 \\
(0.058)\end{array}$ & $\begin{array}{c}0.010 \\
(0.087)\end{array}$ \\
\hline Altitude of plot & $\begin{array}{r}-0.0003^{*} \\
(0.0002)\end{array}$ & $\begin{array}{r}0.0002^{*} \\
(0.0001)\end{array}$ & $\begin{array}{c}0.0001 \\
(0.0002)\end{array}$ \\
\hline Plot is on top of hill & $\begin{array}{c}0.162 \\
(0.155)\end{array}$ & $\begin{array}{c}-0.014 \\
(0.081)\end{array}$ & $\begin{array}{c}-0.028 \\
(0.189)\end{array}$ \\
\hline Plot is at bottom of hill & $\begin{array}{c}0.046 \\
(0.109)\end{array}$ & $\begin{array}{c}0.072 \\
(0.050)\end{array}$ & $\begin{array}{c}0.023 \\
(0.112)\end{array}$ \\
\hline Terraces with hedges & $\begin{array}{c}-0.052 \\
(0.162)\end{array}$ & $\begin{array}{c}0.009 \\
(0.100)\end{array}$ & $\begin{array}{c}-0.028 \\
(0.197)\end{array}$ \\
\hline Anti-erosion ditches without hedges & $\begin{array}{c}0.133 \\
(0.212)\end{array}$ & $\begin{array}{l}0.047 \\
(0.090)\end{array}$ & $\begin{array}{c}0.241 \\
(0.205)\end{array}$ \\
\hline Anti-erosion ditches with hedges & $\begin{array}{c}0.233^{*} \\
(0.129)\end{array}$ & $\begin{array}{c}0.087 \\
(0.075)\end{array}$ & $\begin{array}{c}0.188 \\
(0.133)\end{array}$ \\
\hline Plot is between dwellings & $\begin{array}{c}0.018 \\
(0.086)\end{array}$ & $\begin{array}{c}0.009 \\
(0.050)\end{array}$ & $\begin{array}{r}-0.166^{*} \\
(0.097)\end{array}$ \\
\hline Plot is in the bush with a campsite & $\begin{array}{c}-0.147 \\
(0.134)\end{array}$ & $\begin{array}{c}-0.130 \\
(0.091) \\
\end{array}$ & $\begin{array}{l}0.465^{* * *} \\
(0.155)\end{array}$ \\
\hline Observations & 3,866 & 3,866 & 3,866 \\
\hline
\end{tabular}

The pattern of the impact of household size is remarkably stable across crops in terms of the specific labor demand that is affected: for all six crops, there is no impact of household size on either male or female family labor, as was the case in Tables 4 to 6 . The positive effect of household size on hired labor input intensity that was found earlier is now seen to stem from two crops --maize and bitter cassava. In quantitative terms, a 20 percent (one additional household member) is associated with a 19 percent increase in hired labor intensity for bitter cassava, and with an 18 percent increase in hired labor intensity for maize. This confirms our earlier hypothesis that the pattern of violation stems, for these two crops, from a combination of binding credit and hiring constraints, and not from a combination of a binding credit constraint with a binding marketing constraint. 
Table 8: CLIMBING BEANS. Plot-level labor demand equations: Hausman-TaylorLewbel results. Dependent variable is log labor per $\mathrm{m}^{2}$. Standard errors are clustered at the household level. All specifications control for the degree of multiple cropping and a seasonal dummy. In the Hausman-Taylor-Lewbel specification, the $X_{1 i c h}$ variables are the altitude of the plot, the dummy variable which indicates whether the person in charge of the plot can read and the seasonal dummy, and are assumed to be uncorrelated with field-specific unobservables; all other plot-specific covariates are classified as belonging to $X_{2 i c h}$ and are allowed to be correlated with field-specific unobservables. The person in charge of the plot being female is allowed to be correlated with plot-specific unobservables, and is identified using Lewbel's heteroskedasticity-based instrumental variables, based on all remaining $X_{i c h}$ covariates.

\begin{tabular}{lccc}
\hline \hline & \multicolumn{3}{c}{ Climbing beans } \\
\cline { 2 - 4 } & Male family labor & Female family labor & Hired labor \\
& $(1)$ & $(2)$ & $(3)$ \\
\hline $\log ($ household size) & -0.160 & 0.451 & 0.158 \\
Log(plot surface in $\left.m^{2}\right)$ & $(0.490)$ & $(0.319)$ & $(0.415)$ \\
& $-0.928^{* * *}$ & $-0.994^{* * *}$ & $-0.682^{* * *}$ \\
Log(surface of other plots in $\left.m^{2}\right)$ & $(0.037)$ & $(0.028)$ & $(0.038)$ \\
& 0.147 & $-1.010^{* *}$ & 0.739 \\
Person in charge of plot is female & $(0.566)$ & $(0.448)$ & $(0.543)$ \\
Person in charge of plot can read & $-0.573^{* * *}$ & 0.117 & 0.001 \\
& $(0.142)$ & $(0.106)$ & $(0.134)$ \\
Altitude of plot & -0.008 & -0.083 & $0.182^{* *}$ \\
& $(0.103)$ & $(0.070)$ & $(0.086)$ \\
Plot is on top of hill & $-0.0004^{* *}$ & -0.0002 & $0.001^{* * *}$ \\
& $(0.0002)$ & $(0.0001)$ & $(0.0002)$ \\
Plot is at bottom of hill & 0.060 & -0.044 & 0.061 \\
& $(0.145)$ & $(0.088)$ & $(0.120)$ \\
Terraces with hedges & 0.070 & 0.053 & -0.039 \\
& $(0.101)$ & $(0.076)$ & $(0.098)$ \\
Anti-erosion ditches without hedges & 0.312 & 0.126 & -0.079 \\
& $(0.286)$ & $(0.192)$ & $(0.213)$ \\
Anti-erosion ditches with hedges & 0.169 & 0.151 & 0.101 \\
& $(0.180)$ & $(0.103)$ & $(0.145)$ \\
Plot is between dwellings & 0.059 & -0.012 & 0.152 \\
& $(0.082)$ & $(0.063)$ & $(0.098)$ \\
Plot is in the bush with a campsite & -0.130 & -0.053 & 0.024 \\
& $(0.083)$ & $(0.062)$ & $(0.084)$ \\
Observations & -0.123 & -0.156 & $0.295^{*}$ \\
\hline \hline Note: & $(0.183)$ & $(0.131)$ & $(0.170)$ \\
\hline
\end{tabular}

Now recall that the surface of other plots cultivated by the household was found, in the results reported in Tables 4 to 6 , to have (i) no impact on male family labor intensity, (ii) a negative impact on female family labor intensity and (iii) no impact on hired labor intensity. Once again, the results disaggregated by crop presented in Tables 7 to 12 allow us to identify the particular crops that are generating this overall aggregate pattern in terms of labor use. First, the absence of an effect of the area of other plots on male family labor intensity is common to all six main crops. Second, the negative effect of the area of other plots on female family labor usage stems entirely from climbing beans. Third, the absence of an effect of the area of other plots on hired labor intensity in the HTL results reported in the last column of Table 6 stems from two effects cancelling each other out. On the one hand, hired labor intensity on plots planted to bitter cassava is decreasing in the area of other plots cultivated by the household. On the other, hired labor intensity on plots planted to beer bananas is increasing in the area of other plots cultivated by the household. 
Table 9: MAIZE. Plot-level labor demand equations: Hausman-Taylor-Lewbel results. Dependent variable is log labor per $m^{2}$. Standard errors are clustered at the household level. All specifications control for the degree of multiple cropping and a seasonal dummy. In the Hausman-Taylor-Lewbel specification, the $X_{1 i c h}$ variables are the altitude of the plot, the dummy variable which indicates whether the person in charge of the plot can read and the seasonal dummy, and are assumed to be uncorrelated with field-specific unobservables; all other plot-specific covariates are classified as belonging to $X_{2 i c h}$ and are allowed to be correlated with field-specific unobservables. The person in charge of the plot being female is allowed to be correlated with plot-specific unobservables, and is identified using Lewbel's heteroskedasticity-based instrumental variables, based on all remaining $X_{i c h}$ covariates.

\begin{tabular}{lccc}
\hline \hline & \multicolumn{3}{c}{ Maize } \\
\cline { 2 - 4 } & Male family labor & Female family labor & Hired labor \\
& $(1)$ & $(2)$ & $(3)$ \\
\hline Log(household size) & 0.562 & 0.281 & $0.923^{* *}$ \\
Log(plot surface in $m^{2}$ ) & $(0.360)$ & $(0.225)$ & $(0.378)$ \\
& $-0.827^{* * *}$ & $-0.904^{* * *}$ & $-0.780^{* * *}$ \\
Log(surface of other plots in $\left.m^{2}\right)$ & $(0.025)$ & $(0.015)$ & $(0.026)$ \\
& 0.169 & -0.361 & -0.252 \\
Person in charge of plot is female & $(0.491)$ & $(0.337)$ & $0.543)$ \\
& $-0.662^{* * *}$ & $0.193^{*}$ & 0.051 \\
Person in charge of plot can read & $(0.141)$ & $(0.102)$ & $(0.142)$ \\
& -0.092 & -0.064 & 0.070 \\
Altitude of plot & $(0.070)$ & $(0.045)$ & $(0.072)$ \\
& $-0.0003^{*}$ & 0.0001 & -0.0001 \\
Plot is on top of hill & $(0.0001)$ & $(0.0001)$ & $(0.0002)$ \\
& -0.091 & 0.004 & 0.044 \\
Plot is at bottom of hill & $(0.118)$ & $(0.075)$ & $(0.132)$ \\
& 0.020 & -0.026 & 0.060 \\
Terraces with hedges & $(0.080)$ & $(0.044)$ & $(0.095)$ \\
Anti-erosion ditches without hedges & 0.044 & 0.094 & -0.220 \\
& $(0.145)$ & $(0.071)$ & $(0.215)$ \\
Anti-erosion ditches with hedges & -0.079 & 0.054 & 0.119 \\
& $(0.182)$ & $(0.068)$ & $(0.148)$ \\
Plot is between dwellings & $0.230^{* * *}$ & 0.041 & -0.025 \\
Plot is in the bush with a campsite & $(0.076)$ & $(0.042)$ & $(0.077)$ \\
& 0.061 & 0.065 & $-0.202^{* *}$ \\
Observations & $(0.077)$ & $(0.047)$ & $(0.082)$ \\
\hline \hline Note: & -0.047 & $-0.129^{* *}$ & $0.284^{* * *}$ \\
& $(0.095)$ & $(0.057)$ & $0.106)$ \\
\hline
\end{tabular}

The pattern of the impact of the gender of the person who is in charge of the plot is similar to that found in the HTL estimation results reported in Tables 4, 5 and 6, for five out of six crops. For bush beans, climbing beans, maize, bitter cassava and sweet potatoes, a plot being under the control of a woman significantly increases female family labor intensity (for climbing beans the coefficient is estimated imprecisely), significantly decreases male family labor intensity, and leaves hired labor intensity unchanged. 
Table 10: BITTER CASSAVA. Plot-level labor demand equations: Hausman-TaylorLewbel results. Dependent variable is $\log$ labor per $\mathrm{m}^{2}$. Standard errors are clustered at the household level. All specifications control for the degree of multiple cropping and a seasonal dummy. In the Hausman-Taylor-Lewbel specification, the $X_{1 i c h}$ variables are the altitude of the plot, the dummy variable which indicates whether the person in charge of the plot can read and the seasonal dummy, and are assumed to be uncorrelated with fieldspecific unobservables; all other plot-specific covariates are classified as belonging to $X_{2 i c h}$ and are allowed to be correlated with field-specific unobservables. The person in charge of the plot being female is allowed to be correlated with plot-specific unobservables, and is identified using Lewbel's heteroskedasticity-based instrumental variables, based on all remaining $X_{i c h}$ covariates.

\begin{tabular}{lccc}
\hline \hline & \multicolumn{3}{c}{ Bitter cassava } \\
\cline { 2 - 4 } & Male family labor & Female family labor & Hired labor \\
& $(1)$ & $(2)$ & $(3)$ \\
\hline $\log ($ household size) & -0.062 & -0.272 & $0.948^{* *}$ \\
& $(0.304)$ & $(0.247)$ & $(0.393)$ \\
Log(plot surface in $\left.m^{2}\right)$ & $-0.893^{* * *}$ & $-0.917^{* * *}$ & $-0.799^{* * *}$ \\
& $(0.028)$ & $(0.023)$ & $(0.042)$ \\
Log(surface of other plots in $\left.m^{2}\right)$ & -0.141 & -0.055 & $-1.360^{* *}$ \\
& $(0.459)$ & $(0.349)$ & $(0.615)$ \\
Person in charge of plot is female & $-0.702^{* * *}$ & $0.314^{*}$ & -0.141 \\
& $(0.187)$ & $(0.170)$ & $(0.196)$ \\
Person in charge of plot can read & -0.041 & 0.021 & $0.167^{*}$ \\
& $(0.066)$ & $(0.059)$ & $(0.090)$ \\
Altitude of plot & -0.0001 & $0.0003^{* *}$ & $-0.001^{* * *}$ \\
& $(0.0001)$ & $(0.0001)$ & $(0.0002)$ \\
Plot is on top of hill & -0.016 & -0.021 & 0.257 \\
& $(0.154)$ & $(0.139)$ & $(0.201)$ \\
Plot is at bottom of hill & 0.054 & 0.082 & -0.154 \\
Terraces with hedges & $(0.091)$ & $(0.070)$ & $(0.132)$ \\
& -0.050 & 0.010 & -0.312 \\
Anti-erosion ditches without hedges & $(0.181)$ & $(0.151)$ & $(0.230)$ \\
& -0.003 & 0.027 & 0.046 \\
Anti-erosion ditches with hedges & $(0.175)$ & $(0.103)$ & $(0.212)$ \\
& 0.063 & 0.006 & 0.127 \\
Plot is between dwellings & $(0.084)$ & $(0.065)$ & $(0.116)$ \\
& 0.020 & -0.049 & $0.270^{*}$ \\
Plot is in the bush with a campsite & $(0.110)$ & $(0.085)$ & $(0.148)$ \\
& 0.024 & -0.021 & $0.311^{* *}$ \\
Observations & $(0.089)$ & $(0.079)$ & $(0.142)$ \\
\hline \hline Note: & 3,762 & 3,762 & 3,762 \\
\hline & & $* \mathrm{p}<0.1 ; * * \mathrm{p}<0.05 ; * * *$ & $\mathrm{p}<0.01$ \\
& &
\end{tabular}

The one exception to this remarkably stable pattern is provided by beer bananas: for this one crop, and while male family labor intensity is lower on female-controlled plots as it is for the five other crops, female labor intensity is not higher, while hired labor intensity is. It is interesting to note that plots planted to beer bananas are the least likely to be managed by a woman ( 3 percent less likely). They are also the most likely to be situated between the household's dwellings ( 7 percent more likely), and the least likely to be situated in the bush, either without (6 percent less likely), or with (1 percent less likely) a campsite. Beer bananas therefore appear to be more of a "male" crop, which is planted on plots that are perhaps more easily accessible to hired labor by dint of their physical proximity to the household's dwelling. 
Table 11: BEER BANANAS. Plot-level labor demand equations: Hausman-TaylorLewbel results. Dependent variable is log labor per $m^{2}$. Standard errors are clustered at the household level. All specifications control for the degree of multiple cropping and a seasonal dummy. In the Hausman-Taylor-Lewbel specification, the $X_{1 i c h}$ variables are the altitude of the plot, the dummy variable which indicates whether the person in charge of the plot can read and the seasonal dummy, and are assumed to be uncorrelated with field-specific unobservables; all other plot-specific covariates are classified as belonging to $X_{2 i c h}$ and are allowed to be correlated with field-specific unobservables. The person in charge of the plot being female is allowed to be correlated with plot-specific unobservables, and is identified using Lewbel's heteroskedasticity-based instrumental variables, based on all remaining $X_{i c h}$ covariates.

\begin{tabular}{|c|c|c|c|}
\hline & \multicolumn{3}{|c|}{ Beer bananas } \\
\hline & $\begin{array}{c}\text { Male family labor } \\
\text { (1) }\end{array}$ & $\begin{array}{l}\text { Female family labor } \\
\qquad(2)\end{array}$ & $\begin{array}{c}\text { Hired labor } \\
\text { (3) }\end{array}$ \\
\hline $\log ($ household size $)$ & $\begin{array}{c}-0.465 \\
(0.482)\end{array}$ & $\begin{array}{c}0.662 \\
(0.408)\end{array}$ & $\begin{array}{c}0.295 \\
(0.634)\end{array}$ \\
\hline $\log \left(\right.$ plot surface in $m^{2}$ ) & $\begin{array}{c}-0.889^{* * *} \\
(0.042)\end{array}$ & $\begin{array}{c}-0.981^{* * *} \\
(0.034)\end{array}$ & $\begin{array}{c}-0.804^{* * *} \\
(0.052)\end{array}$ \\
\hline $\log \left(\right.$ surface of other plots in $m^{2}$ ) & $\begin{array}{c}-0.140 \\
(0.759)\end{array}$ & $\begin{array}{c}-0.694 \\
(0.560)\end{array}$ & $\begin{array}{l}1.922^{* *} \\
(0.857)\end{array}$ \\
\hline Person in charge of plot is female & $\begin{array}{l}-0.779^{* * *} \\
(0.252)\end{array}$ & $\begin{array}{c}0.272 \\
(0.173)\end{array}$ & $\begin{array}{l}0.461^{* *} \\
(0.225)\end{array}$ \\
\hline Person in charge of plot can read & $\begin{array}{c}0.107 \\
(0.101)\end{array}$ & $\begin{array}{c}-0.082 \\
(0.069)\end{array}$ & $\begin{array}{c}0.061 \\
(0.093)\end{array}$ \\
\hline Altitude of plot & $\begin{array}{c}-0.0003 \\
(0.0003)\end{array}$ & $\begin{array}{c}-0.00004 \\
(0.0002)\end{array}$ & $\begin{array}{c}0.001^{* *} \\
(0.0003)\end{array}$ \\
\hline Plot is on top of hill & $\begin{array}{c}0.015 \\
(0.169)\end{array}$ & $\begin{array}{c}0.050 \\
(0.107)\end{array}$ & $\begin{array}{c}-0.065 \\
(0.162)\end{array}$ \\
\hline Plot is at bottom of hill & $\begin{array}{c}-0.101 \\
(0.116)\end{array}$ & $\begin{array}{c}-0.164^{* *} \\
(0.083)\end{array}$ & $\begin{array}{c}0.064 \\
(0.117)\end{array}$ \\
\hline Terraces with hedges & $\begin{array}{r}-0.130 \\
(0.185)\end{array}$ & $\begin{array}{c}0.097 \\
(0.126)\end{array}$ & $\begin{array}{c}0.682^{* *} \\
(0.279)\end{array}$ \\
\hline Anti-erosion ditches without hedges & $\begin{array}{c}-0.568^{* *} \\
(0.276)\end{array}$ & $\begin{array}{c}-0.034 \\
(0.140)\end{array}$ & $\begin{array}{c}0.369 \\
(0.248)\end{array}$ \\
\hline Anti-erosion ditches with hedges & $\begin{array}{c}0.023 \\
(0.108)\end{array}$ & $\begin{array}{c}0.003 \\
(0.074)\end{array}$ & $\begin{array}{c}-0.047 \\
(0.111)\end{array}$ \\
\hline Plot is between dwellings & $\begin{array}{c}-0.077 \\
(0.096)\end{array}$ & $\begin{array}{c}0.102 \\
(0.080)\end{array}$ & $\begin{array}{r}-0.203^{*} \\
(0.113)\end{array}$ \\
\hline Plot is in the bush with a campsite & $\begin{array}{c}0.073 \\
(0.150)\end{array}$ & $\begin{array}{c}-0.069 \\
(0.127)\end{array}$ & $\begin{array}{r}0.336^{*} \\
(0.189) \\
\end{array}$ \\
\hline Observations & 2,664 & 2,664 & 2,664 \\
\hline
\end{tabular}


Table 12: SWEET POTATOES. Plot-level labor demand equations: Hausman-TaylorLewbel results. Dependent variable is log labor per $\mathrm{m}^{2}$. Standard errors are clustered at the household level. All specifications control for the degree of multiple cropping and a seasonal dummy. In the Hausman-Taylor-Lewbel specification, the $X_{1 i c h}$ variables are the altitude of the plot, the dummy variable which indicates whether the person in charge of the plot can read and the seasonal dummy, and are assumed to be uncorrelated with fieldspecific unobservables; all other plot-specific covariates are classified as belonging to $X_{2 i c h}$ and are allowed to be correlated with field-specific unobservables. The person in charge of the plot being female is allowed to be correlated with plot-specific unobservables, and is identified using Lewbel's heteroskedasticity-based instrumental variables, based on all remaining $X_{i c h}$ covariates.

\begin{tabular}{|c|c|c|c|}
\hline & \multicolumn{3}{|c|}{ Sweet potatoes } \\
\hline & $\begin{array}{c}\text { Male family labor } \\
(1)\end{array}$ & $\begin{array}{c}\text { Female family labor } \\
(2)\end{array}$ & $\begin{array}{c}\text { Hired labor } \\
(3)\end{array}$ \\
\hline Log(household size) & $\begin{array}{c}0.454 \\
(0.530)\end{array}$ & $\begin{array}{c}0.327 \\
(0.366)\end{array}$ & $\begin{array}{c}0.667 \\
(0.542)\end{array}$ \\
\hline $\log \left(\right.$ plot surface in $\left.m^{2}\right)$ & $\begin{array}{c}-0.844^{* * *} \\
(0.045)\end{array}$ & $\begin{array}{c}-1.015^{* * *} \\
(0.033)\end{array}$ & $\begin{array}{c}-0.840^{* * *} \\
(0.046)\end{array}$ \\
\hline $\log \left(\right.$ surface of other plots in $\left.m^{2}\right)$ & $\begin{array}{c}0.423 \\
(0.610)\end{array}$ & $\begin{array}{c}-0.473 \\
(0.404)\end{array}$ & $\begin{array}{c}-0.333 \\
(0.591)\end{array}$ \\
\hline Person in charge of plot is female & $\begin{array}{c}-0.630^{* * *} \\
(0.174)\end{array}$ & $\begin{array}{l}0.416^{* * *} \\
(0.122)\end{array}$ & $\begin{array}{c}-0.279 \\
(0.175)\end{array}$ \\
\hline Person in charge of plot can read & $\begin{array}{c}-0.089 \\
(0.085)\end{array}$ & $\begin{array}{c}-0.004 \\
(0.068)\end{array}$ & $\begin{array}{c}0.105 \\
(0.096)\end{array}$ \\
\hline Altitude of plot & $\begin{array}{c}-0.00001 \\
(0.0002)\end{array}$ & $\begin{array}{c}0.0001 \\
(0.0002)\end{array}$ & $\begin{array}{c}0.00003 \\
(0.0003)\end{array}$ \\
\hline Plot is on top of hill & $\begin{array}{c}-0.302^{* *} \\
(0.147)\end{array}$ & $\begin{array}{c}0.148 \\
(0.093)\end{array}$ & $\begin{array}{c}0.164 \\
(0.145)\end{array}$ \\
\hline Plot is at bottom of hill & $\begin{array}{c}-0.003 \\
(0.075)\end{array}$ & $\begin{array}{c}0.090^{*} \\
(0.050)\end{array}$ & $\begin{array}{c}0.029 \\
(0.084)\end{array}$ \\
\hline Terraces with hedges & $\begin{array}{c}0.019 \\
(0.180)\end{array}$ & $\begin{array}{c}0.127 \\
(0.142)\end{array}$ & $\begin{array}{c}-0.090 \\
(0.245)\end{array}$ \\
\hline Anti-erosion ditches without hedges & $\begin{array}{c}-0.002 \\
(0.203)\end{array}$ & $\begin{array}{c}-0.010 \\
(0.109)\end{array}$ & $\begin{array}{c}0.030 \\
(0.160)\end{array}$ \\
\hline Anti-erosion ditches with hedges & $\begin{array}{c}-0.027 \\
(0.085)\end{array}$ & $\begin{array}{r}-0.009 \\
(0.065)\end{array}$ & $\begin{array}{c}-0.133 \\
(0.090)\end{array}$ \\
\hline Plot is between dwellings & $\begin{array}{c}0.089 \\
(0.096)\end{array}$ & $\begin{array}{c}0.029 \\
(0.076)\end{array}$ & $\begin{array}{c}-0.218^{* *} \\
(0.110)\end{array}$ \\
\hline Plot is in the bush with a campsite & $\begin{array}{c}-0.095 \\
(0.127) \\
\end{array}$ & $\begin{array}{c}-0.049 \\
(0.098)\end{array}$ & $\begin{array}{c}0.229 \\
(0.189) \\
\end{array}$ \\
\hline Observations & 3,309 & 3,309 & 3,309 \\
\hline
\end{tabular}

